UNIVERSIDADE DE SÃO PAULO

FACULDADE DE ECONOMIA, ADMINISTRAÇÃO E CONTABILIDADE DEPARTAMENTO DE ADMINISTRAÇÃO

PROGRAMA DE PÓS-GRADUAÇÃO EM ADMINISTRAÇÃO

MEDIÇÃO DE DESEMPENHO DO GERENCIAMENTO DE PROCESSOS DE NEGÓCIO - BPM NO PNAFE: UMA PROPOSTA DE MODELO

Francisco Sobreira Netto

Orientadora: Prof ${ }^{\mathrm{a}}$ Dr$^{\mathrm{a}}$ Maria Aparecida Gouvêa

SÃO PAULO 
$\operatorname{Prof}^{\mathrm{a}} \mathrm{Dr}^{\mathrm{a}}$ Suely Vilela

Reitora da Universidade de São Paulo

$\operatorname{Prof}^{\mathrm{a}} \mathrm{Dr}^{\mathrm{a}}$ Maria Tereza Leme Fleury

Diretora da Faculdade de Economia, Administração e Contabilidade

Prof. Dr. Isak Kruglianskas

Chefe do Departamento de Administração

Prof. Dr. Lindolfo Galvão de Albuquerque Coordenador do Programa de Pós-Graduação em Administração 


\section{MEDIÇÃO DE DESEMPENHO DO GERENCIAMENTO DE PROCESSOS DE NEGÓCIO - BPM NO PNAFE: UMA PROPOSTA DE MODELO}

Tese apresentada ao Departamento de Administração da Faculdade de Economia, Administração e Contabilidade da Universidade de São Paulo como requisito para a obtenção do título de Doutor em Administração de Empresas.

Orientadora: Prof ${ }^{\mathrm{a}}$ Dr $^{\mathrm{a}}$ Maria Aparecida Gouvêa

\section{SÃO PAULO}


Tese defendida e aprovada no Departamento de Administração da Faculdade de Economia, Administração e Contabilidade da Universidade de São Paulo - Programa de Pós-Graduação em Administração de Empresas, pela seguinte banca examinadora:

Prof $^{\mathrm{a}} \mathrm{Dr}^{\mathrm{a}}$ Maria Aparecida Gouvêa

Presidente

Prof. Dr. João Eduardo Ferreira

Examinador Interno

Examinador Externo

Examinador Externo

Examinador Externo

\section{FICHA CATALOGRÁFICA}

Elaborada pela Seção de Processamento Técnico do SBD/FEA/USP

Sobreira Netto, Francisco

Medição de desempenho do gerenciamento de processos de negócio - BPM no PNAFE: uma proposta de modelo / Francisco Sobreira Netto. -- São Paulo, 2006.

$212 \mathrm{p}$.

Tese (Doutorado) - Universidade de São Paulo, 2006

Bibliografia.

1. Administração pública 2. Sistemas de informação - Desempenho 3. Administração - Processos 4. Modelos - Desempenho I. Universidade de São Paulo. Faculdade de Economia, Administração e Contabilidade II. Título.

$\mathrm{CDD}-350$ 
Juliana, minha esposa, companheira, amiga, meu apoio e meu amor.

Argemiro e Neuza, meus pais, meu exemplo, caráter, espírito guerreiro e força na fé.

Francisco e Kiara, meus filhos, alegria, esperança, minhas bênçãos, minha vida. 


\section{AGRADECIMENTOS}

Sinto-me um solista de uma grande orquestra sinfônica. Espero não ter desafinado. Peço licença aos leitores deste trabalho para falar do meu sentimento e da minha gratidão para com muitos. Talvez possa esquecer de alguns, mas preciso dizer que assino a autoria deste trabalho ou concluo este processo auxiliado por muita gente. Alguns já se foram, outros estão longe, outros estão muito perto, outros nem sabem o quanto colaboraram. Chego até aqui cansado, mas muito recompensado pelas vitórias já conquistadas e pela perspectiva das próximas.

Ao meu querido Pai do Céu, pelo dom da vida e infinito amor, ao meu Salvador e grande amigo Jesus, pela certeza da ressurreição; à minha querida Mãe Maria, pela proteção; e a São Francisco de Assis, pelo exemplo de apaixonado pelas coisas do alto e pela intercessão por mim. Não posso esquecer também de Santa Clara, por ter ajudado a clarear idéias; de Santa Gianna, protetora das famílias e defensora da vida; e de Santo Expedito, padroeiro do Posto Fiscal Eletrônico, santo das causas mais urgentes. E que urgência!

A todos os professores, funcionários e colegas do Pio XI, da UFF, da Facef e, em especial, do Colégio de São Bento, número um na avaliação nacional do ENEM, número um no meu coração há muito tempo, pela formação intelectual e espiritual. E aos povos da Unifran, por esperarem o professor acabar o doutorado.

A todos os catequistas, religiosos, compadres, padrinhos, afilhados, irmãos na fé e irmãos pelo ecumenismo, pela minha formação cristã e religiosa e principalmente pelas orações de todos durante todo este tempo.

Aos meus chefes Prof. Nakano, Dr. Clóvis e Dr. Tabajara pelo incentivo na loucura do trabalho de modernização da SEFAZ-SP. Aos colegas do Promocat e do Proffis; aos chefes Edna, Oswaldo e Cabrera pelo investimento em mim e paciência nas horas difíceis; a todos da DEAT-SAP e da DRT-6 Ribeirão Preto; ao pessoal da FAZESP e por aqueles que autorizaram minha participação no curso de pós; e aos colegas e amigos próximos: Vandão, Silzer, Marilene, Bianchi, colegas de Franca e de todo o estado, que se prestaram a abraçar o ideal de modernização e me ajudaram neste estudo.

Aos entrevistados do PNAFE Brasil e São Paulo, pela acolhida e partilha do conhecimento. Ao Dr. e Prof. Ueda, por ter aberto as portas do PNAFE e pela contribuição na qualificação. Ao Collet, pelo decisivo auxílio junto ao PNAFE e UCE-SP. Ao pessoal da UCE-RS pela viabilização do trabalho em Porto Alegre.

Aos consultores e profissionais de informática e das áreas de negócio dos projetos PNAFE, pelo empenho e competência; ao Ronnie, programador do instrumento de pesquisa; ao Takai, pela retro-alimentação das programações e demandas do pesquisador; aos colegas do laboratório de banco de dados do IME-USP, pela paciência. Ao amigo Eduardo, pelo entusiasmo e pelo papo decisivo no Enanpad de Salvador.

A todos (todos mesmo) colegas, funcionários, professores, coordenadores da pós, ao pessoal da biblioteca, do laboratório de informática da FEA/USP: muito obrigado de coração! 
A todos que me atrapalharam durante toda a minha vida nos projetos, trabalhos profissionais e estudos: não sabem o quanto me fizeram descobrir a força em Deus e o espírito guerreiro de uma fera ferida! Peço a misericórdia divina para todos.

Ao Wagner, meu primeiro guru da informática. Geneticamente se explica. Você se traduziu num grande co-piloto. O amigo certo nas horas certas e incertas. Não podia esperar menos de tão grande cara.

Aos amigos Devanir e Edson, companheiros de céu e de inferno. Fiéis na alegria e na tristeza, no limbo e na fita. Nunca poucos fizeram tanto em tão pouco tempo. O PFE não teria acontecido sem esta sinergia. Uma abençoada trindade. Pelo respeito, competência, compreensão e, principalmente, companheirismo. Somos realmente um por todos e todos por um.

Aos meus queridos orientadores (co- também é) Profa. Cida e Prof. João. À Profa., pelas horas de trabalho, empenho e dedicação à causa multivariada; e por me ter salvado de ser atropelado pela loucura estatística, sem variâncias e logísticas, de forma multidimensional. Ao Prof. João, também amigo certo nas horas incertas. Digno e eficaz instrumento da N. Sra. Desatadora de Nós. Quando parecia me afogar, lá vinha ele para me salvar no river fish. Você sabe o quanto foi importante neste processo!

À família em Franca, não tenho espaço aqui para agradecimentos. Aos sogros Luiz e Julia, à Madra e à Thê, por acudirem com os filhos. Ao Marcelo, companheiro de sofrimento doutorístico, pela força em São Carlos. Ao Bê e à Marcela: agora agüentem o tio.

Ao povo do meu Rio de Janeiro: que alegria! Aos meus irmãos e sobrinhos Martha e Guilherme, Téti, Vitu, Dani boy, Aninha, Mônica e Milena, pela torcida. Ao mano Renato pela decisiva força na UFRJ. Valeu cara! Ao povo que já está no céu e que continua torcendo pelos daqui. À minha tia e madrinha Arlette, que sempre repetia a profecia do vovô Vicente: "olha, este menino ainda vai ser dotô!" E vamos cantar: "Celebra a vitória..."

Aos meus filhos Francisco e Kiara uma boa notícia: os próximos finais de semana o papai estará brincando, rezando, dormindo, assistindo filmes, viajando, estudando, jogando bola, ..., com vocês. Obrigado pela compreensão mesmo sem entenderem bem. Entenderam? Amo vocês!

Aos meus pais Argemiro e Neuza, aviso que comecei a chorar. Mas de alegria! Se orgulho é pecado, peco todo dia em sentir isso por ser filho de vocês. É benção sobre benção! Se sou guerreiro e não desisto nunca, sou filho da mãe. Se sou dedicado e confiante, sou filho do pai. Tenho o DNA de vocês. Esta vitória é de vocês!

À minha esposa Juliana, aviso que sem você ao meu lado eu não conseguiria. Se não dividir é pecado, peco todo dia, pois não a divido com ninguém. Somos UM diante de Deus! Ligação corpo e alma. O que é meu é seu e o que é seu é meu. Apesar de doutora em Direito, neste caso não dou direito à réplica. Prometo que a tésia acabou. Predicados seus? Todos. Meu amor. A vitória é nossa!

Desejo a todos que gerenciem bem os seus processos de negócio, seja em que esfera for, pois senão o modelo proposto pode denunciá-los. Cuidado! Risos. 
“Um entendido sabe tudo. Um sábio sabe apenas o essencial" Millôr Fernandes

"Talento é sorte, empenho é virtude." Jaime Pinsky

"Se queremos progredir não devemos repetir a história, mas fazer uma história

nova." Mahatma Gandhi

"Poderei fazer tudo com a ajuda de Cristo.

Ele me dará forças." 


\section{RESUMO}

Nas duas últimas décadas pôde-se constatar uma preocupação constante de gestores, tanto da iniciativa privada quanto da administração pública, com a evolução do conhecimento e a busca de soluções para os problemas relacionados às áreas de gestão de organizações e de tecnologia. O conceito de gerenciamento de processos, conhecido desde o início do século passado com o movimento da administração científica, tem ecoado com mais intensidade na consciência do mundo dos negócios nas duas últimas décadas. A busca pelo direcionamento das organizações aos processos de negócio motivou movimentos como o da gestão pela qualidade total (TQM), a reengenharia dos processos de negócio (BPR), o desenvolvimento de sistemas integrados de gestão empresarial (ERP) e, mais recentemente, o gerenciamento de processos de negócio ou BPM - Business Process Management. Contudo, existe na literatura acadêmica uma lacuna de relatos sobre mecanismos de medição de desempenho de BPMs que considerem o processo como um todo, de ponta a ponta, e que contribuam para o cumprimento das metas estratégicas das organizações. A existência de um significativo atraso tanto no aspecto tecnológico quanto no controle de processos de negócio na administração pública fazendária brasileira foi um dos motivos que provocaram a criação do PNAFE Programa Nacional de Apoio aos Fiscos Estaduais no Brasil. Documentos do programa apontam a necessidade de que o gerenciamento de processos de negócio das organizações fazendárias seja mensurado considerando atributos gerenciais, segundo uma visão sistêmica, e não somente com o uso de indicadores de desempenho pontuais ou de caráter operacional. E mais ainda: acusam a falta de um modelo para a medição de desempenho de BPMs no programa. Baseado neste fato, este estudo visou identificar os atributos que devem fazer parte de uma proposta de modelo para medição e avaliação de desempenho de BPMs no PNAFE, bem como desenvolver e validar tal modelo. O construto foi baseado nos atributos dos sistemas de medição de desempenho organizacionais, conhecidos e validados pela literatura acadêmica da administração e da engenharia de produção, compilados em estudos científicos recentes, e no modelo arquitetônico para controle de processos de negócio RiverFish, oriundo da Engenharia de Software. Foi realizada uma pesquisa qualitativa com dirigentes do programa no estado de São Paulo e, posteriormente, uma pesquisa quantitativa (e-survey) com coordenadores estaduais e líderes de projeto da maioria dos estados brasileiros no PNAFE a fim de se conhecerem os atributos e em que grau estiveram presentes nos principais macroprocessos das áreas financeira, tributária e de organização e gestão do programa. Para a análise da relação entre gestores, atributos do modelo e processos de negócio foram empregadas técnicas estatísticas de análise uni, bi e multivariada, por meio das quais se buscou conhecer, por exemplo, quais atributos discriminaram o gerenciamento satisfatório do insatisfatório de BPMs, ou ainda, aqueles que mais contribuíram para o aperfeiçoamento do modelo proposto. Por fim, são apresentadas as principais conclusões do estudo, orientações aos gestores do programa e sugestões para pesquisas futuras, e a proposta de modelo final validado para o gerenciamento de processos de negócio no PNAFE - o SMD-BPM. 


\begin{abstract}
In the last two decades it has been noticed managers being constantly interested about the knowledge evolution and the search for solutions to problems related to the areas of organizations management and technology on the private enterprise and also on the public administration. The concept of process management, which has been known since the beginning of the last century with the scientific administration movement, has echoed more intensely in the business world in the last two decades. The organizations search towards the business processes has motivated movements such as the total quality management (TQM), the business processes reengineering (BPR), the enterprise resources planning (ERP), and more recently, the BPM - Business Process Management. However, there is a gap in the academic literature when it comes to mechanisms for measuring the BPM performance considering the process end-to-end, which contribute for the organizations to reach their strategic goals. The PNAFE - Programa Nacional de Apoio aos Fiscos Estaduais no Brasil (National Programme to Support the State Treasury Department in Brazil) was created mostly in order to minimize the significant delay both in the use of technology and in the business process control within the Brazilian public treasury administration. Documents of the programme indicate that business processes management in the treasury organizations should be assessed for their management attributes in a systemic view, not only by punctual performance indicators or operational ones. Besides, the documents point the absence of a BPM performance measuring model in the programme. Taking this fact into consideration, this study aims at identifying the attributes that should be part of proposed model for measuring and evaluating BPM performance within PNAFE as well as to develop and validate such model. The construct has been based on the attributes of the organizational performance measuring systems, known and validated by the academic literature of administration and production engineering - which have been recently compiled in scientific studies and in the architectural model of RiverFish, a software engineering tool for business process control. A qualitative research has been carried on involving directors of the programme in the state of São Paulo and later a quantitative research (e-survey) involving state coordinators and project leaders in most of the Brazilian states at PNAFE, in order to know which attributes and at which level were present in the main macro-processes of the financial, tax administration and organization management areas in the programme. To analyze the relationships between managers, model attributes and business processes, statistical techniques of uni-, bi- and multivariate analysis were applied. By doing so, it was expected to know, for example, which attributes discriminate between the suceeded management and the unsucceeded one in BPM, or even which attributes have contributed the most to the improvement of the proposed model. Finally, the most important conclusions of the study are shown, together with suggestions both to the programme managers and for further researches, and a proposal of a final validated model for the business process management at PNAFE - the SMD-BPM.
\end{abstract}




\section{SUMÁRIO}

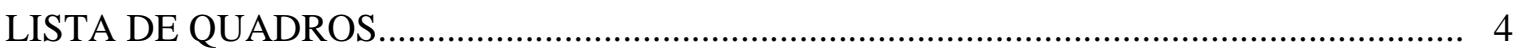

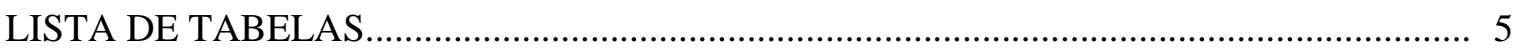

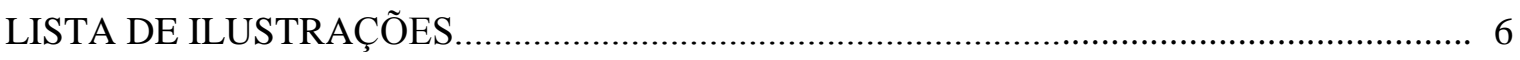

CAPÍTULO 1 - INTRODUÇÃO E CARACTERIZAÇÃO DO PROBLEMA.......................... 7

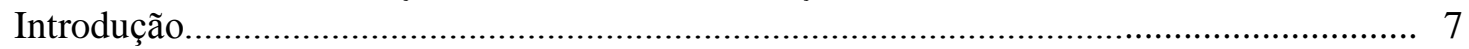

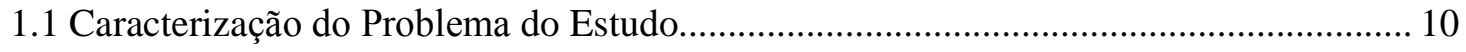

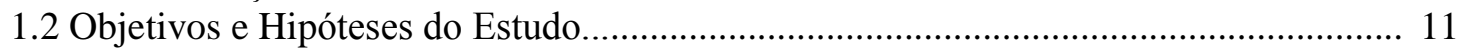

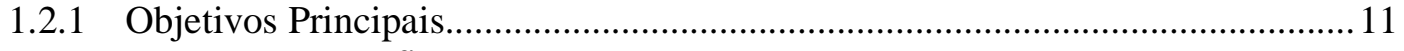

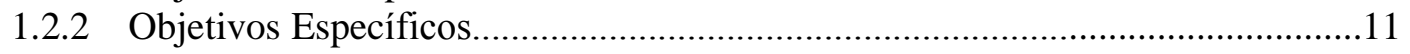

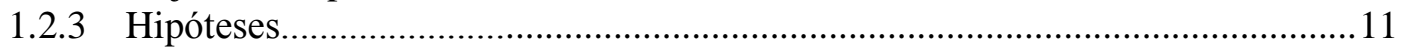

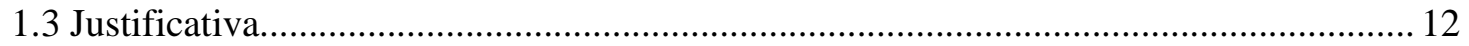

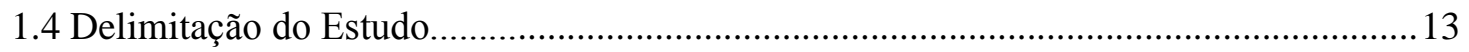

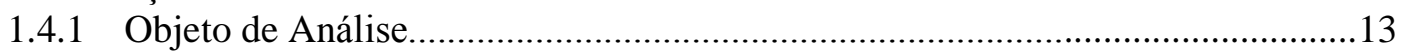

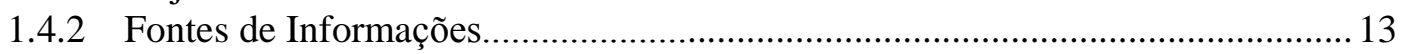

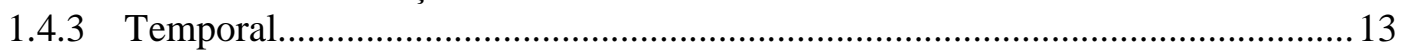

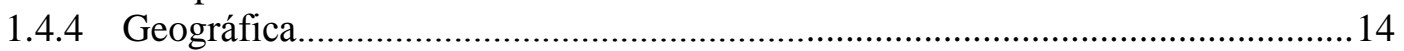

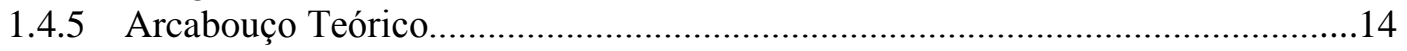

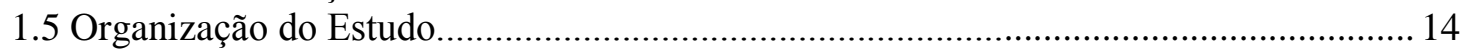

CAPÍTULO 2 - FUNDAMENTAÇÃO TEÓRICA................................................................ 16

2.1 Sistemas de Medição de Desempenho Organizacional.................................................. 16

2.1.1 Cronologia dos Sistemas de Medição de Desempenho Organizacional..................17

2.1.2 Principais Sistemas de Medição de Desempenho Organizacional......................... 20

2.1.3 Atributos dos Sistemas de Medição de Desempenho Organizacional....................30

2.2 O Gerenciamento de Processos de Negócio - BPM....................................................... 37

2.2.1 O BPM sob a ótica da Gestão Empresarial......................................................... 37

2.2.1.1 Contextualização histórica.................................................................. 37

2.2.1.2 Conceito de Processo de Negócio...................................................... 39

2.2.1.3 A demanda por BPM...................................................................... 41

2.2.1.4 Conceito de Gerenciamento de Processos de Negócio......................... 43

2.2.1.5 Fases do Gerenciamento de Processos de Negócio................................ 45

2.2.1.6 Desenvolvimento da Cultura de BPM nas Organizações....................... 48

2.2.1.7 Funcionalidades requeridas pela área de negócio à TIC para os sistemas de BPM............................................................................... 49

2.2.2 O BPM sob a ótica da Tecnologia da Informação e Comunicação...................... 52

2.2.2.1 Fases do Gerenciamento de Processos de Negócio................................. 56

2.2.2.2 Aspectos-Chave do Gerenciamento de Processos de Negócio..................59

2.3 A arquitetura RiverFish e o conceito de Plano de Navegação......................................... 64

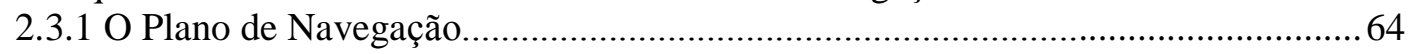

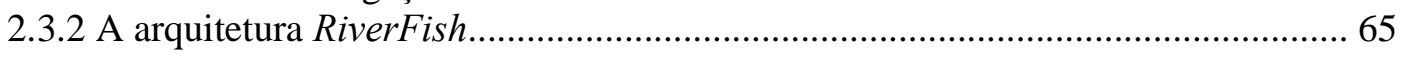

2.3.3 Associação dos conceitos do Plano de Navegação ao RiverFish ......................... 67

2.3.4 Principais características e propriedades do RiverFish ........................................6 69

CAPÍTULO 3 - O PROGRAMA DE MODERNIZAÇÃO DAS ADMINISTRAÇÕES FAZENDÁRIAS ESTADUAIS BRASILEIRAS - PNAFE.............................................. 72 
CAPÍTULO 4 - ASPECTOS METODOLÓGICOS DA PESQUISA....................................... 81

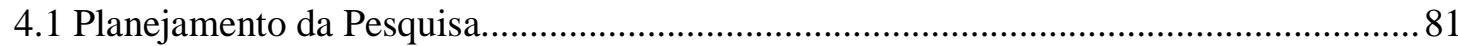

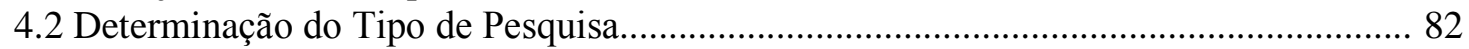

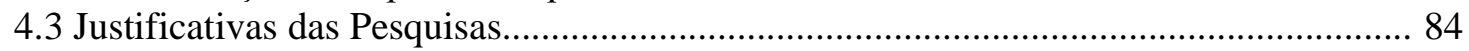

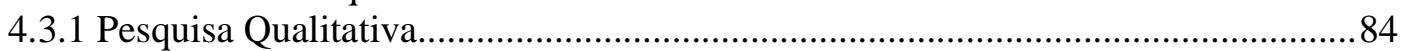

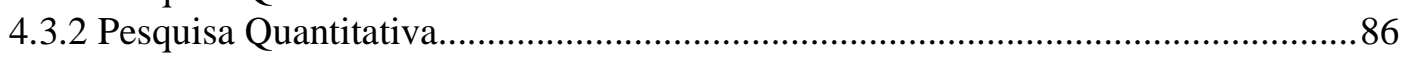

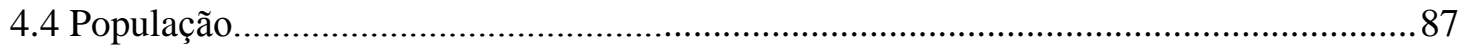

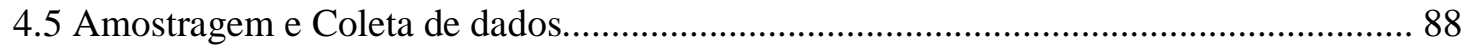

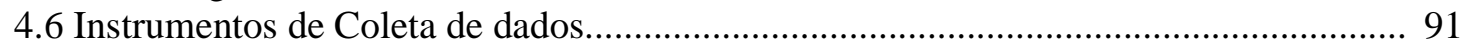

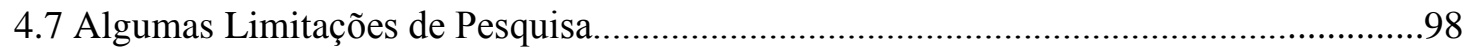

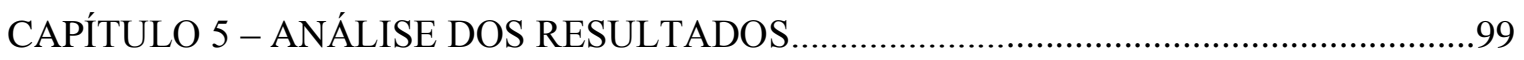

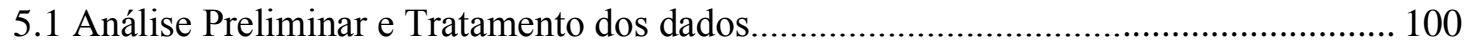

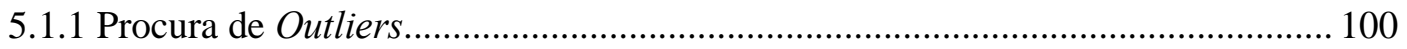

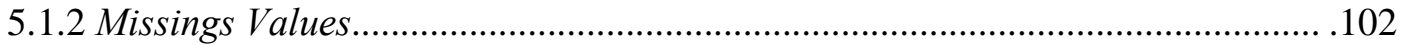

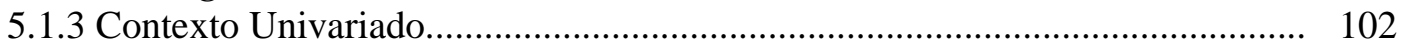

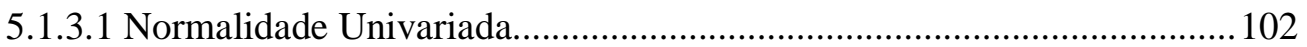

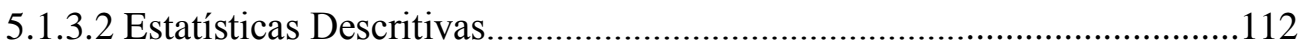

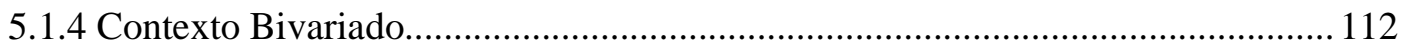

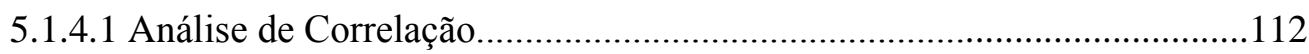

5.1.4.2 Teste Qui-quadrado......................................................................... 114

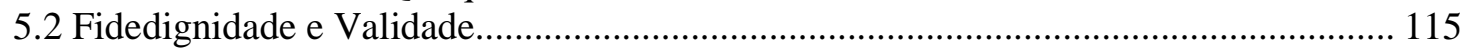

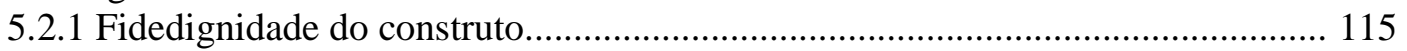

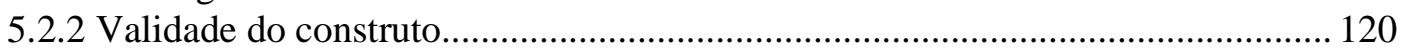

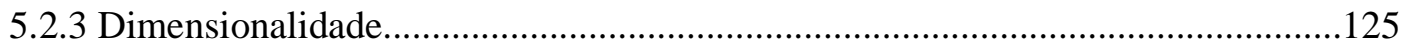

5.3 Análise Multivariada dos Dados - Relação entre Gestores e Processos.........................125

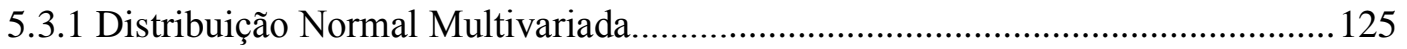

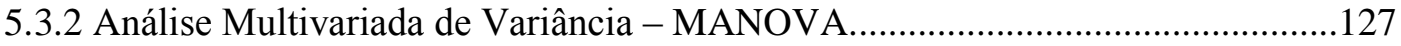

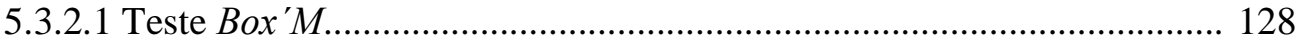

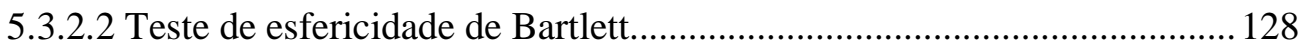

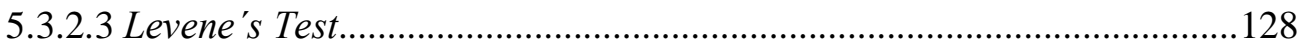

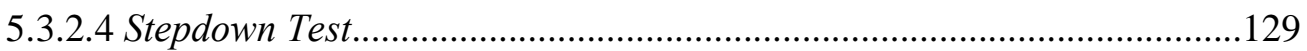

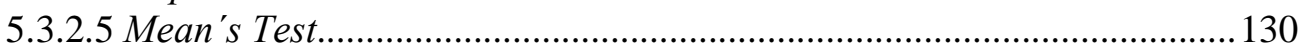

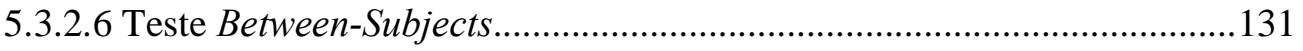

5.3.2.7 Hipóteses do modelo MANOVA........................................................ 131

5.3.2.8 Principais resultados das MANOVAs..................................................133

5.3.2.9 Análise Univariada de Variância - ANOVA............................................136

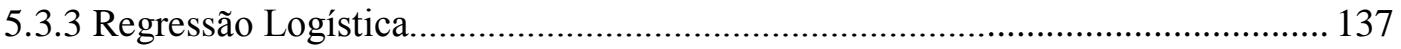

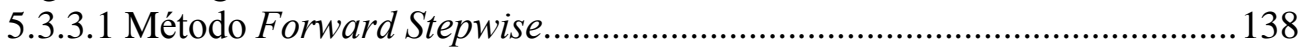

5.3.3.2 Função de Verossimilhança - L...........................................................139

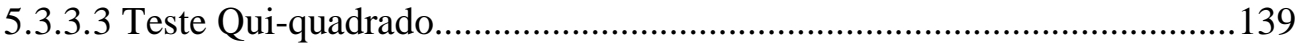

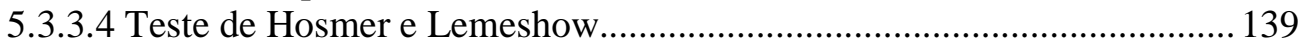

5.3.3.5 Estatísticas Cox \& Snell e Nagelkerke..................................................140

5.3.3.6 Estatística Wald..................................................................................140

5.3.3.7 Nível de Correlação da Classificação....................................................140

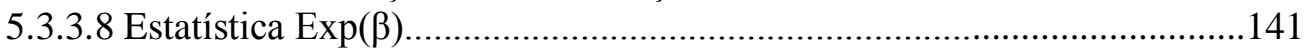

5.3.3.9 Principais resultados da Regressão Logística.........................................141

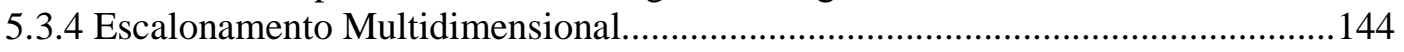

5.3.4.1 Principais resultados do Escalonamento Multidimensional.....................146 


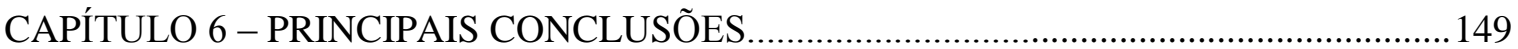

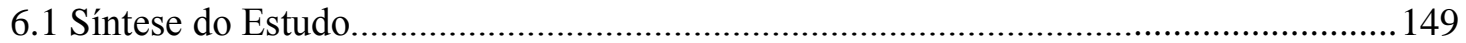

6.2 Contribuições das Análises do Contexto Univariado.....................................................151

6.3 Contribuições das Análises do Contexto Bivariado.......................................................153

6.4 Contribuições das Análises de Fidedignidade e Validade no modelo SMD-BPM........155

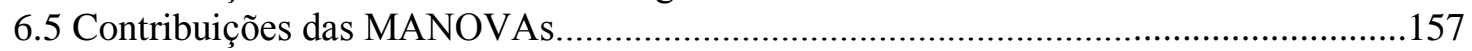

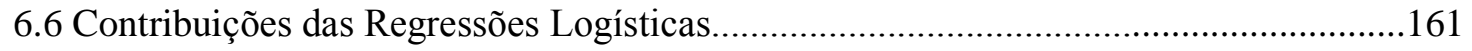

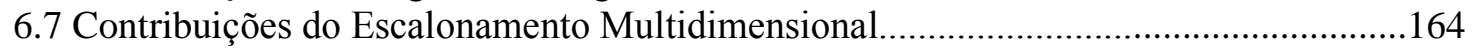

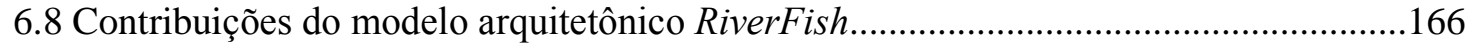

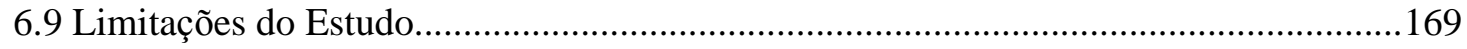

6.10 Algumas propostas para pesquisas futuras...........................................................170

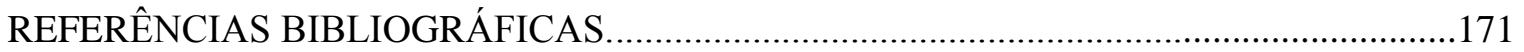

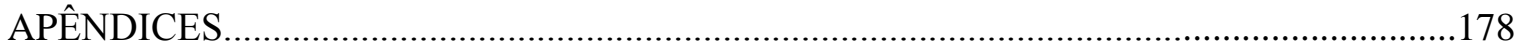

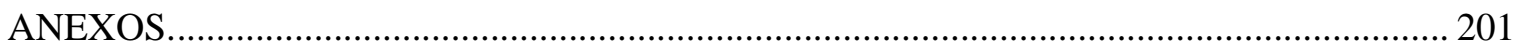




\section{LISTA DE QUADROS}

Quadro 1 - Cronologia da Medição de Desempenho............................................................... 18

Quadro 2 - Características Gerais dos SMDO: PMQ - SMART - MQMD.............................22

Quadro 3 - Características Gerais dos SMDO: SCD - BSC - IDPMSa..................................23

Quadro 4 - Características Gerais dos SMDO: IDPMSb - PP - SMDG................................. 24

Quadro 5 - Vantagens e Desvantagens dos SMDO: PMQ - SMART - MQMD - SCD -

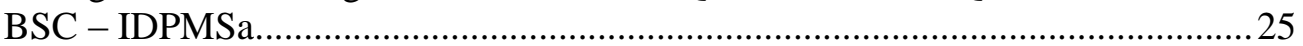

Quadro 6 - Vantagens e Desvantagens dos SMDO: IDPMSb - PP - SMDG........................ 26

Quadro 7 - Características Gerais dos SMDO: BSC - EVA - ICA......................................... 27

Quadro 8-Características Gerais dos SMDO: VE - HSA - VCS........................................ 28

Quadro 9 - Vantagens e Desvantagens dos SMDO: BSC - EVA - ICA - VE - HSA -VCS. 29

Quadro 10 - Atributo Normativo do SMDO - Alinhamento.................................................... 31

Quadro 11 - Atributo Normativo do SMDO - Análise Crítica.................................................. 32

Quadro 12 - Atributo Normativo do SMDO - Aprendizado Organizacional.............................. 32

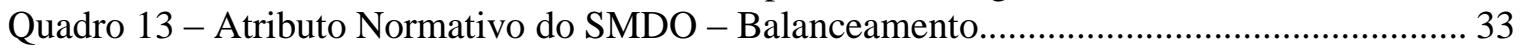

Quadro 14 - Atributo Normativo do SMDO - Clareza................................................................. 33

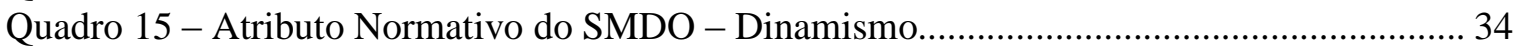

Quadro 16 - Atributo Normativo do SMDO - Dinamismo - Agilidade.....................................35

Quadro 17 - Atributo Normativo do SMDO - Dinamismo - Flexibilidade............................... 35

Quadro 18 - Atributo Normativo do SMDO - Dinamismo - Monitoramento...............................35

Quadro 19 - Atributo Normativo do SMDO - Integração..................................................... 35

Quadro 20 - Atributo Normativo do SMDO - Participação....................................................... 36

Quadro 21 - Atributo Normativo do SMDO - Relacionamento Causal...................................... 36

Quadro 22 - Definições de Processo de Negócio......................................................................... 39

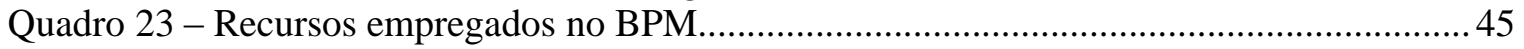

Quadro 24 - Principais barreiras à implantação da cultura de BPM........................................... 48

Quadro 25 - Funcionalidades requeridas pela área de negócio para softwares de BPM............ 49

Quadro 26 - Serviços cadastrais disponíveis aos contribuintes por meio da Internet - Terceiro Benchmark - setembro 2002 ............................................................ 79

Quadro 27 - Serviços cadastrais disponíveis aos contribuintes por meio da Internet

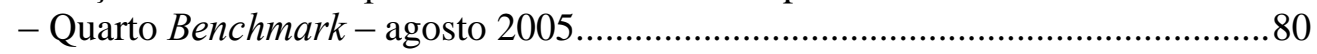

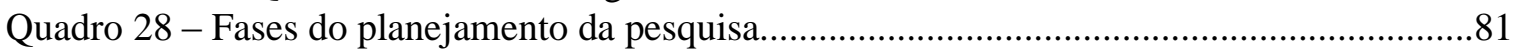

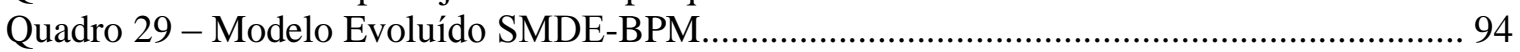

Quadro 30 - Relação de processos e macro-processos do PNAFE.............................................96

Quadro 31 - Técnicas utilizadas para os dados da pesquisa...................................................99

Quadro 32 - Amostra Total dividida por função e região......................................................... 102

Quadro 33 - Altas correlações entre variáveis da Amostra Total.............................................113

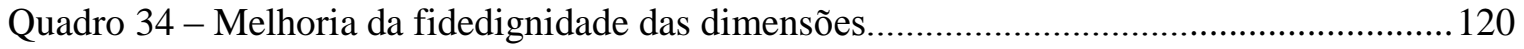

Quadro 35 - Qualidade da análise fatorial.........................................................................122

Quadro 36 - Maiores e menores médias entre as variáveis da amostra................................... 152

Quadro 37 - Variáveis com maior coeficiente de variação.................................................... 153

Quadro 38 - Dimensões cujas médias variaram por Função e Região......................................158

Quadro 39 - Variáveis que mais contribuíram para a melhoria do modelo...............................160

Quadro 40 - Variáveis que mais distinguem o grau do gerenciamento....................................161

Quadro 41 - Variáveis que compõem uma síntese do modelo SMD-BPM...............................163

Quadro 42 - Dimensões do SMD-BPM relacionadas aos macro-processos............................. 165

Quadro 43 - Propriedades do RF encontradas nas variáveis mais influentes do modelo...........167

Quadro 44 - Propriedades do RF na distinção da qualidade do gerenciamento........................168 


\section{LISTA DE TABELAS}

Tabela 1 - Variação da Arrecadação dos principais tributos estaduais no Brasil...................... 74

Tabela 2 - Síntese Econômico / Social e Variação da Arrecadação dos principais tributos estaduais no período de 1997 a 2002 ............................................................ 76

Tabela 3 - Variação da Arrecadação do ICMS x Impostos Federais no Brasil entre

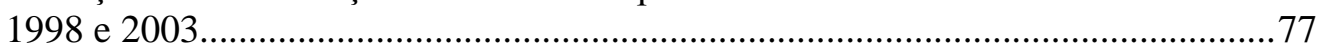

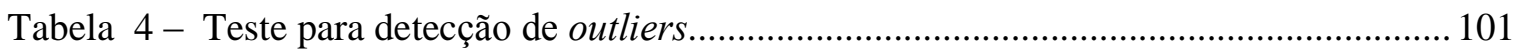

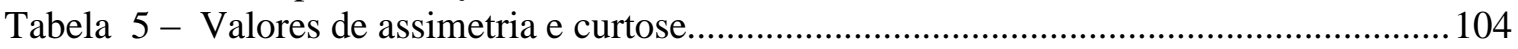

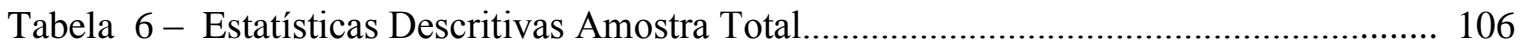

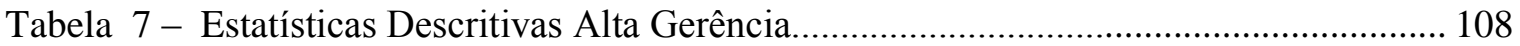

Tabela 8 - Estatísticas Descritivas Média Gerência............................................................. 110

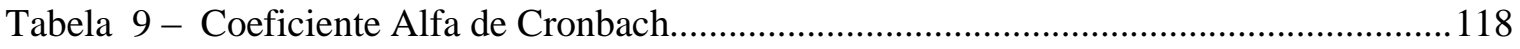

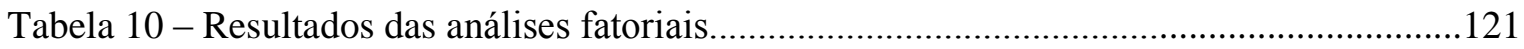

Tabela 11 - Resultados da análise de regressão múltipla....................................................124

Tabela 12 - Normalidade multivariada para as variáveis das dimensões do SMD-BPM..........126

Tabela 13 - Resumo MANOVAs nos Escores Fatoriais......................................................... 133

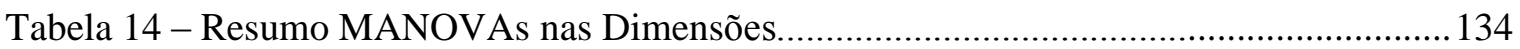

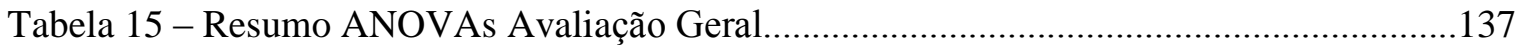

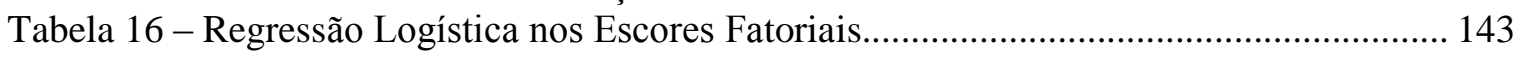

Tabela 17 - Regressão Logística nas Dimensões................................................................144

Tabela 18 - VPGpo para os Escores Fatoriais das Dimensões................................................145

Tabela 19 - Valores das correlações entre dimensões do SMD-BPM e dimensões do EM......147 


\section{LISTA DE ILUSTRAÇÕES}

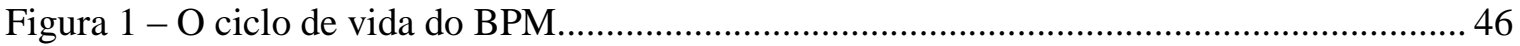

Figura 2 - Ranking of BPM Components and Whole-Product Requirements......................... 50

Figura 3 - Comparison of 'Must Have' Components: 2004 vs. 2003....................................... 51

Figura 4 - Feature Perceived as Needed but Missing from Current BPM Offerings..................52

Figura 5 - Tendências relevantes dos Sistemas de Informação para BPM.................................. 53

Figura 6 - O ciclo de vida do BPM comparado ao ciclo de gerenciamento de workflow.......... 57

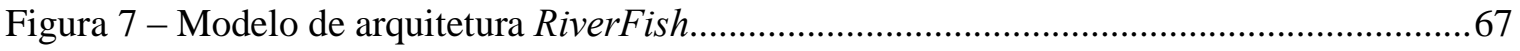

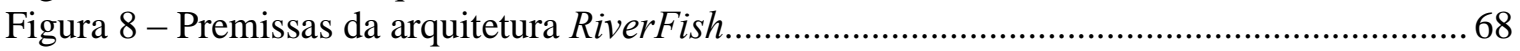

Figura 9 - Exemplo de ação de Check Points num processo de validação de dados................... 69

Figura 10 - Sintaxe do Stepdown Test dimensão Aprendizado x Função................................. 129

Figura 11 - Sintaxe do Stepdown Test dimensão Aprendizado x Região...................................139

Figura 12 - Hipóteses modelo MANOVA Aprendizado x Função......................................... 142

Figura 13 - Hipóteses modelo MANOVA Escores Fatoriais x Função..................................... 142

Figura 14 - Mapa perceptual dos grupos de macro-processos do PNAFE...............................147 


\section{CAPÍTULO 1 - INTRODUÇÃO E CARACTERIZAÇÃO DO PROBLEMA}

\section{Introdução}

Nas duas últimas décadas pôde-se constatar uma preocupação constante de gestores, tanto da iniciativa privada quanto da administração pública, com a evolução do conhecimento e busca de soluções para os problemas relacionados às áreas de gestão de organizações e de tecnologia.

Uma maneira prática e ágil de estruturar conhecimentos e transmiti-los a toda a organização se dá com a conceituação de processos e com o entendimento de suas técnicas de construção, implantação e gerenciamento. Passa-se então para uma visão com foco em gestão por processos, em detrimento do pensamento anterior com foco em dados pontuais e informações estanques.

Os conceitos de processos de negócio e de reengenharia de processos dentro das organizações não são recentes e desconhecidos de gestores e usuários. Remontam ao século passado, no início da década de 20, com o movimento da administração científica, ou movimento taylorista, que apregoava a necessidade de especialização das atividades e dos profissionais nas organizações. Entretanto, segundo Smith e Fingar (2003, p. 12), havia falhas neles que impediam a obtenção de resultados satisfatórios.

O termo process management ecoou com mais intensidade na consciência do mundo dos negócios levando as organizações a buscarem um direcionamento aos seus processos de negócio. A partir daí surgiram movimentos como o da gestão pela qualidade total (TQM Total Quality Management), com foco na eficiência e eficácia da melhoria contínua dos processos, conhecido no Japão do pós-guerra e incipiente no ocidente; e o da reengenharia total de processos (BPR - Business Process Re-engineering), cujo mote era destruir para posteriormente criar novos processos mais simplificados e promover o downsizing.

Posteriormente, vivenciou-se a era dos sistemas integrados de gestão empresarial (ERP Enterprise Resource Planning), com o intuito de implementar o modelo de empresa integrada e promover a mudança da visão departamental para a visão de processos nas empresas. 
Contudo, cada movimento destes não se revelou suficientemente capaz de modificar, entre outras dificuldades, a cultura do gerenciamento por funções nas empresas, bem como diminuir a desconexão cada vez mais evidente entre as necessidades das áreas de negócio e a habilidade da Tecnologia da Informação e Comunicação - TIC em fornecer sistemas informatizados para a gestão organizacional. Não existe consenso entre os gestores de que o capital investido nestes modelos e nas novas tecnologias que os acompanharam trouxe o retorno esperado.

O termo processo pode assumir significados distintos em diversos campos do conhecimento. No contexto deste trabalho, processo é um conjunto de atividades interligadas e ordenadas, dirigidas por uma visão central, que busca alcançar um objetivo determinado. Portanto, atravessa áreas específicas, utiliza-se de recursos de ordens diversificadas, usando e melhorando a qualidade das informações.

As operações nas organizações dependem sempre de um ou mais processos, sejam formalizados ou não, que utilizem tecnologia, em especial a de informação, ou não. A formalização dos processos se dá pelo desenvolvimento de modelos de processos de negócio, que levam em conta, entre outras dimensões: objetivos de negócios, métricas, fluxos, dados, integrações e relacionamentos entre áreas. Para Hammer e Stanton (1995), os processos continuam sendo fragmentados e isolados em diferentes setores de organizações tradicionais. Em conseqüência, permanecem difíceis de serem enxergados como parte de uma engrenagem e, portanto, de difícil gerenciamento e controle.

A última década de 90 foi pródiga em relatos acadêmicos e empresariais sobre o desenvolvimento e uso de sistemas de Workflow e um pouco menos rica em relação ao seu gerenciamento. Em decorrência da evolução destes sistemas ou a fim de suprir as deficiências apontadas por especialistas, surgiu o conceito de Gerenciamento de Processos de Negócio BPM.

Para Smith e Fingar (2003, p. 14), o BPM intenta criar uma definição simples de um processo de tal maneira que profissionais de diferentes áreas de uma organização possam ver e manipular o mesmo processo por meio de uma representação adequada, e agir nele segundo suas competências e responsabilidades. De acordo com os autores, o que diferencia o BPM 
dos demais movimentos é o desenvolvimento de uma capacidade que permite a área de negócio ter controle de suas necessidades presentes e futuras, gozando de visibilidade do processo de ponta a ponta, e de agilidade e comunicação para a inovação dos processos. A partir daí, visa construir uma base de entendimento comum entre as comunidades de negócio, de TI e de sistemas.

Para que o BPM se torne uma metodologia, Aalst et al (2003b) apontam a ausência de mecanismos de aferição de desempenho do gerenciamento de processos de negócio de caráter holístico, já que hoje se dispõe apenas de ferramentas e frameworks para o monitoramento de processos operacionais. Estes instrumentos de medição não consideram o todo do processo e, por conseguinte, não contribuem para o cumprimento de metas estratégicas pelas organizações. De acordo com Kaydos (1991), alcançar um desempenho maximizado é um balanceamento de ações e não apenas a otimização de uma variável.

A existência de um significativo atraso tecnológico e de controle de processos de negócio na administração pública fazendária brasileira, evidenciada no documento Brasil (2005b, p. 1), provocou a criação do Programa Nacional de Apoio aos Fiscos Estaduais - PNAFE. Dispondo de uma base sólida de conhecimento gerencial e tecnológico e de recursos humanos e financeiros, entre outros, trazidos pelo programa, os estados brasileiros vêm promovendo significativos avanços no controle e arrecadação de tributos, combate à sonegação físcal e otimização de serviços públicos colocados à disposição do cidadão brasileiro.

Entretanto, documentos internos do PNAFE apontam a necessidade de que o gerenciamento destes novos processos de negócio seja mensurado considerando atributos gerenciais e não somente operacionais. E mais ainda: falta um modelo para a medição de desempenho destes BPM. Uma das dificuldades apontadas para a mensuração de desempenho de BPM é a carência de um referencial teórico ou de iniciativas de destaque (benchmark), tanto no âmbito circunscrito do PNAFE, quanto da literatura acadêmica empresarial.

Uma revisão bibliográfica dos trabalhos e relatos de experiências com bons resultados no uso de Sistemas de Medição de Desempenho Organizacionais - SMDO, bem como da solução arquitetônica RiverFish - RF para controle dos BPM, suscitou o presente estudo e o levantamento dos atributos dos SMDO, sob a ótica e conceituação do RF, que deveriam fazer 
parte de uma proposta de modelo desenvolvido e validado para medição e avaliação de desempenho de BPM no PNAFE.

Foi realizada uma pesquisa qualitativa com dirigentes do programa no estado de São Paulo e, posteriormente, uma pesquisa quantitativa (e-survey) com coordenadores estaduais e líderes de projeto da maioria dos estados brasileiros no PNAFE, a fim de se conhecerem os atributos e em que grau estiveram presentes nos principais macro-processos das áreas financeira, tributária e de organização e gestão do programa.

Para a análise da relação entre gestores, atributos do modelo e processos de negócio foram empregadas técnicas estatísticas de análise uni, bi e multivariada, por meio das quais se buscou conhecer, por exemplo, quais atributos discriminaram o gerenciamento satisfatório do insatisfatório de BPM, ou ainda, aqueles que mais contribuíram para o aperfeiçoamento do modelo proposto. Por fim, são apresentadas as principais conclusões do estudo, orientações aos gestores do programa e sugestões para pesquisas futuras, e a proposta de modelo final validado para o gerenciamento de processos de negócio no PNAFE.

Este modelo proposto - o SMD-BPM - visa municiar os coordenadores de programas e líderes de projetos de modernização com uma abordagem capaz de auxiliá-los na verificação de desempenho dos BPM já implantados, e em vias de implantação, nas respectivas administrações estaduais fazendárias brasileiras. Numa visão maior, pretende auxiliar os dirigentes do PNAFE a buscar metas estratégicas mais ousadas para criação, acompanhamento e simplificação dos processos de negócio colocados à disposição do cidadão, bem como nos processos internos de controle e na gestão fisco-tributária-financeira das Secretarias de Fazenda estaduais no Brasil.

\subsection{Caracterização do Problema do Estudo}

O problema levantado neste estudo pode ser caracterizado da seguinte forma:

- Quais atributos devem fazer parte da medição e avaliação de desempenho do gerenciamento de processos de negócio (BPM) em programas de modernização na administração fazendária estadual brasileira? 


\subsection{Objetivos e Hipóteses do Estudo}

Os objetivos principais e específicos pretendidos e as hipóteses a serem verificadas neste estudo foram:

\subsubsection{Objetivos Principais}

- Desenvolver um modelo teórico de avaliação e medição de desempenho do gerenciamento de processos de negócio para o PNAFE;

- Validar o modelo desenvolvido para o gerenciamento de processos de negócio do PNAFE.

Para o alcance dos objetivos principais, foram definidos os seguintes objetivos específicos:

\subsubsection{Objetivos Específicos}

- Identificar os critérios (atributos) praticados no monitoramento do gerenciamento de processos de negócio;

- Comparar os procedimentos realizados na prática com os recomendados no modelo desenvolvido;

- Buscar possíveis relações entre gestores e macro-processos do PNAFE e atributos do modelo proposto.

Algumas hipóteses deste estudo foram definidas da seguinte maneira:

\subsubsection{Hipóteses}

- $\quad$ Existem dimensões (atributos normativos) com grande poder discriminante nos grupos de gestores quanto ao desempenho de suas atividades de gerenciamento;

- Em cada dimensão há atributos que permitem a visualização de similaridades e diferenças relativas nos gerenciamentos dos processos;

- Existem diferenças nos graus de gerenciamento decorrentes da função exercida pelos gestores dos processos ou da região a que pertencem;

- Existem similaridades nas atividades de gerenciamento de processos de negócio que permitem posicionar relativamente os macro-processos. 


\subsection{Justificativa}

O presente estudo justificou-se por atender aos critérios de relevância do tema, originalidade e viabilidade do trabalho. O Gerenciamento de Processos de Negócio - BPM é um tema atual, considerado por alguns autores como um aperfeiçoamento do Gerenciamento de Workflow nas organizações, e que se ressente de conceitos multidisciplinares para a aferição de seu desempenho.

A literatura acadêmica descreve a tendência de aperfeiçoamento do BPM neste sentido com a criação de ferramentas, tais como o BPA - Business Process Analysis (Análise de Processos de Negócio) que visa cobrir aspectos negligenciados pelos produtos tradicionais de workflow como, por exemplo, análise e diagnóstico. Descreve ainda o instrumento BAM - Business Activity Monitoring (Monitoramento das Atividades de Negócio), que tem por objetivo usar os dados históricos guardados pelo sistema de informação para diagnosticar os processos operacionais.

Contudo, a literatura carece de relatos de modelos de sistemas de medição de desempenho para BPM, que já tenham sido usados ou sejam aplicáveis em organizações, e que disponham de atributos de caráter holístico (gerencial) e não somente baseados no monitoramento do processo operacional de negócio.

Esta necessidade de modelo de medição foi sentida especialmente no contexto da administração pública fazendária e seus programas de modernização implantados nos estados brasileiros, que desenvolvem um grande esforço na busca de soluções eficazes para a reengenharia de processos de negócio e não dispõem claramente de mecanismos para o acompanhamento sistêmico e gerencial dos processos contidos nos novos produtos.

Portanto, o resultado do estudo possibilitará aos dirigentes dos programas e projetos de modernização da administração pública brasileira uma discussão sobre o gerenciamento de seus processos de negócio, e um conhecimento baseado num modelo conceitual para a medição de desempenho, com atributos normativos (construtos) definidos e validados por técnicas estatísticas. 
A viabilidade do estudo se deu pela facilidade de acesso do pesquisador aos principais dirigentes e líderes do PNAFE, pelo fato de ter participado como líder, por mais de cinco anos, de um dos trinta e seis projetos de modernização desenvolvidos na Secretaria Estadual de Fazenda de São Paulo. O estudo também se mostrou oportuno já que o programa encontrase em sua fase final, época propícia para se observar e analisar seus resultados, bem como lançar novas propostas para os programas de modernização que o sucederão.

O pesquisador contou ainda com o apoio da FAZESP - Escola Fazendária do Estado de São Paulo, nas disciplinas do curso de doutoramento da FEA/USP, e da UCE-SP Unidade Central Estadual de São Paulo, braço do PNAFE no estado, ao viabilizar o acesso às autoridades fazendárias.

\subsection{Delimitação do Estudo}

Este estudo se realizou com enfoques específicos no que se refere ao objeto de análise, fontes de informações, dimensão temporal, dimensão geográfica e arcabouço teórico.

\subsubsection{Objeto de Análise}

Foram estudados elementos dos projetos de modernização que envolveram o gerenciamento de processos de negócio concebidos para áreas da administração pública estadual fazendária brasileira, no âmbito dos programas do PNAFE.

\subsubsection{Fontes de Informações}

O estudo foi desenvolvido com base em informações obtidas junto aos Coordenadores das UCEs - Unidades Centrais Estaduais das unidades da federação brasileira, Sub-coordenadores técnicos e administrativos, Gerentes de macro-projetos, Líderes e membros de equipes de projetos de modernização ligados ao PNAFE.

\subsubsection{Temporal}

Os dados foram coletados no período de agosto a dezembro de 2005. 


\subsubsection{Geográfica}

Pesquisas classificadas nas categorias qualitativa e quantitativa foram realizadas junto a participantes de programas de modernização dos estados brasileiros integrantes do PNAFE.

\subsubsection{Arcabouço Teórico}

O arcabouço teórico foi baseado na fundamentação descrita no capítulo 2. Na seção 2.1 foram levantados e analisados os conceitos fundamentais dos principais Sistemas de Medição de Desempenho Organizacional, relatados em compilações de estudos acadêmicos recentes. $\mathrm{Na}$ seção 2.2 encontram-se descritos os principais conceitos do BPM - Gerenciamento de Processos de Negócio, sob as óticas da gestão empresarial e da TI, sua importância atual, e um comparativo com o gerenciamento de processos de Workflow. Na seção 2.3 foi descrito o modelo arquitetônico para controle de processos de negócio RiverFish e conceitos do Plano de Navegação, que se apresentam como uma solução sistêmica para controle de BPM.

No capítulo 3 foi explicado no que consiste o PNAFE, quais seus principais objetivos e principais resultados no período entre 1997 e 2004, bem como foram relacionados alguns dos seus principais processos de negócio, distribuídos pelos estados brasileiros.

\subsection{Organização do Estudo}

Este estudo é composto por seis capítulos. O capítulo 1 corresponde à introdução, caracterização do problema e objetivos do estudo.

O capítulo 2 apresenta a fundamentação teórica, com conceitos de: gerenciamento de processos de negócio (BPM) e Workflow; sistemas de medição de desempenho organizacional (SMDO); modelo arquitetônico para o desenvolvimento de sistemas de gerenciamento de BPM RiverFish e o seu Plano de Navegação (RF-NP).

O capítulo 3 explica no que consiste o programa de modernização das administrações fazendárias estaduais brasileiras (PNAFE), seus objetivos e alguns resultados alcançados. 
O capítulo 4 apresenta os aspectos metodológicos deste estudo, com a especificação do tipo de pesquisa, plano amostral, técnica de coleta de dados, instrumento de coleta e as técnicas estatísticas aplicadas na fase de análise dos dados.

O capítulo 5 é constituído pela análise dos resultados obtidos e a proposição de um modelo de avaliação e medição do gerenciamento de processos de negócio no PNAFE.

O capítulo 6 traz uma síntese do estudo, das principais conclusões, das suas limitações e de sugestões para novas pesquisas.

Ao final, encontram-se dispostas as referências bibliográficas utilizadas no período do estudo, bem como apêndices e anexos contendo documentos complementares à pesquisa. 


\section{CAPÍTULO 2 - FUNDAMENTAÇÃO TEÓRICA}

Este capítulo encontra-se dividido em três macro seções. Na seção 2.1 encontra-se um resumo de pesquisas acadêmicas recentemente realizadas, contendo uma compilação dos principais conceitos, características, atributos, finalidades, enfoques, vantagens e desvantagens dos modelos de SMDO - Sistemas de Medição de Desempenho de Organizações relatados.

Na seção 2.2 são apresentadas as principais características do Gerenciamento de Processos de Negócio - BPM, contendo definição, fases de desenvolvimento e aspectos-chave, bem como um comparativo e diferenciação com o Gerenciamento de Workflow.

$\mathrm{Na}$ seção 2.3 são descritos os principais conceitos e o embasamento teórico do modelo arquitetônico para gerenciamento e controle de processos de negócio RF - RiverFish e seu NP - Plano de Navegação, que se apresentam como uma proposta de solução de arquitetura de sistemas de informação para BPM.

Portanto, a base teórica para o desenvolvimento do modelo conceitual de sistema de medição e avaliação de desempenho de Gerenciamento de Processos de Negócio - SMD-BPM está fundamentada nos atributos e conceitos abstraídos do estudo do SMDO, do BPM e do RF-NP.

\subsection{Sistemas de Medição de Desempenho Organizacional}

É preocupação recorrente de administradores de diversos tipos de organizações e de setores os mais variados possíveis, o desempenho das organizações que dirigem. A medição do processo produtivo não é um tema novo, remontando aos séculos XIV e XV, quando o comércio, impulsionado pelas grandes navegações e pela busca de novas terras, exigia maior controle em todas as fases das transações realizadas.

Para fins deste trabalho, o sistema organizacional (SO) é definido como o sistema processador que converte diversas entradas de recursos recebidos de sistemas fornecedores, em saídas de produtos e serviços que são fornecidos para sistemas receptores (FIGUEIREDO, 2003, p. 58). 
Este sistema possui uma alça de retro-alimentação que orienta o re-desenho e a melhoria contínua da execução do trabalho.

O SO considera a concorrência que também se utiliza dos recursos dos sistemas fornecedores e introduz produtos e serviços nos sistemas receptores; sofre a influência do ambiente social, econômico e político; transforma entradas em saídas por meio de processos finalísticos e de apoio; e utiliza o gerenciamento para interpretar e reagir aos estímulos internos e externos (SINK e TUTTLE, 1993; RUMMLER e BRACHE, 1994, p. 73).

O Sistema de Medição de Desempenho Organizacional é aqui entendido como o conjunto de pessoas, processos, métodos, ferramentas e indicadores, estruturado para coletar, descrever e representar dados, a fim de gerar informações sobre múltiplas dimensões de desempenho para usuários de diferentes níveis hierárquicos.

Com base nas informações geradas, os usuários podem avaliar o desempenho de equipes, atividades, processos e o próprio Sistema Organizacional, para tomar decisões e executar ações para a melhoria do desempenho (CLARK, 1995; BITITCI et al, 2000; NEELY et al, 2002; FIGUEIREDO, 2003, p. 58).

\subsubsection{Cronologia dos Sistemas de Medição de Desempenho Organizacional}

Os sistemas de medição de desempenho são focos de interesse da atividade humana. Isto pode ser observado ao longo da história, com o período fértil de sua evolução se estendendo pelo século XX. O quadro 1 procura traduzir, de forma resumida, a evolução destes sistemas, em síntese constante da pesquisa KPMG LLP (2001, p. 10).

Note-se que os sistemas de medição descritos acompanharam a evolução dos principais modelos organizacionais concebidos e desenvolvidos neste período, com enfoque em seus conceitos básicos. Percebe-se ainda que, ao longo do tempo, a medição de desempenho veio agregando os atributos relacionados às áreas financeira e de recursos humanos; ao estudo das relações causa-efeito e de integração de atributos da medição de desempenho; ao estudo de cenários de mercado; ao capital intelectual nas empresas; e, com isso, ganhando em multidisciplinaridade de requisitos e complexidade no gerenciamento. 
Quadro 1 - Cronologia da Medição de Desempenho

\begin{tabular}{|c|c|c|c|}
\hline $\begin{array}{l}\text { DATA DE } \\
\text { ORIGEM }\end{array}$ & $\begin{array}{l}\text { ÁREAS DE } \\
\text { MEDIÇÃO }\end{array}$ & $\begin{array}{c}\text { LÍDERES } \\
\text { PRESUMIDOS } \\
\end{array}$ & CONCEITO \\
\hline Pré século XX & Financeira & Diversos & $\begin{array}{l}\text { Medição de áreas financeiras para julgar o } \\
\text { sucesso de empreendimentos comerciais e } \\
\text { governamentais }\end{array}$ \\
\hline $\begin{array}{l}\text { Início dos anos } \\
1900\end{array}$ & $\begin{array}{l}\text { Processos centrais } \\
\text { (Core Processes) }\end{array}$ & $\begin{array}{l}\text { Frederick Taylor e } \\
\text { Frank e Lillian Gilbreth }\end{array}$ & $\begin{array}{l}\text { Aparecimento da escola do pensamento de } \\
\text { tempo e movimento }\end{array}$ \\
\hline \multirow[t]{3}{*}{ 1930s-1940s } & $\begin{array}{l}\text { Painel de controle } \\
\text { de bordo }\end{array}$ & $\begin{array}{l}\text { Engenheiros de } \\
\text { processos franceses }\end{array}$ & $\begin{array}{l}\text { Painel para identificar relações de causa e } \\
\text { efeito - antecessor ao conceito do BSC }\end{array}$ \\
\hline & $\begin{array}{l}\text { Processos } \\
\text { operacionais }\end{array}$ & $\begin{array}{l}\text { W. Edwards Deming e } \\
\text { Walter E. Shewart }\end{array}$ & $\begin{array}{l}\text { Pesquisa em torno do conceito e fontes de } \\
\text { variabilidade e relações entre os } \\
\text { desempenhos correntes e futuros }\end{array}$ \\
\hline & $\begin{array}{l}\text { Desempenho do } \\
\text { funcionário } \\
\text { (Employee } \\
\text { Performance) }\end{array}$ & Diversos & $\begin{array}{l}\text { Pesquisa sobre a importância do } \\
\text { desempenho dos funcionários para o } \\
\text { sucesso organizacional }\end{array}$ \\
\hline 1964 & $\begin{array}{l}\text { Contabilidade de } \\
\text { recursos humanos }\end{array}$ & $\begin{array}{l}\text { Roger H. Hermanson e } \\
\text { outros }\end{array}$ & $\begin{array}{l}\text { Quantificação de valor econômico de } \\
\text { pessoas como insumo de decisões } \\
\text { gerenciais e financeiras }\end{array}$ \\
\hline 1970 & $\begin{array}{l}\text { Planejamento de } \\
\text { Cenário (Scenario } \\
\text { Planning) }\end{array}$ & Diversos & $\begin{array}{l}\text { Técnicas para modelar certos eventos e } \\
\text { avaliar seu impacto na organização (estudo } \\
\text { de cenários) }\end{array}$ \\
\hline $1990 \mathrm{~s}$ & $\begin{array}{l}\text { BSC - } \\
\text { Balanced } \\
\text { scorecard }\end{array}$ & $\begin{array}{l}\text { Robert S. Kaplan e } \\
\text { David P. Norton }\end{array}$ & $\begin{array}{l}\text { Scorecard para medir e estabelecer } \\
\text { relações de causa e efeito de quatro } \\
\text { perspectivas sobre processos financeiros, } \\
\text { de cliente, internos e crescimento }\end{array}$ \\
\hline 1994 & $\begin{array}{l}\text { Valor econômico } \\
\text { adicionado } \\
\text { (Economic Value } \\
\text { Added) }\end{array}$ & $\begin{array}{l}\text { Stern, Stewart \& } \\
\text { Company }\end{array}$ & $\begin{array}{l}\text { Medida de desempenho para apurar as } \\
\text { formas pelas quais o valor da corporação } \\
\text { pode ser incrementado ou perdido }\end{array}$ \\
\hline 1997 & $\begin{array}{l}\text { Enfoque no } \\
\text { capital intelectual }\end{array}$ & $\begin{array}{l}\text { Bontis, Edvinsson, } \\
\text { Malone, Roos \& Roos }\end{array}$ & $\begin{array}{l}\text { Medição em uma estrutura integrada, dos } \\
\text { recursos intangíveis que contribuem para a } \\
\text { criação de valor organizacional }\end{array}$ \\
\hline
\end{tabular}

FONTE: Adaptado de KPMG LLP (2001, p. 10)

Figueiredo (2003, p. 15-16) divide os sistemas de medição de desempenho organizacional em três fases distintas. A primeira fase, no período entre os séculos XIV e XIX, inclui o surgimento das primeiras práticas contábeis para controle dos processos produtivos e o desenvolvimento dos primeiros sistemas de administração e controle da produção.

A segunda fase, no período compreendido entre o início do século XX e o início da década de 80, quando é possível observar que a medição de desempenho passou explicitamente a fazer parte do ciclo de planejamento e controle das organizações, época em que o principal modelo era o da Pirâmide Du Pont.

Neely (1999, p. 90) explica que este modelo começou com a consolidação das pequenas empresas, pertencentes aos três primos $\mathrm{Du}$ Pont, com outras de natureza familiar. Com isto, a 
indústria de explosivos americana foi reorganizada, incorporando na nova estrutura organizacional uma espécie de benchmark de processos, com enfoque financeiro. De acordo com Kennerley e Neely (2002), a pirâmide de medidas desenvolvida interliga uma grande variedade de relações financeiras e tem uma estrutura claramente hierárquica, ligando as medidas dos diferentes níveis organizacionais. Surgem aí medidas financeiras como, por exemplo, o fluxo de caixa (Cash Flow) e o retorno sobre investimento (ROI).

A terceira fase, compreendida no período entre meados da última década de 80 até os dias de hoje, nasce das críticas ao modelo anterior e seus similares, sendo então identificados na literatura consultada outros atributos. Atributos estes baseados em ativos intangíveis e não financeiros, fundamentados mais em fatos do que em histórias (anecdotal), porém necessários à eficácia dos novos modelos de medição de desempenho criados.

Kaplan e Norton (1997, p. 21) acreditam que numa organização o que não é medido não é gerenciado. Saltério e Webb (2003, p. 41) acrescentam que o que é medido e usado nas avaliações de desempenho organizacionais é gerenciado.

A pesquisa KPMG LLP (2001, p. 13) realizada com líderes que representavam organizações globais, num encontro com membros do MIT - Massachusetts Institute of Tecnology, em 1999, a fim de identificar assuntos e desafios que os gerentes estavam enfrentando naquele momento, indica, entre outros, que esses líderes freqüentemente se sentem inundados com o volume de dados.

Entretanto, esses líderes se mostravam carentes de informações relevantes, tempestivas e confiáveis de desempenho organizacional, num mundo caracterizado pelos participantes como em mudança contínua inexorável. Em outras palavras, a ênfase do sistema deveria ser em entender com clareza o que deveria ser medido versus o que é medido.

Corroborando esta percepção, Robson (2004, p. 515) afirma que a medição de desempenho pode ser deteriorada pela quantidade excessiva ou pela insuficiência de medidas qualitativas e quantitativas. Segundo o autor, os gestores devem identificar, em suas organizações, um conjunto mínimo de medidas, a fim de se detectar o momento em que o desempenho global do processo se torna inaceitável. 
Harrington (1993, p. 88) destaca a dificuldade de se lidar com o universo de medidas de desempenho, sugerindo que este controle esteja circunscrito às medidas críticas ou essenciais para o processo organizacional como um todo.

Outra constatação importante da pesquisa foi de que teorias convencionais de medição e práticas de negócio não estavam fornecendo a direção e o suporte necessários à tomada de decisões. Segundo Saltério e Webb (2003, p. 39), cerca de metade das empresas que constavam do rol das mil maiores empresas elencadas na revista Fortune, no ano de 2002, declararam utilizar algum tipo de método de mensuração de desempenho, considerado como atividade empresarial estratégica, crítico para atingir resultados e não somente para medi-los.

Figueiredo (2003, p. 16) complementa que, em que pese o significativo interesse demonstrado pelas organizações em conhecerem e efetivamente usarem algum dos modelos propostos neste

período, cerca de 70\% dos novos sistemas de desempenho de medição organizacional implementados não funcionaram de acordo com o esperado.

A pesquisa KPMG LLP (2001, p. 13) indica ainda a necessidade de uma nova geração de sistemas e ferramentas de medição de desempenho para auxiliar os líderes das organizações a lidar com o caráter dinâmico das mudanças. Esta talvez seja uma das maiores explicações para o fato de Figueiredo (2003, p. 23-25), numa revisão criteriosa de literatura, ter identificado nesta fase cerca de 33 (trinta e três) novos modelos de SMDO.

\subsubsection{Principais Sistemas de Medição de Desempenho Organizacional}

Seguindo critérios de relevância, número de citações na literatura consultada e difusão entre as organizações, Figueiredo (2003, p. 26-52) selecionou os nove principais sistemas de medição de desempenho organizacional, que foram analisados e serviram de referencial teórico para o desenvolvimento de um modelo conceitual para a auto-avaliação de sistemas de medição de desempenho organizacional. São eles: 
1) PMQ - Performance Measure Questionnaire - 1990;

2) SMART - Strategic Measurement and Reporting Technique - 1991;

3) MQMD - Modelo Quantum de Medição de Desempenho - 1994;

4) SCD - Sete Critérios de Desempenho - 1993;

5) BSC - Balanced Scorecard - 1992, 1993, 1996 e 2001;

6) IDPMSa - Integrated and Dynamic Performance Measurement System - 1997, 1998 e 2000 ;

7) IDPMSb - Integrated and Dynamic Performance Measurement System - 1996 e 1997;

8) PP - Performance Prism - 2001 e 2002;

9) SMDG - Sistema de Medição do Desempenho Global - 2001.

Os quadros 2 a 4 apresentam, num breve resumo, as principais características destes modelos de sistemas de medição de desempenho, tais como origem, razão (motivo), finalidade, enfoque, identificadas na literatura da administração de empresas, das ciências econômicas e contábeis, e das engenharias, com ênfase na engenharia de produção.

Entre estas características, merece destaque a preocupação dos formuladores dos SMDO com:

- $\quad$ a efetividade e melhoria da medição de desempenho;

- $\quad$ o desempenho global da organização;

- $\quad$ as medidas operacionais, como chave para bons resultados;

- $\quad$ o alinhamento dos processos com a estratégia organizacional;

- $\quad$ a integração das medidas de desempenho;

- a abrangência das medidas de desempenho (organização, processos e pessoas);

- $\quad$ o equilíbrio e a interação entre as medidas de desempenho;

- $\quad$ a satisfação do cliente e dos participantes (stakeholders) dos processos;

- $\quad$ a comunicação intra e interdepartamental;

- $\quad$ o feedback e atualização de padrões de desempenho;

- $\quad$ as ferramentas de diagnóstico de desempenho. 
Quadro 2 - Características gerais dos SMDO: PMQ - SMART - MQMD

\begin{tabular}{|c|c|c|c|c|}
\hline MODELO & ORIGEM & RAZÃO & FINALIDADE & ENFOQUE \\
\hline $\begin{array}{l}\text { PMQ - } \\
\text { Performance } \\
\text { Measure } \\
\text { Questionnaire }\end{array}$ & $\begin{array}{l}\text { Dixon, Nanni e } \\
\text { Vollmann, } 1990\end{array}$ & $\begin{array}{l}\text { Avalia a efetividade } \\
\text { do sistema de } \\
\text { medição de } \\
\text { desempenho. Pode } \\
\text { ser aplicado a todos } \\
\text { os funcionários ou } \\
\text { aos de nível de } \\
\text { gerência }\end{array}$ & $\begin{array}{l}\text { Identificar as } \\
\text { necessidades de } \\
\text { melhoria das } \\
\text { organizações }\end{array}$ & $\begin{array}{l}\text { Usa um questionário } \\
\text { para coletar dados e } \\
\text { escolher as medidas } \\
\text { que melhor avaliem } \\
\text { o desempenho da } \\
\text { organização. } \\
\text { Avalia quatro } \\
\text { aspectos: } \\
\text { - alinhamento } \\
\text { - congruência } \\
\text { - consenso } \\
\text { (comunicação) } \\
\text { - confusion } \\
\text { (variação entre } \\
\text { respostas } \\
\text { questionários e } \\
\text { consenso opiniões) }\end{array}$ \\
\hline $\begin{array}{l}\text { SMART - } \\
\text { Strategic } \\
\text { Measurement } \\
\text { and } \\
\text { Reporting } \\
\text { Technique }\end{array}$ & $\begin{array}{l}\text { Lynch e Cross, 1991, } \\
\text { desenvolvido pelos } \\
\text { laboratórios Wang } \\
\text { pela insatisfação de } \\
\text { medidas tradicionais } \\
\text { e baseado em } \\
\text { conceitos de } \\
\text { Qualidade Total, } \\
\text { Engenharia Industrial } \\
\text { e Custeio Baseado } \\
\text { em Atividades }\end{array}$ & $\begin{array}{l}\text { As medidas } \\
\text { operacionais são as } \\
\text { chaves para atingir } \\
\text { resultados de alto } \\
\text { nível }\end{array}$ & $\begin{array}{l}\text { Levar a visão da } \\
\text { organização, } \\
\text { traduzida em } \\
\text { objetivos financeiros, } \\
\text { aos sistemas de } \\
\text { operação do negócio, } \\
\text { de forma que as } \\
\text { medidas operacionais } \\
\text { sustentem a visão da } \\
\text { organização. } \\
\text { O modelo usa dois } \\
\text { tipos de medidas: } \\
\text { 1) as que medem a } \\
\text { eficiência interna das } \\
\text { atividades e } \\
\text { departamentos; } \\
\text { 2) as que medem a } \\
\text { efetividade externa } \\
\text { em termos de } \\
\text { mercado }\end{array}$ & $\begin{array}{l}\text { Usa uma pirâmide } \\
\text { com níveis de } \\
\text { objetivos e medidas: } \\
1^{\circ} \text { - visão da } \\
\text { corporação ou } \\
\text { estratégica } \\
2^{\circ} \text { - unidades - } \\
\text { objetivos definidos } \\
\text { em termos } \\
\text { financeiros } \\
3^{\circ} \text { - operações - } \\
\text { objetivos tangíveis } \\
\text { definidos em termos } \\
\text { de qualidade, custo e } \\
\text { tempo de } \\
\text { processamento e de } \\
\text { entrega }\end{array}$ \\
\hline $\begin{array}{l}\text { MQMD - } \\
\text { Modelo } \\
\text { Quantum de } \\
\text { Medição de } \\
\text { Desempenho }\end{array}$ & Hronec, 1994 & $\begin{array}{l}\text { Cria uma matriz } \\
\text { associando todos os } \\
\text { processos à estratégia } \\
\text { da organização por } \\
\text { meio de um conjunto } \\
\text { de medidas de } \\
\text { desempenho }\end{array}$ & $\begin{array}{l}\text { Avaliar o "valor" } \\
\text { para o cliente, que é o } \\
\text { relacionamento entre } \\
\text { custo e qualidade e o } \\
\text { "serviço" para o } \\
\text { cliente, que é o } \\
\text { relacionamento entre } \\
\text { qualidade e tempo. } \\
\text { As medidas } \\
\text { abrangem três níveis: } \\
\text { a organização, os } \\
\text { processos e as } \\
\text { pessoas }\end{array}$ & $\begin{array}{l}\text { Compõe-se de } \\
\text { quatro elementos } \\
\text { básicos: } \\
\text { 1- os Geradores (que } \\
\text { ajudam a } \\
\text { desenvolver a } \\
\text { estratégia focalizada } \\
\text { na missão) } \\
\text { 2- os Facilitadores } \\
\text { (que fornecem apoio } \\
\text { à implementação de } \\
\text { medidas) } \\
\text { 3- o processo } \\
\text { (definição de metas, } \\
\text { medidas de output, } \\
\text { monitoramento de } \\
\text { atividades-chave) } \\
\text { 4- melhoria contínua } \\
\text { (feedback, e ajuste) }\end{array}$ \\
\hline
\end{tabular}




\section{Quadro 3 - Características gerais dos SMDO: SCD - BSC - IDPMSa}

\begin{tabular}{|c|c|c|c|c|}
\hline MODELO & ORIGEM & RAZÃO & FINALIDADE & ENFOQUE \\
\hline $\begin{array}{l}\text { SCD - } \\
\text { Sete } \\
\text { Critérios de } \\
\text { Desempenho }\end{array}$ & Sink e Tuttle, 1993 & $\begin{array}{l}\text { Pressuposto que o } \\
\text { desempenho de um } \\
\text { sistema } \\
\text { organizacional pode } \\
\text { ser medido por sete } \\
\text { critérios básicos }\end{array}$ & $\begin{array}{l}\text { Avaliar o } \\
\text { desempenho global } \\
\text { da organização por } \\
\text { meio de todos os seus } \\
\text { pontos-chave }\end{array}$ & $\begin{array}{l}\text { Os sete critérios } \\
\text { enfocam: } \\
\text { 1- eficácia } \\
\text { 2- eficiência } \\
\text { 3- qualidade } \\
\text { 4- produtividade } \\
\text { 5- qualidade de } \\
\text { vida } \\
\text { 6- inovação } \\
\text { 7- lucratividade }\end{array}$ \\
\hline $\begin{array}{l}\text { BSC - } \\
\text { Balanced } \\
\text { Scorecard }\end{array}$ & $\begin{array}{l}\text { Kaplan e Norton, } \\
\text { desenvolveram o } \\
\text { sistema em 1992, em } \\
1993 \text { apresentam } \\
\text { exemplos reais de } \\
\text { implementação; Em } \\
1996 \text { o BSC é } \\
\text { apresentado como um } \\
\text { novo sistema de } \\
\text { gestão estratégica e } \\
\text { em } 2001 \text { este é } \\
\text { expandido para toda a } \\
\text { organização }\end{array}$ & $\begin{array}{l}\text { O BSC procura } \\
\text { responder cinco } \\
\text { questões básicas: } \\
\text { 1-como devemos ser } \\
\text { vistos pelos } \\
\text { acionistas } \\
\text { 2-como devemos ser } \\
\text { vistos pelos clientes } \\
\text { 3-como sustentar a } \\
\text { capacidade de mudar } \\
\text { e melhorar } \\
\text { 4-em que processos } \\
\text { devemos alcançar a } \\
\text { excelência } \\
\text { 5-como mudar e } \\
\text { melhorar }\end{array}$ & $\begin{array}{l}\text { Medir o desempenho } \\
\text { com medidas } \\
\text { estratégicas, } \\
\text { operacionais e } \\
\text { financeiras }\end{array}$ & $\begin{array}{l}\text { A alta gerência } \\
\text { define um conjunto } \\
\text { de fatores críticos de } \\
\text { sucesso para cada } \\
\text { uma das } \\
\text { perspectivas. } \\
\text { A partir desses } \\
\text { fatores são fixadas } \\
\text { metas específicas e } \\
\text { são desenvolvidos } \\
\text { indicadores para } \\
\text { medir o sucesso de } \\
\text { cumprimento de } \\
\text { cada meta. }\end{array}$ \\
\hline $\begin{array}{l}\text { IDPMSa - } \\
\text { Integrated } \\
\text { and } \\
\text { Dynamic } \\
\text { Performance } \\
\text { Measurement } \\
\text { System }\end{array}$ & $\begin{array}{l}\text { Bititci, Carrie e } \\
\text { McDevitt, 1997, } \\
\text { Bititci, Carrie e } \\
\text { Turner, 1998, Bititci, } \\
\text { Turner e Bergmann, } \\
2000\end{array}$ & $\begin{array}{l}\text { O processo de gestão } \\
\text { de desempenho é o } \\
\text { meio pelo qual a } \\
\text { organização } \\
\text { administra seu } \\
\text { desempenho, de } \\
\text { acordo com suas } \\
\text { estratégias } \\
\text { corporativas e } \\
\text { funcionais, bem } \\
\text { como seus objetivos }\end{array}$ & $\begin{array}{l}\text { Viabilizar o } \\
\text { desdobramento da } \\
\text { visão e da estratégia } \\
\text { por meio da estrutura } \\
\text { hierárquica e } \\
\text { promover a } \\
\text { integração entre a } \\
\text { unidade operacional, } \\
\text { a supervisão, a média } \\
\text { gerência e a alta } \\
\text { direção }\end{array}$ & $\begin{array}{l}\text { O sistema integra } \\
\text { todas as informações } \\
\text { relevantes dos } \\
\text { demais sistemas - } \\
\text { análise crítica e } \\
\text { desenvolvimento da } \\
\text { estratégia, } \\
\text { contabilidade } \\
\text { gerencial, } \\
\text { administração por } \\
\text { objetivos, medidas } \\
\text { de desempenho não- } \\
\text { financeiras formais e } \\
\text { informais, esquemas } \\
\text { de incentivos/ bônus } \\
\text { e avaliações de } \\
\text { desempenho } \\
\text { individual }\end{array}$ \\
\hline
\end{tabular}


Quadro 4 - Características gerais dos SMDO: IDPMSb - PP - SMDG

\begin{tabular}{|c|c|c|c|c|}
\hline MODELO & ORIGEM & RAZÃO & FINALIDADE & ENFOQUE \\
\hline $\begin{array}{l}\text { IDPMSb - } \\
\text { Integrated } \\
\text { and } \\
\text { Dynamic } \\
\text { Performance } \\
\text { Measurement } \\
\text { System }\end{array}$ & $\begin{array}{l}\text { Ghalayimi e Noble, } \\
1996 \\
\text { Ghalayimi, Noble e } \\
\text { Crowe, } 1997\end{array}$ & $\begin{array}{l}\text { IDPMSb busca a } \\
\text { integração das três } \\
\text { principais áreas } \\
\text { funcionais da } \\
\text { empresa (gerência, } \\
\text { equipes de melhoria e } \\
\text { chão de fábrica), } \\
\text { usando três } \\
\text { ferramentas: PMQ } \\
\text { (Performance } \\
\text { Measurement } \\
\text { Questionnaire), o } \\
\text { conceito de Meia } \\
\text { Vida e o Diagrama de } \\
\text { Tempo de Ciclo. }\end{array}$ & $\begin{array}{l}\text { Procurar a melhoria } \\
\text { por meio da } \\
\text { integração das áreas e } \\
\text { a "alça de feedback". } \\
\text { As equipes de } \\
\text { melhoria atualizam os } \\
\text { padrões de } \\
\text { desempenho. }\end{array}$ & $\begin{array}{l}\text { A troca de } \\
\text { informações entre as } \\
\text { áreas e o feedback } \\
\text { são o enfoque } \\
\text { principal do sistema }\end{array}$ \\
\hline $\begin{array}{l}\text { PP - } \\
\text { Performance } \\
\text { Prism }\end{array}$ & $\begin{array}{l}\text { Sistema construído a } \\
\text { partir dos pontos } \\
\text { fortes dos principais } \\
\text { modelos existentes na } \\
\text { literatura, procurando } \\
\text { minimizar os pontos } \\
\text { fracos, por Kennerley } \\
\text { e Neely, } 2002 \text { e por } \\
\text { Neely, Adams e } \\
\text { Crowe, } 2001\end{array}$ & $\begin{array}{l}\text { Busca-se a satisfação } \\
\text { dos interesses dos } \\
\text { interessados por meio } \\
\text { da medição de } \\
\text { desempenho }\end{array}$ & $\begin{array}{l}\text { Utiliza-se o prisma de } \\
\text { desempenho } \\
\text { respondendo-se a } \\
\text { perguntas } \\
\text { relacionadas à } \\
\text { satisfação dos } \\
\text { interessados, às } \\
\text { estratégias, aos } \\
\text { processos, às } \\
\text { capacidades,e à } \\
\text { contribuição dos } \\
\text { interessados }\end{array}$ & $\begin{array}{l}\text { O foco central é a } \\
\text { satisfação dos } \\
\text { interessados } \\
\text { (stakeholders), } \\
\text { sendo os acionistas o } \\
\text { grupo mais } \\
\text { importante }\end{array}$ \\
\hline $\begin{array}{l}\text { SMDG - } \\
\text { Sistema de } \\
\text { Medição de } \\
\text { Desempenho } \\
\text { Global }\end{array}$ & $\begin{array}{l}\text { FPNQ - Fundação } \\
\text { para Prêmio Nacional } \\
\text { da Qualidade, } 2002 \text { - } \\
\text { Modelo do prêmio } \\
\text { nacional da qualidade } \\
\text { brasileiro }\end{array}$ & $\begin{array}{l}\text { Reflete a experiência, } \\
\text { o conhecimento e o } \\
\text { trabalho de pesquisa } \\
\text { de muitas } \\
\text { organizações e } \\
\text { especialistas no } \\
\text { Brasil }\end{array}$ & $\begin{array}{l}\text { Fornece uma visão } \\
\text { abrangente de como } \\
\text { otimizar o } \\
\text { desempenho } \\
\text { organizacional. É } \\
\text { mais uma ferramenta } \\
\text { de diagnóstico do que } \\
\text { um sistema de } \\
\text { medição. }\end{array}$ & $\begin{array}{l}\text { Sete critérios PNQ } \\
\text { (2005) são: } \\
\text { Liderança; } \\
\text { Estratégias e planos; } \\
\text { Clientes e sociedade; } \\
\text { Informação e } \\
\text { conhecimento; } \\
\text { Pessoas; Processos; } \\
\text { Resultados da } \\
\text { organização. }\end{array}$ \\
\hline
\end{tabular}

Os quadros 5 e 6 apresentam, num breve resumo, as principais vantagens e desvantagens dos Modelos de Sistemas de Medição de Desempenho PMQ, SMART, MQMD, SCD, BSC, IDPMSa, IDPMSb, PP, SMDG, identificadas na literatura, e compiladas por Figueiredo (2003, p. 49-52).

A análise das vantagens serve, antes de mais nada, como parâmetro para os gestores na escolha do SMDO que melhor atenda às suas necessidades. Já as desvantagens funcionam como alerta às organizações tanto em relação às deficiências quanto às oportunidades de melhoria destes modelos. 


\section{Quadro 5 - Vantagens e desvantagens dos SMDO: PMQ - SMART - MQMD - SCD - BSC - IDPMSa}

\begin{tabular}{|c|c|c|}
\hline MODELO & $\begin{array}{r}\text { VANTAGENS } \\
\end{array}$ & $\begin{array}{r}\text { DESVANTAGENS } \\
\end{array}$ \\
\hline $\begin{array}{l}\text { PMQ - } \\
\text { Performance } \\
\text { Measure } \\
\text { Questionnaire }\end{array}$ & $\begin{array}{l}\text { - mecanismos de análise crítica do } \\
\text { desempenho global facilitam a avaliação } \\
\text { organizacional } \\
\text { - estimula a participação dos funcionários no } \\
\text { processo de avaliação do SMDO } \\
\text { - fornecimento de informações que facilitam } \\
\text { o aprendizado organizacional }\end{array}$ & $\begin{array}{l}\text { • não utiliza múltiplas dimensões de } \\
\text { desempenho } \\
\text { • não utiliza mecanismos para o } \\
\text { monitoramento do ambiente interno e externo } \\
\text { da organização } \\
\text { • falta de agilidade na colocação à disposição } \\
\text { de informações relevantes de mudanças nos } \\
\text { ambientes interno e externo. }\end{array}$ \\
\hline $\begin{array}{l}\text { SMART - } \\
\text { Strategic } \\
\text { Measurement } \\
\text { and } \\
\text { Reporting } \\
\text { Technique }\end{array}$ & $\begin{array}{l}\text { - uso de medidas vinculadas à estratégia } \\
\text { - desdobramento das medidas do nível } \\
\text { estratégico ao operacional } \\
\text { - relações de causa e efeito entre os } \\
\text { indicadores e os objetivos estratégicos } \\
\text { - utilização de múltiplas dimensões de } \\
\text { desempenho }\end{array}$ & $\begin{array}{l}\text { - ênfase somente na satisfação de clientes e } \\
\text { acionistas, ficando de fora os demais grupos } \\
\text { (funcionários, fornecedores, órgãos } \\
\text { controladores e sociedade) } \\
\text { • não agrega medidas do nível operacional às } \\
\text { do nível estratégico } \\
\text { • não usa mecanismos de retro-alimentação } \\
\text { • não há estímulo à participação de } \\
\text { funcionários }\end{array}$ \\
\hline $\begin{array}{l}\text { MQMD - } \\
\text { Modelo } \\
\text { Quantum de } \\
\text { Medição de } \\
\text { Desempenho }\end{array}$ & $\begin{array}{l}\text { - medidas de desempenho vinculadas à } \\
\text { estratégia e abrangendo três níveis } \\
\text { (organizacional, processos e pessoas) } \\
\text { - ênfase na satisfação dos principais grupos } \\
\text { de interessados (clientes, acionistas, } \\
\text { funcionários, fornecedores, órgãos } \\
\text { controladores, sociedade e meio-ambiente) } \\
\text { - feedback para melhoria contínua do SMDO }\end{array}$ & $\begin{array}{l}\text { - falta de clareza na interação dos sistemas de } \\
\text { medição da integração com as áreas } \\
\text { funcionais da organização } \\
\text { - falta de agilidade na colocação à disposição } \\
\text { de informações relevantes } \\
\text { - falta de clareza na agregação dos indicadores }\end{array}$ \\
\hline $\begin{array}{l}\text { SCD - } \\
\text { Sete Critérios } \\
\text { de } \\
\text { Desempenho }\end{array}$ & $\begin{array}{l}\text { - usa medidas de desempenho em todos os } \\
\text { pontos-chave (sistemas receptores, saídas, } \\
\text { processos, entradas e sistemas fornecedores) } \\
\text { - múltiplas dimensões de desempenho } \\
\text { - mecanismos de realimentação que } \\
\text { fornecem informações do resultado das } \\
\text { ações de melhoria }\end{array}$ & $\begin{array}{l}\text { - falta de clareza na garantia do alinhamento } \\
\text { dos indicadores aos níveis hierárquicos da } \\
\text { organização } \\
\text { - falta de clareza em identificar relações de } \\
\text { causa e efeito entre os indicadores } \\
\text { - falta de agilidade no fornecimento de } \\
\text { informações relevantes no instante em que o } \\
\text { usuário precisa }\end{array}$ \\
\hline $\begin{array}{l}\text { BSC - } \\
\text { Balanced } \\
\text { Scorecard }\end{array}$ & $\begin{array}{l}\text { O BSC tem duas características principais: } \\
\text { 1-resumem em um relatório de gestão } \\
\text { muitos dos elementos aparentemente } \\
\text { discrepantes } \\
\text { 2-previne a sub-otimização forçando os } \\
\text { gerentes a considerar simultaneamente todas } \\
\text { as medidas operacionais }\end{array}$ & $\begin{array}{l}\text { - ênfase em somente três grupos (acionistas, } \\
\text { clientes e funcionários) } \\
\text { • é destinado mais à alta administração e } \\
\text { média gerência } \\
\text { - faltam mecanismos para informações } \\
\text { relevantes rápidas e adaptação do SMDO a } \\
\text { mudanças no ambiente externo e interno }\end{array}$ \\
\hline $\begin{array}{l}\text { IDPMSa - } \\
\text { Integrated } \\
\text { and Dynamic } \\
\text { Performance } \\
\text { Measurement } \\
\text { System }\end{array}$ & $\begin{array}{l}\text { - ênfase na integração de áreas de negócio } \\
\text { - considera todos os grupos interessados } \\
\text { - revisão contínua de objetivos dá um caráter } \\
\text { dinâmico ao SMDO } \\
\text { - monitoramento contínuo do ambiente } \\
\text { externo e interno }\end{array}$ & $\begin{array}{l}\text { - não identifica relações de causa e efeito } \\
\text { - falta de clareza na participação dos usuários } \\
\text { - falta de entendimento dos indicadores pelos } \\
\text { usuários }\end{array}$ \\
\hline
\end{tabular}

FONTE: Figueiredo (2003, p. 49-51) 
Quadro 6 - Vantagens e desvantagens dos SMDO: IDPMSb - PP - SMDG

\begin{tabular}{|c|c|c|}
\hline MODELO & VANTAGENS & DESVANTAGENS \\
\hline $\begin{array}{l}\text { IDPMSb - } \\
\text { Integrated } \\
\text { and Dynamic } \\
\text { Performance } \\
\text { Measurement } \\
\text { System }\end{array}$ & $\begin{array}{l}\text { - visa a melhoria de desempenho apoiada em } \\
\text { feedback } \\
\text { - integra gerência, equipes de melhoria de } \\
\text { processos e chão de fábrica } \\
\text { • estimula atualização de medidas dando } \\
\text { caráter dinâmico ao SMDO } \\
\text { - estimula o aprendizado e a análise crítica }\end{array}$ & $\begin{array}{l}\text { - falta de entendimento dos indicadores pelos } \\
\text { usuários }\end{array}$ \\
\hline $\begin{array}{l}\text { PP - } \\
\text { Performance } \\
\text { Prism }\end{array}$ & $\begin{array}{l}\text { - usa diferentes perspectivas de desempenho } \\
\text { - ênfase na satisfação dos diferentes grupos } \\
\text { de interessados } \\
\text { - processo claro de criação de valor } \\
\text { - metodologia facilita alinhamento } \\
\text { estratégico, alinhamento horizontal e } \\
\text { relações de causa e efeito }\end{array}$ & $\begin{array}{l}\text { - falta de integração com os sistemas de } \\
\text { informação da organização } \\
\text { - falta de agregação dos indicadores de } \\
\text { desempenho } \\
\text { • não usa mecanismos de avaliação } \\
\text { organizacional }\end{array}$ \\
\hline $\begin{array}{l}\text { SMDG - } \\
\text { Sistema de } \\
\text { Medição de } \\
\text { Desempenho } \\
\text { Global }\end{array}$ & $\begin{array}{l}\text { - usa mecanismos de análise crítica do } \\
\text { desempenho global } \\
\text { - estimula aprendizado } \\
\text { - usa múltiplas dimensões de desempenho } \\
\text { - identifica relações de causa e efeito } \\
\text { - busca o alinhamento com a estratégia e a } \\
\text { estrutura organizacional }\end{array}$ & $\begin{array}{l}\text { - falta de clareza de como as informações } \\
\text { relevantes foram colocadas à disposição no } \\
\text { momento necessário } \\
\text { - falta de mecanismo de adaptação a mudanças } \\
\text { no ambiente externo e interno }\end{array}$ \\
\hline
\end{tabular}

FONTE: Figueiredo (2003, p. 51-52)

Na pesquisa KPMG LLP (2001, p. 14) aproximadamente 93\% dos líderes pesquisados acreditam que a medição influi "muito ou em grande parte" nos resultados do departamento ou da organização que representam. Contudo, apenas 51\% estão "muito ou em grande parte" satisfeitos com os sistemas atuais, e somente $15 \%$ estão "muito satisfeitos". Mesmo assim, $87 \%$ consideram a boa informação, proveniente do SMDO, como "muito ou em grande parte" importante para a evolução organizacional. A mesma pesquisa arrola ainda seis modelos de medição de desempenho organizacional que considera relevantes, quais sejam:
a) BSC - Balanced Scorecard;
b) EVA - Economic Value Added;
c) ICA - Intellectual Capital Approaches;
d) VE - Value Explorer;
e) HRA - Human Resource Accounting;
f) VCS - Value Chain Scoreboard.

Os quadros 7 a 9 apresentam, num breve resumo, as características gerais, vantagens e desvantagens dos Modelos de Sistemas de Medição de Desempenho BSC, EVA, ICA, VE, 
HRA, VCS, identificadas na literatura, e compiladas na pesquisa KPMG LLP (2001, p. 1617).

Quadro 7 - Características gerais dos SMDO: BSC - EVA - ICA

\begin{tabular}{|c|c|c|c|c|}
\hline MODELO & ORIGEM & RAZÃO & FINALIDADE & ENFOQUE \\
\hline $\begin{array}{l}\text { BSC - } \\
\text { Balanced } \\
\text { Scorecard }\end{array}$ & $\begin{array}{l}\text { Apresentado nos anos } \\
\text { 1990s por Kaplan e } \\
\text { Norton, em conexão } \\
\text { com sua pesquisa no } \\
\text { Nolan Norton } \\
\text { Institute (KPMG) } \\
\text { envolvendo várias } \\
\text { companhias e } \\
\text { indústrias. }\end{array}$ & $\begin{array}{l}\text { As companhias } \\
\text { precisam um sistema } \\
\text { de criação e } \\
\text { manutenção de } \\
\text { indicadores internos e } \\
\text { externos. }\end{array}$ & $\begin{array}{l}\text { - Medir e administrar } \\
\text { a execução de } \\
\text { estratégia } \\
\text { - Incluir perspectivas } \\
\text { financeiras e não- } \\
\text { financeiras } \\
\text { - Servir como uma } \\
\text { ferramenta de } \\
\text { administração para } \\
\text { toda a empresa } \\
\text { (holística) }\end{array}$ & $\begin{array}{l}\text { - BSC organiza o } \\
\text { sistema de medição } \\
\text { em quatro } \\
\text { perspectivas: } \\
\text { financeira, cliente, } \\
\text { negócios internos e } \\
\text { crescimento. } \\
\text { - Relações de causa e } \\
\text { efeito interligam as } \\
\text { quatro perspectivas } \\
\text { do } \text { scorecard. }\end{array}$ \\
\hline $\begin{array}{l}\text { EVA - } \\
\text { Valor } \\
\text { Econômico } \\
\text { Adicionado }\end{array}$ & $\begin{array}{l}\text { Apresentado em } 1994 \\
\text { por Stern, Stewart \& } \\
\text { Co. como uma } \\
\text { ferramenta para } \\
\text { buscar melhores } \\
\text { práticas financeiras, } \\
\text { ajudando a } \\
\text { maximizar a riqueza } \\
\text { de seus acionistas. }\end{array}$ & $\begin{array}{l}\text { O propósito de uma } \\
\text { empresa é valorizar } \\
\text { ao máximo as ações } \\
\text { em poder dos } \\
\text { acionistas e } \\
\text { maximizar o efetivo } \\
\text { uso do capital. - um } \\
\text { propósito que deveria } \\
\text { ser refletido em toda } \\
\text { decisão, em qualquer } \\
\text { nível da organização. }\end{array}$ & $\begin{array}{l}\text { Desenvolver uma } \\
\text { medição de } \\
\text { desempenho que } \\
\text { considere } \\
\text { apropriadamente } \\
\text { todas as formas pelas } \\
\text { quais o valor da } \\
\text { corporação possa ser } \\
\text { elevado ou reduzido. }\end{array}$ & $\begin{array}{l}\text { EVA é o resultado de } \\
\text { vendas líquidas } \\
\text { menos as despesas } \\
\text { operacionais, menos } \\
\text { impostos, menos } \\
\text { despesas de capital, } \\
\text { considerando } \\
\text { despesas de capital } \\
\text { como o custo médio } \\
\text { ponderado de capital } \\
\text { multiplicado pelo } \\
\text { capital total } \\
\text { investido. Na prática, } \\
\text { o EVA é } \\
\text { incrementado se o } \\
\text { custo médio } \\
\text { ponderado de capital } \\
\text { for menor que o } \\
\text { retorno do ativo } \\
\text { líquido e vice-versa. }\end{array}$ \\
\hline $\begin{array}{l}\text { ICA - } \\
\text { Intellectual } \\
\text { Capital } \\
\text { Approaches } \\
\text { (Enfoques de } \\
\text { Capital } \\
\text { Intelectual) }\end{array}$ & $\begin{array}{l}\text { Apresentado em } 1997 \\
\text { por Bontis, } \\
\text { Edvinsson, Malone. } \\
\text { Roos \& Roos. A } \\
\text { Skandia foi um } \\
\text { pioneiro, usando este } \\
\text { enfoque para refletir } \\
\text { as mudanças em seu } \\
\text { ambiente } \\
\text { competitivo. }\end{array}$ & $\begin{array}{l}\text { Uma boa parcela do } \\
\text { valor gerado por uma } \\
\text { empresa vem de } \\
\text { fontes intangíveis, } \\
\text { que também devem } \\
\text { ser medidas e } \\
\text { monitoradas. Porém, } \\
\text { bens intangíveis não } \\
\text { obedecem as leis } \\
\text { convencionais de } \\
\text { rendimentos } \\
\text { decrescentes e por } \\
\text { isso requerem um } \\
\text { novo enfoque para } \\
\text { serem medidos, } \\
\text { gerenciados e } \\
\text { relatados. }\end{array}$ & $\begin{array}{l}\text { - Medir IC em uma } \\
\text { estrutura integrada } \\
\text { - Combinar capital } \\
\text { financeiro com IC } \\
\text { - Fornecer novos } \\
\text { conhecimentos para a } \\
\text { criação de valor por } \\
\text { meio da revelação e } \\
\text { medição da } \\
\text { contribuição de IC } \\
\text { - Alcançar um } \\
\text { sistema inovador de } \\
\text { relatórios }\end{array}$ & $\begin{array}{l}\text { - IC inclui todos os } \\
\text { recursos intangíveis } \\
\text { que contribuem para } \\
\text { a criação de valor } \\
\text { para a organização } \\
\text { (monetário, físico, } \\
\text { humano, de } \\
\text { relacionamento e } \\
\text { organizacional) } \\
\text { - O enfoque mede IC } \\
\text { em conjunto com o } \\
\text { capital financeiro } \\
\text { - Apresenta } \\
\text { sofisticada } \\
\text { metodologia para } \\
\text { calcular o índice IC } \\
\text { global }\end{array}$ \\
\hline
\end{tabular}

FONTE: Adaptado de KPMG LLP (2001, p. 16-17) 
Quadro 8 - Características gerais dos SMDO: VE - HSA - VCS

\begin{tabular}{|c|c|c|c|c|}
\hline MODELO & ORIGEM & RAZÃO & FINALIDADE & ENFOQUE \\
\hline $\begin{array}{l}\text { VE - } \\
\text { Value Explorer }\end{array}$ & $\begin{array}{l}\text { Criado em } 2000 \\
\text { por Andriessen \& } \\
\text { Tissen da KPMG } \\
\text { Knowledge } \\
\text { Advisory Services } \\
\text { (Países Baixos) }\end{array}$ & $\begin{array}{l}\text { Dar uma percepção do } \\
\text { potencial futuro de ativos } \\
\text { intangíveis, levando em } \\
\text { conta: } \\
\text { - Valor adicionado para } \\
\text { clientes } \\
\text { - Competitividade } \\
\text { - Sustentabilidade } \\
\text { - Robustez }\end{array}$ & $\begin{array}{l}\text { Ajudar as } \\
\text { organizações a } \\
\text { entender e medir o } \\
\text { valor de suas } \\
\text { competências } \\
\text { centrais }\end{array}$ & $\begin{array}{l}\text { Uma metodologia } \\
\text { para: } \\
\text { - identificar } \\
\text { competências centrais } \\
\text { / ativos intangíveis } \\
\text { que são de } \\
\text { importância } \\
\text { estratégica. } \\
\text { - Avaliar os pontos } \\
\text { fortes e fracos de } \\
\text { intangíveis em relação } \\
\text { ao potencial futuro } \\
\text { - Alocar as receitas } \\
\text { da organização pelas } \\
\text { competências centrais }\end{array}$ \\
\hline $\begin{array}{l}\text { HRA - } \\
\text { Human } \\
\text { Resource } \\
\text { Accounting } \\
\text { (Contabilidade } \\
\text { de Recursos } \\
\text { Humanos) }\end{array}$ & $\begin{array}{l}\text { Desde o estudo } \\
\text { clássico de } \\
\text { Hermanson várias } \\
\text { décadas atrás } \\
\text { (1964), o tanto o } \\
\text { tópico de se } \\
\text { avaliar quanto o } \\
\text { de como avaliar } \\
\text { ativos humanos } \\
\text { tem sido debatido } \\
\text { por contadores e } \\
\text { teóricos de } \\
\text { recursos humanos. }\end{array}$ & $\begin{array}{l}\text { O valor de capital } \\
\text { humano, como expresso } \\
\text { em termos financeiros, } \\
\text { deveria ser parte do } \\
\text { capital no balanço, em } \\
\text { vez de aparecer como } \\
\text { despesa no } \\
\text { demonstrativo de } \\
\text { receitas. }\end{array}$ & $\begin{array}{l}\text { Quantificar o } \\
\text { valor econômico } \\
\text { de pessoas para a } \\
\text { organização com a } \\
\text { finalidade de } \\
\text { fornecer dados } \\
\text { para decisões } \\
\text { gerenciais e } \\
\text { financeiras }\end{array}$ & $\begin{array}{l}\text { Pesquisadores } \\
\text { propõem três tipos de } \\
\text { modelos de HRA: } \\
\text { - Modelos de custo, } \\
\text { que consideram custo } \\
\text { histórico, de } \\
\text { reposição ou de } \\
\text { oportunidade dos } \\
\text { ativos humanos } \\
\text { - Modelos de valor de } \\
\text { HR, que combinam } \\
\text { modelos } \\
\text { comportamentais não- } \\
\text { monetários com } \\
\text { modelos econômicos } \\
\text { monetários } \\
\text { - Modelos de ênfase } \\
\text { monetária, que } \\
\text { calculam a estimativa } \\
\text { descontada de salários } \\
\text { ou recebimentos } \\
\text { futuros }\end{array}$ \\
\hline $\begin{array}{l}\text { VCS - } \\
\text { Value Chain } \\
\text { Scoreboard }\end{array}$ & $\begin{array}{l}\text { Originado em } \\
2001 \text { por Baruch } \\
\text { Lev. Philip } \\
\text { Bardes, professor } \\
\text { de Contabilidade e } \\
\text { Finanças na Stern } \\
\text { School of } \\
\text { Business da New } \\
\text { York University }\end{array}$ & $\begin{array}{l}\text { Como a inovação vem se } \\
\text { tornando o ponto central } \\
\text { para se conseguir uma } \\
\text { posição competitiva } \\
\text { dominante, as } \\
\text { corporações precisarão } \\
\text { investir maciçamente em } \\
\text { ativos intangíveis e os } \\
\text { monitorar de perto. Mas, } \\
\text { o montante de } \\
\text { informação disponível } \\
\text { sobre intangíveis } \\
\text { continua limitado. Essas } \\
\text { deficiências de } \\
\text { informação resultam em } \\
\text { prejuízo econômico e } \\
\text { societário. }\end{array}$ & $\begin{array}{l}\text { Aperfeiçoar os } \\
\text { relatórios de } \\
\text { investimentos em } \\
\text { inovação }\end{array}$ & $\begin{array}{l}\text { - O scoreboard usa } \\
\text { uma cadeia de valor, } \\
\text { que consiste em três } \\
\text { fases: descoberta de } \\
\text { novos produtos ou } \\
\text { serviços ou processos, } \\
\text { estabilização de } \\
\text { exeqüibilidade } \\
\text { tecnológica e } \\
\text { comercialização de } \\
\text { novos produtos e } \\
\text { serviços. } \\
\text { - Em cada fase há três } \\
\text { caixas de informação } \\
\text { que contêm um } \\
\text { determinado número } \\
\text { de indicadores }\end{array}$ \\
\hline
\end{tabular}

FONTE: Adaptado de KPMG LLP (2001, p. 16-17) 
Quadro 9 - Vantagens e desvantagens dos SMDO BSC - EVA - ICA - VE - HSA - VCS

\begin{tabular}{|c|c|c|}
\hline MODELO & VANTAGENS & DESVANTAGENS \\
\hline $\begin{array}{l}\text { BSC - } \\
\text { Balanced } \\
\text { Scorecard }\end{array}$ & $\begin{array}{l}\text { - lógica convincente } \\
\text { - correlação clara entre indicadores e } \\
\text { desempenho financeiro } \\
\text { - relações de causa e efeito } \\
\text { - pode ser adaptado para um sistema de } \\
\text { gerenciamento de patrimônio intelectual } \\
\text { - literatura bem desenvolvida e } \\
\text { consistente } \\
\text { - na prática é muito usado para formular } \\
\text { estratégia e ganhar comprometimento } \\
\text { interno }\end{array}$ & $\begin{array}{l}\text { - rígido, estático, sem consideração de } \\
\text { dinâmicas } \\
\text { - quatro perspectivas são limitativas. } \\
\text { Insuficiente consideração de recursos } \\
\text { humanos e processos de conhecimento e de } \\
\text { criação. } \\
\text { - tratamento limitado de ambiente externo } \\
\text { (isto é: foco exclusivamente em clientes) } \\
\text { - uso interno somente, comparações externas } \\
\text { são difíceis }\end{array}$ \\
\hline $\begin{array}{l}\text { EVA - } \\
\text { Valor } \\
\text { Econômico } \\
\text { Adicionado }\end{array}$ & $\begin{array}{l}\text { - tem uma boa correlação com o preço } \\
\text { das ações. } \\
\text { • amarra orçamento, planejamento } \\
\text { financeiro, fixação de metas, e } \\
\text { compensação de incentivo. } \\
\text { • estabelece uma linguagem comum e } \\
\text { benchmark para gerentes discutirem a } \\
\text { criação de valor }\end{array}$ & $\begin{array}{l}\text { - procedimentos de ajuste complicados } \\
\text { - necessidade de optar entre precisão e } \\
\text { complexidade } \\
\text { - baseado em ativos líquidos versus valor de } \\
\text { mercado dos ativos } \\
\text { - pouco poder de esclarecimento adicional } \\
\text { - assume estrutura de governança somente no } \\
\text { interesse de acionistas }\end{array}$ \\
\hline $\begin{array}{l}\text { ICA - } \\
\text { Intellectual } \\
\text { Capital } \\
\text { Approaches } \\
\text { (Enfoques de } \\
\text { Capital } \\
\text { Intelectual) }\end{array}$ & $\begin{array}{l}\text { - flexível } \\
\text { - modelo dinâmico } \\
\text { - índice IC permite comparação externa } \\
\text { entre companhias e entre indústrias } \\
\text { - inicia estudando a questão da criação de } \\
\text { valor baseada no uso de recursos (fluxo) e } \\
\text { não na sua simples existência (estoques) }\end{array}$ & $\begin{array}{l}\text { - impreciso e complexo } \\
\text { - requer maior desenvolvimento métrico } \\
\text { - algumas pessoas reclamam de muita ênfase } \\
\text { em estoques versus fluxos } \\
\text { - diferenças entre organizações (e portanto da } \\
\text { especificidade de contexto) limitam toda } \\
\text { comparação possível entre companhias. } \\
\text { - fornece medida de desempenho e não } \\
\text { valores absolutos - assim se presta mais a } \\
\text { relatar processos, em vez de valores }\end{array}$ \\
\hline $\begin{array}{l}\text { VE - } \\
\text { Value Explorer }\end{array}$ & $\begin{array}{l}\text { - identifica competências centrais da } \\
\text { organização } \\
\text { - ferramentas e processos envolvidos são } \\
\text { relativamente simples e práticos } \\
\text { - proporciona diretrizes práticas para a } \\
\text { tomada de decisão estratégica e } \\
\text { priorização de intangíveis que ajudem a } \\
\text { desenvolver a agenda estratégica } \\
\text { - conceitos são similares aos termos } \\
\text { financeiros }\end{array}$ & $\begin{array}{l}\text { - dependente de dados subjetivos para as } \\
\text { avaliações } \\
\text { - dá uma medida de valor, não de desempenho } \\
\text { dos processos envolvidos } \\
\text { - requer uma análise detalhada das forças } \\
\text { diretoras ocultas da companhia }\end{array}$ \\
\hline $\begin{array}{l}\text { HRA - } \\
\text { Human } \\
\text { Resource } \\
\text { Accounting } \\
\text { (Contabilidade } \\
\text { de Recursos } \\
\text { Humanos) }\end{array}$ & $\begin{array}{l}\text { - calculada em termos financeiros } \\
\text { - uso interno intensivo em algumas } \\
\text { indústrias de serviços }\end{array}$ & $\begin{array}{l}\text { - têm que ser feitos pressupostos demais, } \\
\text { alguns dos quais não podem ser mantidos } \\
\text { - subjetivo e impreciso } \\
\text { - falta de confiabilidade porque essas medidas } \\
\text { não podem ser auditadas com nenhuma } \\
\text { segurança }\end{array}$ \\
\hline $\begin{array}{l}\text { VCS - } \\
\text { Value Chain } \\
\text { Scoreboard }\end{array}$ & $\begin{array}{l}\text { - baseado em minuciosa pesquisa } \\
\text { científica sobre o relacionamento entre } \\
\text { intangíveis e valor de mercado da } \\
\text { companhia. } \\
\text { - baseado em pesquisa sobre as } \\
\text { necessidades de informação para analistas } \\
\text { e outros acionistas } \\
\text { - simples e abrangente }\end{array}$ & $\begin{array}{l}\text { - focado somente em inovação } \\
\text { - parece adequado principalmente a empresas } \\
\text { de tecnologia que investem maciçamente em } \\
\text { pesquisa e desenvolvimento } \\
\text { - focado basicamente a relatórios externos. } \\
\text { - pouca força de esclarecimentos adicionais }\end{array}$ \\
\hline
\end{tabular}

FONTE: Adaptado de KPMG LLP (2001, p. 16-17) 


\subsubsection{Atributos dos Sistemas de Medição de Desempenho Organizacional}

Encontram-se na literatura pesquisada sobre os sistemas de desempenho organizacional alguns trabalhos de destaque que procuram identificar os atributos necessários para a eficácia destes sistemas. Dentre eles, as pesquisas de doutorado de Clark (1995) e de Martins (1998), e de mestrado de Ratton (1998) e de Hourneaux Jr (2005), bem como as obras de Ghalayini et al (1997), Neely et al (1997), Bititci et al (2000), Bourne et al (2000), De Toni e Tonchia (2001), Keneerly e Neely (2002) e Figueiredo (2003).

Este último autor identificou 122 atributos e classificou-os segundo critérios de afinidade e correspondência, em nove atributos ditos normativos, sendo um deles dividido em outros três. Segundo Laudon, K. e Laudon, J. (2004, p. 227), um atributo é cada característica ou qualidade que descreve uma entidade, que pode ser uma pessoa, um lugar, uma coisa ou um evento sobre os quais se dispõe de informações. Já um atributo normativo é definido por Clark (1995) como a característica geral de um sistema de medição de desempenho organizacional que o qualifica e que é estabelecida como base para sua avaliação.

Os quadros de 10 a 21 contêm atributos associados a cada um dos nove atributos normativos (e três derivados), bem como a respectiva definição, com base na revisão de literatura realizada por Figueiredo (2003, p. 61-84). São atributos normativos dos SMDO:
a) Alinhamento;
b) Análise Crítica;
c) Aprendizado Organizacional;
d) Balanceamento;
e) Clareza;
f) Dinamismo (subdividido em: Agilidade, Flexibilidade, Monitoramento);
g) Integração;
h) Participação;
i) Relacionamento Causal. 


\section{Quadro 10 - Atributo Normativo de SMDO - Alinhamento}

\begin{tabular}{|c|c|c|}
\hline $\begin{array}{l}\text { Atributo } \\
\text { Normativo }\end{array}$ & Definição & Atributos identificados \\
\hline \multirow[t]{21}{*}{ Alinhamento } & \multirow{21}{*}{$\begin{array}{l}\text { Capacidade } \text { de o } \\
\text { SMDO utilizar } \\
\text { indicadores } \\
\text { vinculados com a } \\
\text { estratégia e os } \\
\text { principais processos } \\
\text { organizacionais, } \\
\text { combinados, } \\
\text { interligados ou } \\
\text { agrupados de forma } \\
\text { a possibilitar uma } \\
\text { percepção global do } \\
\text { desempenho } \\
\text { organizacional }\end{array}$} & $\begin{array}{l}\text { Integrar de forma harmoniosa as estratégias, as ações, e as medições } \\
\text { realizadas }\end{array}$ \\
\hline & & Utilizar medidas relacionadas com a estratégia da organização \\
\hline & & Utilizar medidas derivadas da estratégia \\
\hline & & $\begin{array}{l}\text { Utilizar medidas que tenham relações com metas específicas da } \\
\text { organização }\end{array}$ \\
\hline & & Ser congruente com a estratégia competitiva \\
\hline & & $\begin{array}{l}\text { Ter medidas congruentes com a estratégia da organização e forte } \\
\text { relação com as seis prioridades competitivas (qualidade, custos, } \\
\text { flexibilidade, tempo, entrega e crescimento futuro) }\end{array}$ \\
\hline & & Ser usado para desafiar as hipóteses estratégicas da organização \\
\hline & & $\begin{array}{l}\text { Utilizar medidas que reflitam o "processo de negócio" (ex: } \\
\text { fornecedor e cliente participarem da definição da medida) }\end{array}$ \\
\hline & & Ser direcionado para os processos-chave de negócio \\
\hline & & Cobrir todas as áreas funcionais da organização \\
\hline & & Abranger todo o processo, desde o fornecedor até o cliente \\
\hline & & $\begin{array}{l}\text { Ter um sistema de desdobramento distribua os objetivos revisados e } \\
\text { prioridades para as unidades de negócio, processos e atividades, } \\
\text { usando medidas de desempenho }\end{array}$ \\
\hline & & Integrar horizontalmente (medidas inter-funcionais) \\
\hline & & Prevalecerem as medidas inter-funcionais \\
\hline & & $\begin{array}{l}\text { Ter um sistema de desdobramento interno dos objetivos revisados e } \\
\text { prioridades para as partes críticas do sistema }\end{array}$ \\
\hline & & $\begin{array}{l}\text { Integrar verticalmente (medidas agregadas segundo a estrutura } \\
\text { hierárquica), estimulando a congruência de metas e ações }\end{array}$ \\
\hline & & Incluir medidas de desempenho individual \\
\hline & & Incluir medidas de desempenho em nível de equipe \\
\hline & & $\begin{array}{l}\text { Incluir medidas de desempenho em nível organizacional, de forma a } \\
\text { promover a cooperação, evitando a competição interna e a sub- } \\
\text { otimização }\end{array}$ \\
\hline & & $\begin{array}{l}\text { Permitir o alinhamento ascendente entre as medidas (as medidas de } \\
\text { um nível devem estar associadas àquelas do nível acima) }\end{array}$ \\
\hline & & $\begin{array}{l}\text { Agregar as medidas ao longo dos níveis hierárquicos da organização } \\
\text { (as medidas de um determinado nível devem ser o resultado da } \\
\text { agregação de medidas dos níveis anteriores) }\end{array}$ \\
\hline
\end{tabular}

FONTE: Adaptado de Figueiredo (2003, p. 78-79) 
Quadro 11 - Atributo Normativo de SMDO - Análise Crítica

\begin{tabular}{|c|c|c|}
\hline $\begin{array}{l}\text { Atributo } \\
\text { Normativo }\end{array}$ & Definição & Atributos identificados \\
\hline \multirow[t]{8}{*}{$\begin{array}{l}\text { Análise } \\
\text { crítica }\end{array}$} & \multirow{8}{*}{ 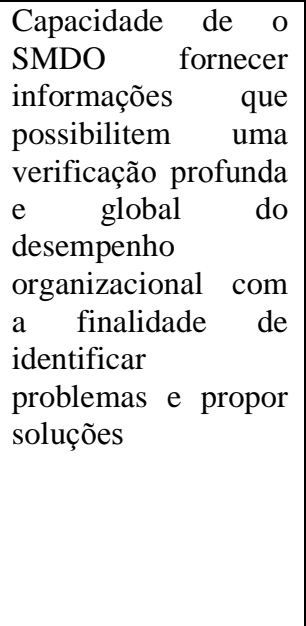 } & $\begin{array}{l}\text { Ter capacidade de auditar o sistema de medição existente, quanto ao } \\
\text { grau de atualização e medição de assuntos críticos }\end{array}$ \\
\hline & & $\begin{array}{l}\text { Ter um mecanismo de análise crítica que use as informações de } \\
\text { desempenho fornecidas pelos monitores internos e externos e os } \\
\text { objetivos e prioridades aplicadas pelos sistemas de mais alto nível } \\
\text { para decidir sobre os objetivos e prioridades internos }\end{array}$ \\
\hline & & $\begin{array}{l}\text { Ter um mecanismo efetivo de análise crítica e revisão de metas e } \\
\text { padrões }\end{array}$ \\
\hline & & $\begin{array}{l}\text { Ter um processo de análise crítica e revisão completa do conjunto de } \\
\text { medidas de uso }\end{array}$ \\
\hline & & Ter como principais objetivos a avaliação e o envolvimento \\
\hline & & $\begin{array}{l}\text { Fornecer informações que possibilitem uma avaliação global do } \\
\text { desempenho da organização }\end{array}$ \\
\hline & & $\begin{array}{l}\text { Proporcionar uma perspectiva do desempenho passado, presente e } \\
\text { futuro }\end{array}$ \\
\hline & & Servir de comparação com padrões externos - benchmarking \\
\hline
\end{tabular}

FONTE: Adaptado de Figueiredo (2003, p. 65)

Quadro 12 - Atributo Normativo de SMDO - Aprendizado Organizacional

\begin{tabular}{|c|c|c|}
\hline $\begin{array}{l}\text { Atributo } \\
\text { Normativo }\end{array}$ & Definição & Atributos identificados \\
\hline \multirow[t]{9}{*}{$\begin{array}{l}\text { Aprendizado } \\
\text { Organizacional }\end{array}$} & \multirow{9}{*}{$\begin{array}{l}\text { Capacidade de o SMDO fornecer informações que } \\
\text { facilitem o questionamento, a avaliação ou a } \\
\text { inovação do SO, de forma a contribuir não só para } \\
\text { a criação, aquisição e transferência de } \\
\text { conhecimento, mas também para modificação do } \\
\text { comportamento do SO, refletindo os novos } \\
\text { conhecimentos e percepções obtidos. }\end{array}$} & $\begin{array}{l}\text { Apoiar o aprendizado organizacional e a } \\
\text { melhoria contínua, estimulando as fases } \\
\text { Study e } A c t \text { do ciclo PDCA }\end{array}$ \\
\hline & & $\begin{array}{l}\text { Ter medidas de desempenho que sejam } \\
\text { utilizadas, principalmente, para a } \\
\text { melhoria de desempenho }\end{array}$ \\
\hline & & $\begin{array}{lllll}\begin{array}{l}\text { Facilitar } \\
\text { contínua }\end{array} & \text { processo de melhoria } \\
\end{array}$ \\
\hline & & Ter um ciclo fechado de gerenciamento \\
\hline & & $\begin{array}{l}\text { Focalizar mais a melhoria do que o } \\
\text { controle }\end{array}$ \\
\hline & & $\begin{array}{l}\text { Apoiar o processo de aprendizado } \\
\text { individual e organizacional }\end{array}$ \\
\hline & & $\begin{array}{l}\text { Permitir diferenciar medidas de controle } \\
\text { e medidas de melhoria }\end{array}$ \\
\hline & & $\begin{array}{l}\text { Ser consistente com as técnicas de } \\
\text { administração e iniciativas de melhoria } \\
\text { utilizadas pela organização: } \\
\text { benchmarking, administração de custo } \\
\text { baseado em atividade, Administração } \\
\text { Qualidade Total e Reengenharia } \\
\text { Processo de Negócio }\end{array}$ \\
\hline & & $\begin{array}{l}\text { Garantir que ganhos obtidos com os } \\
\text { resultados de iniciativas de melhoria } \\
\text { sejam mantidos por meio de medidas de } \\
\text { desempenho locais, usadas pelas } \\
\text { pessoas que trabalham nas atividades e } \\
\text { processos. }\end{array}$ \\
\hline
\end{tabular}

FONTE: Adaptado de Figueiredo (2003, p. 62-63) 
Quadro 13 - Atributo Normativo de SMDO - Balanceamento

\begin{tabular}{|c|c|c|}
\hline $\begin{array}{l}\text { Atributo } \\
\text { Normativo }\end{array}$ & Definição & Atributos identificados \\
\hline \multirow[t]{15}{*}{ Balanceamento } & \multirow{15}{*}{$\begin{array}{l}\text { Capacidade } \\
\text { SMDO de fornecer } \\
\text { informações, } \\
\text { segundo diferentes } \\
\text { dimensões de } \\
\text { desempenho, que } \\
\text { possibilitem obter } \\
\text { uma percepção } \\
\text { multidimensional do } \\
\text { comportamento da } \\
\text { organização }\end{array}$} & Apresentar medidas de eficiência e eficácia \\
\hline & & Medir resultados e processos \\
\hline & & $\begin{array}{l}\text { Utilizar critérios balanceados. As medidas devem refletir um } \\
\text { balanceamento entre as diversas dimensões de desempenho }\end{array}$ \\
\hline & & $\begin{array}{l}\text { Enfatizar o cliente e fornecer informações que permitam avaliar se } \\
\text { suas expectativas e necessidades estão sendo satisfeitas }\end{array}$ \\
\hline & & $\begin{array}{l}\text { Utilizar abordagens de medição de desempenho que permitam um } \\
\text { equilíbrio entre medidas quantitativas e qualitativas }\end{array}$ \\
\hline & & $\begin{array}{l}\text { Ter medidas primárias não financeiras (ex: operacionais) de forma } \\
\text { que possam prover os gerentes, supervisores e operadores as } \\
\text { informações requeridas para tomada de decisão diária }\end{array}$ \\
\hline & & Utilizar, principalmente, medidas não financeiras \\
\hline & & Ter medidas financeiras e não financeiras \\
\hline & & Apresentar medidas internas e externas, com integração de ambas \\
\hline & & $\begin{array}{l}\text { Fornecer um "quadro balanceado" do negócio, incluindo medidas } \\
\text { financeiras e não financeiras, internas e externas, de eficiência e } \\
\text { efetividade }\end{array}$ \\
\hline & & $\begin{array}{l}\text { Ser multidimensional, refletindo a necessidade de mensurar todas as } \\
\text { áreas de desempenho que são importantes para o sucesso da } \\
\text { organização }\end{array}$ \\
\hline & & Ser compreensivo e multidimensional \\
\hline & & São baseados no valor \\
\hline & & Compatibilizar os desempenhos \\
\hline & & Serem orientados para os clientes \\
\hline
\end{tabular}

FONTE: Adaptado de Figueiredo (2003, p. 67)

\section{Quadro 14 - Atributo Normativo de SMDO - Clareza}

\begin{tabular}{|c|c|c|}
\hline $\begin{array}{l}\text { Atributo } \\
\text { Normativo }\end{array}$ & Definição & Atributos identificados \\
\hline \multirow[t]{17}{*}{ Clareza } & \multirow{17}{*}{ 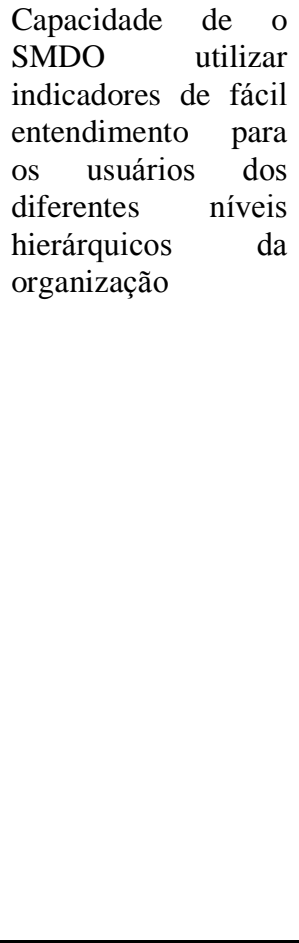 } & Ter objetivos explícitos \\
\hline & & Conter procedimento para implementação de medidas \\
\hline & & Empregar relações em lugar de números absolutos \\
\hline & & Ter medidas claramente definidas \\
\hline & & $\begin{array}{l}\text { As medidas serem baseadas em uma fórmula explicitamente definida } \\
\text { e fonte de dados }\end{array}$ \\
\hline & & Ser preciso em relação ao que está sendo medido \\
\hline & & Ser objetivo e não baseado em opiniões \\
\hline & & $\begin{array}{l}\text { Utilizar definições operacionais claras de forma que todos os } \\
\text { usuários possam ter um conhecimento comum das medidas, que } \\
\text { devem ser obtidas a partir das definições }\end{array}$ \\
\hline & & $\begin{array}{l}\text { Ter um processo de desenvolvimento de medidas individuais de } \\
\text { desempenho }\end{array}$ \\
\hline & & $\begin{array}{l}\text { Utilizar medidas que tenham a precisão necessária para seus fins } \\
\text { (margens de erro conhecidas) }\end{array}$ \\
\hline & & Ser visível para todos os usuários \\
\hline & & $\begin{array}{l}\text { Apresentar os dados longitudinalmente de forma a permitir a análise } \\
\text { de séries temporais, dos ciclos de negócio e outras tendências }\end{array}$ \\
\hline & & Apresentar os dados, utilizando gráficos em lugar de tabelas \\
\hline & & $\begin{array}{l}\text { Utilizar a análise estatística para o estudo da variabilidade do sistema } \\
\text { organizacional }\end{array}$ \\
\hline & & Ter medidas voltadas para todos os empregados \\
\hline & & Ter impacto visual \\
\hline & & Basear-se mais em tendências do que em instantâneos \\
\hline
\end{tabular}

FONTE: Adaptado de Figueiredo (2003, p. 69-70) 


\section{Quadro 15 - Atributo Normativo de SMDO - Dinamismo}

\begin{tabular}{|c|c|c|}
\hline $\begin{array}{l}\text { Atributo } \\
\text { Normativo }\end{array}$ & Definição & Atributos identificados \\
\hline \multirow[t]{31}{*}{ Dinamismo } & \multirow{31}{*}{ 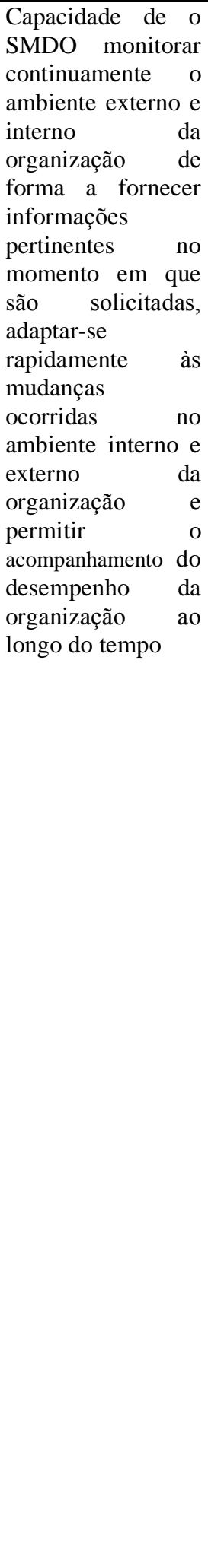 } & Mudar como é requerido pelo dinamismo do mercado \\
\hline & & Modificar-se com o passar do tempo e com a necessidade de mudança \\
\hline & & $\begin{array}{l}\text { Ter medidas consistentes que mantenham o seu significado ao longo } \\
\text { do tempo }\end{array}$ \\
\hline & & Ser dinâmico \\
\hline & & $\begin{array}{l}\text { Enfatizar a integridade do sistema, a agilidade e a capacidade de } \\
\text { resposta da organização }\end{array}$ \\
\hline & & Coletar e processar os dados continuamente \\
\hline & & $\begin{array}{l}\text { Ter uma plataforma de TI flexível que permita a organização de } \\
\text { maneira eficaz e eficiente administrar a dinâmica dos seus sistemas de } \\
\text { medição de desempenho }\end{array}$ \\
\hline & & $\begin{array}{l}\text { Usar dados coletados automaticamente como parte de um processo, } \\
\text { sempre que possível }\end{array}$ \\
\hline & & $\begin{array}{l}\text { Ser atualizado de forma a manter a regularidade por meio de uma } \\
\text { freqüência pré-determinada }\end{array}$ \\
\hline & & Fornecer informações para indivíduos e grupos \\
\hline & & $\begin{array}{l}\text { Colocar à disposição informações em tempo real para toda a } \\
\text { organização }\end{array}$ \\
\hline & & $\begin{array}{l}\text { Facilitar a identificação e uso de limites de desempenho para gerar } \\
\text { sinais de alarme sobre os problemas de desempenho potenciais }\end{array}$ \\
\hline & & $\begin{array}{l}\text { Permitir divulgação dos resultados, fornecendo informações sobre o } \\
\text { andamento das mudanças planejadas e aquelas ocorridas ao longo do } \\
\text { tempo }\end{array}$ \\
\hline & & Permitir o acompanhamento do desempenho ao longo do tempo \\
\hline & & Prover feedback rápido \\
\hline & & Conter medidas de hora em hora ou diariamente \\
\hline & & Ser oportuno e prover feedback preciso \\
\hline & & Identificar tendências e progressos \\
\hline & & Utilizar medidas de desempenho orientadas para o longo prazo \\
\hline & & Fornecer toda a informação necessária \\
\hline & & Prover informação \\
\hline & & $\begin{array}{l}\text { Prover um sistema de informação para executivos e não um meio para } \\
\text { manter o sistema de medição }\end{array}$ \\
\hline & & $\begin{array}{l}\text { Considerar outras técnicas de medição, tais como, metodologia de } \\
\text { valor adicionado e custos de qualidade }\end{array}$ \\
\hline & & Permitir mudanças em função das situações \\
\hline & & Ser aplicável para JIT, TQM, CIM, FNS, RPR, OPTEM, etc. \\
\hline & & Utilizar medidas que não tenham um formato fixo \\
\hline & & $\begin{array}{l}\text { Ser flexível ao longo do tempo para responder as mudanças de } \\
\text { ambiente ou necessidades dos usuários de modo a ser adaptável ao } \\
\text { longo do tempo e fazer frente às novas situações }\end{array}$ \\
\hline & & $\begin{array}{l}\text { Ter um sistema de controle externo que use medidas de desempenho } \\
\text { para continuamente monitorar os parâmetros críticos do ambiente } \\
\text { externo para detectar as mudanças ocorridas }\end{array}$ \\
\hline & & $\begin{array}{l}\text { Ter um sistema de controle interno que use medidas de desempenho } \\
\text { que monitorem continuamente os parâmetros críticos no ambiente } \\
\text { interno para detectar as mudanças ocorridas }\end{array}$ \\
\hline & & $\begin{array}{l}\text { Ter um sistema de monitoramento externo que forneça informações } \\
\text { continuamente sobre desdobramentos e mudanças no ambiente } \\
\text { externo }\end{array}$ \\
\hline & & $\begin{array}{l}\text { Ter um sistema de monitoramento interno que forneça informações } \\
\text { continuamente sobre desdobramentos e mudanças no ambiente interno } \\
\text { e sinalize quando certos limites forem alcançados }\end{array}$ \\
\hline
\end{tabular}

FONTE: Adaptado de Figueiredo (2003, p. 72-74) 
Quadro 16 - Atributo Normativo de SMDO - Dinamismo-Agilidade

\begin{tabular}{|l|l|}
\hline $\begin{array}{l}\text { Atributo } \\
\text { Normativo }\end{array}$ & Definição \\
\hline $\begin{array}{l}\text { Dinamismo - } \\
\text { Agilidade }\end{array}$ & $\begin{array}{l}\text { Capacidade de o SMDO colocar à disposição informações pertinentes no momento em que } \\
\text { são solicitadas pelos usuários dos diferentes níveis hierárquicos da organização }\end{array}$ \\
\hline
\end{tabular}

FONTE: Adaptado de Figueiredo (2003, p. 73)

\section{Quadro 17 - Atributo Normativo de SMDO - Dinamismo-Flexibilidade}

\begin{tabular}{|l|l|}
\hline $\begin{array}{l}\text { Atributo } \\
\text { Normativo }\end{array}$ & Definição \\
\hline $\begin{array}{l}\text { Dinamismo - } \\
\text { Flexibilidade }\end{array}$ & $\begin{array}{l}\text { Capacidade de o SMDO adaptar-se rapidamente às mudanças no ambiente interno e externo } \\
\text { da organização e às necessidades dos usuários dos diferentes níveis hierárquicos }\end{array}$ \\
\hline
\end{tabular}

FONTE: Adaptado de Figueiredo (2003, p. 73)

\section{Quadro 18 - Atributo Normativo de SMDO - Dinamismo-Monitoramento}

\begin{tabular}{|l|l|}
\hline $\begin{array}{l}\text { Atributo } \\
\text { Normativo }\end{array}$ & Definição \\
\hline $\begin{array}{l}\text { Dinamismo - } \\
\text { Monitoramento }\end{array}$ & $\begin{array}{l}\text { Capacidade de o SMDO acompanhar continuamente o ambiente externo e interno da } \\
\text { organização a fim de detectar a ocorrência de problemas potenciais }\end{array}$ \\
\hline
\end{tabular}

FONTE: Adaptado de Figueiredo (2003, p. 73)

\section{Quadro 19 - Atributo Normativo de SMDO - Integração}

\begin{tabular}{|c|c|c|}
\hline $\begin{array}{l}\text { Atributo } \\
\text { Normativo }\end{array}$ & Definição & Atributos identificados \\
\hline \multirow[t]{8}{*}{ Integração } & \multirow{8}{*}{$\begin{array}{l}\text { Capacidade de o } \\
\text { SMDO interagir } \\
\text { com todas as partes } \\
\text { da organização e } \\
\text { seus principais } \\
\text { sistemas } \\
\text { informação }\end{array}$} & Ser parte integrante dos sistemas de gestão da empresa \\
\hline & & $\begin{array}{l}\text { Ser hábil para quantificar as relações entre as medidas dentro de um } \\
\text { sistema }\end{array}$ \\
\hline & & $\begin{array}{l}\text { Ser integrada com os sistemas de negócio existentes (ex: o ambiente } \\
\text { de ERP existente) }\end{array}$ \\
\hline & & $\begin{array}{l}\text { Ter um banco de dados de medidas agrupadas segundo as seis } \\
\text { prioridades competitivas }\end{array}$ \\
\hline & & $\begin{array}{l}\text { Ter uma abordagem de workbook que seja fácil de usar e aplicar, } \\
\text { seguindo uma metodologia passo a passo e sem requerer consultoria } \\
\text { externa para implementá-la }\end{array}$ \\
\hline & & $\begin{array}{l}\text { Fornecer uma avaliação sucinta do desempenho da organização de } \\
\text { forma a facilitar sua compreensão, adoção e aplicação }\end{array}$ \\
\hline & & Prevalecer as medidas de equipe \\
\hline & & Utilizar medidas que avaliem o grupo e não o indivíduo \\
\hline
\end{tabular}

FONTE: Adaptado de Figueiredo (2003, p. 76-77) 


\section{Quadro 20 - Atributo Normativo de SMDO - Participação}

\begin{tabular}{|c|c|c|}
\hline $\begin{array}{l}\text { Atributo } \\
\text { Normativo }\end{array}$ & Definição & Atributos identificados \\
\hline \multirow[t]{6}{*}{ Participação } & \multirow{6}{*}{$\begin{array}{l}\text { Capacidade de o } \\
\text { SMDO permitir que } \\
\text { representantes dos } \\
\text { diferentes grupos de } \\
\text { usuários e } \\
\text { interessados } \\
\text { (fornecedores, } \\
\text { controladores, } \\
\text { acionistas, } \\
\text { comunidade, etc.) } \\
\text { tomem parte ativa } \\
\text { em todas as fases do } \\
\text { seu ciclo de vida } \\
\text { (desenvolvimento } \\
\text { implementação, } \\
\text { utilização, avaliação } \\
\text { e aperfeiçoamento) }\end{array}$} & $\begin{array}{l}\text { Permitir a participação de representantes dos diferentes grupos de } \\
\text { futuros usuários no desenvolvimento do sistema de medição }\end{array}$ \\
\hline & & Estimular a satisfação do empregado \\
\hline & & Ser muito utilizado no chão de fábrica \\
\hline & & $\begin{array}{l}\text { Utilizar medidas baseadas em quantidades que podem ser } \\
\text { influenciadas ou controladas pelo usuário ou em cooperação com } \\
\text { outros usuários }\end{array}$ \\
\hline & & Ser facilmente inteligível para os funcionários \\
\hline & & Influenciar a atitude dos funcionários \\
\hline
\end{tabular}

FONTE: Adaptado de Figueiredo (2003, p. 81)

\section{Quadro 21 - Atributo Normativo de SMDO - Relacionamento Causal}

\begin{tabular}{|c|c|c|}
\hline $\begin{array}{l}\text { Atributo } \\
\text { Normativo }\end{array}$ & Definição & Atributos identificados \\
\hline \multirow[t]{4}{*}{$\begin{array}{l}\text { Relacionamento } \\
\text { Causal }\end{array}$} & \multirow{4}{*}{ 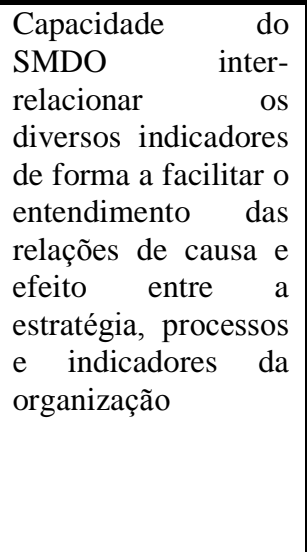 } & $\begin{array}{l}\text { Desenvolver relações causais entre objetivos competitivos e } \\
\text { estratégicos, e processos e atividades }\end{array}$ \\
\hline & & Facilitar o entendimento das relações causa efeito \\
\hline & & $\begin{array}{l}\text { Facilitar o gerenciamento das relações causais para quantificar } \\
\text { criticamente e identificar prioridades }\end{array}$ \\
\hline & & $\begin{array}{l}\text { Explicar as relações de causa e efeito entre as medidas de resultado e } \\
\text { de alavancagem, de forma que o sistema de medição de desempenho } \\
\text { possa fornecer dados para o monitoramento do desempenho passado } \\
\text { e planejamento do desempenho futuro }\end{array}$ \\
\hline
\end{tabular}

FONTE: Adaptado de Figueiredo (2003, p. 83)

Hampton (1992, p. 475) ressalta que existem três questões recorrentes quando da formulação de um sistema de medição de desempenho: o quê, como e quando medir. Para o autor, o levantamento dos principais atributos para medição é o primeiro passo para responder ao questionamento do que deve ser efetivamente medido. Assim sendo, com base no conhecimento gerado pelos SMDO, bem como nas demandas por mecanismos de mensuração de desempenho do gerenciamento de processos de negócio, relatadas na próxima seção, pôde ser concebido um primeiro esboço de sistema de medição de desempenho específico para BPM, conforme detalhado no capítulo 4. 


\subsection{O Gerenciamento de Processos de Negócio - BPM}

Nesta seção serão apresentados os principais conceitos de BPM, segundo as óticas das áreas da Gestão Empresarial e da Tecnologia da Informação e de Comunicação.

\subsubsection{O BPM sob a ótica da Gestão Empresarial}

Para o melhor entendimento sobre o BPM no contexto da gestão empresarial, foi realizada uma breve contextualização histórica e conceitual do processo de negócio nas organizações. Em seguida, foi descrita a demanda pelo gerenciamento dos processos, sua base teórica e suas fases de desenvolvimento e implantação, e como ele deve estar inserido na cultura organizacional. Por fim, foram destacadas as principais funcionalidades requeridas pela área de negócio nos softwares de BPM.

\subsubsection{Contextualização histórica}

Segundo Smith e Fingar (2003, p. 11-12), o gerenciamento de processos não é novo para a maior parte das corporações. Entretanto, houve mudanças significativas ao longo do tempo na forma como ele é alcançado. Estudos de Taylor, junto com o movimento da administração científica, introduziram no início do século passado os conceitos de eficiência, especialização e medição do processo nas organizações. Em decorrência disso, as organizações se viram cada vez mais inclinadas tanto à especialização de atividades quanto à formação de profissionais especialistas em seus processos de negócio.

Nas últimas décadas, houve um movimento ainda maior na busca pela particularização das áreas funcionais em torno de competências básicas, motivado pela gestão da qualidade total (TQM), absorvido no Ocidente na década de 1980 e intensamente adotado pelas organizações na década seguinte. $\mathrm{O}$ conceito de TQM encorajava as organizações a se concentrarem na análise crítica de seus processos, produtos e serviços para a identificação de pequenos pontos de melhoria possíveis. Ao final do anos 1980 surgiu o movimento da reengenharia total de

processos (BPR), que se propunha a, primordialmente, recriar um processo de maneira mais simples e implementá-lo de uma só vez por meio de um programa de mudança organizacional. 
Para Smith e Fingar (2003, p. 12), ambos os movimentos não atenderam às expectativas de gestores e clientes. Entre outros motivos, por estarem muito voltados para ações no ambiente interno das organizações, sem ouvir os anseios por melhor atendimento de demandas externas. Ou ainda, por se preocuparem demasiadamente em redesenhar processos internamente e não torná-los mais flexíveis ou integráveis com outras áreas das organizações.

Em seguida a estes movimentos emergiu a era dos sistemas integrados de gestão empresarial (ERP). Os ERP visavam implementar um modelo de empresa integrada e promover a mudança da visão departamental para a visão de processos nas empresas. Estas mudanças se dariam com a implantação de pacotes de aplicativos de software contendo as melhores práticas empresariais e tudo o que fosse essencial às necessidades dos processos nas organizações. Souza (2000, p. 248-253) identificou entre algumas dificuldades relacionadas aos sistemas ERP: a redução da flexibilidade para acompanhar as mudanças de negócio; o alto custo relativo à adaptação contínua do sistema; a perda de funcionalidades de sistemas anteriores; a resistência de usuários pelo aumento de trabalho nas áreas de inserção de dados; a possível perda de vantagens competitivas decorrentes de diferenças entre seus processos e os de empresas concorrentes; e a falta de integração com organizações e processos externos.

Mais recentemente surgiu o movimento do workflow, descrito detalhadamente na seção 2.2.2. Despontaram também novas ferramentas para mapeamento de processos que podiam capturar e gerenciar processos empresariais de uma forma mais flexível e com possibilidade de subseqüente análise. De acordo com Cruz $(2004$, p. 81) o propósito primordial do workflow visava a automação de processos de negócio, racionalizando-os e conseqüentemente aumentando sua produtividade por meio de dois componentes básicos: organização e tecnologia. Para Smith e Fingar (2003, p. 83) as ferramentas de mapeamento de processos intentavam produzir documentação sobre a forma de trabalho das organizações e como apoio para a revisão e o refinamento dos processos.

Contudo, estas duas propostas não atingiram os resultados esperados. Segundo De Sordi (2005, p. 31) o grande problema encontrado pelas empresas para a aplicabilidade das soluções de workflow foi a integração dos novos sistemas de informação com os já existentes nas organizações, conhecidos como sistemas legados. 
Com relação às ferramentas de mapeamento, Smith e Fingar (2003, p. 84) concluíram que elas não permitiam levar os modelos de processo diretamente à execução, já que usavam formatos proprietários e notações de difícil compreensão para os responsáveis das áreas de negócio. $\mathrm{O}$ enfoque destas estava na modelagem das atividades de entrada e saída de dados nos fluxos de trabalho, dando insuficiente atenção aos aspectos colaborativos dos processos do mundo real e à sua complexidade. Estes fatos ocorreram, entre outros motivos, pelo descompasso entre a TIC e a área de negócio que ainda separavam as metas estratégicas organizacionais das implementações tecnológicas.

\subsubsection{Conceito de Processo de Negócio}

Para De Sordi (2005, p. 21) o processo de negócio, assim como o processo produtivo, é composto por diversas etapas de produção ou atividades a serem executadas. Ressalta que a idéia de dividir o trabalho em atividades seqüenciais apareceu no início do século passado com os 14 princípios gerenciais de Fayol. Acrescenta também que esta idéia se constitui no único ponto de consenso entre alguns dos principais pesquisadores que definiram o que é o processo de negócio, conforme compilação mostrada no quadro 22.

\section{Quadro 22 - Definições de Processo de Negócio}

\begin{tabular}{|c|c|}
\hline Autores & Definição de Processo de Negócio \\
\hline Harrington (1993) & $\begin{array}{l}\text { É um grupo de tarefas interligadas logicamente, que utilizam os recursos da } \\
\text { organização para a geração de resultados predefinidos, visando apoiar os objetivos da } \\
\text { empresa }\end{array}$ \\
\hline Davenport (1994) & $\begin{array}{l}\text { É um conjunto estruturado e dimensionado de atividades de trabalho, com começo e } \\
\text { fim, e com insumos e produtos claramente especificados para um cliente ou mercado } \\
\text { em particular }\end{array}$ \\
\hline $\begin{array}{l}\text { Rummler e Brache } \\
\text { (1995) }\end{array}$ & $\begin{array}{l}\text { É uma série de etapas criadas para produzir um produto ou serviço, incluindo várias } \\
\text { funções e preenchendo as lacunas existentes entre as diversas áreas organizacionais, } \\
\text { objetivando com isso estruturar uma cadeia de agregação de valor ao cliente }\end{array}$ \\
\hline $\begin{array}{l}\text { Hammer e Champy } \\
\text { (1997) }\end{array}$ & $\begin{array}{l}\text { É um conjunto de atividades cuja operação simultânea produz um resultado de valor } \\
\text { para o cliente }\end{array}$ \\
\hline Beretta (2002) & $\begin{array}{l}\text { É o local em que os recursos e as competências da empresa são ativados a fim de criar } \\
\text { uma competência organizacional capaz de preencher suas lacunas com o objetivo de } \\
\text { gerar uma vantagem competitiva sustentável }\end{array}$ \\
\hline $\begin{array}{l}\text { Smith e Fingar } \\
(2003)\end{array}$ & $\begin{array}{l}\text { É um conjunto completo e dinamicamente coordenado de uma série de atividades } \\
\text { colaborativas e transacionais que gera valor aos clientes }\end{array}$ \\
\hline Spanyi (2003) & $\begin{array}{l}\text { É a coordenação de ponta a ponta das diversas fases de um trabalho, com a participação } \\
\text { de diferentes departamentos de uma organização, que criam e fornecem produtos aos } \\
\text { clientes, podendo se constituir numa cadeia de valor entre parceiros comerciais }\end{array}$ \\
\hline Cruz (2004) & $\begin{array}{l}\text { É o conjunto de atividades (cadeia de eventos) que tem por objetivo transformar } \\
\text { entradas por meio de procedimentos, em saídas (bens ou serviços) que serão entregues } \\
\text { a clientes }\end{array}$ \\
\hline De Sordi (2005) & $\begin{array}{l}\text { É um fluxo de atividades, de diferentes áreas funcionais, ou mesmo de diferentes } \\
\text { empresas, que geram algo de valor para seus clientes }\end{array}$ \\
\hline
\end{tabular}

FONTE: Criado a partir de De Sordi (2005, p. 21-22) 
Independentemente da definição escolhida como a que melhor expressa o conceito de processo de negócio, Smith e Fingar (2003, p. 47) consideram como inerentes a ele as seguintes características:

- grandes e complexos, envolvendo fluxo de materiais, informações e compromissos de negócio de ponta a ponta;

- $\quad$ dinâmicos, respondendo a demandas de clientes e às condições de mercado em mudança;

- $\quad$ amplamente distribuídos e customizados por meio de fronteiras tanto dentro quanto entre negócios, freqüentemente abrangendo múltiplos aplicativos em plataformas autônomas;

- $\quad$ duradouros, já que uma simples instância de um processo como "encomenda a receber" ou "desenvolver produto" pode durar meses ou até anos;

- $\quad$ automatizáveis, ainda que em parte. Atividades triviais e de rotina são informatizadas, sempre que possível, visando rapidez e confiabilidade;

- $\quad$ de natureza técnica e de negócio: processos de TI são sub-processos de negócio e dão suporte a processos maiores que envolvem pessoas e máquinas. Processos vistos de ponta a ponta dependem de sistemas de informação distribuídos, colaborativos e transacionais. Modelos de processos podem, portanto, compreender modelos de redes, modelos de objetos, fluxos de controles, fluxos de mensagens, regras de negócio, medições, exceções, transformações e definições;

- $\quad$ dependentes e que dêem suporte à inteligência e ao entendimento humano, uma vez que as pessoas executam tarefas desestruturadas demais para serem delegadas a um sistema informatizado e que requeiram interação pessoal com os clientes. As pessoas também dão sentido às valiosas informações que fluem pela cadeia de valor, resolvendo problemas antes que eles irritem o cliente, e criando estratégias para obter vantagens competitivas e novas oportunidades de mercado;

- $\quad$ difíceis de serem visualizados, considerando que em várias empresas os processos de negócio não são claros e explícitos. Eles podem não ser documentados, implícitos, e inerentes à cultura organizacional. Uma vez documentados, suas definições ou formalizações são mantidas independentes dos sistemas informatizados que lhes dão suporte. 


\subsubsection{A demanda por BPM}

Para Smith e Fingar (2003, p. 68) os processos de negócio são o cerne de muitas teorias da área de administração. Destacam que o movimento da gestão pela qualidade total indicava que a melhoria da qualidade era $90 \%$ devida ao sistema, em outras palavras, ao processo. Outros exemplos de teorias de administração relacionadas com o processo ressaltados pelos autores incluem:

- $\quad$ Análise da cadeia de valor: Porter, M (1980) Competitive Advantage;

- $\quad$ Gestão pela Excelência: Peters, T. \& Waterman, R., (1982), In Search of Excellence;

- $\quad$ Reengenharia: Hammer, M., (1990), Don't automate, obliterate;

- Inovação em processos com tecnologia: Davenport, T. \& Short J., (1990), The new industrial engineering: Information Technology and Business Process Redesign;

- Gestão de negócio voltada ao cliente: Whiteley, R. (1991), The customer-driven company,

- Gestão do conhecimento: Drucker, P. (1993), Post-capitalist society;

- $\quad$ Administração da cadeia de valor: Schonberger, R. (1996), World class manufacturing.

Todas estas teorias trouxeram avanços no atendimento das demandas da gestão empresarial. Contudo, sabe-se que ao longo do tempo as organizações estão sujeitas a pressões oriundas de diversas frentes. E assim, surgem novas propostas na busca de soluções para velhos e novos problemas.

O fato é que nos dias de hoje os clientes exigem cada vez mais melhoria nos custos, rapidez, qualidade, customização e serviço satisfatórios. Para Smith e Fingar (2003, p. 68-69) não basta mais ser excelente no fornecimento de um produto ou na colocação à disposição de um serviço num destes aspectos, porque os clientes querem ver todos estes aspectos atendidos ao mesmo tempo. Em conseqüência disso, as novas tecnologias não atendem à rapidez e a pluralidade das mudanças requeridas pelas áreas de negócio.

Os processos de negócio organizacionais são fortemente influenciados pelos requisitos exigidos por parceiros, clientes e órgãos regulamentadores de governo. A habilidade de uma organização em responder a estas demandas está em grande parte determinada por três fatores: 
1) considerando que os processos de negócio encontram-se implícitos, sedimentados e gozam de pouca flexibilidade, as influências de processos externos criam fragilidades, rupturas e a necessidade da expansão da organização e dos seus sistemas;

2) os processos de negócio são normalmente de natureza complexa e, mesmo que sejam explícitos, são necessárias ferramentas de TIC não somente para manipulá-los e para criar novos modelos de negócio, como também para criar alternativas a sua execução e, subseqüentemente, operação destes novos processos;

3) a concepção e o desenvolvimento de processos fora do contexto do negócio é um convite ao fracasso. Os processos precisam ser empregados considerando o legado e aplicados sobre a infra-estrutura existente, procurando alavancar todos os ativos disponíveis.

Para Spanyi (2003, p. 22) as organizações contemporâneas precisam então tornar seus processos de negócio mais gerenciáveis, com informações formalizadas e acesso facilitado às melhores práticas de mercado. Elas necessitam administrar não apenas os seus próprios processos, mas também a sua colaboração em todos os processos de cada participante da cadeia de valor até se chegar ao cliente.

As organizações precisam de meios para responder às expectativas de clientes em constante mudança. Precisam lidar com mudanças inesperadas no negócio, bem como implementar novos padrões tecnológicos. Necessitam ainda de meios para consolidar seus negócios em tempos de recessão, utilizando novas ferramentas com custo mínimo para a integração do processo de negócio. Alcançar tudo isso, segundo Smith e Fingar (2003, p. 69), requer uma linguagem de processo padrão e uma plataforma gerencial que permita aos parceiros a participação no desenho dos processos e o entendimento mútuo detalhado das operações.

Mesmo querendo adotar as melhores práticas na busca da eficiência, ou desenvolvendo processos customizados para obter vantagem competitiva, os dirigentes das organizações querem evitar ao máximo os altos custos que já foram associados à reengenharia, à gestão da mudança organizacional e à implementação de sistemas de TIC. Em resumo: hoje se busca uma virada significativa no entendimento do conceito de gerenciamento de processos de negócio e, não apenas, mais uma teoria de administração de empresas ou um aplicativo de TIC que resolva tudo de uma vez. 
A conclusão a qual se chega é que as organizações reconhecem que precisam evoluir de uma situação corrente "as is" para uma que os projetistas de processos chamam de estado "to be", tornando-se uma corporação gerenciada por processo.

Drucker (1999, p. 92) definiu dois objetivos desejáveis para a gestão empresarial do século XXI: o desenvolvimento de um método sistemático e organizado para obter informações sobre o contexto do negócio na economia, seus mercados e concorrentes; e a integração do que antes eram vários procedimentos - análise de valor, análise de processo, gestão da qualidade e de custo - em uma simples análise. Pode-se entender na descrição destes objetivos que as necessidades internas e externas das organizações contemporâneas continuam sendo basicamente a captação, sistematização, integração e análise de informações para a consecução de seus objetivos estratégicos e operacionais.

\subsubsection{Conceito de Gerenciamento de Processos de Negócio}

Segundo De Sordi (2005, p. 23) os termos gestão e gerenciamento são freqüentemente utilizados como sinônimos. Em que pese guardarem o mesmo valor semântico na língua portuguesa, no âmbito dos negócios apresentam significados diferentes. O autor acrescenta que o termo gerenciamento é restritivo às funções de controle e monitoramento dos recursos, enquanto que gestão por processos tem um significado maior, relativo a todas as etapas de evolução de um recurso num processo.

Sem entrar no mérito desta ressalva, para fins deste estudo será adotado o termo gerenciamento de processos de negócio, com o sentido holístico e mais abrangente de coordenação de todas as fases pelas quais os recursos perpassam pelos processos, uma vez que é o termo mais consagrado na literatura e em trabalhos acadêmicos de língua portuguesa.

Segundo Spanyi (2003, p. 25) o gerenciamento de processos de negócio compreende a definição, o aperfeiçoamento e a administração dos processos de negócio de uma organização, desde o seu início até o seu final, envolvendo todos os departamentos e fases, até mesmo parceiros e terceiros, com apoio colaborativo e deliberado da tecnologia, a fim de alcançar três pontos de importância crucial para uma empresa dirigida ao cliente e baseada no desempenho: clareza na direção estratégica, alinhamento dos recursos da organização; e a crescente disciplina nas operações diárias. 
Para Smith e Fingar (2003, p. 18) vive-se hoje a terceira onda de BPM. A primeira se deu com o movimento taylorista da década de 20, do século passado. Neste contexto, os processos estavam implícitos nos trabalhos, mas não eram automatizados. A segunda onda se refere ao movimento da reengenharia, complementada pelos ERP, quando os processos foram automatizados, mas se ressentiam de flexibilidade e de agilidade para atender às mudanças internas e externas. A terceira onda, em fase de consolidação, é fundamentalmente voltada ao gerenciamento dos processos, dividida em fases determinadas, e dirigida à satisfação dos clientes. Para os autores, este modelo considera a habilidade para mudar mais fundamental do que a habilidade para criar processos.

De forma entusiasta, Smith e Fingar (2003, p. 73) acreditam ainda que o BPM seja uma espécie de síntese entre a representação de processos e as tecnologias de colaboração, que promove a remoção dos obstáculos que bloqueiam a execução dos objetivos organizacionais (Idem, p. 73). Em suma: BPM é, para os autores, uma espécie de convergência das teorias da administração - gestão da qualidade total, reengenharia, Six Sigma, gerenciamento de projetos, com tecnologias modernas - desenvolvimento de aplicativos, integração de sistemas de informação, arquitetura orientada ao serviço, workflow, XML e web services.

Spanyi (2003, p. 46-47) afirma que o gerenciamento de processos de negócio (BPM) deve ser implementado nas organizações do topo do organograma para baixo, o que facilita a atuação interdepartamental e melhora o desempenho dos processos na organização como um todo. Adicionalmente, afirma que toda a atividade de implantação de BPM é centrada em "pensar" o processo de negócio. A crença central é de que os processos de negócio são complexos, interdepartamentais, viabilizados pela tecnologia e que, fundamentalmente, devem criar valor para os clientes e para os acionistas.

Para Spanyi (2003, p. 48), o BPM essencialmente se inicia com a observação da organização e dos seus processos de negócio pela perspectiva do cliente, ou seja, de fora para dentro, na mesma proporção em que se visualizam os processos de dentro para fora. Por fim, conclui que é virtualmente impossível administrar atividades que não são documentadas, nem medidas.

Segundo De Sordi (2005, p. 25-27), o processo de negócio é um meio integrador de todos os ativos organizacionais. E o seu gerenciamento acontece quando estes ativos trabalham em 
sincronia, assegurando-lhes eficiência. Para o autor, os principais recursos empregados no BPM encontram-se descritos no quadro 23 a seguir.

\section{Quadro 23 - Recursos empregados no BPM}

\begin{tabular}{|l|l|}
\hline \multicolumn{1}{|c|}{ Recurso } & \multicolumn{1}{|c|}{ Significado } \\
\hline Recursos Humanos & $\begin{array}{l}\text { Conciliar os interesses e os momentos de integração e interação dos funcionários para } \\
\text { que se obtenha um bom desempenho do processo }\end{array}$ \\
\hline Responsabilidades & Fortalecer a autonomia do agir e pensar dos funcionários (empowerment) \\
Organizacional & $\begin{array}{l}\text { Funcionários são entendidos como nós de uma rede de trabalho, e não como funções } \\
\text { isoladas no organograma }\end{array}$ \\
\hline Políticas e Regras & $\begin{array}{l}\text { Direcionar o comportamento e o desempenho dos RH internos e sua interação com os } \\
\text { processos de negócio }\end{array}$ \\
\hline $\begin{array}{l}\text { Tecnologia } \\
\text { Informação }\end{array}$ & $\begin{array}{l}\text { Empregadas para a automação de regras e atividades, para monitoramento do } \\
\text { desempenho e para formação de ambientes colaborativos de trabalho }\end{array}$ \\
\hline Infra-estrutura & Todos os recursos de apoio e suporte aos processos \\
\hline Conhecimento & $\begin{array}{l}\text { O conhecimento capturado e compartilhado com a organização proporciona o } \\
\text { aprimoramento de todos os demais ativos de negócio }\end{array}$ \\
\hline
\end{tabular}

FONTE: Criado a partir de De Sordi (2005, p. 25-27)

A partir da análise dos principais conceitos de BPM, torna-se necessário entender o seu funcionamento e as principais fases que o compõem.

\subsubsection{Fases do Gerenciamento de Processos de Negócio}

Armistead et al (1999, p. 106) dividem o gerenciamento de processos de negócio em fases, da seguinte maneira:

1) a organização analisa a cadeia de valor no mercado externo e identifica nela seus principais processos. Para isso, é necessário ter uma gerência forte e bem articulada;

2) desenvolve-se uma arquitetura de processo a fim de entender a organização. Isso pode envolver o mapeamento de processos de negócio;

3) são apontados os proprietários do processo (process owners) que serão os responsáveis pelos processos; 
4) é visualizado um processo sem falhas, o qual se mostra uma técnica simples especialmente em processos operacionais. Deve-se, neste momento, ouvir o cliente a fim de se dimensionar competências necessárias e estipular metas;

5) métricas de processo são estabelecidas e apresentadas às equipes da linha-de-frente;

6) o monitoramento do desempenho é ajustado à amplitude do processo;

7) oportunidades de melhoria são identificadas e acionadas;

8) a organização planeja, comunica e treina sua equipe com base no modelo de controle;

9) em alguns casos a estrutura da organização é alterada para refletir seu real direcionamento a processos. Isto não significa obrigatoriamente a perda de funções, mas que elas devem ser absorvidas pelo processo.

Smith e Fingar (2003, p. 90-94) apontam, de forma mais completa e organizada, o gerenciamento de processos de negócio compreendendo oito grandes fases: pesquisa, projeto, preparação, execução, interação, controle e monitoramento, melhoria e análise de processos. Essas etapas, ilustradas na figura 1, formam o ciclo de vida do BPM.

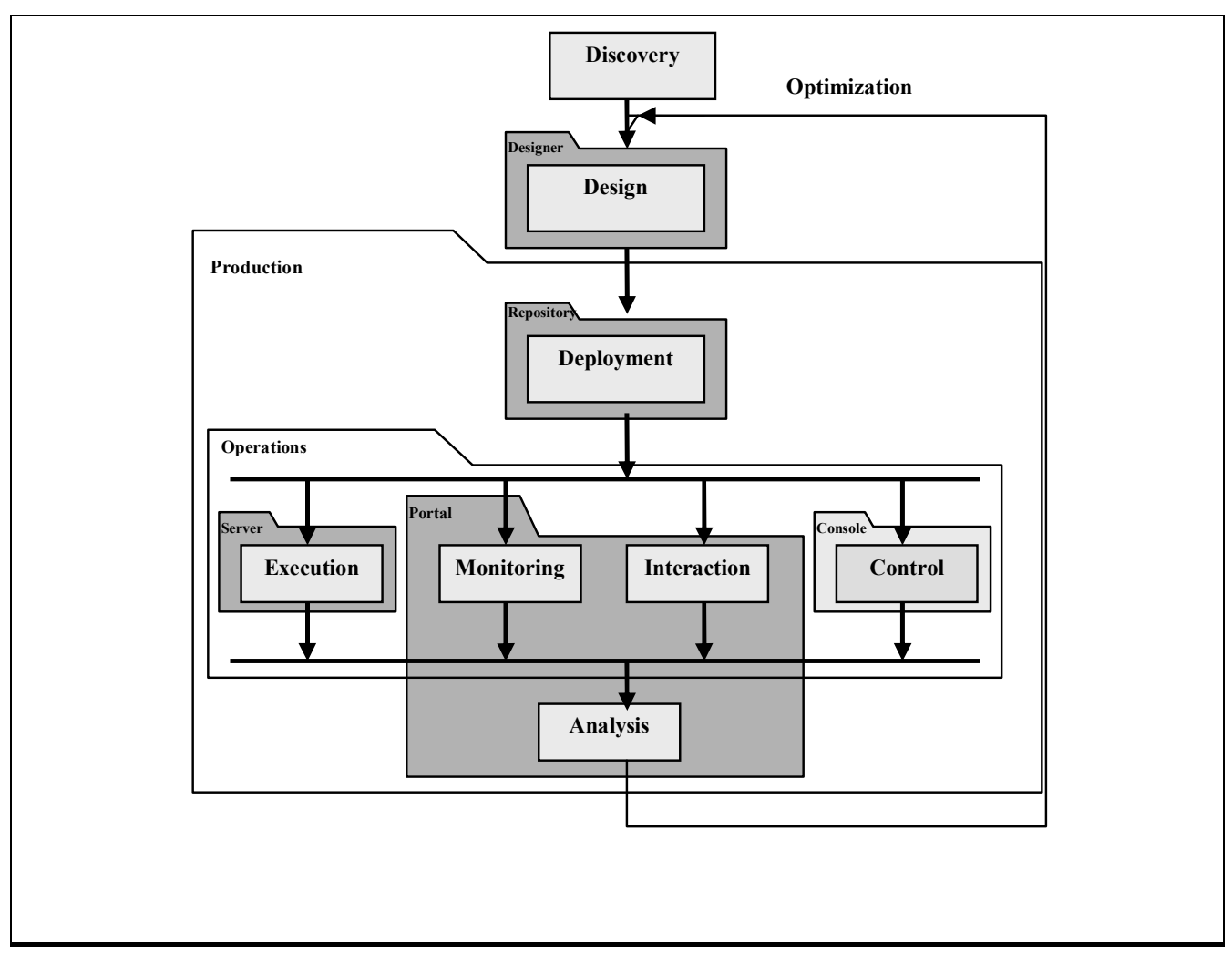

Figura 1 - O ciclo de vida do BPM

FONTE: Smith e Fingar (2003, p. 90) 
1) Discovery - a fase de pesquisa ou descoberta implica em tornar explícitas as indicações de como as atividades são efetivamente feitas. Essa descoberta é amplamente manual, amplamente automática, ou um misto das duas formas. Trata de desenvolver uma imagem de como funcionam os processos de negócio, tanto internamente quanto externamente;

2) Design - a fase de projeto compreende modelagem, manipulação e redesenho de processos, na medida em que a organização passa pelo aprendizado por meio da primeira fase. Lida com atividades, regras, participantes, interações e relacionamentos. Esta fase inclui também a fixação das métricas para o acompanhamento dos processos;

3) Deployment - a preparação ou refinamento é a fase em que os modelos são distribuídos a todos os participantes, com a finalidade de se verificarem os ajustes e alterações necessários. Nesta etapa podem ser juntados novos processos, redistribuídos ou customizados;

4) Execution - a fase de execução garante que todos os participantes irão desempenhar seu papel no processo: pessoas, sistemas de computador, outras organizações e outros processos;

5) $\quad$ Interaction - a fase de interação compreende o uso de portais de processos ou de sistemas aplicativos que auxiliem as pessoas a interagirem plenamente com os processos de negócio. Isso inclui o gerenciamento da interface entre o trabalho manual e a automação;

6) Monitoring and Control - as fases de monitoramento e controle se aplicam tanto aos processos, quanto aos sistemas de gerenciamento de processos sobre os quais eles trabalham. Correspondem às atividades necessárias para manter o bom funcionamento dos processos, do ponto de vista técnico-gerencial;

7) Optimization - na fase de melhoria ou otimização o sistema de gerenciamento de processos pode identificar "gargalos" e inconsistências no processo, no âmbito global da organização, sugerindo ajustes, com ou sem a intervenção humana. A melhoria se apóia fundamentalmente na fase de análise;

8) Analysis - a fase de análise compreende a medição de desempenho do processo para a fixação de métricas e a inteligência de negócio necessárias à melhoria das estratégias organizacionais e para descobrir oportunidades direcionadas à inovação. 


\subsubsection{Desenvolvimento da Cultura de BPM nas Organizações}

Para De Sordi (2005, p. 159) é fundamental que os dirigentes da alta administração tenham um entendimento sedimentado acerca das principais barreiras a serem superadas com a implantação da cultura do gerenciamento de processos de negócio em suas organizações. Hammer e Champy (1997) classificaram estas barreiras em quatro módulos, conforme o quadro 24 a seguir.

\section{Quadro 24 - Principais barreiras à implantação da cultura de BPM}

\begin{tabular}{|c|c|}
\hline Restrições à cultura BPM & $\begin{array}{c}\text { Principais Barreiras } \\
\end{array}$ \\
\hline \multirow{11}{*}{$\begin{array}{l}\text { Desvantagens da existência de } \\
\text { barreiras internas }\end{array}$} & Fluxo de informações difuso e comunicação ineficaz \\
\hline & Falta de visão global do negócio \\
\hline & Falta de definição clara sobre o dono do processo \\
\hline & Maior alienação das pessoas \\
\hline & Trabalho seqüencial \\
\hline & Problemas somente são percebidos no produto pronto \\
\hline & Atrasos e demoras \\
\hline & Duplicidade de esforços e trabalhos repetitivos \\
\hline & Falta de sinergia entre funcionários e entre departamentos \\
\hline & Pouca flexibilidade e ciclo de processo muito extenso \\
\hline & Dificuldades na identificação das atividades desnecessárias \\
\hline \multirow{8}{*}{$\begin{array}{l}\text { Desvantagens da existência de } \\
\text { barreiras externas }\end{array}$} & Empresas envolvidas perdem em flexibilidade, tempo e competitividade \\
\hline & Dificuldades de negociação \\
\hline & Atrasos no atendimento a clientes \\
\hline & Acúmulo de estoques e aumento de custos \\
\hline & Duplicidade de trabalhos \\
\hline & Maior necessidade de investimento em qualidade e inovações \\
\hline & Minimiza as margens de lucro \\
\hline & Ineficiência na cadeia de suprimentos \\
\hline \multirow{11}{*}{$\begin{array}{l}\text { Dificuldades na remoção de } \\
\text { barreiras internas }\end{array}$} & Competitividade entre departamentos \\
\hline & Diferenças de cultura e métodos de trabalho \\
\hline & Disputas pelo poder \\
\hline & Falta de consciência da responsabilidade de cada um no produto final \\
\hline & Sobrecarga de trabalho em alguns setores \\
\hline & Falta de visão do processo como um todo \\
\hline & Falta de foco no cliente \\
\hline & Dificuldades de comunicação entre departamentos e do trabalho em equipe \\
\hline & Cultura de informações não compartilhadas \\
\hline & Necessidade de integração entre sistemas de informação \\
\hline & Necessidades ergonômicas do ambiente de trabalho \\
\hline \multirow{7}{*}{$\begin{array}{l}\text { Dificuldades de remoção de } \\
\text { barreiras externas }\end{array}$} & Dificuldade de visualização do processo fora da organização \\
\hline & Busca do cumprimento de metas pessoais em detrimento das organizacionais \\
\hline & Dificuldade de fazer prevalecer o espírito de parceria \\
\hline & Dificuldade na partilha do conhecimento entre organizações \\
\hline & Dificuldade de integração e adoção de novas tecnologias \\
\hline & Visão focalizada no ganho local em detrimento ao da cadeia de valor \\
\hline & Dificuldades de integração de culturas organizacionais diferentes \\
\hline
\end{tabular}

FONTE: Criado a partir de De Sordi (2005, p. 159-161) 
De Sordi (2005, p. 161) complementa que uma das formas de se suplantar as barreiras, relacionadas no quadro 24 , se dá com a intensificação de medidas voltadas ao desenvolvimento do aprendizado organizacional, tais como seminários, treinamentos, visitas a empresas que já implementaram o BPM, entre outras. Nesta etapa devem ser incluídos não somente o público interno da organização, como também clientes, fornecedores e parceiros.

\subsubsection{Funcionalidades requeridas pela área de negócio à TIC para os sistemas de BPM}

Venkatraman (1993, p. 122) observou que a estratégia de emprego da tecnologia pelas organizações deve estar direcionada à exploração de suas capacidades de criar novos e efetivos processos de negócio, em vez de simplesmente automatizar funções empresariais.

De Sordi (2005, p. 77) afirma que a indústria da Tecnologia de Informação e Comunicação tem sido desafiada não só a integrar as diversidades de sistemas de informação e fazer manutenção no volume crescente de softwares, mas também, no aspecto gerencial, a acompanhar a operação e os eventos tratados por diversos sistemas a partir de uma camada de software para o gerenciamento de processos de negócio. Neste sentido, o autor relaciona as principais funcionalidades demandadas pela área de negócio à área de TIC para os softwares de BPM, classificadas por objetivo, em três grupos, e resumidas no quadro 25.

\section{Quadro 25 - Funcionalidades requeridas pela área de negócio para softwares de BPM}

\begin{tabular}{|c|c|}
\hline Objetivo & Funcionalidades \\
\hline \multirow{7}{*}{$\begin{array}{l}\text { Otimização e } \\
\text { flexibilização } \\
\text { da operação do } \\
\text { processo }\end{array}$} & Flexibilidade para alteração de softwares conectados para a execução de atividades \\
\hline & Monitoramento das ocorrências de problemas nos ambientes computacionais \\
\hline & Interação humana na operação do processo \\
\hline & $\begin{array}{l}\text { Flexibilidade para alteração do fluxo de atividades conforme o contexto (ambiente centrado } \\
\text { em orquestração) }\end{array}$ \\
\hline & Manuais e instruções on-line que empregam os diagramas operacionais do processo \\
\hline & Gerenciamento de versões operacionais de processos (histórico de versões) \\
\hline & Assinalamento de instâncias do processo para análise posterior (casos reais) \\
\hline \multirow{8}{*}{$\begin{array}{c}\text { Gerenciamento } \\
\text { da operação de } \\
\text { processos }\end{array}$} & Identificação de atividades que reduzam a capacidade produtiva do processo (gargalos) \\
\hline & Sugestão de potenciais pontos de melhoria \\
\hline & $\begin{array}{l}\text { Apontamento do caminho crítico e demais dados da operação em tempo real (indicadores de } \\
\text { desempenho) }\end{array}$ \\
\hline & Análise dos recursos alocados ao processo (projetado, instalado, em uso, ocioso) \\
\hline & Identificação de recursos necessários (humanos, computacionais, operacionais) \\
\hline & Apuração de custos (previsto e realizado) \\
\hline & Atribuição de metas (benchmarking) \\
\hline & Painel de controle (interação, acompanhamento e análise de desempenho) \\
\hline \multirow{2}{*}{$\begin{array}{c}\text { Planejamento } \\
\text { e projeto do } \\
\text { processo }\end{array}$} & Simulações (ajustes e comparações) \\
\hline & Histórico evolutivo do processo (armazenamento de versões e indicadores de desempenho) \\
\hline
\end{tabular}

FONTE: Criado a partir de De Sordi (2005, p. 83-87) 
Em recente pesquisa sobre as perspectivas de mercado de softwares de BPM, alguns dados reforçam a oportunidade do presente estudo na busca dos principais atributos para medição de desempenho do gerenciamento de processos de negócio.

A figura 2 apresenta um gráfico contendo o ranking dos principais requisitos exigidos por dirigentes de empresas, desenvolvedores de sistemas, consultores de negócio e de TIC, entre outros, em softwares de BPM, relativos ao ano de 2004. Para surpresa dos analistas da pesquisa, o monitoramento de desempenho que se dá pela presença de métricas de desempenho (ou indicadores) e de relatórios analíticos dos processos de negócio nestes softwares alcançou o primeiro lugar, com $63 \%$ dos respondentes considerando-os como requisitos essenciais.

Ranking of BPM Components and Whole-Product Requirements

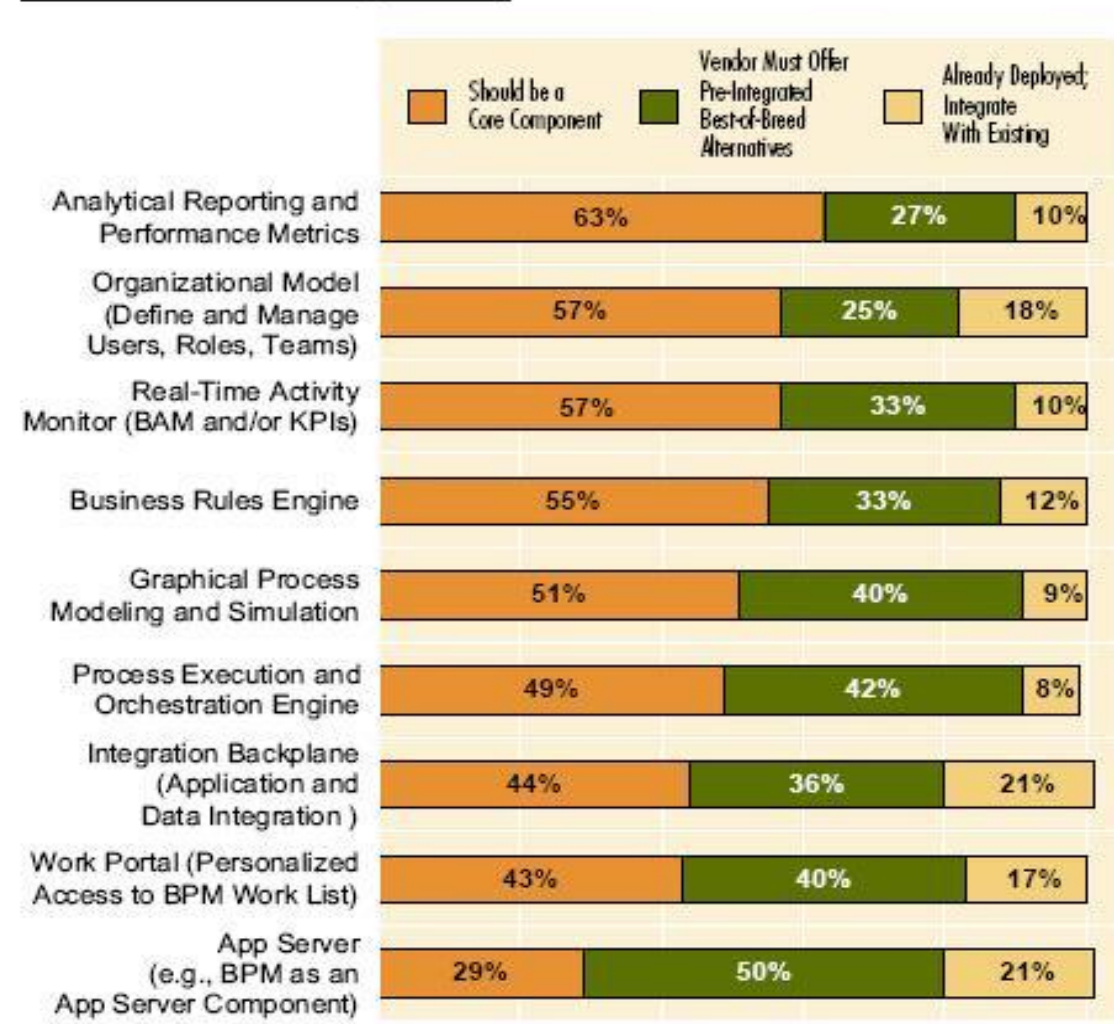

Figura 2-Ranking of BPM Components and Whole-Product Requirements FONTE: Delphi Group (2005, p. 6) 
A figura 3 exibe uma comparação entre os resultados da pesquisa realizada em 2004 e a de 2003, mostrando que o requisito de monitoramento do desempenho se encontrava anteriormente como um dos últimos em grau de importância. Ao mesmo tempo, destaca que as capacidades essenciais como engine de regras e de execução caíram significativamente de $67 \%$ para $55 \%$. Para os analistas, certamente não se admite uma solução BPM sem a habilidade de executar os processos. No entanto, deve ser ressaltada a tendência crescente de ver o BPM não necessariamente como processo de execução, mas principalmente, sua habilidade de monitoramento e medição de desempenho da área de negócio como um todo.

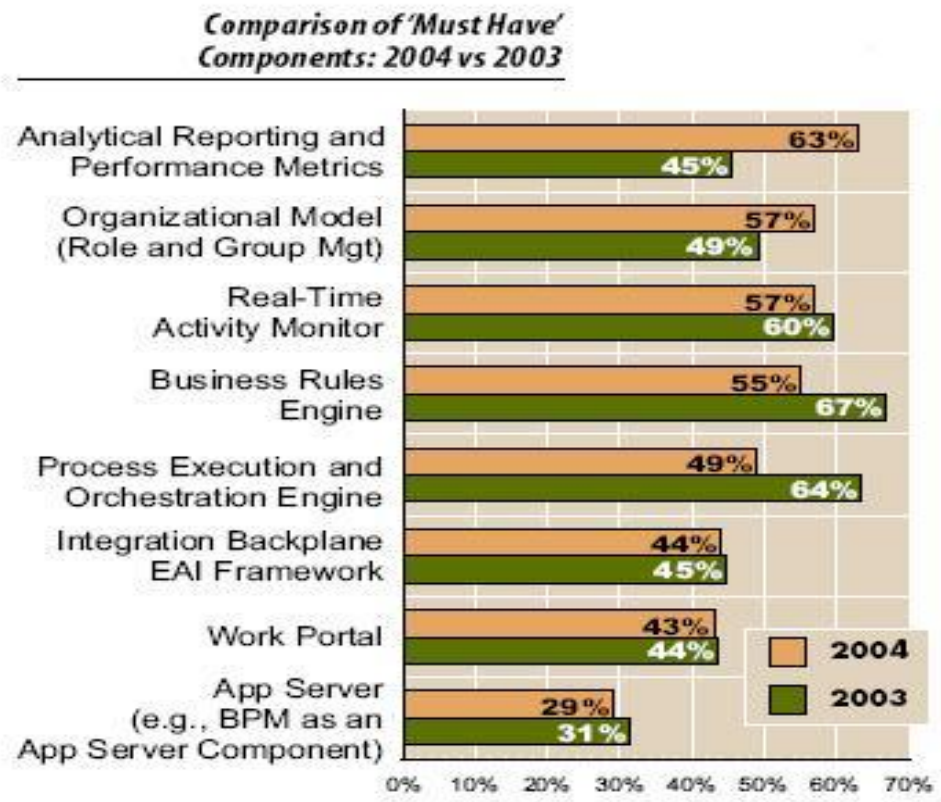

Figura 3 - Comparison of 'Must Have' Components: 2004 vs.2003

FONTE: Delphi Group (2005, p. 6)

$\mathrm{Na}$ figura 4 constam os resultados do pedido realizado aos entrevistados para que indicassem, em uma lista de requisitos essenciais, quais as habilidades que eles sentiam falta nas atuais soluções informatizadas de BPM. Entre elas, em primeiro lugar, 22\% indicaram a ausência de padrões de modelos de processos. E, em segundo lugar, 17\% citaram o gerenciamento do desempenho de negócio. 


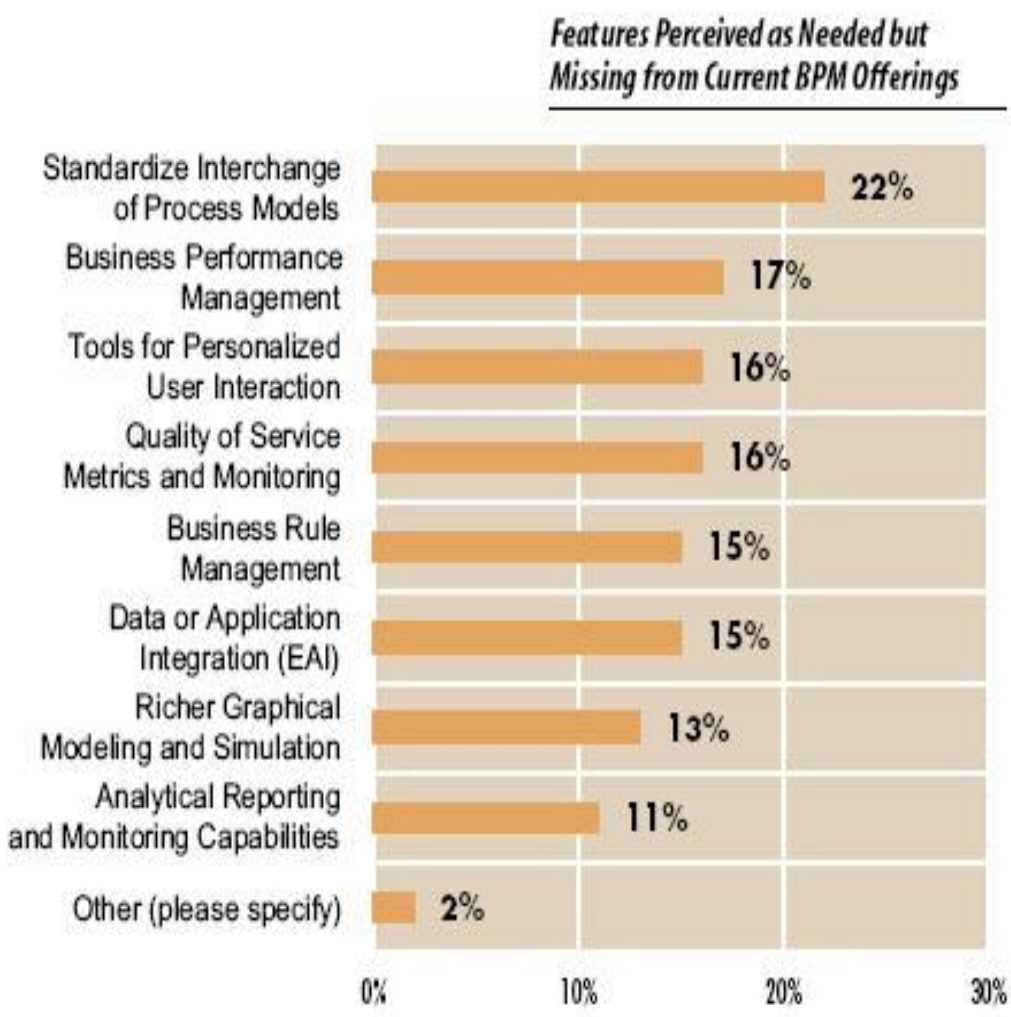

Figura 4 - Feature Perceived as Needed but Missing form Current BPM Offerings FONTE: Delphi Group (2005, p. 7)

Estes fatos comprovam que a medição de desempenho de BPM e sua conseqüente presença entre as principais funcionalidades das diversas soluções informatizadas de mercado não se encontram ainda satisfatoriamente equacionadas.

$\mathrm{Na}$ seqüência, a fim de se identificarem similaridades e diferenças entre os principais conceitos de gerenciamento de processos de negócio, à luz do entendimento de pesquisadores de diferentes áreas do conhecimento acadêmico-científico, será apresentado o BPM sob a ótica tecnológica.

\subsubsection{O BPM sob a ótica da Tecnologia da Informação e Comunicação}

Segundo Aaslt et al (2003b, p. 1), um sistema de gerenciamento de processos de negócio é um sistema de informação genérico, para computador (software), que é guiado por desenhos de processos explícitos a fim de executar e gerenciar processos operacionais de negócio. Para 
ilustrar a relevância destes sistemas, é interessante colocá-los dentro de uma perspectiva histórica (AALST, 2002). A figura 5, ao ilustrar algumas das atuais tendências em sistemas de informação, mostra que os atuais sistemas são compostos por camadas.

A camada central é formada pelo sistema operacional, ou seja, o software que controla o hardware. A segunda camada é formada por aplicações genéricas que podem ser usadas em diversas organizações. Além disso, tais aplicações são tipicamente usadas em vários departamentos dentro de uma mesma organização, tais como o sistema de gerenciamento de banco de dados, o editor de texto e as planilhas eletrônicas.

A terceira camada é formada por aplicações específicas de domínio (ex: web services, call center, sistemas de RH). Tais aplicações são usadas apenas dentro de determinados tipos de empresas e departamentos. Os sistemas de apoio à decisão para software de call center e software de gerenciamento de recursos humanos são alguns exemplos dessas aplicações.

A quarta camada é formada por aplicações personalizadas. Tais aplicações são desenvolvidas para organizações específicas como, por exemplo, o sistema de cadastro e controle de freqüência e notas dos cursos de graduação (Júpiter) e pós-graduação (Fênix) da Universidade de São Paulo - USP. Este sistema foi desenvolvido atendendo os requisitos específicos da USP e funciona somente para suprir as suas demandas, não sendo auto-aplicável ou até utilizável em outras instituições de ensino superior.

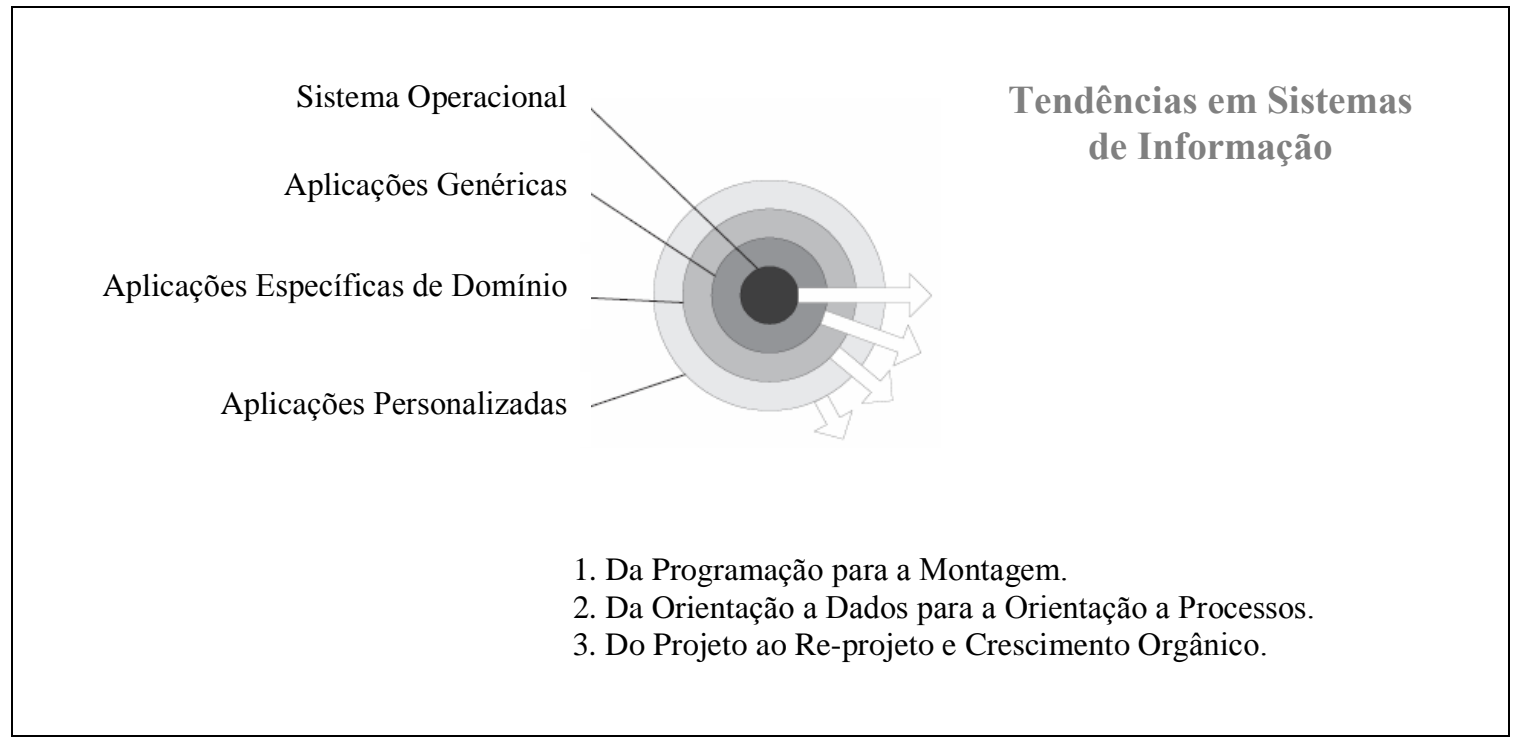

Figura 5 - Tendências relevantes dos Sistemas de Informação para BPM

FONTE: Adaptado de Aalst (2002) 
Na década de sessenta, a segunda e a terceira camadas não existiam. Para Aalst et al (2003b, p. 2) os sistemas de informação eram construídos no topo de um pequeno sistema operacional com funcionalidades limitadas. Como não existia nenhum software específico de domínio ou genérico, tais sistemas eram formados principalmente por aplicações personalizadas. A partir deste período, a segunda e a terceira camadas começaram a ser desenvolvidas, fazendo com que a tendência das quatro camadas fosse no sentido de aumentar de tamanho enquanto absorviam novas funcionalidades.

Atualmente, os sistemas operacionais oferecem muito mais funcionalidades. Os sistemas gerenciadores de banco de dados que se localizam na segunda camada fornecem funcionalidades que são usadas por aplicações personalizadas. Como resultado desta tendência, a ênfase saiu da programação para a montagem de sistemas de software complexos. O desafio não está mais na codificação de módulos individuais, mas sim na organização e junção de peças de software existentes em cada uma das quatro camadas.

De acordo com Aaslt et al (2003b, p. 3), uma outra tendência é a mudança de foco de dados para processos. Os anos setenta e oitenta foram dominados por abordagens orientadas a dados. O foco da TI estava em armazenar e recuperar informações e como resultado, a modelagem de dados era o ponto de partida para construir sistemas de informação. A modelagem de processos de negócio era normalmente negligenciada e os processos tinham que se adaptar à TI. A tendência de gerenciamento, tal como a reengenharia de processos de negócio, ilustra a maior ênfase nos processos. Como resultado, os engenheiros de sistemas estão recorrendo a uma abordagem mais orientada a processos.

A última tendência destacada por Aalst et al (2003b, p. 3) é a mudança de foco dos projetos cuidadosamente planejados para o reprojeto e o crescimento orgânico. Castells (1999) identifica nos tempos atuais uma revolução tecnológica, focalizada nas TIs, que está remodelando a base material da sociedade num ritmo acelerado, ditada entre outros, pela disseminação e uso da Internet e seus padrões. Com isso, os sistemas de informação vão mudando durante o seu uso e, como resultado, poucos são construídos saindo do zero. Em muitos casos, aplicações existentes são parcialmente usadas em novos sistemas. Embora o desenvolvimento de software baseado em componentes ainda tenha seus problemas, o objetivo é claro, ficando a constatação de que o desenvolvimento de software tornou-se mais dinâmico. 
Os sistemas de BPM ou são aplicações separadas que residem na segunda camada ou são componentes integrados às aplicações específicas de domínio, contidas na terceira camada (AALST, 2002). Exemplos clássicos de sistemas de gerenciamento de processos de negócio que residem na segunda camada são os sistemas de gerenciamento de workflow (JABLONSKI e BUSSLER, 1996; LEYMANN e ROLLER, 1999; AALST e HEE, 2002), tais como Staffware, MQSeries e COSA, e handling systems tal como o FLOWer.

Os sistemas de planejamento de recursos organizacionais lideram a terceira camada e também possuem um módulo de gerenciamento de workflow. Os sistemas de workflow do SAP, Baan, PeopleSoft, Oracle, e JD Edwards podem ser considerados como sistemas de BPM integrados. A idéia de isolar o gerenciamento dos processos de negócio num componente separado é consistente com as três tendências identificadas.

Em suma: os sistemas de BPM podem ser usados para evitar o árduo trabalho de codificação na construção de aplicações personalizadas e assim apoiar a mudança de foco na programação para foco na composição. Além disso, estes sistemas apóiam a orientação a processos, reprojeto e crescimento orgânico. Por exemplo, os sistemas atuais de gerenciamento de workflow podem ser usados para integrar as aplicações existentes e apoiar a mudança do processo mudando simplesmente o diagrama workflow. $\mathrm{O}$ isolamento do gerenciamento dos processos de negócio num componente separado é também consistente com os recentes desenvolvimentos no domínio de web services.

Um interessante ponto de partida da perspectiva científica são os primeiros trabalhos sobre sistemas de automação de escritórios. Nos anos setenta, de acordo com Ellis (1979), Holt (1985), Zisman (1977), os funcionários de escritórios já trabalhavam com estes sistemas, que eram dirigidos por modelos de processo explícito. Durante os anos setenta e oitenta era notável o otimismo sobre a aplicabilidade dos sistemas de automação de escritórios. Contudo, poucas aplicações foram bem sucedidas. Como resultado dessas experiências, tanto a aplicação dessa tecnologia quanto as pesquisas quase que pararam por uma década. Em conseqüência, quase não houve avanços neste período.

Nos anos noventa, houve novamente um enorme interesse nos sistemas de gerenciamento de workflow e um número significativo de artigos sobre tecnologia de workflow ilustra o renascimento dos sistemas de automação de escritórios. Atualmente, existem vários sistemas 
de gerenciamento de workflow (LAWRENCE, 1997). No entanto, segundo Aalst et al (2003b, p. 4), sua aplicação ainda ficou relativamente limitada a setores específicos tais como banco e seguradoras. Conforme Ellis e Nutt (1996), houve importante aprendizado com esses altos e baixos.

As falhas nos anos oitenta puderam ser explicadas tanto por problemas técnicos quanto por problemas conceituais. Neste período, as redes eram lentas ou não estavam presentes em todos os lugares, e não havia interfaces gráficas amigáveis e nem um software apropriado desenvolvido. Além disso, havia também problemas mais fundamentais: não existia uma maneira unificada de modelar processos e os sistemas eram rígidos demais a ponto de poderem ser usados por pessoas somente em seus locais de trabalho.

Para Aalst et al (2003b, p. 4), muitos dos problemas técnicos foram resolvidos. No entanto, os problemas mais conceituais permaneceram. Ainda faltam bons padrões de modelagem de processos de negócio e mesmo os atuais sistemas de gerenciamento de workflow reforçam desnecessariamente as restrições sobre a lógica dos processos (por exemplo, os processos são na maioria seqüenciais).

\subsubsection{Fases do Gerenciamento de Processos de Negócio}

Muitos pesquisadores consideram o Gerenciamento de Processos de Negócio o passo seguinte à onda dos workflows dos anos noventa. Por isso, usa-se a terminologia de workflow para definir o BPM. Hollingsworth (1995, p. 3) define workflow como a automação de um processo de negócio, no todo ou em parte, por meio da qual documentos, informações ou tarefas são passadas de um participante ao outro por ações, e de acordo com um conjunto de regras definidas.

Para Lawrence (1997) um WFMS - Workflow Management System (Sistema de Gerenciamento de Workflow) é definido como um sistema que determina, cria e gerencia a execução de workflows pelo uso de software, trabalhando em uma ou mais estruturas de workflow, e que está apto a interpretar a definição do processo, interagir com os stakeholders do workflow e, quando necessário, solicitar o uso de ferramentas e aplicações de TI. 
Em ambas as definições pode-se notar a ênfase sobre a execução, ou seja, o uso de software para apoiar a execução dos processos operacionais. Nos últimos anos, muitos pesquisadores e profissionais começaram a perceber que o foco tradicional sobre a execução era muito restritivo. Como resultado, novos termos como os do BPM foram inventados. Hoje, existem muitas definições de BPM que, na sua maioria, incluem explicitamente o Gerenciamento de Workflow.

Para Aalst et al (2003b, p. 4), o BPM é definido como o apoio aos processos de negócio usando métodos, técnicas e sistemas de informação computadorizados (softwares) para projetar, executar, controlar e analisar processos operacionais envolvendo pessoas, organizações, aplicações, documentos e outras fontes de informação. Esta definição restringe o BPM aos processos operacionais, excluindo assim os processos de nível estratégico ou aqueles processos que não puderam ser explicitados.

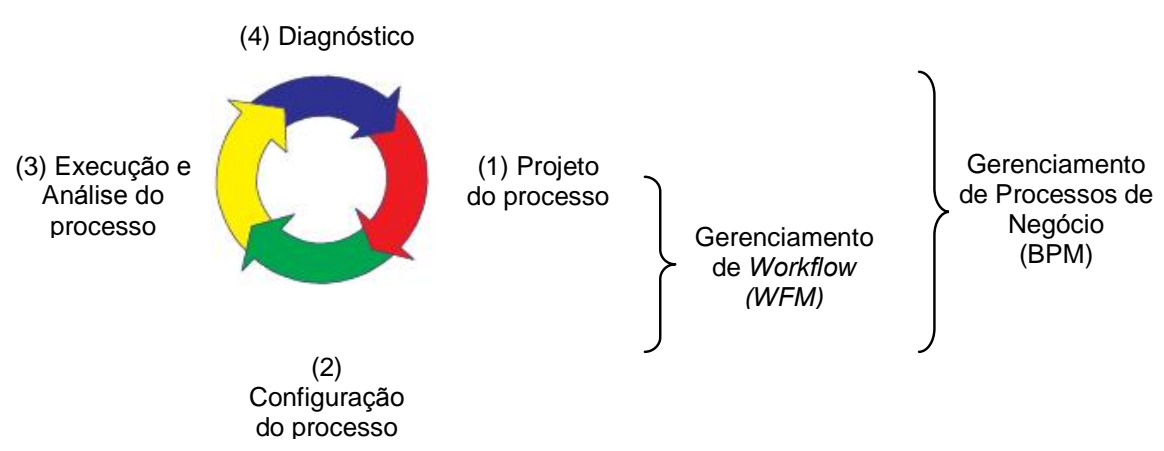

Figura 6 - O ciclo de vida do BPM comparado ao ciclo do Gerenciamento de Workflow FONTE: Adaptado de Aalst et al (2003b), p. 5

A figura 6 exibe a relação entre o WFM e o BPM, usando o ciclo de vida do Gerenciamento de Processos de Negócio. O ciclo de vida do BPM descreve as várias fases no suporte operacional aos processos de negócio. $\mathrm{Na}$ fase de projeto (1), os processos são re-desenhados. $\mathrm{Na}$ fase de configuração (2), os projetos são implementados pela configuração de um sistema de informação consciente do processo, como, por exemplo, um WFM. Depois da fase de configuração, a fase de execução (3) se inicia quando os processos operacionais de negócio são executados usando o sistema configurado. $\mathrm{Na}$ fase de diagnóstico (4), os processos operacionais são analisados para identificar problemas e encontrar elementos que podem ser melhorados. 
O foco dos sistemas de gerenciamento de workflow tradicionais está na metade inferior do ciclo de vida do BPM, fases (1) e (2). Como resultado, existe pouco apoio à fase de diagnóstico. Mais ainda, o apoio à fase de projeto é limitado ao fornecimento de um editor, similar a um editor de textos, já que o suporte à análise e ao desenho real dos processos não existe (AALST et al, 2003b, p. 5). Pode-se considerar que poucos sistemas WFM apóiam a simulação, verificação e validação dos projetos de processos. É também extraordinário que alguns sistemas apóiem a coleta e interpretação de dados em tempo real. Merece destaque o fato de que a maioria dos sistemas WFM guarda os dados sobre os casos e tarefas executadas. E ainda assim, não se conhecem relatos de que alguma ferramenta de apoio a qualquer forma de diagnóstico seja oferecida pelos sistemas tradicionais.

Atualmente, muitos fornecedores de sistemas de workflow estão posicionando seus sistemas como sistemas BPM. O grupo Gartner (2002) acredita no crescimento do mercado de BPM e que também seja reconhecido o BPA - Business Process Analysis (Análise de Processos de Negócio) como um importante aspecto. Para Aalst et al (2003a) o BPA cobre aspectos negligenciados pelos produtos tradicionais de workflow, como por exemplo, análise, diagnóstico, simulação, entre outros.

O BAM - Business Activity Monitoring (Monitoramento das Atividades de Negócio) é uma das áreas emergentes no BPA. O objetivo das ferramentas do BAM é usar os dados históricos guardados pelo sistema de informação para diagnosticar os processos operacionais. Um exemplo é o ARIS PPM - ARIS Process Performance Manager (Gerente de Desempenho de Processo ARIS) do IDS Scheer. O ARIS PPM extrai informações a partir das trilhas de auditoria, ou seja, informações históricas guardadas durante a execução dos casos $(\log s)$ e exibe essas informações de forma gráfica (por exemplo, fluxo de tempo, gargalos, nível de utilização, etc.). O BAM também inclui o mining de processos, qual seja, a extração de modelos de processos a partir dos dados históricos (AALST et al, 2003a).

Quando se chega ao reprojeto de processos operacionais, duas tendências podem ser identificadas: STP - Straight Through Processing (Processamento Direto) e CH - Case Handling (Tratamento de Casos). O STP refere-se à completa automação de um processo de negócio, pela manipulação de casos sem o envolvimento humano. Normalmente o STP somente é possível se o processo é re-projetado. E ainda mais, o STP somente é possível para um conjunto seleto de casos. Os casos podem ser classificados em dois grupos: casos que 
podem ser manipulados automaticamente e casos que exigem o envolvimento humano. Devido à separação em grupos, normalmente é possível reduzir o tempo de fluxo e o custo de redução.

Para Aalst e Berens (2001, p. 43-44), enquanto o STP se esforça na maior automatização, o $\mathrm{CH}$ ataca o problema daqueles vários processos que variam muito ou são muito complexos de serem capturados num diagrama de processos. $\mathrm{No} \mathrm{CH}$, a rota normal de um caso é modelada, mas ao mesmo tempo, outras rotas são permitidas se não estiverem excluídas. Uma maneira de fazer isso é tornar os workflows dirigidos por dados ao invés de dirigidos a processos e permitir que autorizações sejam omitidas ou atividades desfeitas. Além disso, o foco está nos casos como um todo ao invés de estar nos itens de trabalho individuais distribuídos sobre as listas de trabalho.

Em resumo, segundo Aalst et al (2003b), o BPM estende a abordagem tradicional do WFM ao apoiar a fase de diagnóstico (software BPA e BAM) e permite novas maneiras de apoiar processos operacionais (CH e STP).

\subsubsection{Aspectos-Chave do Gerenciamento de Processos de Negócio}

Segundo Wodtke e Weikum (1997) os modelos de processos de negócio necessitam de uma fundamentação formal. As razões conhecidas incluem: modelos formais não permitem qualquer ambigüidade; e modelos formais elevam o potencial de análise. Para Aalst et al (2003b, p. 6), é desejável que um modelo de processo de negócio possa ser entendido por todas as pessoas envolvidas da maneira mais simples possível. Isso pode, por exemplo, ser alcançado por meio do uso de representações gráficas.

Ao mesmo tempo, essas pessoas devem associar o mesmo significado para um mesmo modelo, não devendo existir abertura para qualquer interpretação alternativa e discricionária. Os modelos de processos de negócio podem ser tão complexos que o uso de uma linguagem formal para a sua especificação é a única maneira de garantir que as interpretações alternativas sejam eliminadas.

Após atingir o consenso entre os stakeholders, o modelo do processo de negócio pode ser implantado e, se uma linguagem formal foi usada, seu comportamento pode ser explicado em termos das semânticas formais da linguagem de especificação. Conforme Kiepuszewski et al 
(2002), a falha de uma semântica formal tem provocado diferentes interpretações até por fornecedores de construtores de fluxos de controle básicos. Assim sendo, definições em linguagens naturais tais como as fornecidas pelo WfMC - Workflow Management Coalition não são suficientemente precisas.

Um dos principais aspectos e certamente uma atividade tipicamente conduzida nas fases iniciais nos projetos de BPM é o projeto dos processos de negócio. Existe um relacionamento intrínseco entre o projeto e a modelagem de processos de negócio. O primeiro refere-se ao processo de projeto global, envolvendo múltiplos passos, e o segundo refere-se à representação efetiva dos processos, em termos de um modelo, usando uma linguagem de processos.

Para este fim, o termo modelagem de processo de negócio é usado para caracterizar a identificação e especificação (normalmente informal) dos processos de negócio. As fases incluem a modelagem de atividades e seus relacionamentos causais e temporais, bem como as regras de negócio específicas que as execuções de processos precisam cumprir.

A modelagem de processos de negócio já é estudada há mais de uma década e existe uma variedade de produtos comercialmente disponíveis para apoiar esta fase, com base nas diferentes linguagens de processos. Dada esta situação, não é surpresa que a seleção de um produto em particular seja um importante passo em muitos projetos de BPM e, conseqüentemente, os critérios de seleção apropriados têm sido estudados intensivamente. Destacam-se, entre eles, os aspectos organizacionais e econômicos associados à infraestrutura de TI das empresas, bem como o poder de expressividade da linguagem de processos e das interfaces associadas aos sistemas de software.

A maioria destas linguagens destaca as interfaces dos sistemas de execução de processos (tais como os sistemas de gerenciamento de workflows) e dos softwares responsáveis por modelar estruturas pessoais e organizacionais da empresa. Não só o poder de expressividade, mas também a semântica da linguagem de processos merece um papel central durante a seleção do produto. No entanto, este aspecto é considerado apenas num pequeno número de recentes projetos de BPM. 
A fase de análise dos processos de negócio tem o objetivo de investigar as propriedades dos processos de negócio que não são nem óbvios e nem triviais (AALST et al, 2003b, p. 8). Para esta finalidade, o termo análise é usado com vários significados. Incluem-se nele, por exemplo, a simulação e o diagnóstico, já que ao simular casos do mundo real os especialistas da área de negócio (domínio) podem confirmar a adequação da modelagem ou propor modificações no modelo de processo original. Se os modelos de processo de negócio forem expressos em linguagens de processos com uma clara semântica, suas propriedades estruturais podem ser analisadas. Se, por exemplo, certas partes dos processos nunca puderem ser atingidas, uma óbvia falha de modelagem ocorreu e deve ser corrigida.

Apesar das propriedades estruturais básicas dos modelos de processo já serem estudadas há algum tempo, é significativamente pequeno o número de produtos de software que as apóiam. Mas a semântica estrutural dos modelos de processos exige uma semântica formal clara da linguagem de processos subjacente, que pode não estar presente. Em alguns produtos, uma abordagem pragmática de modelagem de processos é preferível a uma abordagem formal, especialmente se o principal objetivo da modelagem de processos for a discussão com os especialistas de negócio ao invés da análise ou execução do processo. No entanto, as semânticas formais das linguagens de processos, a perceptividade, e a facilidade de uso não são metas contraditórias, e recentes abordagens parecem apoiar este entendimento.

A próxima fase do BPM e a mais intensa é a da execução do processo. Nesta etapa se faz necessário verificar quais os tipos de processos de negócio existentes para a posterior determinação dos tipos de sistemas desses processos. No período de concepção do BPM, quando a modelagem de processos de negócio do lado da aplicação e o gerenciamento de workflow do lado da execução de TI eram apenas as únicas opções, o foco estava nos processos com uma estrutura estática.

A principal razão implícita nesta óbvia limitação era a seguinte: a modelagem de um processo e o fornecimento de infra-estrutura para a sua execução exigiam um esforço considerável. A fim de fornecer um ROI (Retorno sobre o Investimento) satisfatório, um grande número de casos individuais foi beneficiado pelas novas tecnologias. Este tipo de adequação do processo é chamado workflow de produção (LEYMANN e ROLLER, 1999). 
De acordo com Aalst et al (2003b, p. 9) embora existam projetos de workflow bem sucedidos neste tipo de adequação de processos, esta restrição tecnológica do workflow provou ser crucial para as aplicações em ambientes mais dinâmicos. Em alguns casos nos quais a tecnologia de workflow tradicional foi utilizada, novas soluções de workflow foram parcialmente evitadas ou até negligenciadas. Em resposta a esta situação, consideráveis trabalhos foram e estão sendo conduzidos, tanto pela comunidade acadêmica quanto pela indústria, para flexibilizar os workflows existentes, com base nos casos.

Recentemente, o tratamento ou manipulação de casos (case handling) tem sido estudado em profundidade como um novo paradigma para apoiar os processos de negócio que exijam forte conhecimento com baixa estruturação. Com base nesta breve caracterização do tratamento de casos, pode-se entender que no paradigma do case handling os especialistas da área de negócio possuem alto grau de liberdade para organizar e realizar o trabalho que eles sabem fazer. Alguns conceitos de manipulação de casos já estão presentes atualmente nos sistemas comerciais de case handling systems.

A padronização tem uma longa história no gerenciamento de workflow. Enriquecidas pelos sistemas de informação heterogêneos, que também possuem sistemas de gerenciamento de workflow, as organizações começaram a formar grupos de interesse comum com o objetivo de padronizar interfaces entre sistemas de gerenciamento de workflow e componentes, com o objetivo de aprimorar a interoperabilidade e estimular o mercado de workflow.

Segundo Lawrence (1997), a organização mais proeminente neste contexto é a WfMC Workflow Management Coalition, que foi formada em 1993 e hoje tem mais de 300 membros, incluindo todos os principais fornecedores de softwares de workflow, bem como usuários e acadêmicos interessados. A atividade básica da WfMC é a chamada WfMC Reference Architecture que define o padrão para interfaces de componentes de sistemas de workflow. Apesar do fato de todos os fornecedores estarem organizados no WfMC e de várias contribuições importantes sobre aspectos práticos de workflow tenham sido realizadas, muitas pessoas sentem que a almejada meta da WfMC ainda precisa ser alcançada.

Um esforço mais recente de padronização no contexto do BPM está relacionado ao momento atual das tecnologias XML e web services. Para Burbeck (2000) o web services é uma tecnologia promissora, pois encoraja a interoperabilidade entre sistemas de informação que 
sejam baseados conceitualmente no paradigma da arquitetura orientada a serviços e, tecnologicamente, em padrões abertos, e em protocolo e sistemas de peso leve. Embora a tecnologia web services ainda não tenha atingido a maturidade, existe considerável esforço nesse sentido por praticamente todos os principais fornecedores.

A necessidade de padronização é claramente conhecida neste contexto e importantes contribuições têm sido feitas. No entanto, as recentes tendências dos novos padrões propostos, bem como a junção de propostas podem ser experimentadas no contexto de web services. Além dos recentes desenvolvimentos, os web services aparecem como uma infra-estrutura importante para estimular os processos de negócio por compor web services individuais para representar processos complexos, os quais podem até transpor múltiplas organizações.

Embora a composição de web services seja uma disciplina recente e um bom número de propostas já esteja em discussão, Aalst et al (2003b, p. 9) apontam para uma lenta consolidação dos recentes esforços de padronização sobre composição de web services e propostas associadas. Em muitos casos pode-se esperar de web services em geral e composição de web services em particular, que eles venham exercer importante papel no futuro tecnológico dos sistemas de processamento de negócios. Isso inclui tanto os processos dentro das organizações quanto, mais fortemente, entre organizações.

Portanto, a criação de um modelo para a medição de desempenho de BPM, contendo atributos normativos já conhecidos e academicamente sedimentados dos sistemas de medição de desempenho das organizações, acrescido de conceitos fundamentais de um modelo arquitetônico para controle de processos de negócio, recém desenvolvido como o RiverFish, e a ser explicado em seguida, apresenta-se como uma oportuna necessidade de pesquisa na área de administração de TIC, ao propor uma solução para a lacuna ainda existente na fase de diagnóstico dos BPM (software BPA e BAM) e no apoio ao reprojeto de processos operacionais (CH e STP). 


\subsection{A arquitetura RiverFish e o conceito de Plano de Navegação}

Aalst et al (2001) e Aalst et al (2003b) destacam na literatura científica uma série de iniciativas para resolver problemas com a representação e execução de regras de negócio utilizando-se de linguagens e abordagens para BPM e workflow. Compilações destas abordagens encontram-se em Thatte (2001) e WSFL (2005).

Contudo, a representação e execução de regras de consistências nos ambientes de BPM e workflow têm gerado alguns desafios. Um dos que merece destaque é o que questiona a melhor fundamentação matemática e a melhor linguagem para o controle de padrões de workflow. Boa parte dos desenvolvedores de linguagens de BPM e workflow defende a utilização de Redes de Petri ou de Álgebra de Processos na fundamentação e controle destes padrões.

Aalst et al (2001) advogam que as Redes de Petri são uma boa alternativa para representação, controle e execução de padrões workflow. Quanto à Álgebra de Processos, são encontrados poucos relatos na literatura acadêmica de sua utilização como base teórica para implementações destes padrões.

Segundo Ferreira et al (2005b) o RiverFish - RF é um modelo arquitetônico para a representação, controle e execução de processos de negócio. Esta arquitetura possui uma linguagem de modelagem descrita pelo conceito de Navigation Plan - NP (Plano de Navegação). Tal conceito utiliza a Álgebra de Processos para representar o ciclo de um processo de negócio (BERGSTRA et al, 2001; BERGSTRA e MIDDELBURG, 2003; FORKKINK, 2000).

\subsubsection{O Plano de Navegação}

O NP é definido por Ferreira et al (2005a) como um conjunto de todos os processos de negócio exigidos em uma aplicação para se atingirem os objetivos de negócio. O Plano de Navegação mapeia todas as regras de consistência em função dos dados pertencentes às requisições dos serviços eletrônicos de todos os objetivos de negócio.

Passos de negócio são condições a serem satisfeitas pelos dados até que eles sejam armazenados numa base de dados. Cada passo de negócio realizado para um determinado 
dado significa uma mudança de estado desse dado. Requisições são solicitações de serviços (transações) num sistema de informação.

Para os autores, o objetivo do NP é vincular os formulários de requisição de serviços eletrônicos aos respectivos passos de negócio. Esta ligação entre requisições e os passos do processo de negócio é representada pelas instâncias do plano navegacional.

Uma instância do NP é aqui entendida como a representação de um processo requerido por um determinado usuário. Cada nova requisição do processo gera uma nova instância no seu plano de navegação. A arquitetura RiverFish propõe o uso de instâncias do Plano de Navegação para controle da ordem de processamento das requisições. Quando um plano de navegação é instanciado, um vínculo é criado entre os dados do processo e os passos de negócio.

Segundo Ferreira et al (2005b), fazendo-se um paralelo com a teoria de processos, o plano de navegação é a representação canônica de todos os processos em um domínio de aplicação.

\subsubsection{A arquitetura RiverFish}

O ponto central da arquitetura RiverFish, segundo Ferreira et al (2005a), é a representação do processamento de requisições de serviços, modelando e executando passos para alcançar um determinado objetivo de negócio. Em outras palavras, é uma nova abordagem para integração de dados em sistemas autônomos pelo tratamento unificado das requisições.

A materialização desta arquitetura se dá com a divisão do processo de negócio em três estágios. No primeiro estágio, um usuário do serviço gera uma requisição de processo (uma solicitação de informação, de produto ou de serviço). No segundo estágio, a requisição é submetida a uma série de passos de negócio e recebe sua validação somente depois de satisfeitas as exigências especificadas. No terceiro estágio, a requisição é legitimada depois da execução de todos os passos de negócio presentes no plano de navegação.

Uma requisição de serviços eletrônicos em um BPM, como por exemplo uma solicitação de abertura de uma empresa no cadastro de contribuintes de um órgão público, navega por vários passos de negócio até ser armazenada numa base de dados específica de um determinado 
sistema autônomo. Sistemas autônomos são sistemas de informação independentes, contendo transações auto-contidas.

Este modelo arquitetônico é composto por três módulos básicos, ilustrados na figura 7:

1) de Controle unificado;

2) de Instanciação (execução de instâncias do NP);

3) de Armazenamento de dados.

O módulo de Controle unificado (Unified Control) representa o gerenciamento de três bases de dados. A base de dados chamada db-AC (database for the Access Control) armazena dados de todos os usuários, seus perfis e permissões de acesso aos serviços eletrônicos. $\mathrm{O}$ dbNP (database for the Navigation Plans) armazena os passos de negócio para cada conjunto de dados pertencentes às requisições de serviços eletrônicos (planos de navegação). A base de dados db-AI (database for Arrived data and navigation plan Instances) armazena as requisições, os dados contidos nas requisições e nas instâncias do plano navegacional.

O módulo de Instanciação (Execution of the NP Instances) é responsável por instanciar (interpretar) e executar os passos de negócio descritos pelo NP.

O módulo de Armazenamento de Dados (Data Storage), como o próprio nome traduz, armazena os passos de negócio executados, bem como os resultados alcançados pelos dados nas diversas instâncias. 


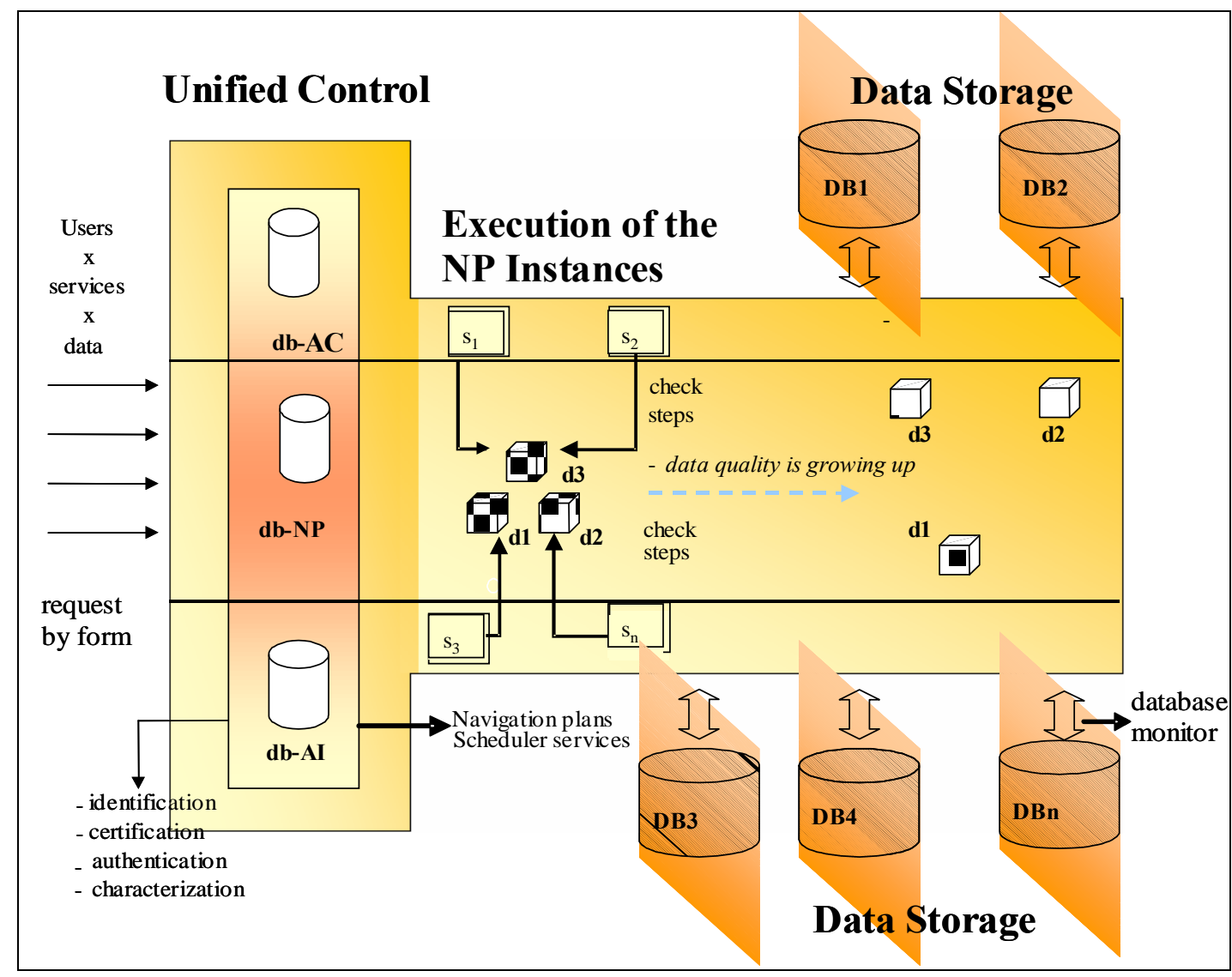

Figura 7 - Modelo da arquitetura RiverFish

FONTE: Ferreira et al (2005a)

\subsubsection{Associação dos conceitos do Plano de Navegação ao RiverFish}

O conceito de Plano de Navegação simplifica a representação e o gerenciamento de processos de negócio complexos. O RF assume o conceito de qualidade do dado, ou seja, a cada passo executado com sucesso pelo monitor de execução junto à instância do NP, aumenta-se a qualidade do dado pertencente à requisição. A arquitetura RiverFish considera como qualidade do dado um conjunto mínimo de regras e consistências satisfeitas. Um verificador de qualidade controla a requisição até que ela atinja a qualidade desejada.

As premissas da arquitetura RiverFish, baseadas nas definições formais do plano navegacional, ilustradas pela figura 8, são: 


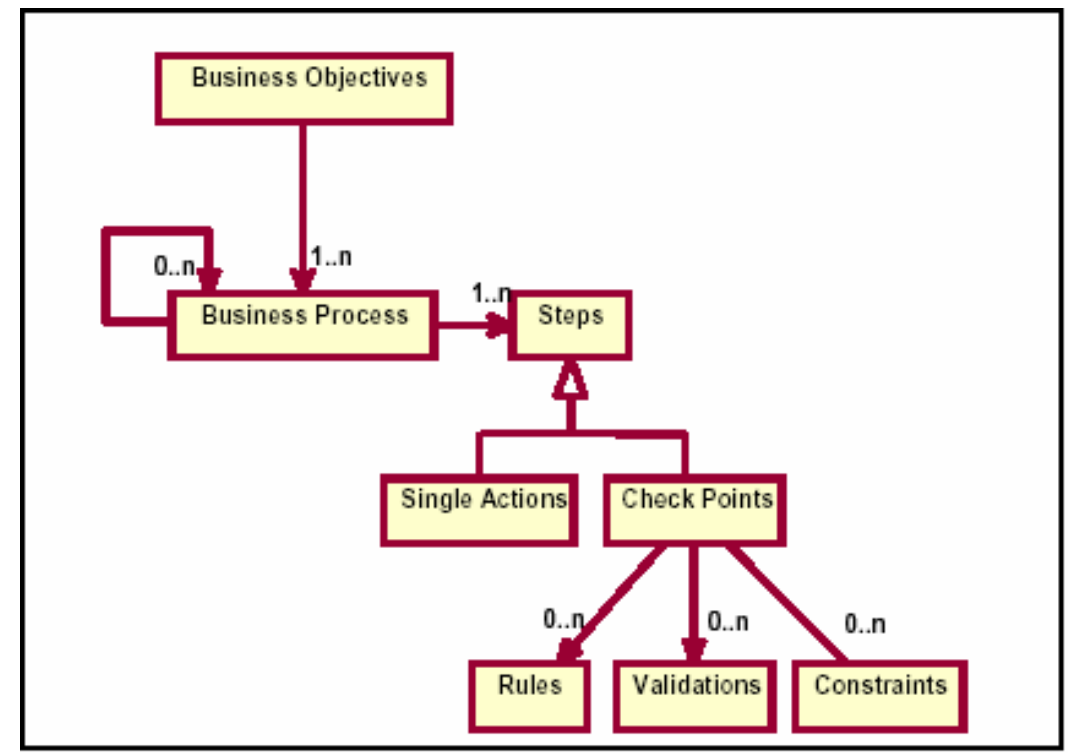

Figura 8 - Premissas da arquitetura RiverFish

FONTE: Ferreira et al (2005a)

1) processos de negócio são iniciados por meio de requisições;

2) um processo de negócio pode ser associado a outro para gerar um processo composto (composição de processos) ;

3) cada processo de negócio é descrito por meio de um conjunto de passos;

4) um passo de negócio pode ser uma Single Action (Ação Simples) ou um Check Point (Ponto de Verificação);

5) um Check Point implementa Rules (Regras), Validations (Validações) e Constraints (Restrições);

6) Single Action e Check Point são usados para a manipulação dos dados.

Uma Single Action é uma tarefa atômica (isolada), que não pode ser decomposta, executada em um processo. Já um Check Point é uma generalização de uma regra, de uma restrição ou de uma validação.

Por exemplo, no processo de validação de um cliente de uma empresa, o dado pode seguir o seguinte caminho (figura 9): 


\section{Exemplo de processo de validação do dado Cliente em um Sistema de Informação}

1. Obter dados do cliente.

(AÇÃO SIMPLES)

2. Validar(CPF é válido) .

(VALIDAÇÃO)

3. Validar(Idade é numérico?)

(VALIDAÇÃO)

4. Se idade $<18$ então

(RESTRIÇÃO)

a. Enviar mensagem: "Idade incorreta".

(AÇÃO SIMPLES)

b. Vá para o passo 1 .

5. resultado $=$ Consultar SPC.

(AÇÃO SIMPLES)

6. Se (resultado = possui pendências) então

(AÇÃO SIMPLES)

(REGRA)

a. Enviar mensagem: "Não autorizar operação". (AÇÃO SIMPLES)

b. Fim.

(AÇÃO SIMPLES)

7. Enviar mensagem: "Cliente sem pendências"

(AÇÃO SIMPLES)

Figura 9 - Exemplo da ação de Check Points num processo de validação de dados

Para Ferreira et al (2005a) uma validação é uma ação que verifica se um dado atende ou não a um conjunto de passos de negócio (ações simples e pontos de verificação) previamente estabelecidos. Por exemplo, se um dado é numérico ou se pertence ao conjunto de números válidos de CPF - Cadastro de Pessoa Física da Secretaria da Receita Federal. Uma restrição estabelece os limites de um dado válido. Já a regra é uma restrição mais complexa que estabelece condições para que um processo prossiga, não prossiga ou altere o seu fluxo normal de execução.

Em suma: o formalismo do ciclo de consistências do processo de negócio na arquitetura RiverFish é representado pelo conceito de Plano de Navegação. O RF é uma proposta de solução arquitetônica para o controle de um ou mais processos de negócio de uma organização.

\subsubsection{Principais características e propriedades do RiverFish}

Segundo Ferreira et al (2005b), o modelo arquitetônico RiverFish apresenta duas principais características: 
1) a reutilização de um determinado passo de negócio na definição de outros processos de negócio;

2) o controle de execução das instâncias de planos de navegação em bancos de dados relacionais.

Para os autores, estas duas características aliadas à definição formal do Plano de Navegação, ratificam as seguintes propriedades da arquitetura RiverFish:

1) Reaproveitamento - propriedade que traduz a reutilização de processos, ou de parte deles, a fim de otimizar o funcionamento dos passos de negócio, de reduzir custos e de diminuir o trabalho repetitivo. Essa propriedade é garantida pela representação atômica de cada passo de negócio no conceito de Plano de Navegação. Um passo de negócio pode pertencer a mais de um Plano de Navegação;

2) Formalização - propriedade que garante a fundamentação matemática para representação de processos de negócio. É sustentada pelo conceito de vinculação das requisições aos passos de negócio. Por meio desta vinculação é possível representar formalmente os passos de negócio e sua ordenação, bem como os pontos de verificação e suas respectivas regras. Essa propriedade é fundamental no RF, já que o Plano de Navegação está fundamentado na Álgebra de Processos;

3) Instanciação - propriedade que viabiliza a especificidade do controle e execução de cada requisição. Quando uma requisição é realizada, um plano de navegação específico é associado. Essa propriedade é assegurada pelo elemento de software Monitor de instanciação;

4) Precisão na localização da interação - propriedade que estabelece a interação precisa entre dados e processos. Ela é viabilizada pela vinculação, em tempo de execução, de uma requisição de processo de negócio e seu respectivo plano de navegação. A requisição contém os dados necessários para a realização de verificações descritas no plano de navegação. Essa vinculação propicia uma precisão na localização da interação entre dados e processos, uma vez que na descrição do plano de navegação dados e processos são tratados separadamente. 
Estas quatro propriedades do RF-NP estão fundamentadas em sete definições da Álgebra de Processos, relacionadas à representação do formalismo do ciclo de regras. Tais definições, extraídas de Bergstra et al (2001) e Ferreira et al (2005b), por estarem mais ligadas à Ciência da Computação e Engenharia de Software, foram incluídas no Anexo C do presente estudo.

Na busca de um modelo de medição de desempenho para o BPM, os atributos já existentes na literatura sobre Sistemas de Medição de Desempenho Organizacional foram analisados segundo a ótica destas quatro propriedades do RF-NP, cuja composição deu origem a uma coleção reformulada de atributos específicos para medição de desempenho de BPM, denominada SMDI-BPM, conforme quadro do Apêndice 1. 


\section{CAPÍTULO 3 - O PROGRAMA DE MODERNIZAÇÃO DAS ADMINISTRAÇÕES FAZENDÁRIAS ESTADUAIS BRASILEIRAS - PNAFE}

Conforme o documento Brasil (2005b, p. 1), o PNAFE - Programa de Modernização das Administrações Fiscais dos Estados Brasileiros, iniciado em 1997 e com apresentação de relatório final previsto para setembro de 2006, com recursos provenientes do BID - Banco Interamericano de Desenvolvimento e de contrapartida local (50\% para cada um), tem por objetivo melhorar a eficiência administrativa, a racionalização e a transparência na gestão dos recursos públicos estaduais.

Os principais resultados esperados pelos dirigentes do Programa e pela alta administração fazendária dos estados são o crescimento da arrecadação de tributos e a racionalização com a qualidade dos gastos públicos de seus governos (BRASIL, 2005c, p. 1).

Abrangendo todos os 26 estados da federação e o Distrito Federal, o Programa contempla ações de modernização nas áreas tributária e financeira, além da implantação de sistemáticas de cooperação entre as Unidades da Federação envolvidas, privilegiando a reengenharia de processos operacionais e de gestão, a capacitação adequada de todos os funcionários e a utilização das tecnologias da informação e das comunicações (TICs) como pilares fundamentais. A ênfase nestas áreas pode ser verificada pela recomendação para direcionamento do investimento total, repartido em $25 \%$ para capacitação, $25 \%$ para consultorias, $30 \%$ para tecnologia da informação, $10 \%$ para equipamentos de apoio e $10 \%$ para infra-estrutura.

$\mathrm{Na}$ área tributária, o Programa está fundamentado na modernização dos processos de negócio ligados à arrecadação, declaração, cadastro, fiscalização, cobrança administrativa e judicial, contencioso administrativo e judicial, atendimento ao contribuinte, legislação e estudos econômico-tributários. $\mathrm{Na}$ área financeira, são enfatizados os processos relacionados com o orçamento, controle financeiro, dívida pública, contabilidade, auditoria e controle interno e sistema integrado de administração financeira (BRASIL, 2005b, p. 1).

Como garantia do cumprimento dos objetivos do PNAFE, na maioria das Unidades da Federação, foram assinados convênios entre as Secretarias Estaduais de Fazenda, gestoras do 
Programa, e outras entidades estaduais essenciais ao processo de modernização fiscal: Procuradorias, Tribunais de Conta, Secretarias de Planejamento ou Administração, Ministério Público.

A cooperação entre as Unidades da Federação na gestão do ICMS - Imposto sobre a Circulação de Mercadoria e Serviços, tributo responsável por mais de $80 \%$ da arrecadação própria, foi impulsionada pela concepção e desenvolvimento do SINTEGRA (Sistema Integrado de Informações sobre Operações Interestaduais com Mercadorias e Serviços) (http://www.sintegra.gov.br).

Baseado em uma Intranet (rede interna) conectando as 27 Unidades da Federação, apoiada por sistemas de bases de dados locais, o sistema possibilita o intercâmbio de informações para a verificação do pagamento adequado das alíquotas interestaduais, além da solicitação e acompanhamento formais de pedidos de fiscalização e de informações complementares.

Por meio da Internet, o SINTEGRA também oferece uma série de serviços aos contribuintes, sendo o mais requisitado a consulta pública aos cadastros estaduais de ICMS para verificação de endereço e de situação fiscal de contribuintes. Este site, em três anos, teve mais de 26 milhões de acessos por parte dos contribuintes, excluídos os acessos internos de cada secretaria. Vale ressaltar que não existe base de dados central no SINTEGRA, sendo todo o sistema completamente descentralizado.

O documento PNUD (2005, p. 2) menciona a instituição de uma espécie de comunidade virtual de práticas nacionais e internacionais, com o uso da ferramenta CST - Cooperação de Soluções Técnicas. Esta comunidade é organizada pela UCP - Unidade de Coordenação de Programas, na qual os estados fazem o intercâmbio estruturado de experiências na implantação de soluções técnicas e são propostas melhores práticas nos diversos componentes do Programa (http://www.esaf.fazenda.gov.br/cst).

O auto-atendimento dos contribuintes, por meio de quiosques eletrônicos e da Internet, foi enfatizado em todos os projetos estaduais de modernização. No inicio do Programa, apenas duas Unidades da Federação dispunham de site fiscal na Internet, contendo basicamente informações institucionais estáticas. Atualmente, todas as Unidades possuem site fiscal, oferecendo aos contribuintes de 10 a 50 tipos diferentes de serviços, alguns deles bastante 
sofisticados como, por exemplo, o cadastramento on line de contribuintes, abdicando completamente dos formulários e de documentos em papel. Internamente, a implementação deste serviço obrigou uma significativa reengenharia de processos de negócio, exigindo interação em tempo real com outras entidades governamentais para validação e atualização das informações prestadas.

Para o PNAFE, algumas Unidades da Federação, como, por exemplo, São Paulo (http://pfe.fazenda.sp.gov.br), Bahia (http://www.sefaz.ba.gov.br) e Paraná (http://www.fazenda.pr.gov.br), em um primeiro momento (BRASIL, 2002, p. 7); e Mato Grosso (http://www.sefaz.mt.gov.br), Santa Catarina (http://www.sef.sc.gov.br), Pernambuco (http://www.sefaz.pe.gov.br) e Sergipe (http://www.sefaz.se.gov.br), em um segundo momento (BRASIL, 2005a, p. 10), estabeleceram a Internet como meio principal de prestação de serviços aos contribuintes, por meio dos chamados Postos Fiscais Eletrônicos.

Sendo os contribuintes do ICMS basicamente pessoas jurídicas, com os médios e pequenos negócios sendo em geral escriturados por contadores autônomos ou escritórios de contabilidade, a provisão de serviços via Internet possui um potencial de utilização muito maior que em outros grandes tributos relacionados com as pessoas físicas.

Como resultado da implementação da cobrança e fiscalização tributárias, a partir das ações do PNAFE, apresentado na tabela 1 , o somatório das arrecadações nos estados e no Distrito Federal do ICMS - Imposto sobre a Circulação de Mercadoria e Serviços e do IPVA Imposto sobre Veículos Automotores, comportou-se da seguinte forma entre 1997 e 2002 (BRASIL, 2005b, p. 1-40).

\section{Tabela 1 - Variação da arrecadação dos principais tributos estaduais no Brasil}

\begin{tabular}{lcccc}
\hline & $\mathbf{1 9 9 7}$ & $\mathbf{2 0 0 2}$ & $\begin{array}{c}\text { Crescimento \% } \\
\text { (correntes) }\end{array}$ & $\begin{array}{c}\text { Crescimento \% } \\
\text { (corrigido IPCA) }\end{array}$ \\
\hline ICMS & 58.524 & 104.850 & $+79,2$ & $+34,8$ \\
\hline IPVA & 3.817 & 7.026 & $+84,1$ & $+38,5$ \\
\hline
\end{tabular}

FONTE: BRASIL, 2005b. (valores correntes, em milhões R\$) 
O documento Brasil (2005b, p. 2-3) ressalta que o comportamento da arrecadação, ainda assim, sofreu uma influência negativa devido a eventos econômicos ocorridos no período, tais como:

- $\quad$ as crises do México, da Ásia e da Rússia e suas repercussões na aquisição de insumos industriais importados;

- $\quad$ a ruptura da âncora cambial, com a mudança do câmbio fixo para flutuante, que resultou em uma forte desvalorização do Real, onerando substancialmente o preço final dos produtos;

- o aumento das taxas de juros, para conter a inflação, em decorrência daquela desvalorização da moeda;

- $\quad$ a crise do Mercosul, com o colapso do mercado argentino;

- a crise energética (conhecida popularmente como "apagão") que, entre outros problemas, limitou o consumo de produtos eletro-eletrônicos.

Para ilustrar o desempenho do Programa, apresenta-se a seguir um resumo dos resultados obtidos em todos os estados brasileiros e no Distrito Federal, de distintos perfis econômicos e sociais, incluindo quadros de variação da arrecadação de 1997 (início oficial do Programa) até 2002, corrigidos pela inflação medida pelo índice IPCA, do IBGE - Instituto Brasileiro de Geografia e Estatística (Tabela 2).

Observa-se que, entre outras constatações, houve aumento de arrecadação de ICMS e IPVA neste período em rigorosamente todos os estados da federação, tendo ocorrido em alguns deles acréscimos da ordem de 100,4\% no ICMS e 205,8\% no IPVA, como no estado de Tocantins. 
Tabela 2 - Síntese Econômico / Social e Variação da Arrecadação dos principais tributos estaduais no período de 1997 a 2002

\begin{tabular}{|c|c|c|c|c|c|c|c|c|c|c|c|c|}
\hline UF & 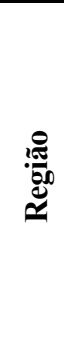 & 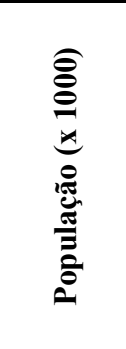 & 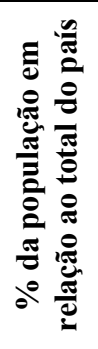 & 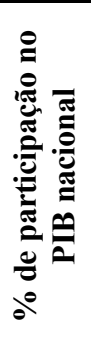 & 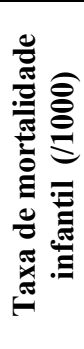 & 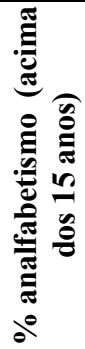 & 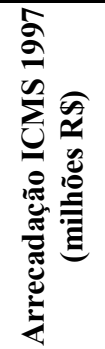 & 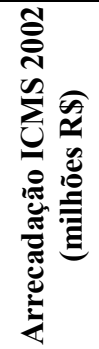 & 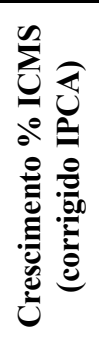 & 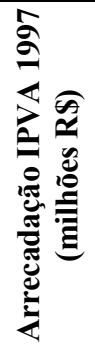 & 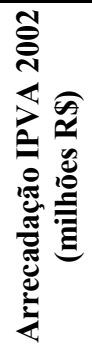 & 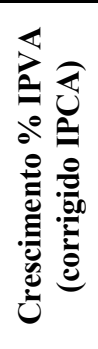 \\
\hline $\mathbf{A C}$ & $\mathrm{N}$ & 557,5 & 0,32 & 0,16 & 44,2 & 15,5 & 51 & 111 & 63,8 & 3 & 6 & 38,3 \\
\hline $\mathbf{A L}$ & $\mathrm{NE}$ & $2.822,6$ & 1,60 & 0,66 & 66,1 & 32,8 & 375 & 673 & 35,2 & 21 & 29 & 3,0 \\
\hline $\mathbf{A M}$ & $\mathrm{N}$ & 477,0 & 0,28 & 0,16 & 31,7 & 9,5 & 55 & 139 & 89,4 & 4 & 8 & 35,1 \\
\hline $\mathbf{A P}$ & $\mathrm{N}$ & $2.812,5$ & 1,60 & 1,60 & 31,8 & 8,8 & 1.225 & 1.938 & 19,0 & 26 & 40 & 17,8 \\
\hline BA & $\mathrm{NE}$ & $13.070,2$ & 7,70 & 4,30 & 45,4 & 24,7 & 2.537 & 5.154 & 52,8 & 65 & 122 & 40,8 \\
\hline $\mathrm{CE}$ & $\mathrm{NE}$ & $7.430,6$ & 4,30 & 2,00 & 52,4 & 27,8 & 1.242 & 2.424 & 46,8 & 52 & 99 & 42,7 \\
\hline DF & $\mathrm{CO}$ & $2.051,1$ & 1,20 & 2,28 & 22,6 & 5,1 & 904 & 1.794 & 49,3 & 86 & 157 & 37,4 \\
\hline ES & SE & $3.097,2$ & 1,80 & 1,93 & 26,0 & 11,1 & 1.623 & 2.382 & 10,4 & 45 & 66 & 11,7 \\
\hline GO & $\mathrm{CO}$ & $5.003,2$ & 3,00 & 1,84 & 25,0 & 12,5 & 1.511 & 2.914 & 45,0 & 77 & 175 & 71,9 \\
\hline MA & $\mathrm{NE}$ & $5.651,4$ & 3,30 & 0,81 & 54,2 & 28,8 & 403 & 922 & 72,2 & 19 & 36 & 41,6 \\
\hline MG & SE & $17.891,4$ & 10,50 & 9,63 & 26,3 & 12,2 & 5.492 & 9.544 & 30,7 & 313 & 746 & 79,4 \\
\hline MS & $\mathrm{CO}$ & $2.078,0$ & 1,20 & 1,12 & 24,4 & 10,9 & 667 & 1.342 & 51,4 & 33 & 56 & 25,8 \\
\hline MT & $\mathrm{CO}$ & $2.504,3$ & 1,47 & 1,20 & 27,5 & 11,8 & 974 & 1.864 & 44,0 & 21 & 81 & $\begin{array}{l}191,9 \\
\end{array}$ \\
\hline PA & $\mathrm{N}$ & $6.192,3$ & 3,60 & 1,70 & 34,6 & 12,4 & 769 & 1.689 & 65,1 & 40 & 56 & 4,1 \\
\hline PB & $\mathrm{NE}$ & 443,8 & 2,00 & 0,82 & 60,3 & 25,9 & 491 & 925 & 41,7 & 17 & 35 & 51,0 \\
\hline PE & $\mathrm{NE}$ & $7.918,3$ & 4,60 & 2,67 & 58,2 & 24,7 & 1.616 & 2.871 & 33,6 & 68 & 118 & 30,9 \\
\hline PI & $\mathrm{NE}$ & $2.843,2$ & 1,70 & 0,49 & 45,3 & 31,6 & 306 & 544 & 34,0 & 11 & 25 & 63,3 \\
\hline PR & $\mathrm{S}$ & $9.563,4$ & 5,60 & 6,30 & 24,3 & 10,2 & 2.839 & 5.787 & 53,3 & 206 & 398 & 45,1 \\
\hline RJ & SE & $14.391,2$ & 8,50 & 11,75 & 24,4 & 6,0 & 5.209 & 10.409 & 50,3 & 342 & 672 & 47,8 \\
\hline RN & $\mathrm{NE}$ & $2.776,7$ & 1,60 & 0,79 & 48,7 & 25,5 & 460 & 1.016 & 66,2 & 19 & 41 & 61,1 \\
\hline RO & $\mathrm{N}$ & $1.379,7$ & 0,80 & 0,52 & 31,6 & 9,6 & 366 & 626 & 28,7 & 12 & 25 & 62,8 \\
\hline RR & $\mathrm{N}$ & 324,3 & 0,20 & 0,08 & 38,3 & 8,6 & 52 & 124 & 79,2 & 2 & 4 & 60,5 \\
\hline RS & $S$ & $10.187,7$ & 6,00 & 7,70 & 18,4 & 6,1 & 4.007 & 7.441 & 39,7 & 272 & 489 & 35,0 \\
\hline SC & $\mathrm{S}$ & $5.356,3$ & 3,10 & 3,66 & 22,2 & 6,8 & 2.033 & 3.858 & 42,7 & 115 & 242 & 58,8 \\
\hline SE & $\mathrm{NE}$ & $1.784,4$ & 1,05 & 0,56 & 45,5 & 23,9 & 367 & 690 & 41,6 & 12 & 17 & 10,8 \\
\hline SP & SE & $37.032,4$ & 21,80 & 35,0 & 21,9 & 6,2 & 22.795 & 37.254 & 22,9 & 1.931 & 3.266 & 27,2 \\
\hline TO & $\mathrm{N}$ & $1.157,0$ & 0,68 & 0,22 & 33,0 & 21,0 & 156 & 416 & 100,4 & 4 & 16 & 205,8 \\
\hline
\end{tabular}

FONTE: Adaptado de BRASIL (2005b, p. 3-39)

O documento PNUD (2005, p. 1) menciona ainda que, a despeito de fatores como o crescimento da economia e da inflação, o PNAFE teve um papel de destaque no aumento de R \$ 57 bilhões, somadas as arrecadações do ICMS de todos os estados da federação, no período de 1998 a 2003, acusando um impacto positivo de aproximadamente $94 \%$.

A tabela 3 apresenta um comparativo entre os valores de ICMS e os dos impostos do governo federal arrecadados no período. Note-se que, enquanto a arrecadação de impostos federais aumentou em $69 \%$, somente a arrecadação do ICMS quase dobrou em seis anos. 


\section{Tabela 3 -Variação da arrecadação do ICMS x Impostos Federais no Brasil entre 1998 e 2003}

\begin{tabular}{lccc}
\hline & $\mathbf{1 9 9 8}$ & $\mathbf{2 0 0 3}$ & Crescimento \% \\
\hline ICMS & 61 & 118 & +94 \\
\hline $\begin{array}{l}\text { Impostos } \\
\text { Federais }\end{array}$ & 66,9 & 113,1 & +69 \\
\hline FONTE: PNUD (2005, p. 2) (valores correntes, em bilhões R\$)
\end{tabular}

FONTE: PNUD (2005, p. 2)（valores correntes, em bilhões R\$)

Em relação aos processos de negócio e a sua reengenharia, pode-se observar durante a execução do PNAFE que conceitos associados ao tema e-Gov (Governo Eletrônico) poderiam alavancar vários componentes ligados à administração tributária, principalmente devido à alta taxa de crescimento do acesso à Internet no Brasil. Adiciona-se ainda o fato do ICMS estar associado a empresas e ao cumprimento de suas obrigações a cargo de contabilistas, ambos com maior facilidade e possibilidade de acesso à Internet, que o cidadão pessoa física.

De acordo com o documento Brasil (2005b, p. 8), observa-se que muitos países estão realizando esforços no sentido de prover a seus cidadãos uma entrada coordenada, oportuna e equânime na sociedade da informação. Neste sentido, há uma preocupação de grande parte da administração pública em colocar à disposição dos cidadãos serviços governamentais utilizando-se de ferramentas da TIC com a simultânea e conseqüente reengenharia de processos internos de suas organizações.

Em que pese o significativo número de serviços públicos de diversos setores da administração pública que ainda necessitam ser atingidos por uma eficiente remodelagem de processos de negócio e a sua informatização, as administrações tributárias de grande parte dos países têm sido pioneiras na introdução de novas tecnologias no governo.

Em parte isto se explica pela necessidade dos governos em aumentar o controle e a administração dos produtos da arrecadação de tributos, e assim obter recursos para o financiamento de seus projetos e programas governamentais. 
Os quadros PNAFE - Web Sites de Administrações Tributárias Estaduais e DF (e-fisco), relativos aos anos de 2002 e 2005, e constantes dos Anexos A e B deste estudo, relacionam os principais serviços eletrônicos colocados à disposição de contribuintes de tributos estaduais, via Internet, pelas unidades federadas brasileiras.

São processos de negócio ligados à Legislação, Cadastro, Declarações, AIDF - Autorização para Impressão de Documentos Fiscais, Conta Fiscal (espécie de Conta Corrente de créditos e débitos dos contribuintes), IPVA e Serviços Diversos.

No que diz respeito especificamente ao comportamento e à evolução dos processos cadastrais no PNAFE, tomados aqui como exemplo, conforme quadros 26 e 27, são destacadas as nove principais funcionalidades a eles relacionadas e o registro da sua implementação, ou não, em todos os estados e no Distrito Federal.

Passada a fase de projeto e implantação destes novos serviços, a alta administração fazendária de todas as unidades da federação se vê diante de um novo desafio: a manutenção, o desenvolvimento incremental e o gerenciamento dos processos de negócio cadastrais de forma a atender cada vez mais às demandas internas e externas de simplificação e otimização promovidas pelos cidadãos e funcionários fazendários envolvidos nestes processos.

O PNAFE identifica, em documentos internos de avaliação do programa, a falta de um modelo de medição de desempenho no gerenciamento da maioria de seus processos de negócio, principalmente aqueles que envolvem soluções com o uso de ferramentas da TIC, como uma lacuna a ser preenchida para a solidificação dos avanços já obtidos. Muitos destes processos possuem controles pontuais que prescindem de um conhecimento multidisciplinar mais amplo e integrado com demais processos de negócio organizacionais. 
Quadro 26 - Serviços cadastrais disponíveis aos contribuintes por meio da Internet Terceiro Benchmark - setembro de 2002

\begin{tabular}{|c|c|c|c|c|c|c|c|c|c|c|c|}
\hline UF & SITE & 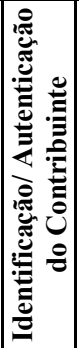 & 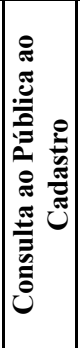 & 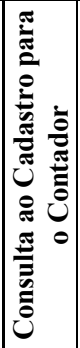 & 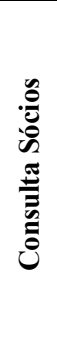 & 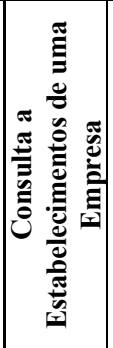 & 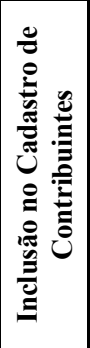 & 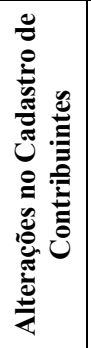 & 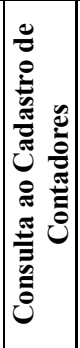 & 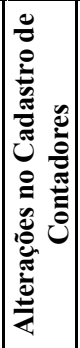 & 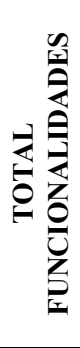 \\
\hline $\mathbf{A C}$ & www.ac.gov.br/sefaz & - & $\mathrm{X}$ & - & - & - & - & - & - & - & 1 \\
\hline $\mathbf{A L}$ & www.sefaz.al.gov.br & - & $\mathrm{X}$ & - & - & - & - & - & - & - & 1 \\
\hline $\mathbf{A M}$ & www.sefaz.am.gov.br & $\mathrm{X}$ & $\mathrm{X}$ & - & - & - & - & - & - & - & 2 \\
\hline $\mathbf{A P}$ & www.sefaz.ap.gov.br & - & $\mathrm{X}$ & - & - & - & - & - & - & - & 1 \\
\hline BA & www.sefaz.ba.gov.br & $\mathrm{X}$ & $\mathrm{X}$ & $\mathrm{X}$ & $\mathrm{X}$ & $\mathrm{X}$ & $\mathrm{X}$ & $\mathrm{X}$ & $\mathrm{X}$ & $\mathrm{X}$ & 9 \\
\hline $\mathbf{C E}$ & www.sefaz.ce.gov.br & $\mathrm{X}$ & $\mathrm{X}$ & $\mathrm{X}$ & $\mathrm{X}$ & $\mathrm{X}$ & $\mathrm{X}$ & - & - & - & 6 \\
\hline DF & www.sefp.df.gov.br & $\mathrm{X}$ & $\mathrm{X}$ & - & - & - & - & - & $\mathrm{X}$ & - & 3 \\
\hline ES & www.sefa.es.gov.br & - & $\mathrm{X}$ & - & - & - & - & - & - & - & 1 \\
\hline GO & www.sefaz.go.gov.br & - & $\mathrm{X}$ & $X$ & - & - & - & $\mathrm{X}$ & - & - & 3 \\
\hline MA & www.gere.ma.gov.br & $X$ & $\mathrm{X}$ & - & - & - & - & - & - & - & 2 \\
\hline MG & www.sef.mg.gov.br & - & $\mathrm{X}$ & - & - & - & - & - & - & - & 1 \\
\hline MS & www.sefaz.ms.gov.br & - & $\mathrm{X}$ & - & - & - & - & - & - & - & 1 \\
\hline MT & www.sefaz.mt.gov.br & $X$ & $\mathrm{X}$ & $\mathrm{X}$ & - & - & - & - & $\mathrm{X}$ & $X$ & 5 \\
\hline $\mathbf{P A}$ & www.sefa.pa.gov.br & $\mathrm{X}$ & $\mathrm{X}$ & $\mathrm{X}$ & $\mathrm{X}$ & $\mathrm{X}$ & - & - & $\mathrm{X}$ & - & 6 \\
\hline PB & www.sefin.pb.gov.br & - & $\mathrm{X}$ & - & - & $\mathrm{X}$ & - & - & - & - & 2 \\
\hline $\mathbf{P E}$ & www.sefaz.pe.gov.br & $\mathrm{X}$ & $\mathrm{X}$ & $\mathrm{X}$ & $\mathrm{X}$ & $\mathrm{X}$ & $\mathrm{X}$ & $\mathrm{X}$ & $\mathrm{X}$ & $\mathrm{X}$ & 9 \\
\hline PI & www.sefa.pi.gov.br & - & $\mathrm{X}$ & - & - & - & - & - & - & - & 1 \\
\hline PR & www.fazenda.pr.gov.br & $X$ & $\mathrm{X}$ & $X$ & $\mathrm{X}$ & $\mathrm{X}$ & $X$ & $\mathrm{X}$ & - & $X$ & 8 \\
\hline RJ & www.sef.rj.gov.br & - & $\mathrm{X}$ & - & - & - & - & - & - & - & 1 \\
\hline $\mathbf{R N}$ & www.set.rn.gov.br & $X$ & $\mathrm{X}$ & $\mathrm{X}$ & $\mathrm{X}$ & - & - & - & $\mathrm{X}$ & - & 5 \\
\hline RO & www.sefin.ro.gov.br & - & $\mathrm{X}$ & - & - & - & - & - & - & - & 1 \\
\hline $\mathbf{R R}$ & sintegra.sefaz.rr.gov.br & - & $\mathrm{X}$ & - & - & - & - & - & - & - & 1 \\
\hline RS & www.sefaz.rs.gov.br & $\mathrm{X}$ & $\mathrm{X}$ & - & - & - & - & $\mathrm{X}$ & - & $\mathrm{X}$ & 4 \\
\hline SC & www.sef.sc.gov.br & $\mathrm{X}$ & $\mathrm{X}$ & - & - & - & - & - & - & - & 2 \\
\hline SE & www.sefaz.se.gov.br & $\mathrm{X}$ & $\mathrm{X}$ & $X$ & $\mathrm{X}$ & $\mathrm{X}$ & $X$ & $\mathrm{X}$ & $X$ & $X$ & 9 \\
\hline $\mathbf{S P}$ & www.fazenda.sp.gov.br & $\mathrm{X}$ & $\mathrm{X}$ & $\mathrm{X}$ & $\mathrm{X}$ & $\mathrm{X}$ & $\mathrm{X}$ & $\mathrm{X}$ & $\mathrm{X}$ & $\mathrm{X}$ & 9 \\
\hline TO & www.sefaz.to.gov.br & - & $\mathrm{X}$ & - & - & - & - & - & - & - & 1 \\
\hline \multicolumn{2}{|c|}{ TOTAL SERVIÇOS ESTADUAIS } & 14 & 27 & 10 & 8 & 8 & 6 & 7 & 8 & 7 & 95 \\
\hline
\end{tabular}

FONTE: Brasil (2002, p. 14) 
Quadro 27 - Serviços cadastrais disponíveis aos contribuintes por meio da Internet Quarto Benchmark - agosto de 2005

\begin{tabular}{|c|c|c|c|c|c|c|c|c|c|c|c|}
\hline UF & SITE & 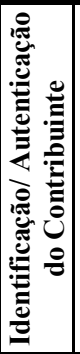 & 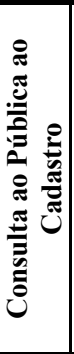 & 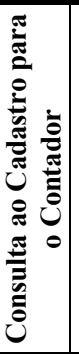 & 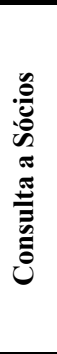 & 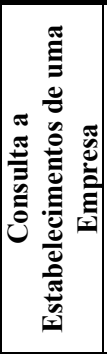 & 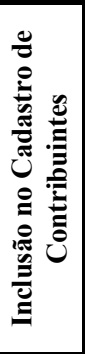 & 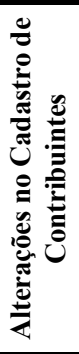 & 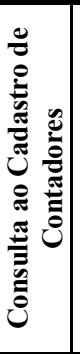 & 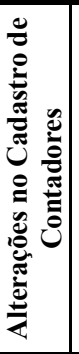 & 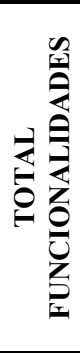 \\
\hline $\mathbf{A C}$ & www.ac.gov.br/sefaz & - & $\mathrm{X}$ & - & - & - & - & - & - & - & 1 \\
\hline $\mathbf{A L}$ & www.sefaz.al.gov.br & - & $\mathrm{X}$ & $\mathrm{X}$ & $\mathrm{X}$ & $\mathrm{X}$ & - & - & - & - & 4 \\
\hline $\mathbf{A M}$ & www.sefaz.am.gov.br & $\mathrm{X}$ & $\mathrm{X}$ & - & - & $\mathrm{X}$ & - & - & - & - & 3 \\
\hline $\mathbf{A P}$ & www.sefaz.ap.gov.br & - & $\mathrm{X}$ & - & $\mathrm{X}$ & $\mathrm{X}$ & $\mathrm{X}$ & - & - & - & 4 \\
\hline $\mathbf{B A}$ & www.sefaz.ba.gov.br & $\mathrm{X}$ & $\mathrm{X}$ & $\mathrm{X}$ & $\mathrm{X}$ & $\mathrm{X}$ & $\mathrm{X}$ & $\mathrm{X}$ & $\mathrm{X}$ & $\mathrm{X}$ & 9 \\
\hline $\mathbf{C E}$ & www.sefaz.ce.gov.br & $\mathrm{X}$ & $\mathrm{X}$ & $\mathrm{X}$ & $\mathrm{X}$ & $X$ & $\mathrm{X}$ & $\mathrm{X}$ & - & $\mathrm{X}$ & 8 \\
\hline DF & www.fazenda.df.gov.br & $\mathrm{X}$ & $\mathrm{X}$ & $\mathrm{X}$ & - & - & - & - & $\mathrm{X}$ & - & 4 \\
\hline $\mathbf{E S}$ & www.sefa.es.gov.br & - & $\mathrm{X}$ & - & - & - & - & - & - & - & 1 \\
\hline GO & www.sefaz.go.gov.br & - & $\mathrm{X}$ & $\mathrm{X}$ & - & - & - & $\mathrm{X}$ & - & - & 3 \\
\hline MA & www.gere.ma.gov.br & $\mathrm{X}$ & $\mathrm{X}$ & $\mathrm{X}$ & $\mathrm{X}$ & $\mathrm{X}$ & - & - & - & - & 5 \\
\hline MG & www.sef.mg.gov.br & $\mathrm{X}$ & $\mathrm{X}$ & - & - & - & $\mathrm{X}$ & $\mathrm{X}$ & - & $\mathrm{X}$ & 5 \\
\hline MS & www.sefaz.ms.gov.br & - & $\mathrm{X}$ & - & - & - & $\mathrm{X}$ & - & - & - & 2 \\
\hline MT & www.sefaz.mt.gov.br & $\mathrm{X}$ & $\mathrm{X}$ & $\mathrm{X}$ & $\mathrm{X}$ & $X$ & $\mathrm{X}$ & $\mathrm{X}$ & $\mathrm{X}$ & $\mathrm{X}$ & 9 \\
\hline $\mathbf{P A}$ & www.sefa.pa.gov.br & $\mathrm{X}$ & $\mathrm{X}$ & $\mathrm{X}$ & $\mathrm{X}$ & $\mathrm{X}$ & - & - & $\mathrm{X}$ & - & 6 \\
\hline PB & www.sre.pb.gov.br & - & $\mathrm{X}$ & - & - & $\mathrm{X}$ & $\mathrm{X}$ & $\mathrm{X}$ & - & $\mathrm{X}$ & 5 \\
\hline $\mathbf{P E}$ & www.sefaz.pe.gov.br & $\mathrm{X}$ & $\mathrm{X}$ & $\mathrm{X}$ & $\mathrm{X}$ & $\mathrm{X}$ & $\mathrm{X}$ & $\mathrm{X}$ & $\mathrm{X}$ & $\mathrm{X}$ & 9 \\
\hline PI & www.sefa.pi.gov.br & - & $\mathrm{X}$ & - & - & - & - & - & - & - & 1 \\
\hline PR & www.fazenda.pr.gov.br & $\mathrm{X}$ & $\mathrm{X}$ & $\mathrm{X}$ & $\mathrm{X}$ & $\mathrm{X}$ & $\mathrm{X}$ & $\mathrm{X}$ & - & $\mathrm{X}$ & 8 \\
\hline RJ & www.sef.rj.gov.br & - & $\mathrm{X}$ & - & - & - & - & - & - & - & 1 \\
\hline $\mathbf{R N}$ & www.set.rn.gov.br & $\mathrm{X}$ & $\mathrm{X}$ & $\mathrm{X}$ & $\mathrm{X}$ & - & $\mathrm{X}$ & $\mathrm{X}$ & $\mathrm{X}$ & - & 7 \\
\hline RO & www.sefin.ro.gov.br & $\mathrm{X}$ & $\mathrm{X}$ & - & - & - & - & - & - & - & 2 \\
\hline $\mathbf{R R}$ & www.sefaz.rr.gov.br & - & $\mathrm{X}$ & - & - & - & - & - & - & - & 2 \\
\hline $\mathbf{R S}$ & www.sefaz.rs.gov.br & $\mathrm{X}$ & $\mathrm{X}$ & $\mathrm{X}$ & $\mathrm{X}$ & $\mathrm{X}$ & $\mathrm{X}$ & $\mathrm{X}$ & $\mathrm{X}$ & $\mathrm{X}$ & 9 \\
\hline SC & www.sef.sc.gov.br & $X$ & $\mathrm{X}$ & $\mathrm{X}$ & $\mathrm{X}$ & $X$ & $\mathrm{X}$ & $\mathrm{X}$ & $\mathrm{X}$ & $\mathrm{X}$ & 9 \\
\hline SE & www.sefaz.se.gov.br & $\mathrm{X}$ & $\mathrm{X}$ & $\mathrm{X}$ & $\mathrm{X}$ & $\mathrm{X}$ & $\mathrm{X}$ & $\mathrm{X}$ & $\mathrm{X}$ & $\mathrm{X}$ & 9 \\
\hline SP & pfe.fazenda.sp.gov.br & $\mathrm{X}$ & $\mathrm{X}$ & $\mathrm{X}$ & $\mathrm{X}$ & $\mathrm{X}$ & $\mathrm{X}$ & $\mathrm{X}$ & $\mathrm{X}$ & $\mathrm{X}$ & 9 \\
\hline TO & www.sefaz.to.gov.br & - & $\mathrm{X}$ & - & - & - & - & - & - & - & 1 \\
\hline \multicolumn{2}{|c|}{ TOTAL SERVIÇOS ESTADUAIS } & 17 & 27 & 15 & 14 & 15 & 14 & 13 & 10 & 11 & 136 \\
\hline
\end{tabular}

FONTE: Brasil (2005a, p. 20) 


\section{CAPÍTULO 4 - ASPECTOS METODOLÓGICOS DA PESQUISA}

O referencial teórico apresentado neste estudo pôde sustentar o desenvolvimento de um procedimento metodológico para a criação de um modelo conceitual para avaliação de desempenho do gerenciamento de processos de negócio do PNAFE. Em consonância com os objetivos deste estudo foram definidos o planejamento da pesquisa, o tipo e as técnicas de pesquisa empregadas, o instrumento de coleta de dados e as técnicas estatísticas de análise de dados adotadas.

\subsection{Planejamento da Pesquisa}

As fases que fizeram parte do planejamento da pesquisa, bem como os principais resultados obtidos, podem ser sintetizados no quadro 28 , como segue:

\section{Quadro 28 - Fases do Planejamento da Pesquisa}

\begin{tabular}{|c|c|}
\hline Fases & Resultados Obtidos \\
\hline 1. Revisão Bibliográfica SMDO, BPM, RF-NP & $\begin{array}{l}\text { - Fundamentação teórica para o desenvolvimento do } \\
\text { Modelo Inicial SMDI-BPM }\end{array}$ \\
\hline $\begin{array}{l}\text { 2. Desenvolvimento de um modelo conceitual para } \\
\text { medição de desempenho BPM - Pesquisa } \\
\text { Qualitativa }\end{array}$ & • Definição do Modelo Evoluído: SMDE-BPM \\
\hline $\begin{array}{l}\text { 3. Pesquisa de Sondagem no PNAFE (survey) } \\
\text { - Pesquisa Quantitativa }\end{array}$ & $\begin{array}{l}\text { - Teste piloto do instrumento de pesquisa } \\
\text { - Validação dos construtos do SMDE-BPM } \\
\text { - Aplicação de técnicas estatísticas de análise } \\
\text { multivariada - Relação entre processos, gestores, } \\
\text { atributos }\end{array}$ \\
\hline $\begin{array}{l}\text { 4. Aperfeiçoamento do modelo evoluído SMDE- } \\
\text { BPM }\end{array}$ & $\begin{array}{l}\text { - Formalização da proposta do modelo final: SMD- } \\
\text { BPM } \\
\text { - Resultados e conclusões para gestores do PNAFE }\end{array}$ \\
\hline
\end{tabular}

$\mathrm{Na}$ primeira fase foi realizada uma revisão bibliográfica, composta pela compilação de alguns dos mais recentes estudos sobre os principais atributos dos sistemas de medição de desempenho organizacionais, bem como pelo levantamento de publicações sobre o Gerenciamento de Processos de Negócio - BPM, sobre o modelo arquitetônico de controle de processos RiverFish e sobre os principais conceitos da linguagem de modelagem de processos Navigation Plan. 
$\mathrm{Na}$ segunda fase foi realizada uma pesquisa qualitativa visando o desenvolvimento do modelo conceitual para o SMDE-BPM (Modelo Evoluído de Sistema de Medição de Desempenho para BPM) a partir do levantamento dos principais conceitos utilizados nos sistemas de medição de desempenho do gerenciamento de processos de negócio das UCEs, bem como os atributos considerados e efetivamente aplicados nestes sistemas, no âmbito do PNAFE.

$\mathrm{Na}$ terceira fase foi realizada uma pesquisa quantitativa, por meio de uma pesquisa de sondagem (survey) com os principais gestores e dirigentes das UCEs, materializada pelas seguintes evidências:

- $\quad$ teste do instrumento de pesquisa;

- $\quad$ avaliação da fidedignidade e validação dos construtos do modelo conceitual proposto;

- $\quad$ análise das possíveis relações entre as variáveis construídas que compõem o modelo.

$\mathrm{Na}$ quarta fase, com base na análise dos resultados das pesquisas qualitativa e quantitativa, foi aperfeiçoado o modelo evoluído e formalizada a proposta de Modelo Final de Sistema de Medição de Desempenho para BPM.

\subsection{Determinação do Tipo de Pesquisa}

Os tipos de pesquisa diferem quanto às formas de análise de dados e quanto aos objetivos. Quanto à forma de análise de dados, a pesquisa pode ser qualitativa ou quantitativa. Quanto aos objetivos, a pesquisa pode ser exploratória ou conclusiva, sendo que esta última classificação ainda pode ser subdividida em descritiva ou causal.

O enfoque do gerenciamento de processos de negócio, visando a uma avaliação de seu desempenho, envolveu a realização de duas pesquisas, uma de natureza qualitativa e outra de caráter quantitativo. Tal enfoque pressupõe uma fundamentação teórica apresentada no capítulo 2; a caracterização do programa de modernização das administrações fazendárias estaduais brasileiras, no capítulo 3; e a formulação de modelo conceitual inicial do SMDIBPM, apresentada na seção 4.6. 
A primeira pesquisa é caracterizada como uma pesquisa qualitativa exploratória. A segunda classifica-se na categoria de pesquisa quantitativa descritiva conclusiva. As duas pesquisas foram realizadas no âmbito das UCEs - Unidades Centrais Estaduais de coordenação do PNAFE e Secretarias Estaduais de Fazenda dos estados brasileiros.

O principal objetivo da pesquisa qualitativa foi o levantamento detalhado dos principais conceitos utilizados nos sistemas de medição de desempenho do gerenciamento de processos de negócio da organização, bem como os atributos considerados e efetivamente aplicados nestes sistemas.

Para o alcance deste objetivo procurou-se detectar a visão e o conhecimento dos Coordenadores das Unidades Centrais Estaduais, Sub-coordenadores, Gerentes de Macroprojetos e Líderes de projetos de modernização do PNAFE a respeito de uma série de aspectos relacionados ao desempenho dos BPM. A pesquisa qualitativa foi realizada para cumprir ainda os seguintes objetivos:

- $\quad$ identificar lacunas existentes na literatura sobre sistemas de medição de desempenho em BPM em projetos de modernização da administração fazendária brasileira;

- $\quad$ identificar os atributos utilizados para avaliar o desempenho dos BPM;

- $\quad$ detectar os atributos necessários para o bom funcionamento de um SMD de BPM.

Já a pesquisa quantitativa teve como principais objetivos validar os construtos do modelo proposto para a medição de desempenho dos BPM do PNAFE (seção 4.6), bem como associar múltiplas variáveis vinculadas a gestores e a macro-processos, utilizando técnicas estatísticas de análise multivariada. Visou ainda:

- $\quad$ identificar o perfil da amostra;

- $\quad$ identificar as características diferenciadoras entre os dirigentes e líderes que adotam ou não referências teóricas para o gerenciamento de processos de negócio;

- $\quad$ conhecer vantagens e desvantagens dos métodos utilizados;

- $\quad$ apresentar os principais resultados das experiências do SMD-BPM no PNAFE. 


\subsection{Justificativa das Pesquisas}

Uma vez determinados os tipos de pesquisa adotados neste estudo, necessário se faz apresentar suas justificativas, considerando a conveniência da aplicação tanto da pesquisa qualitativa quanto da quantitativa.

\subsubsection{Pesquisa Qualitativa}

Para Kinnear e Taylor (1996, p.305) uma pesquisa qualitativa pode ter como objetivos:

- $\quad$ elevar o conhecimento e a compreensão de um problema de pesquisa;

- $\quad$ auxiliar a desenvolver uma formulação mais precisa do problema de pesquisa;

- acumular informações disponíveis relacionadas a um problema de pesquisa conclusiva;

- $\quad$ ajudar no desenvolvimento de hipóteses a serem testadas em uma pesquisa causal;

- $\quad$ ajudar no desenvolvimento de questões de pesquisa relevantes;

- $\quad$ auxiliar na determinação de variáveis relevantes para um problema de pesquisa;

- $\quad$ tornar os conceitos claros;

- $\quad$ ajudar a delinear o projeto final da pesquisa;

- $\quad$ verificar a existência de pesquisas semelhantes realizadas, métodos e resultados obtidos;

- $\quad$ estabelecer prioridades para novas pesquisas.

Segundo Reis (1994, p. 12), a decisão pelo método qualitativo deve ser tomada de acordo com os seguintes critérios relativos ao estudo do fenômeno:

- $\quad$ abrangência: quando se objetiva estudar características holísticas, sua orientação para a exploração e descrição dos fenômenos;

- quantidade de informação: quanto menos informação se tem sobre o assunto, maior a dificuldade de se usarem medidas controladas;

- complexidade: quanto mais complexo é o assunto da investigação, maior a necessidade de se obter profundidade nas informações;

- natureza: quanto mais subjetivo é o objeto de estudo, maior a adequação de um método qualitativo de coleta e análise de dados; 
- tempo e os recursos disponíveis: quanto menor a disponibilidade de tempo e recursos para a pesquisa, mais pertinente o uso da pesquisa qualitativa, desde que o objetivo da pesquisa seja entender o fenômeno, e não medir a sua ocorrência.

As pesquisas qualitativas possibilitam maior profundidade na análise dos dados coletados, porém com pequena amplitude, sem a propriedade de generalização dos resultados da amostra para a respectiva população. Nas pesquisas qualitativas ocorre a centralização em menos casos ou características, mas cada alvo de estudo tem os detalhes analisados. Saber o porquê dos fatos é a meta essencial desse tipo de pesquisa.

As pesquisas qualitativas costumam ser aplicadas para fins exploratórios. Parasuraman (1991, p. 120) na definição de pesquisa exploratória afirma que esta visa a desenvolver as primeiras idéias e conhecimentos que possibilitem orientar as demais pesquisas necessárias. Afirma que este tipo de pesquisa procura tornar mais clara a natureza da situação e identificar alguns objetivos específicos ou necessidades de dados que podem ser alcançados em pesquisas posteriores.

A medição de desempenho dos BPM sob a ótica dos Coordenadores e Sub-coordenadores das UCEs, Gerentes de macro-projetos, e Líderes de projetos de modernização das administrações fazendárias nos estados brasileiros representa uma tarefa complexa, pois requer uma abordagem cuidadosa e detalhada de como estes vêem a realização das atividades de gerenciamento, bem como os atributos que efetivamente são nelas considerados.

As características da pesquisa qualitativa e as circunstâncias favoráveis ao seu uso reforçam a sua adequação aos objetivos específicos da primeira pesquisa deste estudo. Por meio da pesquisa qualitativa foi possível captar sinalizações a respeito do conhecimento e experiência dos Coordenadores, Sub-coordenadores e Gerentes de Macro-projetos das UCEs quanto ao gerenciamento dos processos de negócio nos programas que dirigem, e dos Líderes de projetos de modernização, subordinados a estes Coordenadores, e seus sistemas de medição de desempenho. 


\subsection{2 - Pesquisa Quantitativa}

Diferentemente da pesquisa qualitativa, a pesquisa quantitativa, segundo Reichardt e Cook apud REIS (1994, p. 9), caracteriza-se por:

- $\quad$ utilização predominante de métodos quantitativos;

- $\quad$ preocupação em encontrar os fatos e as causas do fenômeno social sem subjetivismo;

- $\quad$ uso de sistemas de medição controlada;

- $\quad$ objetividade, perspectiva externa e distanciamento dos dados;

- $\quad$ superficialidade, orientação para a verificação, baseada na inferência hipotéticodedutiva;

- $\quad$ orientação para o resultado;

- $\quad$ foco crítico na fidedignidade, busca por dados sólidos e replicáveis;

- caráter particularizado, visando à análise.

A pesquisa quantitativa deste estudo enquadra-se como conclusiva e descritiva. A característica de pesquisa conclusiva contrapõe-se ao caráter exploratório da pesquisa qualitativa desenvolvida neste trabalho. Parasuraman (1991, p. 121) define pesquisa conclusiva como aquela em que os objetos estão bem definidos assim como estão claros os dados a serem coletados. Este tipo de pesquisa tem o objetivo de sugerir uma direção para a ação a ser empreendida pelos tomadores de decisão.

As pesquisas conclusivas são voltadas para a ação. De acordo com Kinnear e Taylor (1996, p. 346), a pesquisa conclusiva prevê informações que ajudam o gerente a avaliar e selecionar o curso da ação. Esses autores afirmam que as pesquisas conclusivas são caracterizadas por possuírem objetivos bem definidos, procedimentos formais, serem bem estruturadas e dirigidas para a solução de problemas ou avaliação de alternativas de curso de ação.

Existem dois tipos de pesquisa conclusiva: a descritiva e a experimental. A primeira é voltada para a descrição de alguma característica ou algum fenômeno. A segunda, também conhecida como pesquisa causal, apresenta inferências causais sobre as relações entre as variáveis do problema. $\mathrm{O}$ tratamento quantitativo dos dados em pesquisa de caráter conclusivo e descritivo com os Coordenadores, Sub-coordenadores, Gerentes de Macro-projetos e Líderes de projetos de modernização do PNAFE mostrou-se convergente com os demais objetivos deste estudo. 
Segundo Lakatos e Marconi (2003, p. 41) os métodos de pesquisa podem ser divididos em duas classes: os métodos gerais e os métodos de procedimento. Os métodos gerais tratam das questões de maneira holística e abstrata. Já os métodos de procedimento são as etapas mais concretas de busca de solução, sendo restritos a certos tipos de fenômenos. Para Bryman (1989, p. 29) os principais métodos de procedimento de pesquisa empregados nas ciências sociais são: a pesquisa experimental, a pesquisa de sondagem ou levantamento survey o estudo de caso e a pesquisa-ação. Na presente pesquisa foi adotado o método de pesquisa de sondagem, com a criação de um banco de dados que possibilitou validar estatisticamente os construtos do modelo SMDI-BPM e testar as relações entre as variáveis criadas.

\subsection{População}

Segundo Kinnear e Taylor (1996, p. 407), a população da pesquisa "é o agregado de todos os casos que se enquadram num conjunto de especificações previamente estabelecidas". De acordo com Kish (1965, p. 7), as unidades para as quais se buscam informações denominamse elementos de uma população e esta se define em conjunto com os elementos. Para o autor, a população é o agregado de elementos, e os elementos são as unidades básicas que compõem e definem a população. A população deve ser definida em termos de características, unidades, extensão e tempo.

Martins (2001, p. 184) afirma que o conceito de população é intuitivo e esta compreende um conjunto de indivíduos ou objetos que apresentam em comum determinadas características definidas para o estudo. Parasuraman (1991, p. 446) define população ou universo como "o conjunto completo de unidades de interesse para os tomadores de decisão em uma situação".

As duas pesquisas foram realizadas no âmbito das UCEs - Unidades Centrais Estaduais de coordenação do PNAFE, nos estados brasileiros, com a participação de alguns dirigentes da UCP - Unidade Central de Planejamento, órgão responsável pela coordenação geral do PNAFE junto às UCEs. As duas populações de interesse foram compostas por representantes dos estados que reconhecidamente desenvolveram e implantaram novos processos de negócio em órgãos e departamentos das respectivas Secretarias Estaduais de Fazenda, e que sentiram dificuldades em verificar o desempenho no gerenciamento desses processos. Foram eles: 
(1) os Dirigentes da UCP e os Coordenadores, Sub-coordenadores Técnicos e Administrativos, Gerentes de Macro-projetos e Membros de Equipe das UCEs;

(2) os Líderes e Membros de equipes dos projetos de modernização subordinados às UCEs da maioria dos estados brasileiros participantes do programa.

O documento Brasil (2002, p. 14-15), apresentado no Anexo A, relaciona alguns dos principais BPM colocados à disposição de usuários de serviços públicos, via Internet, e sua implementação, mostrando-se oportuna a pesquisa no âmbito da maioria dos estados brasileiros.

\subsection{Amostragem e Coleta de dados}

De acordo com Kinnear e Taylor (1996, p. 411-418), as amostragens podem ser divididas em dois grandes campos: probabilísticas e não probabilísticas. A amostragem não probabilística é a seleção do elemento da população de acordo com o julgamento do pesquisador ou do entrevistador de campo. As chances de escolha de algum elemento particular são desconhecidas neste tipo de amostragem, assim como não é possível determinar o erro amostral que possa ocorrer. Forza (2002, p. 164-165) considera que quando o principal objetivo não é a generalização dos resultados, usualmente a amostragem não probabilística é considerada adequada.

Segundo Aaker et al (1995, p. 375) a amostragem não probabilística é usada tipicamente em situações tais como (1) estágios exploratórios de um projeto de pesquisa, (2) pré-teste de um questionário, (3) consideração de uma população homogênea, (4) falta de conhecimento estatístico, e (5) necessidade de facilidade operacional.

Para Selltiz et al (1987, p. 84) a característica essencial da amostragem probabilística é a de se poder especificar para cada elemento da população a probabilidade dele ser incluído na amostra. O principal fator determinante da decisão de se usar amostragem probabilística é a possibilidade de inferências estatísticas.

Tendo em vista o caráter exploratório da pesquisa qualitativa deste trabalho, foi empregado o processo de amostragem não probabilística, aplicando-se o processo de amostragem 
intencional, dita por julgamento (COOPER e SCHINDLER, 2003, p. 169), na seleção dos Coordenadores das UCEs, Sub-coordenadores, Gerentes de Macro-projetos e líderes de projeto do PNAFE que realmente tiveram maiores conhecimentos sobre o tema deste estudo, descritos na seção 4.2. A amostra intencional empregada foi constituída por 15 gestores do estado de São Paulo, entre dirigentes da UCE e líderes de projeto, e realizada no período de 20 de agosto a 30 de setembro de 2005.

Os dados provenientes da pesquisa qualitativa foram obtidos por meio da técnica de entrevista em profundidade, segundo o roteiro de itens constante do modelo apresentado no Apêndice 1. Segundo Cooper e Schindler (2003, p. 278) a entrevista em profundidade encoraja os respondentes a compartilhar o máximo de informações possível, em um ambiente sem constrangimento. Nela, o entrevistador usa um mínimo de sugestões e questões de orientação. Este tipo de questionamento é freqüentemente usado em pesquisa exploratória ou quando o pesquisador está lidando com tópicos complexos, que não se encaixariam em entrevistas estruturadas.

Por ocasião da pesquisa quantitativa, foi empregada a amostragem probabilística, atendendose a possibilidade de se realizarem inferências estatísticas. Planejou-se uma amostra aleatória simples de 158 entrevistas e foram respondidos 127 formulários, correspondendo a uma taxa de retorno de $80,3 \%$.

O número de entrevistados pretendidos na primeira população, qual seja, dos dirigentes da alta administração do PNAFE, era de 28, correspondendo à totalidade dos estados brasileiros, e mais um representante nacional da UCP. Deste universo, 24 representantes estaduais atenderam ao solicitado, bem como o representante nacional, correspondendo a $89,3 \%$ de retorno, ficando ausentes apenas representantes dos estados do Ceará, Sergipe e Piauí.

Devido ao conhecimento acumulado por estes dirigentes da alta gerência na condução dos programas estaduais de modernização do PNAFE, foi solicitado que cada um deles respondesse a dois formulários de entrevista, de tal forma que cada dirigente pudesse relatar sua experiência em dois macro-processos com os quais estivesse mais familiarizado ou que, porventura, tivesse acompanhado com maior atenção. 
A coleta de dados desta primeira população aconteceu no dia 8 de novembro de 2005, fazendo parte da agenda de atividades da $4^{\mathrm{a}}$. Reunião UCEs/UCP - 2005, na cidade de Porto Alegre, estado do Rio Grande do Sul. Para tal, foi formalizada a solicitação do pesquisador pela UCESP a UCE-RS, organizadora do evento, com aprovação da coordenação da UCP-Brasília, considerando a pesquisa pertinente e oportuna ao PNAFE.

Como instrumento de coleta de dados foi utilizado questionário estruturado não disfarçado, com predomínio de perguntas fechadas. Os questionários em formulários-papel foram entregues pessoalmente pelo pesquisador aos entrevistados, considerando a falta de estrutura de informática no local do evento, qual seja, a colocação à disposição de um microcomputador para cada respondente. Este recurso de distribuição de questionários em papel foi aplicado também a fim de que todos os entrevistados pudessem responder às questões da pesquisa no espaço de tempo reservado pela organização do evento para a coleta de dados.

Para a segunda população, qual seja, a dos líderes de projeto do estado de São Paulo, num contingente de 102 líderes, 77 responderam à demanda, correspondendo a uma de taxa de retorno de 75,4\%. De início, o pesquisador obteve da UCE-SP a relação de todos os líderes de projeto de São Paulo no PNAFE. A esta lista foram acrescidos alguns membros de projeto que não foram formalmente designados para a função de liderança, mas que participaram com destaque na condução e gerenciamento de alguns dos projetos de maior escopo e abrangência de objetivos.

Em seguida, foi enviado e-mail a todos os nomes constantes da lista, apresentando as razões da investigação e os responsáveis pela pesquisa, com destaque para o alerta dado a cada respondente de que a qualidade dos resultados obtidos e que seriam encaminhados ao PNAFE dependeria fundamentalmente da qualidade das respostas dadas ao questionário pelos entrevistados. No e-mail constava também o endereço de acesso a um site pré-estabelecido ( $e$ survey), http://143.107.45.215:2005, sitiado no laboratório de banco de dados do Departamento de Computação do Instituto de Matemática e Estatística - IME da USP. As dúvidas porventura pertinentes podiam ser endereçadas ao e-mail pesquisa.uce@gmail.com, especialmente criado para este fim. 
O site esteve disponível aos respondentes no período de pré-testes da pesquisa entre os dias 9 e 22 de outubro de 2005. O formulário eletrônico definitivo pôde ser respondido entre os dias 25 de outubro e 4 de dezembro de 2005.

Para Forza (2002, p. 167) as vantagens da e-survey, comparada a outros meios de coleta de dados, são: baixo custo, facilidade de acesso ao instrumento, preenchimento de acordo com a conveniência do respondente; inexistência de restrição de tempo; auxílio à garantia do anonimato; e eliminação da influência do entrevistador.

De acordo com Hair et al (2005, p. 31), para um poder de teste de 0,80, a um nível de significância $\alpha=0,05$ e um tamanho de efeito $E S=0,35$, o tamanho da amostra encontra-se rigorosamente dentro do recomendado.

\subsection{Instrumentos de Coleta de dados}

Até se chegar aos modelos de instrumentos definitivos de coleta de dados constantes do Apêndice 3, realizaram-se pré-testes do roteiro da pesquisa qualitativa e dos questionários eletrônicos da pesquisa quantitativa, a fim de se verificar a adequação destes instrumentos aos objetivos da pesquisa. De acordo com Kinnear e Taylor (1996, p. 501), o pré-teste é necessário para se avaliarem um ou mais aspectos do roteiro ou do questionário e modificálos, se for o caso. Mediante o pré-teste pode-se verificar:

- $\quad$ se os termos utilizados nas perguntas eram de compreensão dos respondentes;

- $\quad$ se as perguntas foram entendidas como deveriam ser;

- $\quad$ se as opções de respostas nas perguntas fechadas estavam completas;

- $\quad$ se a seqüência das perguntas estava correta;

- $\quad$ se não havia objeções na obtenção das respostas;

- $\quad$ se a forma de apresentar a pergunta não estava causando dúvidas, viés, etc.

A realização dos pré-testes gerou melhorias no roteiro da pesquisa qualitativa e fez surgir a necessidade da definição prévia e detalhamento de alguns conceitos básicos sobre medição de desempenho e sobre processos de negócio e BPM. Isto se deu para que houvesse uma 
uniformidade no entendimento dos entrevistados quanto ao real teor das perguntas formuladas e uma conseqüente melhoria de qualidade das respostas conferidas.

Nos questionários da pesquisa quantitativa, o pré-teste aconteceu com o uso de oito versões distintas de formulário eletrônico, já que o formulário em papel foi utilizado apenas na versão definitiva do questionário na data da "4a Reunião UCEs/UCP - 2005".

Nas versões iniciais, o formulário era constituído por um texto introdutório explicativo da pesquisa, um primeiro bloco com as características gerais do respondente, um segundo bloco com a pergunta chave da pesquisa, dependente da condição de o respondente reconhecer ter ou não gerenciado algum processo de negócio do PNAFE, e um terceiro bloco em que constavam 95 perguntas relativas a variáveis independentes da pesquisa.

Com a redação do texto introdutório e das variáveis ajustada ao longo do tempo, por sugestões e críticas dos respondentes, o pesquisador realizou alguns desmembramentos e até algumas eliminações de variáveis, chegando-se por fim ao modelo constante do Apêndice 3.

A mudança que mereceu maior destaque foi quanto à necessidade de criação de uma variável dependente no final do questionário e o uso de 101 variáveis independentes, a fim de que fosse viabilizada a aplicação de algumas técnicas de análise multivariada (item 5.3).

No primeiro bloco do formulário da pesquisa quantitativa, relativo às características do respondente, foram criadas as variáveis de v0 a v4, em que v0 referia-se ao número do formulário respondido. Nos formulários em papel o número foi designado pelo pesquisador. Nos formulários eletrônicos, o número do formulário foi gerado automaticamente pelo sistema informatizado criado.

As variáveis v1 a v4 referiam-se respectivamente ao (1) estado da federação a que pertencia o entrevistado, (2) ao cargo ou função exercido no PNAFE, (3) há quanto tempo o respondente estava desenvolvendo trabalhos de gestão no PNAFE e (4) se havia ou não gerenciado algum processo de negócio no programa de modernização. 
Com o resultado da pesquisa qualitativa foi possível delinear uma proposta evoluída de modelo conceitual de sistema de avaliação do gerenciamento de processos do PNAFE, conforme quadros 29 e 30 . Na coluna da esquerda constam os atributos normativos do SMDE - BPM, criados pelo pesquisador a partir da base teórica dos SMDOs, dos BPM, e do modelo arquitetônico RF-NP (item 2.3), que se constituíram nos construtos testados quanto à validade e fidedignidade, bem como permitiram a verificação de possíveis relações entre eles. $\mathrm{Na}$ coluna da direita constam as variáveis observadas na pesquisa quantitativa.

Segundo Cooper e Schindler (2003, p. 53), construto é uma imagem ou idéia inventada especificamente para uma determinada pesquisa e/ ou criação de teoria. Os construtos são construídos pela combinação de conceitos mais simples, especialmente quando a idéia ou imagem que se pretende construir não está diretamente ligada à observação.

Considerando que expressões tais como "atributos normativos" ou "construtos" não eram facilmente entendidas por boa parte dos dirigentes do PNAFE, por sugestão de dois entrevistados na fase de teste piloto da pesquisa quantitativa, foi utilizada a palavra "dimensão" para descrever a classificação em grupos menores das variáveis do SMDE-BPM, segundo características básicas em comum.

Também por sugestão de alguns entrevistados, foram substituídos no SMDI-BPM os rótulos dos atributos normativos Relacionamento Causal e Balanceamento respectivamente pelos termos Relação Causal e Equilíbrio. O motivo alegado para esta modificação, que aconteceu durante a confecção do SMDE-BPM, se deu a fim de que os nomes das dimensões do modelo pudessem refletir com mais clareza os conceitos fundamentais dos atributos a elas pertencentes. 
Quadro 29 - Modelo evoluído SMDE - BPM

\begin{tabular}{|c|c|}
\hline Dimensão & Atributo \\
\hline I - Aprendizado & $\begin{array}{l}\text { 1. conhecimento do processo como um todo pelos usuários } \\
\text { 2. incentivo ao aprendizado do processo pelos usuários } \\
\text { 3. incentivo ao aprendizado organizacional do processo } \\
\text { 4. foco na melhoria do processo } \\
\text { 5. visão crítica para o aperfeiçoamento do processo } \\
\text { 6. identificação de ações corretivas do processo } \\
\text { 7. diferenciação entre medidas de controle e medidas de melhoria } \\
\text { 8. percepção do usuário quanto ao comportamento do processo ao longo do tempo } \\
\text { 9. retenção dos ganhos obtidos com iniciativas de melhoria } \\
\text { 10. identificação de conflitos entre indicadores de desempenho do processo } \\
\text { 11. apoio ao debate entre usuários do processo de diversos níveis hierárquicos } \\
\text { 12. coerência com técnicas administrativas de melhoria contínua do processo }\end{array}$ \\
\hline $\begin{array}{l}\text { II. Análise } \\
\text { Crítica }\end{array}$ & $\begin{array}{l}\text { 13. análise crítica da avaliação de desempenho do processo } \\
\text { 14. envolvimento de usuários na crítica dos indicadores de desempenho do processo } \\
\text { 15. capacidade de auditoria da medição de desempenho } \\
\text { 16. análise crítica para revisão de metas e padrões de desempenho do processo } \\
\text { 17. análise crítica para revisão do conjunto de indicadores de desempenho } \\
\text { 18. conhecimento do desempenho do processo no passado } \\
\text { 19. conhecimento do desempenho do processo no presente } \\
\text { 20. projeção do desempenho do processo no futuro } \\
\text { 21. comparação com padrões externos de excelência (benchmarking) } \\
\text { 22. integração e correlação entre indicadores de desempenho } \\
\text { 23. uso de indicadores com metas de curto e longo prazo } \\
\text { 24. uso de indicadores de desempenho para a tomada de decisão }\end{array}$ \\
\hline III- Clareza & $\begin{array}{l}\text { 25. fórmula de cálculo do indicador claramente definida } \\
\text { 26. clareza na definição de metas e objetivos dos processos } \\
\text { 27. definição clara das margens de erro das medições dos processos } \\
\text { 28. clareza na definição dos dados coletados para medir desempenho de processos } \\
\text { 29. definição clara da fonte de dados para medir desempenho de processos } \\
\text { 30. ênfase maior em tendências do que em medições pontuais de desempenho } \\
\text { 31. demonstração clara dos resultados das medições de desempenho (gráfico, tabela) } \\
\text { 32. facilidade de compreensão de indicadores de desempenho pelos usuários } \\
\text { 33. clareza na definição das regras (internas) dos processos } \\
\text { 34. procedimentos claros para implementação de medidas de desempenho } \\
\text { 35. definição objetiva das medidas de desempenho (não embasadas em opiniões) } \\
\text { 36. divulgação dos resultados das medições para todos os envolvidos no processo } \\
\text { 37. uso de técnicas estatísticas para validação dos resultados das medições }\end{array}$ \\
\hline IV- Equilíbrio & $\begin{array}{l}\text { 38. equilíbrio entre medidas de desempenho financeiras e não financeiras } \\
\text { 39. equilíbrio entre medidas de eficiência e de eficácia do processo } \\
\text { 40. equilíbrio entre medidas de eficiência e de efetividade do processo } \\
\text { 41. equilíbrio entre medidas quantitativas e qualitativas } \\
\text { 48. uso de indicadores de resultados e de processos } \\
\text { 49. satisfação de expectativas e necessidades do cliente } \\
\text { 50. uso de indicadores de todas as áreas envolvidas no processo } \\
\text { 51. conhecimento de ameaças e oportunidades no ambiente externo da organização } \\
\text { 52. identificação de pontos fortes e oportunidades de melhoria no ambiente interno da } \\
\text { organização } \\
\text { 53. uso de diversas dimensões de desempenho (financeira, cliente, inovação) }\end{array}$ \\
\hline
\end{tabular}


Quadro 29 - Modelo evoluído SMDE - BPM (Continuação)

\begin{tabular}{|c|c|}
\hline Dimensão & Atributo \\
\hline V-Dinamismo & $\begin{array}{l}\text { 54. acesso imediato do usuário às informaçães de que necessita } \\
\text { 55. relevância dos indicadores de desempenho para a tomada de decisão } \\
\text { 56. flexibilidade na modificação de indicadores de desempenho } \\
\text { 57. sinais de alarme para desempenho fora dos limites estabelecidos } \\
\text { 58. identificação de curvas de tendências e dos progressos dos processos } \\
\text { 59. resposta rápida e precisa ao usuário } \\
\text { 60. coleta de dados automatizada para sistema de medição } \\
\text { 61. customização dos indicadores às necessidades de diferentes grupos de usuários } \\
\text { 62. informação pertinente em tempo real para toda a organização } \\
\text { 63. monitoramento de parâmetros críticos para detectar mudanças no ambiente externo } \\
\text { 64. monitoramento de parâmetros críticos para detectar mudanças no ambiente interno } \\
\text { 65. adaptação rápida a mudanças nos ambientes interno e externo } \\
\text { 66. atualização constante da medição de desempenho dentro de períodos programados } \\
\text { 67. acompanhamento da medição de desempenho do processo ao longo do tempo } \\
\text { 68. medidas de desempenho orientadas para o longo prazo } \\
\text { 69. fornecimento de subsídios para o conhecimento do desempenho da organização ao } \\
\text { longo do tempo }\end{array}$ \\
\hline VI- Alinhamento & $\begin{array}{l}\text { 70. uso de medidas derivadas da estratégia da organização } \\
\text { 71. uso de medidas relacionadas com a estratégia da organização } \\
\text { 72. uso de medidas relacionadas com a qualidade do processo } \\
\text { 73. uso de medidas relacionadas com o custo do processo } \\
\text { 74. uso de medidas relacionadas com a flexibilidade do processo } \\
\text { 75. uso de medidas relacionadas com o tempo despendido no processo } \\
\text { 76. uso de medidas relacionadas com o resultado do processo } \\
\text { 77. uso de medidas relacionadas com o crescimento futuro do negócio } \\
\text { 78. direcionamento aos processos-chave de negócio } \\
\text { 79. abrangência de todo o processo (do início ao fim) } \\
\text { 80. cobertura de todas as áreas funcionais da organização } \\
\text { 81. alinhamento entre medidas de desempenho individuais, de equipe e da organização } \\
\text { 82. associação das medidas de um nível hierárquico às de nível imediatamente superior } \\
\text { 83. uso de indicadores segundo a estrutura hierárquica da organização } \\
\text { 84. uso de medidas homogêneas em nível organizacional }\end{array}$ \\
\hline $\begin{array}{l}\text { VII- } \\
\text { Participação }\end{array}$ & $\begin{array}{l}\text { 85. participação de usuários no desenvolvimento do sistema de medição } \\
\text { 86. motivação dos funcionários } \\
\text { 87. satisfação dos funcionários } \\
\text { 88. entendimento por todos os funcionários das metas propostas } \\
\text { 89. possibilidade de alteração do sistema de medição a partir de reclamações e sugestões } \\
\text { de usuários } \\
\text { 90. uso de medidas de desempenho que possam ser controladas pelo usuário }\end{array}$ \\
\hline VIII- Integração & $\begin{array}{l}\text { 91. integração dos indicadores de desempenho com o sistema de gestão da organização } \\
\text { 92. integração dos indicadores de desempenho com sistemas de negócio (ex: ERP) } \\
\text { 93. ênfase maior nas medidas de avaliação de equipe sobre as individuais } \\
\text { 94. interação entre as áreas funcionais da organização } \\
\text { 95. incentivo à cooperação entre departamentos participantes do processo }\end{array}$ \\
\hline $\begin{array}{l}\text { IX- Relação } \\
\text { Causal }\end{array}$ & $\begin{array}{l}\text { 96. relação de causa e efeito entre objetivos e processos } \\
\text { 97. identificação das relações de causa e efeito entre os diversos indicadores de } \\
\text { desempenho } \\
\text { 98. relação de causa e efeito entre ações e indicadores de desempenho } \\
\text { 99. relação de causa e efeito entre medidas de resultado e de alavancagem de processos } \\
\text { 100. relação de causa e efeito entre objetivos e atividades dos processos } \\
\text { 101. relação de causa e efeito entre o desempenho passado e o planejamento de } \\
\text { desempenho futuro dos processos }\end{array}$ \\
\hline
\end{tabular}


Os macro-processos analisados pelos entrevistados foram obtidos da tabela constante do documento Brasil (2002, p. 14-15), Terceiro Benchmark do PNAFE, acrescidos de três outros, a fim de atender não só a dirigentes e líderes da área tributária do programa, mas também àqueles que desenvolveram liderança nas áreas financeira e de organização e gestão.

\section{Quadro 30 - Relação de processos e macro-processos do PNAFE}

\begin{tabular}{|c|c|}
\hline Macro-processo & $\begin{array}{ll}\text { Processos } \\
\end{array}$ \\
\hline A. Controle de Acesso & - Identificação / Autenticação do Contribuinte \\
\hline B. Legislação & $\begin{array}{l}\text { - Consulta à legislação vigente } \\
\text { - Consulta à legislação por data } \\
\text { - Verbetes tributários ou afins }\end{array}$ \\
\hline C. Cadastro & $\begin{array}{l}\text { - Consulta pública ao cadastro } \\
\text { - Consulta ao cadastro para o contador e a sócios } \\
\text { - Consulta a estabelecimentos de uma empresa } \\
\text { - Inclusão e consulta ao cadastro de contribuintes } \\
\text { - Consulta ao cadastro de contadores } \\
\text { - Alterações no cadastro de contadores } \\
\end{array}$ \\
\hline D. Declarações & $\begin{array}{l}\text { - Entrega de declarações } \\
\text { - Consulta a declarações }\end{array}$ \\
\hline E. AIDF & $\begin{array}{l}\text { - Requisição e consulta de AIDF } \\
\text { - Ficha histórica de AIDFs concedidas } \\
\text { - Consulta de validade de nota fiscal }\end{array}$ \\
\hline F. Conta Fiscal & $\begin{array}{l}\text { - Consulta a pagamento específico } \\
\text { - Emissão de documento de arrecadação } \\
\text { - Extrato de débitos } \\
\text { - Emissão de certidão de regularidade e negativa } \\
\text { - Consulta a certidões emitidas } \\
\text { - Solicitação de parcelamento da dívida } \\
\text { - Extrato de parcelas } \\
\text { - Notificação de irregularidade e/ ou consulta }\end{array}$ \\
\hline G. IPVA & $\begin{array}{l}\text { - Consulta ao IPVA (Renavan ou placa) } \\
\text { - Emissão de documento de arrecadação }\end{array}$ \\
\hline $\begin{array}{l}\text { H. Serviços Diversos - } \\
\text { Área Tributária }\end{array}$ & $\begin{array}{l}\text { - Cálculo para pagamento de débitos atrasados } \\
\text { - Arrecadação e cobrança } \\
\text { - Notícias tributárias } \\
\text { - Fiscalização } \\
\text { - Contencioso administrativo e judicial } \\
\text { - Solicitação de uso /cessação / Intervenção de PD } \\
\text { - Consulta à tramitação de processos } \\
\text { - Atendimento a consultas via e-mail } \\
\text { - Download de software } \\
\text { - Estudos econômico-tributários } \\
\text { - Outros }\end{array}$ \\
\hline $\begin{array}{l}\text { I. Serviços Diversos - Área } \\
\text { Financeira }\end{array}$ & $\begin{array}{l}\text { - Sistema de compras governamentais } \\
\text { - Sistema de controle orçamentário-financeiro } \\
\text { - Sistema contábil-financeiro } \\
\text { - Outros }\end{array}$ \\
\hline J. Organização / Gestão & $\begin{array}{l}\text { - Administração e política de pessoal } \\
\text { - Estrutura organizacional } \\
\text { - Infra-estrutura física e de TI } \\
\text { - Informações estratégicas e gerenciais } \\
\text { - Auditoria e controle interno } \\
\text { - Coordenação do projeto } \\
\text { - Outros }\end{array}$ \\
\hline
\end{tabular}

Fonte: Brasil (2002, p. 14-15) adaptado pelo autor 
Os processos incluídos nos macro-processos considerados constam do quadro 30 . O indicativo do macro-processo escolhido pelo respondente foi denominado $\mathrm{vP}$, com rol de opções variando de A a J, conforme a coluna da direita do quadro. A fim de que fosse diminuída ao máximo a falta de entendimento da pergunta chave da pesquisa para todas as variáveis de v5 a v99 foi apresentado, aos entrevistados que responderam SIM ao questionamento contido na v4, o seguinte texto constante do formulário do Apêndice 3:

Dentro de cada fator serão apresentados aspectos a serem avaliados por você, em uma escala de intensidade de 0 a 10 , onde 0 representa que o aspecto esteve totalmente ausente e 10 que esteve totalmente presente no gerenciamento do processo.

Por exemplo:

Fator: Aprendizado

Aspecto: Conhecimento do processo como um todo pelos usuários

Quanto mais próximo de 0 , menos se confirma este conhecimento.

Analogamente, quanto mais próximo de 10, mais se confirma este conhecimento.

Para aqueles que responderam NÃO a v4, os textos sublinhados no primeiro parágrafo foram substituídos pelas expressões poderia estar totalmente ausente e deveria estar totalmente presente. E, no exemplo do Fator e Aspecto, os trechos foram substituídos pelas expressões menor a necessidade e maior a necessidade dos conhecimentos.

Além da escala de intensidade de 0 a 10 , em que 0 significava fator totalmente ausente e 10 fator totalmente presente, constou ainda das respostas a opção "Não Sei", indicativa da impossibilidade de se responder à questão por algum motivo.

Segundo Cooper e Schindler (2003, p.201-202) a escala escolhida é classificada como escala de lista de classificação múltipla, similar às escalas numérica e de Likert. Ela possui intervalos iguais que separam seus pontos da escala numérica, bem como uma âncora verbal que atua como rótulo nos pontos extremos. As escalas numéricas podem ser de cinco, sete ou dez pontos. No caso presente utilizou-se a de dez pontos. Ainda para os autores, a vantagem do uso deste tipo de escala é a possibilidade de se assinalar uma resposta para cada uma das perguntas efetuadas, como também dispor visualmente os resultados de maneira mais clara (mapa mental da avaliação). 
$\mathrm{Na}$ última seção do formulário de pesquisa, foi apresentada a variável dependente v100, que solicitava do entrevistado, numa escala de 0 (totalmente inadequado) a 10 (totalmente adequado), uma avaliação do gerenciamento realizado no macro-processo por ele escolhido. $\mathrm{E}$ ainda, se existiam outros aspectos não mencionados no questionário que o respondente gostaria de acrescentar.

\subsection{Algumas Limitações da Pesquisa}

Algumas limitações estão associadas aos métodos utilizados. A primeira diz respeito à amostra de conveniência, composta por gestores de programas e projetos de modernização do PNAFE de alguns estados da federação, que reconhecidamente se depararam com o problema da medição de desempenho em seus BPM. A amostra selecionada pode não refletir toda a população do PNAFE, principalmente considerando que somente foi possível entrevistar os gestores da média gerência do estado de São Paulo. Portanto, os resultados não podem ser generalizados.

A segunda limitação se deve ao fato de que os dados foram coletados por meio de uma pesquisa de sondagem (survey). Este procedimento pode ter deixado de captar toda a dinâmica dos SMD-BPM ao longo do tempo, se restringindo a uma espécie de fotografia do momento vivenciado pelos gestores no PNAFE.

A terceira limitação pode ter vindo de um possível efeito viés dos não respondentes, bem como daqueles que responderam ao questionário sem conhecer efetivamente a realidade de seu gerenciamento de processos de negócio ou que porventura se sentiram obrigados a fazê-lo e o fizeram sem o esmero necessário.

Uma quarta limitação, semelhante à anterior, pode ter acontecido em decorrência do receio dos gestores em verem questionados seus desempenhos na gestão de BPM do programa ou até mesmo receosos de verem seus esforços comprometidos com a possibilidade de os resultados da pesquisa se mostrarem abaixo da expectativa de seus superiores locais ou dos órgãos fiscalizadores do programa de modernização, ou até mesmo do órgão internacional financiador do PNAFE. 


\section{CAPÍTULO 5 - ANÁLISE DOS RESULTADOS}

A análise dos resultados a partir dos dados coletados na pesquisa quantitativa foi dividida em três fases: (1) análise preliminar e tratamento dos dados; (2) verificação de fidedignidade e validade do construto e (3) análise da relação entre gestores e processos.

Para as análises especificadas nestas três fases foi utilizada a ferramenta (software) de análise multivariada SPSS - Statistical Package for the Social Sciences, versão 9.0, de propriedade do laboratório de informática do setor de pós-graduação da FEA-USP. O quadro 31 relaciona, para cada item deste capítulo, as técnicas utilizadas no tratamento estatístico dos dados, bem como os objetivos pretendidos com o uso de cada técnica.

\section{Quadro 31 - Técnicas utilizadas para os dados da pesquisa}

\begin{tabular}{|c|c|c|}
\hline Item & Técnica & Objetivo \\
\hline 5.1.1 & $\begin{array}{l}\text { Cálculo da distância } \mathrm{D}^{2} \mathrm{de} \\
\text { Mahalanobis }\end{array}$ & Identificar Outliers \\
\hline 5.1 .2 & Análise de Missings Values & Identificar dados perdidos e ações pertinentes \\
\hline 5.1.3.1 & Teste de Kolmogorov-Smirnov & Testar a normalidade univariada (assimetria e curtose) \\
\hline 5.1.3.2 & Distribuição de frequência & Conhecer estatísticas descritivas da amostra total e segmentada \\
\hline 5.1.4.1 & Análise de Correlação & Identificar correlação entre variáveis \\
\hline 5.1.4.2 & Teste Qui-quadrado & $\begin{array}{l}\text { Identificar se avaliação BPM independe da Função ou Região do } \\
\text { gestor }\end{array}$ \\
\hline 5.2.1 & Cálculo do Alfa de Cronbach & $\begin{array}{l}\text { Testar a fidedignidade da mensuração de cada dimensão do } \\
\text { SMD-BPM }\end{array}$ \\
\hline 5.2 .2 & Análise Fatorial & Encontrar escores fatoriais das dimensões do SMD-BPM \\
\hline 5.2 .2 & Regressão Linear Múltipla & Testar a validade dos construtos do SMD-BPM \\
\hline 5.3.1 & Teste do coeficiente de Mardia & Testar a normalidade multivariada \\
\hline 5.3.2 & $\begin{array}{l}\text { Análise Multivariada } \\
\text { Variância- MANOVA }\end{array}$ & $\begin{array}{l}\text { Avaliar o impacto da Função e Região dos gestores sobre as } \\
\text { dimensões e as variáveis das dimensões cujas médias sofrem } \\
\text { mais influência sob estas estratificações, visando o } \\
\text { aperfeiçoamento do modelo do SMD-BPM }\end{array}$ \\
\hline 5.3.3 & Regressão Logística & $\begin{array}{l}\text { Identificar as dimensões que mais discriminam os gestores em } \\
\text { termos de desempenho satisfatório ou insatisfatório no } \\
\text { gerenciamento dos processos }\end{array}$ \\
\hline 5.3.4 & $\begin{array}{l}\text { Escalonamento } \\
\text { Multidimensional }\end{array}$ & $\begin{array}{l}\text { Fazer mapeamento das similaridades entre macro-processos e } \\
\text { seus posicionamentos frente às dimensões do SMD-BPM }\end{array}$ \\
\hline
\end{tabular}




\subsection{Análise Preliminar e Tratamento dos dados}

A análise preliminar dos dados se constituiu de quatro grupos de verificações: Presença de Outliers, Ocorrência de Missing Values, Distribuição Normal Univariada e Normalidade Multivariada.

\subsubsection{Procura de Outliers}

A fim de se identificarem outliers, Hair et al (2005, p. 72) recomendam uma avaliação multivariada de cada observação em um conjunto de variáveis. Com a aplicação do cálculo da Distância de Mahalanobis - $\mathrm{D}^{2}$, que avalia a posição de cada observação comparada com o centro de todas as observações em um conjunto de variáveis, foram removidos dados que por meio de testes da significância dos valores dessa distância fossem considerados observações atípicas. Os testes foram realizados para cada uma das nove dimensões. Foram enunciadas as seguintes hipóteses:

$\mathrm{H}_{0,1}$ :A distância de Mahalanobis para a dimensão aprendizado não é estatisticamente significante, ou seja, a dimensão não possui outlier segundo a distância de Mahalanobis.

$\mathrm{H}_{1,1}$ :A distância de Mahalanobis para a dimensão aprendizado é estatisticamente significante, ou seja, a dimensão possui outlier segundo a distância de Mahalanobis.

Para as demais dimensões, as hipóteses $\mathrm{H}_{0}$ e $\mathrm{H}_{1}$ foram enunciadas da seguinte maneira:

$\mathrm{H}_{0,2}$ : A distância de Mahalanobis para a dimensão clareza não é estatisticamente significante, ou seja, a dimensão não possui outlier segundo a distância de Mahalanobis.

$\mathrm{H}_{1,2}$ : A distância de Mahalanobis para a dimensão clareza é estatisticamente significante, ou seja, a dimensão possui outlier segundo a distância de Mahalanobis.

$\mathrm{H}_{0,3}$ : A distância de Mahalanobis para a dimensão dinamismo não é estatisticamente significante, ou seja, a dimensão não possui outlier segundo a distância de Mahalanobis.

$\mathrm{H}_{1,3}$ : A distância de Mahalanobis para a dimensão dinamismo é estatisticamente significante, ou seja, a dimensão possui outlier segundo a distância de Mahalanobis.

$\mathrm{H}_{0,4}$ : A distância de Mahalanobis para a dimensão integração não é estatisticamente significante, ou seja, a dimensão não possui outlier segundo a distância de Mahalanobis.

$\mathrm{H}_{1,4}$ : A distância de Mahalanobis para a dimensão integração é estatisticamente significante, ou seja, a dimensão possui outlier segundo a distância de Mahalanobis. 
$\mathrm{H}_{0,5}$ : A distância de Mahalanobis para a dimensão alinhamento não é estatisticamente significante, ou seja, a dimensão não possui outlier segundo a distância de Mahalanobis.

$\mathrm{H}_{1,5}$ : A distância de Mahalanobis para a dimensão alinhamento é estatisticamente significante, ou seja, a dimensão possui outlier segundo a distância de Mahalanobis.

$\mathrm{H}_{0,6}$ : A distância de Mahalanobis para a dimensão participação não é estatisticamente significante, ou seja, a dimensão não possui outlier segundo a distância de Mahalanobis.

$\mathrm{H}_{1,6}$ : A distância de Mahalanobis para a dimensão participação é estatisticamente significante, ou seja, a dimensão possui outlier segundo a distância de Mahalanobis.

$\mathrm{H}_{0,7}$ : A distância de Mahalanobis para a dimensão relação causal não é estatisticamente significante, ou seja, a dimensão não possui outlier segundo a distância de Mahalanobis.

$\mathrm{H}_{1,7}$ : A distância de Mahalanobis para a dimensão relação causal é estatisticamente significante, ou seja, a dimensão possui outlier segundo a distância de Mahalanobis.

$\mathrm{H}_{0,8}$ : A distância de Mahalanobis para a dimensão equilíbrio não é estatisticamente significante, ou seja, a dimensão não possui outlier segundo a distância de Mahalanobis.

$\mathrm{H}_{1,8}$ : A distância de Mahalanobis para a dimensão equilíbrio é estatisticamente significante, ou seja, a dimensão possui outlier segundo a distância de Mahalanobis.

$\mathrm{H}_{0,9}$ : A distância de Mahalanobis para a dimensão análise crítica não é estatisticamente significante, ou seja, a dimensão não possui outlier segundo a distância de Mahalanobis.

$\mathrm{H}_{1,9}$ : A distância de Mahalanobis para a dimensão análise crítica é estatisticamente significante, ou seja, a dimensão possui outlier segundo a distância de Mahalanobis.

No total, houve nove testes de hipóteses. Em cada dimensão realizou-se um teste $t$-student, com nível de significância de $0,2 \%$ e número de graus de liberdade igual ao número de aspectos de cada dimensão. A tabela 4 apresenta os resultados em cada dimensão.

Tabela 4 - Teste para detecção de outliers

\begin{tabular}{lccc}
\hline \multicolumn{1}{c}{ Dimensão } & g.l. ( ${ }^{\mathbf{0}}$ var) & $\mathbf{t}_{\text {crítico }}$ & $\begin{array}{c}\text { Valor acima de } \\
\mathbf{t}_{\text {crítico }}\end{array}$ \\
\hline Aprendizado & 12 & 3,930 & \\
\hline Clareza & 14 & 3,787 & \\
\hline Dinamismo & 16 & 3,686 & 3,81 \\
\hline Integração & 5 & 5,893 & $5,97-5,28-5 ; 95$ \\
\hline Alinhamento & 14 & 3,787 & \\
\hline Participação & 6 & 5,208 & 4,20 \\
\hline Relação Causal & 6 & 5,208 & \\
\hline Equilíbrio & 10 & 4,144 & 3,930 \\
\hline Análise Crítica & 12 & &
\end{tabular}


Foram identificados cinco valores acima de $\mathbf{t}_{\text {crítico }}$ e retirados da amostra quatro outliers, já que uma observação esteve presente em duas dimensões. Logo, a hipótese $\mathrm{H}_{0}$ foi rejeitada para as dimensões Alinhamento, Participação e Equilíbrio $\left(\mathrm{H}_{0,5}-\mathrm{H}_{0,6}-\mathrm{H}_{0,8}\right)$.

\subsubsection{Missing Values}

Em seguida, foram investigados e identificados cinco casos em que houve abstenção do entrevistado em responder a mais de $10 \%$ das informações solicitadas. Em um outro formulário, o entrevistado respondeu "Não Sei" a todas as questões, sendo também este considerado um dado perdido. Portanto, considerando-se Outliers e Missings Values, foram descartados 10 questionários.

\subsubsection{Contexto Univariado}

Para o melhor atendimento dos requisitos das análises estatísticas nos contextos univariado, bivariado e multivariado, a amostra total foi estratificada em dois grupos, atendendo a critérios de função do entrevistado no PNAFE e região do país a que pertence. Isto porque a maior parte das técnicas de análise empregadas neste trabalho exige que o número mínimo de observações em cada estratificação formada não seja inferior a 20 . O quadro 32, a seguir, mostra o resultado desta estratificação.

Quadro 32 - Amostra total dividida por função e região

\begin{tabular}{|c|c|c|c|c|}
\hline \multirow{4}{*}{ Função } & \multicolumn{4}{|c|}{ Região } \\
\hline & & Demais Estados & SP & Total \\
\cline { 2 - 5 } & Alta Gerência & 48 & 10 & 58 \\
\cline { 2 - 5 } & Média Gerência & 0 & 59 & 59 \\
\cline { 2 - 5 } & Total & 48 & 69 & 117 \\
\hline
\end{tabular}

\subsubsection{Normalidade Univariada}

Segundo Hair et al (2005, p. 76) uma das principais suposições em análise multivariada é a normalidade, que se refere à forma da distribuição de dados para uma variável métrica individual e sua correspondência com a distribuição normal, ou seja, o padrão de referência para métodos estatísticos. Se a variação em relação à distribuição normal é grande, todos os 
testes estatísticos resultantes são considerados inválidos. Para esta avaliação, os autores recomendam usar testes estatísticos baseados em valores das chamadas medidas de forma, quais sejam, assimetria e curtose.

De acordo com Hair et al (2005, p. 50-51), assimetria é a medida da simetria de uma distribuição, sendo na maioria dos casos a comparação efetuada com uma distribuição normal. Uma distribuição positivamente assimétrica tem relativamente poucos valores grandes e uma cauda mais longa à direita, sendo que uma distribuição negativamente assimétrica possui poucos valores pequenos e uma cauda mais alongada à esquerda.

Para os mesmos autores, curtose é a medida da elevação ou do achatamento de uma distribuição quando comparada a uma distribuição normal, sendo um valor positivo a indicação de uma distribuição relativamente elevada e um valor negativo, uma relativamente achatada.

$\mathrm{Na}$ tabela 5, a seguir apresentada, constam os valores encontrados para assimetria e curtose de todas as variáveis propostas neste trabalho.

Para Marcoulides (1998), as variáveis observáveis com assimetria entre -1 e +1 e curtose entre +2 e -2 estão dentro dos limites de normalidade univariada. $\mathrm{Na}$ análise realizada, as variáveis v8, v9, v10, v13, v18, v31, v72, v76, v77, v83 e v86 registraram valores fora do intervalo [-1,1] para assimetria. E a v8 apresentou valor fora do intervalo [-2,2] para curtose.

Considerando que apenas a v8 extrapolou os limites aceitáveis nas duas condições, esta foi excluída do rol de variáveis para a seqüência de aplicação de técnicas de análise multivariada, por não se enquadrar na condição de normalidade univariada. 
Tabela 5 - Valores de assimetria e curtose

\begin{tabular}{|c|c|c|c|c|c|c|c|c|c|}
\hline $\mathbf{V}$ & $\begin{array}{c}\text { Assimetria } \\
\text { Z-Score }\end{array}$ & $\begin{array}{c}\text { Erro Pad } \\
\text { Assimetria }\end{array}$ & $\begin{array}{l}\text { Curtose } \\
\text { Z-Score }\end{array}$ & $\begin{array}{c}\text { Erro } \\
\text { Pad. } \\
\text { Curtose }\end{array}$ & V & $\begin{array}{c}\text { Assimetria } \\
\text { Z-Score }\end{array}$ & $\begin{array}{c}\text { Erro Pad. } \\
\text { Assimetria }\end{array}$ & $\begin{array}{l}\text { Curtose } \\
\text { Z-Score }\end{array}$ & $\begin{array}{c}\text { Erro } \\
\text { Pad. } \\
\text { Curtose }\end{array}$ \\
\hline V5 & $-0,696$ & 0,224 & 0,019 & 0,444 & V53 & $-0,671$ & 0,224 & $-0,352$ & 0,444 \\
\hline V6 & $-0,746$ & 0,224 & 0,429 & 0,444 & V54 & $-0,585$ & 0,224 & $-0,767$ & 0,444 \\
\hline V7 & $-0,801$ & 0,224 & 0,238 & 0,444 & V55 & $-0,412$ & 0,226 & $-0,918$ & 0,447 \\
\hline V8 & $-1,406$ & 0,224 & 2,128 & 0,444 & V56 & $-0,418$ & 0,224 & $-1,016$ & 0,444 \\
\hline V9 & $-1,149$ & 0,225 & 1,254 & 0,446 & V57 & $-0,362$ & 0,224 & $-0,844$ & 0,444 \\
\hline V10 & $-1,176$ & 0,224 & 1,202 & 0,444 & V58 & $-0,892$ & 0,224 & $-0,230$ & 0,444 \\
\hline V11 & $-0,926$ & 0,225 & 0,692 & 0,446 & V59 & $-0,661$ & 0,224 & $-0,636$ & 0,444 \\
\hline V12 & $-0,975$ & 0,226 & 0,779 & 0,447 & V60 & $-0,912$ & 0,225 & 0,224 & 0,446 \\
\hline V13 & $-1,089$ & 0,224 & 1,110 & 0,444 & V61 & $-0,811$ & 0,224 & $-0,008$ & 0,444 \\
\hline V14 & $-0,469$ & 0,226 & $-0,900$ & 0,447 & V62 & $-0,326$ & 0,224 & $-1,069$ & 0,444 \\
\hline V15 & $-0,705$ & 0,224 & $-0,329$ & 0,444 & V63 & $-0,251$ & 0,224 & $-1,148$ & 0,444 \\
\hline V16 & $-0,857$ & 0,224 & 0,090 & 0,444 & V64 & $-0,111$ & 0,224 & $-1,353$ & 0,444 \\
\hline V17 & $-0,430$ & 0,226 & $-0,802$ & 0,447 & V65 & $-0,418$ & 0,224 & $-0,987$ & 0,444 \\
\hline V18 & $-1,066$ & 0,224 & 0,664 & 0,444 & V66 & $-0,387$ & 0,224 & $-0,743$ & 0,444 \\
\hline V19 & $-0,371$ & 0,225 & $-0,822$ & 0,446 & V67 & $-0,493$ & 0,225 & $-0,878$ & 0,446 \\
\hline V20 & $-0,490$ & 0,224 & $-0,598$ & 0,444 & V68 & $-0,452$ & 0,224 & $-0,918$ & 0,444 \\
\hline V21 & $-0,615$ & 0,224 & $-0,578$ & 0,444 & V69 & $-0,289$ & 0,224 & $-0,648$ & 0,444 \\
\hline V22 & $-0,416$ & 0,225 & $-0,594$ & 0,446 & V70 & $-0,220$ & 0,224 & $-1,100$ & 0,444 \\
\hline V23 & $-0,400$ & 0,224 & $-0,637$ & 0,444 & V71 & $-0,211$ & 0,225 & $-1,095$ & 0,446 \\
\hline V24 & $-0,267$ & 0,224 & $-1,066$ & 0,444 & V72 & $-1,072$ & 0,224 & 0,731 & 0,444 \\
\hline V25 & $-0,791$ & 0,224 & 0,263 & 0,444 & V73 & $-0,617$ & 0,225 & $-0,564$ & 0,446 \\
\hline V26 & $-0,527$ & 0,227 & $-0,442$ & 0,451 & V74 & $-0,555$ & 0,224 & $-0,583$ & 0,444 \\
\hline V27 & $-0,466$ & 0,225 & $-0,559$ & 0,446 & V75 & $-0,757$ & 0,224 & $-0,107$ & 0,444 \\
\hline V28 & $-0,560$ & 0,225 & $-0,472$ & 0,446 & V76 & $-1,036$ & 0,224 & 0,918 & 0,444 \\
\hline V29 & $-0,442$ & 0,224 & $-0,753$ & 0,444 & V77 & $-1,150$ & 0,225 & 0,746 & 0,446 \\
\hline V30 & 0,017 & 0,224 & $-1,267$ & 0,444 & V78 & $-0,491$ & 0,226 & $-0,658$ & 0,447 \\
\hline V31 & $-1,121$ & 0,224 & 1,250 & 0,444 & V79 & $-0,671$ & 0,224 & $-0,200$ & 0,444 \\
\hline V32 & $-0,624$ & 0,226 & $-0,592$ & 0,447 & V80 & $-0,721$ & 0,224 & 0,272 & 0,444 \\
\hline V33 & $-0,428$ & 0,224 & $-0,744$ & 0,444 & V81 & $-0,595$ & 0,224 & $-0,432$ & 0,444 \\
\hline V34 & $-0,188$ & 0,226 & $-1,145$ & 0,447 & V82 & $-0,275$ & 0,224 & $-0,993$ & 0,444 \\
\hline V35 & $-0,593$ & 0,224 & $-0,455$ & 0,444 & V83 & $-1,048$ & 0,225 & 0,700 & 0,446 \\
\hline V36 & $-0,885$ & 0,224 & 1,008 & 0,444 & V84 & $-0,295$ & 0,224 & $-0,943$ & 0,444 \\
\hline V37 & $-0,546$ & 0,224 & $-0,870$ & 0,444 & V85 & $-0,881$ & 0,225 & 0,417 & 0,446 \\
\hline V38 & $-0,201$ & 0,225 & $-1,167$ & 0,446 & V86 & $-1,274$ & 0,224 & 1,304 & 0,444 \\
\hline V39 & $-0,618$ & 0,224 & $-0,763$ & 0,444 & V87 & $-0,300$ & 0,224 & $-0,947$ & 0,444 \\
\hline V40 & $-0,316$ & 0,224 & $-0,952$ & 0,444 & V88 & $-0,490$ & 0,224 & $-0,775$ & 0,444 \\
\hline V41 & $-0,485$ & 0,224 & $-0,860$ & 0,444 & V89 & $-0,219$ & 0,224 & $-1,098$ & 0,444 \\
\hline V42 & $-0,502$ & 0,224 & $-0,505$ & 0,444 & V90 & $-0,158$ & 0,225 & $-1,073$ & 0,446 \\
\hline V43 & $-0,357$ & 0,224 & $-1,116$ & 0,444 & V91 & $-0,494$ & 0,224 & $-0,828$ & 0,444 \\
\hline V44 & $-0,593$ & 0,224 & $-0,647$ & 0,444 & V92 & $-0,352$ & 0,224 & $-0,920$ & 0,444 \\
\hline V45 & $-0,403$ & 0,226 & $-0,916$ & 0,447 & V93 & $-0,486$ & 0,224 & $-0,617$ & 0,444 \\
\hline V46 & $-0,546$ & 0,224 & $-0,750$ & 0,444 & V94 & $-0,941$ & 0,224 & 0,251 & 0,444 \\
\hline V47 & $-0,433$ & 0,224 & $-0,938$ & 0,444 & V95 & $-0,555$ & 0,224 & $-0,529$ & 0,444 \\
\hline V48 & $-0,118$ & 0,226 & $-1,312$ & 0,447 & V96 & $-0,622$ & 0,224 & $-0,279$ & 0,444 \\
\hline V49 & $-0,553$ & 0,225 & $-0,741$ & 0,446 & V97 & $-0,439$ & 0,224 & $-0,867$ & 0,444 \\
\hline V50 & $-0,536$ & 0,224 & $-0,621$ & 0,444 & V98 & $-0,494$ & 0,224 & $-0,871$ & 0,444 \\
\hline V51 & $-0,515$ & 0,224 & $-0,508$ & 0,444 & V99 & $-0,628$ & 0,224 & $-0,727$ & 0,444 \\
\hline V52 & $-0,513$ & 0,224 & $-0,722$ & 0,444 & V100 & $-0,510$ & 0,224 & $-0,320$ & 0,444 \\
\hline
\end{tabular}




\subsubsection{Estatísticas Descritivas}

Para Cooper e Schindler (2003, p. 356), além da verificação dos dados válidos e dados faltantes (missings) e das medidas ditas de forma (assimetria e curtose), medidas de localização e dispersão são ferramentas úteis para entender mais e resumir as distribuições. Compreendem-se aqui por medidas, as sínteses que representam um conjunto de dados referentes a uma variável de interesse.

A fim de conhecer este rol de estatísticas chamadas descritivas, foram elaboradas três tabelas, classificadas como Amostra Total - Tabela 6, dados da Alta Gerência - Tabela 7 e dados da Média Gerência - Tabela 8, dispostas a seguir, contendo para cada variável:

a) quantidade de valores válidos e missings;

b) medidas de localização ou de tendência central, tais como média aritmética, mediana e moda;

c) medidas de dispersão ou variabilidade, tais como desvio-padrão, amplitude, máximo e mínimo, quartis $\left(1^{\circ}, 2^{\circ}, 3^{\circ}\right)$ e coeficiente de variação.

Analisando-se, por exemplo, os valores do coeficiente de variação das variáveis distribuídas nos três grupos, e considerando que acima do valor de 30\% tem-se alta dispersão, conclui-se que em todas as variáveis houve grande dispersão nas respostas.

Destaque-se, neste contexto, que a maior variabilidade nos dados da Amostra Total foi encontrada nas variáveis v30, v48 e v64 com valores acima de 70\%. As variáveis v30, v38, v48, v64 e v71, relativas ao grupo da Alta Gerência, também estiveram acima de 70\%. Para o grupo da Média Gerência, o coeficiente de variação esteve acima de $60 \%$ para as variáveis v14, v30, v34, v47, v48 e v64.

\begin{tabular}{|ll|}
\hline & Legenda Tabelas 6-7-8 \\
V - Variável & Amp - Amplitude \\
Vál - Número de observações válidas & Mínimo - Valor Mínimo \\
Mis - Número de dados Missings & Máximo - Valor Máximo \\
Méd - Média & Qa25 - Quartil 25 \\
Mna - Mediana & Qa50 - Quartil 50 \\
Mod - Moda & Qa 75 - Quartil 75 \\
DPd - Desvio Padrão & Coef Var - Coeficiente de Variação \\
\hline
\end{tabular}


Tabela 6 - Estatísticas Descritivas Amostra Total

\begin{tabular}{|c|c|c|c|c|c|c|c|c|c|c|c|c|c|}
\hline $\mathbf{V}$ & Vál & Mis & Med & Mna & Mod & DPd & Amp & Mín & Máx & Qa25 & Qa50 & Qa75 & Coef Var \\
\hline V5 & 117 & 0 & 6,7949 & 7 & 7 & 2,242 & 9 & 1 & 10 & 6 & 7 & 8 & 32,995 \\
\hline V6 & 117 & 0 & 6,9915 & 7 & 7 & 2,1395 & 9 & 1 & 10 & 6 & 7 & 8 & 30,601 \\
\hline V7 & 117 & 0 & 6,9829 & 7 & 8 & 2,3156 & 10 & 0 & 10 & 6 & 7 & 9 & 33,161 \\
\hline V9 & 116 & 1 & 7,1983 & 8 & 8 & 2,2115 & 10 & 0 & 10 & 6 & 8 & 9 & 30,723 \\
\hline V10 & 117 & 0 & 6,9658 & 8 & 8 & 2,1851 & 10 & 0 & 10 & 6 & 8 & 8 & 31,369 \\
\hline V11 & 116 & 1 & 6,1121 & 7 & 7 & 2,3656 & 10 & 0 & 10 & 5 & 7 & 8 & 38,704 \\
\hline V12 & 115 & 2 & 6,6348 & 7 & 8 & 2,3446 & 10 & 0 & 10 & 5 & 7 & 8 & 35,338 \\
\hline V13 & 117 & 0 & 7,0513 & 7 & 7 & 2,2547 & 10 & 0 & 10 & 6 & 7 & 9 & 31,976 \\
\hline V14 & 115 & 2 & 5,1391 & 6 & 8 & 2,9466 & 10 & 0 & 10 & 3 & 6 & 8 & 57,337 \\
\hline V15 & 117 & 0 & 6,2991 & 7 & 7 & 2,6401 & 10 & 0 & 10 & 5 & 7 & 8 & 41,912 \\
\hline V16 & 117 & 0 & 6,8632 & 7 & 7 & 2,5048 & 10 & 0 & 10 & 5 & 7 & 9 & 36,496 \\
\hline V17 & 115 & 2 & 5,4348 & 6 & 5 & 3,1038 & 10 & 0 & 10 & 4 & 6 & 8 & 57,11 \\
\hline V18 & 117 & 0 & 6,9487 & 8 & 8 & 2,655 & 10 & 0 & 10 & 6 & 8 & 9 & 38,209 \\
\hline V19 & 116 & 1 & 5,2069 & 6 & 7 & 2,9178 & 10 & 0 & 10 & 3 & 6 & 7 & 56,037 \\
\hline V20 & 117 & 0 & 5,6752 & 6 & 7 & 2,9209 & 10 & 0 & 10 & 4 & 6 & 8 & 51,468 \\
\hline V21 & 117 & 0 & 5,8889 & 7 & 7 & 2,985 & 10 & 0 & 10 & 4 & 7 & 8 & 50,689 \\
\hline V22 & 116 & 1 & 4,8362 & 5 & 5 & 2,6075 & 10 & 0 & 10 & 3 & 5 & 7 & 53,916 \\
\hline V23 & 117 & 0 & 5,7607 & 6 & 6 & 2,8486 & 10 & 0 & 10 & 4 & 6 & 8 & 49,449 \\
\hline V24 & 117 & 0 & 5,547 & 6 & 5 & 3,0014 & 10 & 0 & 10 & 3 & 6 & 8 & 54,109 \\
\hline V25 & 117 & 0 & 6,6667 & 7 & 8 & 2,4354 & 10 & 0 & 10 & 5 & 7 & 8 & 36,531 \\
\hline V26 & 113 & 4 & 5,7257 & 6 & 7 & 2,4394 & 10 & 0 & 10 & 4 & 6 & 8 & 42,604 \\
\hline V27 & 116 & 1 & 5,4741 & 6 & 7 & 2,7425 & 10 & 0 & 10 & 3 & 6 & 7 & 50,1 \\
\hline V28 & 116 & 1 & 5,7672 & 6 & 8 & 2,7642 & 10 & 0 & 10 & 4 & 6 & 8 & 47,93 \\
\hline V29 & 117 & 0 & 5,4274 & 6 & 8 & 2,8687 & 10 & 0 & 10 & 3,5 & 6 & 8 & 52,856 \\
\hline V30 & 117 & 0 & 4,1026 & 5 & 0 & 3,1497 & 10 & 0 & 10 & 0,5 & 5 & 7 & 76,773 \\
\hline V31 & 117 & 0 & 7,2308 & 8 & 8 & 2,3975 & 10 & 0 & 10 & 6 & 8 & 9 & 33,157 \\
\hline V32 & 115 & 2 & 6,0087 & 7 & 8 & 2,9335 & 10 & 0 & 10 & 4 & 7 & 8 & 48,821 \\
\hline V33 & 117 & 0 & 5,3504 & 6 & 7 & 2,7864 & 10 & 0 & 10 & 3 & 6 & 7 & 52,078 \\
\hline V34 & 115 & 2 & 4,9391 & 5 & 8 & 3,0183 & 10 & 0 & 10 & 3 & 5 & 8 & 61,11 \\
\hline V35 & 117 & 0 & 5,547 & 6 & 7 & 2,7621 & 10 & 0 & 10 & 4 & 6 & 8 & 49,794 \\
\hline V36 & 117 & 0 & 6,8462 & 7 & 7 & 2,373 & 10 & 0 & 10 & 6 & 7 & 9 & 34,662 \\
\hline V37 & 117 & 0 & 5,812 & 7 & 8 & 3,0736 & 10 & 0 & 10 & 3 & 7 & 8 & 52,884 \\
\hline V38 & 116 & 1 & 4,75 & 5 & 0 & 3,0727 & 10 & 0 & 10 & 2 & 5 & 7 & 64,688 \\
\hline V39 & 117 & 0 & 5,9231 & 7 & 8 & 3,0574 & 10 & 0 & 10 & 3,5 & 7 & 8 & 51,618 \\
\hline V40 & 117 & 0 & 4,8889 & 5 & 5 & 2,843 & 10 & 0 & 10 & 2 & 5 & 7 & 58,152 \\
\hline V41 & 117 & 0 & 5,2991 & 6 & 8 & 2,9133 & 10 & 0 & 10 & 3 & 6 & 8 & 54,977 \\
\hline V42 & 117 & 0 & 5,7521 & 6 & 8 & 2,4667 & 10 & 0 & 10 & 4 & 6 & 8 & 42,883 \\
\hline V43 & 117 & 0 & 5,265 & 6 & 6 & 3,1 & 10 & 0 & 10 & 2 & 6 & 8 & 58,879 \\
\hline V44 & 117 & 0 & 5,8803 & 7 & 7 & 2,9307 & 10 & 0 & 10 & 4 & 7 & 8 & 49,839 \\
\hline V45 & 115 & 2 & 5,1043 & 6 & 7 & 2,9091 & 10 & 0 & 10 & 3 & 6 & 7 & 56,993 \\
\hline V46 & 117 & 0 & 5,6838 & 6 & 8 & 2,7626 & 10 & 0 & 10 & 3,5 & 6 & 8 & 48,605 \\
\hline V47 & 117 & 0 & 5,4786 & 6 & 7 & 2,9758 & 10 & 0 & 10 & 3 & 6 & 8 & 54,317 \\
\hline V48 & 115 & 2 & 4,4522 & 5 & 0 & 3,1518 & 10 & 0 & 10 & 1 & 5 & 7 & 70,792 \\
\hline V49 & 116 & 1 & 5,4569 & 6 & 8 & 2,9441 & 10 & 0 & 10 & 3,3 & 6 & 8 & 53,952 \\
\hline V50 & 117 & 0 & 6,3162 & 7 & 8 & 2,5483 & 10 & 0 & 10 & 4,5 & 7 & 8 & 40,345 \\
\hline V51 & 117 & 0 & 6,4359 & 7 & 7 & 2,5373 & 10 & 0 & 10 & 5 & 7 & 8 & 39,424 \\
\hline V52 & 117 & 0 & 5,4444 & 6 & 7 & 2,7274 & 10 & 0 & 10 & 3 & 6 & 8 & 50,096 \\
\hline V53 & 117 & 0 & 5,8803 & 7 & 7 & 2,7517 & 10 & 0 & 10 & 4 & 7 & 8 & 46,795 \\
\hline
\end{tabular}


Tabela 6 - Estatísticas Descritivas Amostra Total (Continuação)

\begin{tabular}{|c|c|c|c|c|c|c|c|c|c|c|c|c|c|}
\hline $\mathbf{V}$ & Vál & Mis & Med & Mna & Mod & DPd & Amp & Mín & Máx & Qa25 & Qa50 & Qa75 & Coef Var \\
\hline V54 & 117 & 0 & 5,5897 & 7 & 7 & 2,8772 & 10 & 0 & 10 & 3 & 7 & 8 & 51,473 \\
\hline V55 & 115 & 2 & 4,7826 & 5 & 7 & 2,7267 & 10 & 0 & 10 & 3 & 5 & 7 & 57,013 \\
\hline V56 & 117 & 0 & 4,906 & 6 & 7 & 2,7228 & 10 & 0 & 10 & 2,5 & 6 & 7 & 55,499 \\
\hline V57 & 117 & 0 & 4,9573 & 5 & 7 & 2,689 & 10 & 0 & 10 & 3 & 5 & 7 & 54,243 \\
\hline V58 & 117 & 0 & 6,1282 & 7 & 7 & 2,8483 & 10 & 0 & 10 & 5 & 7 & 8 & 46,479 \\
\hline V59 & 117 & 0 & 5,6496 & 7 & 8 & 2,8597 & 10 & 0 & 10 & 4 & 7 & 8 & 50,618 \\
\hline V60 & 116 & 1 & 6,8103 & 7 & 8 & 2,6074 & 10 & 0 & 10 & 5 & 7 & 9 & 38,286 \\
\hline V61 & 117 & 0 & 6,3419 & 7 & 8 & 2,7011 & 10 & 0 & 10 & 5 & 7 & 8 & 42,591 \\
\hline V62 & 117 & 0 & 4,8632 & 5 & 6 & 2,8944 & 10 & 0 & 10 & 2 & 5 & 7 & 59,516 \\
\hline V63 & 117 & 0 & 4,7863 & 5 & 8 & 2,8279 & 10 & 0 & 10 & 2 & 5 & 7 & 59,083 \\
\hline V64 & 117 & 0 & 4,3419 & 5 & 0 & 3,1518 & 10 & 0 & 10 & 1 & 5 & 7 & 72,59 \\
\hline V65 & 117 & 0 & 4,7863 & 5 & 6 & 2,8552 & 10 & 0 & 10 & 2 & 5 & 7 & 59,654 \\
\hline V66 & 117 & 0 & 5,3932 & 6 & 5 & 2,7036 & 10 & 0 & 10 & 3 & 6 & 8 & 50,13 \\
\hline V67 & 116 & 1 & 5,3534 & 6 & 7 & 2,7858 & 10 & 0 & 10 & 3 & 6 & 8 & 52,038 \\
\hline V68 & 117 & 0 & 5,1282 & 6 & 8 & 2,8574 & 10 & 0 & 10 & 3 & 6 & 8 & 55,719 \\
\hline V69 & 117 & 0 & 5,7863 & 6 & 5 & 2,5217 & 10 & 0 & 10 & 4 & 6 & 8 & 43,581 \\
\hline V70 & 117 & 0 & 5,2393 & 6 & 8 & 2,9817 & 10 & 0 & 10 & 3 & 6 & 8 & 56,91 \\
\hline V71 & 116 & 1 & 4,4052 & 5 & 6 & 2,862 & 10 & 0 & 10 & 1,3 & 5 & 6 & 64,969 \\
\hline V72 & 117 & 0 & 6,9573 & 8 & 8 & 2,3722 & 10 & 0 & 10 & 6 & 8 & 8 & 34,097 \\
\hline V73 & 116 & 1 & 5,6207 & 6 & 7 & 2,8427 & 10 & 0 & 10 & 4 & 6 & 8 & 50,576 \\
\hline V74 & 117 & 0 & 5,7521 & 6 & 8 & 2,7067 & 10 & 0 & 10 & 4 & 6 & 8 & 47,056 \\
\hline V75 & 117 & 0 & 5,2821 & 6 & 7 & 2,6322 & 10 & 0 & 10 & 4,5 & 6 & 7 & 49,832 \\
\hline V76 & 117 & 0 & 6,7607 & 7 & 7 & 2,3985 & 10 & 0 & 10 & 6 & 7 & 8 & 35,477 \\
\hline V77 & 116 & 1 & 6,5603 & 7 & 8 & 2,5101 & 10 & 0 & 10 & 6 & 7 & 8 & 38,262 \\
\hline V78 & 115 & 2 & 4,8435 & 5 & 5 & 2,6278 & 9 & 0 & 9 & 3 & 5 & 7 & 54,254 \\
\hline V79 & 117 & 0 & 5,8974 & 6 & 8 & 2,5099 & 10 & 0 & 10 & 5 & 6 & 8 & 42,559 \\
\hline V80 & 117 & 0 & 6,3077 & 7 & 7 & 2,2417 & 10 & 0 & 10 & 5 & 7 & 8 & 35,539 \\
\hline V81 & 117 & 0 & 5,4957 & 6 & 7 & 2,3803 & 10 & 0 & 10 & 4 & 6 & 7 & 43,312 \\
\hline V82 & 117 & 0 & 5,0513 & 5 & 7 & 2,8613 & 10 & 0 & 10 & 2 & 5 & 7 & 56,645 \\
\hline V83 & 116 & 1 & 6,931 & 7 & 7 & 2,5082 & 10 & 0 & 10 & 6 & 7 & 9 & 36,188 \\
\hline V84 & 117 & 0 & 5,1453 & 5 & 7 & 2,9163 & 10 & 0 & 10 & 3 & 5 & 7 & 56,679 \\
\hline V85 & 116 & 1 & 6,4052 & 7 & 7 & 2,4064 & 10 & 0 & 10 & 5 & 7 & 8 & 37,569 \\
\hline V86 & 117 & 0 & 6,9316 & 7 & 7 & 2,4131 & 10 & 0 & 10 & 6 & 7 & 9 & 34,813 \\
\hline V87 & 117 & 0 & 5,2479 & 6 & 7 & 2,7003 & 10 & 0 & 10 & 3 & 6 & 7 & 51,455 \\
\hline V88 & 117 & 0 & 5,7094 & 6 & 8 & 2,8859 & 10 & 0 & 10 & 4 & 6 & 8 & 50,546 \\
\hline V89 & 117 & 0 & 5,0085 & 5 & 8 & 2,9258 & 10 & 0 & 10 & 2 & 5 & 8 & 58,417 \\
\hline V90 & 116 & 1 & 4,6638 & 5 & 7 & 2,8097 & 10 & 0 & 10 & 3 & 5 & 7 & 60,245 \\
\hline V91 & 117 & 0 & 5,4786 & 6 & 7 & 2,7405 & 10 & 0 & 10 & 3 & 6 & 8 & 50,022 \\
\hline V92 & 117 & 0 & 5,1709 & 5 & 8 & 2,7863 & 10 & 0 & 10 & 3 & 5 & 8 & 53,884 \\
\hline V93 & 117 & 0 & 5,4359 & 6 & 7 & 2,6437 & 10 & 0 & 10 & 4 & 6 & 7 & 48,634 \\
\hline V94 & 117 & 0 & 6,8291 & 7 & 7 & 2,5707 & 10 & 0 & 10 & 6 & 7 & 9 & 37,643 \\
\hline V95 & 117 & 0 & 6,3504 & 7 & 7 & 2,4259 & 9 & 1 & 10 & 5 & 7 & 8 & 38,201 \\
\hline V96 & 117 & 0 & 6,094 & 7 & 8 & 2,6424 & 10 & 0 & 10 & 5 & 7 & 8 & 43,361 \\
\hline V97 & 117 & 0 & 5,0256 & 5 & 5 & 2,7899 & 10 & 0 & 10 & 3 & 5 & 7 & 55,514 \\
\hline V98 & 117 & 0 & 5,1111 & 6 & 7 & 2,658 & 10 & 0 & 10 & 3 & 6 & 7 & 52,004 \\
\hline V99 & 117 & 0 & 5,5043 & 6 & 8 & 2,97 & 10 & 0 & 10 & 4 & 6 & 8 & 53,958 \\
\hline V100 & 117 & 0 & 5,735 & 6 & 7 & 2,1671 & 10 & 0 & 10 & 4 & 6 & 7 & 37,787 \\
\hline
\end{tabular}


Tabela 7 - Estatísticas Descritivas da Alta Gerência

\begin{tabular}{|c|c|c|c|c|c|c|c|c|c|c|c|c|c|}
\hline $\mathbf{V}$ & Vál & Mis & Med & Mna & Mod & DPd & Amp & Mín & Máx & Qa25 & Qa50 & Qa75 & Coef Var \\
\hline V5 & 58 & 0 & 7,0172 & 7 & 8 & 2,1316 & 9 & 1 & 10 & 6 & 7 & 8 & 30,37679 \\
\hline V6 & 58 & 0 & 7,3966 & 7 & 7 & 1,6323 & 7 & 3 & 10 & 6 & 7 & 8 & 22,06825 \\
\hline V7 & 58 & 0 & 7,3793 & 7,5 & 7 & 1,8241 & 8 & 2 & 10 & 6 & 7,5 & 9 & 24,71915 \\
\hline V9 & 57 & 1 & 7,193 & 8 & 7 & 2,0826 & 9 & 1 & 10 & 6 & 8 & 9 & 28,95315 \\
\hline V10 & 58 & 0 & 7,1034 & 8 & 8 & 2,0148 & 9 & 1 & 10 & 6 & 8 & 8 & 28,36388 \\
\hline V11 & 58 & 0 & 6,069 & 7 & 7 & 2,346 & 10 & 0 & 10 & 5 & 7 & 8 & 38,65546 \\
\hline V12 & 56 & 2 & 7,0893 & 8 & 8 & 2,1 & 10 & 0 & 10 & 6 & 8 & 8 & 29,62211 \\
\hline V13 & 58 & 0 & 7,1897 & 7 & 7 & 2,1961 & 9 & 1 & 10 & 6 & 7 & 9 & 30,54509 \\
\hline V14 & 58 & 0 & 5,3276 & 6 & 6 & 2,9042 & 10 & 0 & 10 & 4 & 6 & 8 & 54,51235 \\
\hline V15 & 58 & 0 & 6,3276 & 7 & 7 & 2,5088 & 10 & 0 & 10 & 5 & 7 & 8 & 39,64852 \\
\hline V16 & 58 & 0 & 6,9655 & 7 & 7 & 2,4204 & 9 & 1 & 10 & 5 & 7 & 9 & 34,7484 \\
\hline V17 & 58 & 0 & 5,4138 & 6 & 5 & 2,9738 & 10 & 0 & 10 & 4 & 6 & 8 & 54,92999 \\
\hline V18 & 58 & 0 & 6,9483 & 8 & 8 & 2,7493 & 10 & 0 & 10 & 6 & 8 & 9 & 39,56795 \\
\hline V19 & 57 & 1 & 5,1228 & 5 & 5 & 2,7971 & 10 & 0 & 10 & 3 & 5 & 7 & 54,601 \\
\hline V20 & 58 & 0 & 5,6207 & 6 & 7 & 2,7583 & 10 & 0 & 10 & 4 & 6 & 7,3 & 49,07396 \\
\hline V21 & 58 & 0 & 5,9655 & 7 & 7 & 2,8896 & 10 & 0 & 10 & 4 & 7 & 8 & 48,43852 \\
\hline V22 & 57 & 1 & 4,7193 & 5 & 5 & 2,6576 & 10 & 0 & 10 & 3 & 5 & 7 & 56,31344 \\
\hline V23 & 58 & 0 & 5,4483 & 6 & 6 & 2,8542 & 10 & 0 & 10 & 3,8 & 6 & 7,3 & 52,38698 \\
\hline V24 & 58 & 0 & 5,0862 & 5 & 5 & 2,9277 & 10 & 0 & 10 & 2,8 & 5 & 8 & 57,56164 \\
\hline $\mathrm{V} 25$ & 58 & 0 & 6,5 & 7 & 7 & 2,2341 & 9 & 1 & 10 & 5 & 7 & 8 & 34,37077 \\
\hline V26 & 56 & 2 & 5,4464 & 6 & 6 & 2,2877 & 9 & 1 & 10 & 3,3 & 6 & 7 & 42,00389 \\
\hline V27 & 58 & 0 & 5,2241 & 6 & 7 & 2,7212 & 10 & 0 & 10 & 3 & 6 & 7 & 52,08936 \\
\hline V28 & 58 & 0 & 5,569 & 6 & 7 & 2,5963 & 10 & 0 & 10 & 4 & 6 & 7,3 & 46,62058 \\
\hline V29 & 58 & 0 & 5,0345 & 5 & 6 & 2,74 & 10 & 0 & 10 & 3 & 5 & 7 & 54,42447 \\
\hline $\mathrm{V} 30$ & 58 & 0 & 3,4483 & 3,5 & 0 & 2,8542 & 10 & 0 & 10 & 0 & 3,5 & 6 & 82,77122 \\
\hline V31 & 58 & 0 & 7,1034 & 7 & 7 & 2,3597 & 10 & 0 & 10 & 6 & 7 & 9 & 33,2193 \\
\hline V32 & 56 & 2 & 5,6429 & 6 & 8 & 3,0833 & 10 & 0 & 10 & 3 & 6 & 8 & 54,64034 \\
\hline V33 & 58 & 0 & 4,6724 & 5 & 3 & 3,0515 & 10 & 0 & 10 & 2,8 & 5 & 7 & 65,30905 \\
\hline V34 & 57 & 1 & 4,5439 & 5 & 6 & 2,765 & 9 & 0 & 9 & 2,5 & 5 & 7 & 60,85081 \\
\hline V35 & 58 & 0 & 5,5 & 6 & 7 & 2,7354 & 10 & 0 & 10 & 3,8 & 6 & 7,3 & 49,73455 \\
\hline V36 & 58 & 0 & 6,6207 & 7 & 7 & 2,3681 & 10 & 0 & 10 & 5 & 7 & 8 & 35,76812 \\
\hline V37 & 58 & 0 & 6,0172 & 7 & 8 & 2,9528 & 10 & 0 & 10 & 3 & 7 & 8 & 49,07266 \\
\hline V38 & 58 & 0 & 4 & 4 & 0 & 2,8284 & 10 & 0 & 10 & 2 & 4 & 7 & 70,71 \\
\hline V39 & 58 & 0 & 5,3793 & 6 & 8 & 3,1889 & 10 & 0 & 10 & 2,8 & 6 & 8 & 59,28095 \\
\hline V40 & 58 & 0 & 4,6724 & 5 & 5 & 2,7491 & 10 & 0 & 10 & 2 & 5 & 7 & 58,837 \\
\hline V41 & 58 & 0 & 5,0345 & 6 & 6 & 3,026 & 10 & 0 & 10 & 2 & 6 & 7,3 & 60,10527 \\
\hline V42 & 58 & 0 & 5,5862 & 6 & 7 & 2,3172 & 10 & 0 & 10 & 4 & 6 & 7 & 41,48079 \\
\hline V43 & 58 & 0 & 4,8621 & 5,5 & 2 & 3,3792 & 10 & 0 & 10 & 2 & 5,5 & 8 & 69,50083 \\
\hline V44 & 58 & 0 & 5,9483 & 6 & 6 & 2,9878 & 10 & 0 & 10 & 4 & 6 & 8,3 & 50,22948 \\
\hline V45 & 57 & 1 & 4,9474 & 6 & 6 & 3,0789 & 10 & 0 & 10 & 2 & 6 & 7 & 62,23269 \\
\hline V46 & 58 & 0 & 5,4483 & 6 & 8 & 2,8969 & 10 & 0 & 10 & 3 & 6 & 8 & 53,17071 \\
\hline V47 & 58 & 0 & 5,8621 & 6 & 7 & 2,8559 & 10 & 0 & 10 & 4 & 6 & 8 & 48,71804 \\
\hline V48 & 57 & 1 & 4,1404 & 5 & 0 & 3,2151 & 10 & 0 & 10 & 1 & 5 & 7 & 77,65192 \\
\hline V49 & 57 & 1 & 5,3684 & 6 & 8 & 3,1995 & 10 & 0 & 10 & 2,5 & 6 & 8 & 59,59876 \\
\hline V50 & 58 & 0 & 6,6552 & 7 & 8 & 2,3809 & 9 & 1 & 10 & 5 & 7 & 8 & 35,77503 \\
\hline V51 & 58 & 0 & 6,6552 & 7 & 8 & 2,3735 & 9 & 1 & 10 & 5 & 7 & 8 & 35,66384 \\
\hline V52 & 58 & 0 & 5,4138 & 6 & 7 & 2,8717 & 10 & 0 & 10 & 3 & 6 & 8 & 53,04407 \\
\hline V53 & 58 & 0 & 5,8276 & 6 & 8 & 2,8967 & 10 & 0 & 10 & 4 & 6 & 8 & 49,70657 \\
\hline
\end{tabular}


Tabela 7 - Estatísticas Descritivas da Alta Gerência (Continuação)

\begin{tabular}{|c|c|c|c|c|c|c|c|c|c|c|c|c|c|}
\hline $\mathbf{V}$ & Vál & Mis & Med & Mna & Mod & DPd & Amp & Mín & Máx & Qa25 & Qa50 & Qa75 & Coef Var \\
\hline V54 & 58 & 0 & 5,3966 & 6 & 7 & 3,0026 & 10 & 0 & 10 & 2 & 6 & 8 & 55,63874 \\
\hline V55 & 57 & 1 & 4,1754 & 5 & 7 & 2,6868 & 10 & 0 & 10 & 2 & 5 & 7 & 64,34833 \\
\hline V56 & 58 & 0 & 4,4655 & 5 & 7 & 2,9807 & 10 & 0 & 10 & 2 & 5 & 7 & 66,74952 \\
\hline V57 & 58 & 0 & 4,6207 & 5 & 1 & 2,8705 & 10 & 0 & 10 & 1,8 & 5 & 7 & 62,12262 \\
\hline V58 & 58 & 0 & 6,2414 & 7 & 7 & 2,9338 & 10 & 0 & 10 & 4,5 & 7 & 8 & 47,00548 \\
\hline V59 & 58 & 0 & 5,5345 & 7 & 8 & 3,0677 & 10 & 0 & 10 & 2,8 & 7 & 8 & 55,42867 \\
\hline V60 & 57 & 1 & 6,5088 & 7 & 8 & 2,8481 & 10 & 0 & 10 & 5 & 7 & 8,5 & 43,75768 \\
\hline V61 & 58 & 0 & 6,6034 & 8 & 8 & 2,9555 & 10 & 0 & 10 & 5 & 8 & 9 & 44,75725 \\
\hline V62 & 58 & 0 & 4,6552 & 5,5 & 8 & 3,1263 & 9 & 0 & 9 & 1 & 5,5 & 7,3 & 67,15716 \\
\hline V63 & 58 & 0 & 4,6207 & 5 & 1 & 2,8643 & 9 & 0 & 9 & 1,8 & 5 & 7 & 61,98844 \\
\hline V64 & 58 & 0 & 4,3103 & 5 & 0 & 3,3204 & 10 & 0 & 10 & 1 & 5 & 7 & 77,03408 \\
\hline V65 & 58 & 0 & 4,7759 & 5 & 5 & 3,0206 & 10 & 0 & 10 & 1,8 & 5 & 7 & 63,24672 \\
\hline V66 & 58 & 0 & 5,3966 & 5,5 & 5 & 2,8466 & 10 & 0 & 10 & 2,8 & 5,5 & 7,3 & 52,74803 \\
\hline V67 & 58 & 0 & 5,2069 & 6 & 7 & 2,978 & 10 & 0 & 10 & 3 & 6 & 7,3 & 57,19334 \\
\hline V68 & 58 & 0 & 5 & 5,5 & 8 & 3,0029 & 10 & 0 & 10 & 3 & 5,5 & 8 & 60,058 \\
\hline V69 & 58 & 0 & 5,5517 & 6 & 5 & 2,3707 & 10 & 0 & 10 & 4 & 6 & 7 & 42,70224 \\
\hline V70 & 58 & 0 & 5,1724 & 5,5 & 8 & 2,992 & 10 & 0 & 10 & 3 & 5,5 & 8 & 57,84549 \\
\hline V71 & 57 & 1 & 4,2105 & 5 & 5 & 2,9805 & 10 & 0 & 10 & 1 & 5 & 6 & 70,78732 \\
\hline V72 & 58 & 0 & 7,4483 & 8 & 8 & 2,3031 & 8 & 2 & 10 & 7 & 8 & 9 & 30,92115 \\
\hline V73 & 57 & 1 & 6,2105 & 7 & 7 & 2,8457 & 10 & 0 & 10 & 4 & 7 & 8 & 45,82079 \\
\hline V74 & 58 & 0 & 6,1552 & 7 & 8 & 2,7067 & 10 & 0 & 10 & 4 & 7 & 8 & 43,9742 \\
\hline V75 & 58 & 0 & 5,2931 & 6 & 7 & 2,816 & 10 & 0 & 10 & 4 & 6 & 7 & 53,20134 \\
\hline V76 & 58 & 0 & 7,069 & 7 & 7 & 2,4269 & 10 & 0 & 10 & 6 & 7 & 9 & 34,33159 \\
\hline V77 & 57 & 1 & 7,0175 & 8 & 8 & 2,4458 & 10 & 0 & 10 & 7 & 8 & 8 & 34,85287 \\
\hline V78 & 58 & 0 & 4,8103 & 5 & 5 & 2,8251 & 9 & 0 & 9 & 3 & 5 & 7 & 58,73022 \\
\hline V79 & 58 & 0 & 5,7241 & 6 & 8 & 2,6872 & 10 & 0 & 10 & 4 & 6 & 8 & 46,94537 \\
\hline V80 & 58 & 0 & 6,6552 & 7 & 7 & 2,0395 & 10 & 0 & 10 & 5,8 & 7 & 8 & 30,64521 \\
\hline V81 & 58 & 0 & 5,6552 & 6 & 7 & 2,2599 & 10 & 0 & 10 & 5 & 6 & 7 & 39,96145 \\
\hline V82 & 58 & 0 & 4,9828 & 5 & 5 & 2,9468 & 10 & 0 & 10 & 2 & 5 & 7 & 59,13944 \\
\hline V83 & 58 & 0 & 7,069 & 7 & 7 & 2,3159 & 9 & 1 & 10 & 6 & 7 & 9 & 32,76135 \\
\hline V84 & 58 & 0 & 5,3793 & 6 & 7 & 3,139 & 10 & 0 & 10 & 3 & 6 & 8 & 58,35332 \\
\hline V85 & 57 & 1 & 6,8596 & 7 & 7 & 2,2074 & 10 & 0 & 10 & 6 & 7 & 8 & 32,17972 \\
\hline V86 & 58 & 0 & 7,1034 & 7,5 & 7 & 2,4184 & 10 & 0 & 10 & 6,8 & 7,5 & 9 & 34,04567 \\
\hline V87 & 58 & 0 & 5,2586 & 6 & 7 & 2,8688 & 10 & 0 & 10 & 2 & 6 & 7 & 54,55444 \\
\hline V88 & 58 & 0 & 5,9138 & 6 & 8 & 2,7675 & 10 & 0 & 10 & 4 & 6 & 8 & 46,79732 \\
\hline V89 & 58 & 0 & 4,7759 & 5 & 8 & 3,1009 & 10 & 0 & 10 & 2 & 5 & 8 & 64,92808 \\
\hline V90 & 58 & 0 & 4,3103 & 4 & 7 & 2,8297 & 9 & 0 & 9 & 1 & 4 & 7 & 65,64972 \\
\hline V91 & 58 & 0 & 5,2931 & 6 & 8 & 2,7467 & 9 & 0 & 9 & 3 & 6 & 8 & 51,89209 \\
\hline V92 & 58 & 0 & 4,9828 & 5 & 8 & 2,85 & 9 & 0 & 9 & 2,8 & 5 & 8 & 57,19676 \\
\hline V93 & 58 & 0 & 5,0517 & 5,5 & 8 & 2,8863 & 10 & 0 & 10 & 3 & 5,5 & 8 & 57,13522 \\
\hline V94 & 58 & 0 & 7,1207 & 8 & 8 & 2,5893 & 10 & 0 & 10 & 5,8 & 8 & 9 & 36,363 \\
\hline V95 & 58 & 0 & 6,3793 & 7 & 8 & 2,4979 & 9 & 1 & 10 & 4,8 & 7 & 8 & 39,15633 \\
\hline V96 & 58 & 0 & 6,1724 & 7 & 5 & 2,61 & 10 & 0 & 10 & 5 & 7 & 8 & 42,28501 \\
\hline V97 & 58 & 0 & 5,3448 & 6 & 5 & 2,7818 & 10 & 0 & 10 & 4 & 6 & 8 & 52,04685 \\
\hline V98 & 58 & 0 & 5,0172 & 6 & 7 & 2,7561 & 9 & 0 & 9 & 3 & 6 & 7 & 54,93303 \\
\hline V99 & 58 & 0 & 5,3966 & 6 & 8 & 3,1951 & 10 & 0 & 10 & 2,5 & 6 & 8 & 59,2058 \\
\hline V100 & 58 & 0 & 5,8276 & 6,5 & 7 & 2,2175 & 10 & 0 & 10 & 5 & 6,5 & 7 & 38,05169 \\
\hline
\end{tabular}


Tabela 8 - Estatísticas Descritivas Média Gerência

\begin{tabular}{|c|c|c|c|c|c|c|c|c|c|c|c|c|c|}
\hline $\mathbf{V}$ & Vál & Mis & Med & Mna & Mod & DPd & Amp & Mín & Máx & Qa25 & Qa50 & Qa75 & Coef Var \\
\hline V5 & 59 & 0 & 6,5763 & 7 & 7 & 2,343 & 9 & 1 & 10 & 5 & 7 & 8 & 35,62794 \\
\hline V6 & 59 & 0 & 6,5932 & 7 & 7 & 2,4922 & 9 & 1 & 10 & 5 & 7 & 9 & 37,79955 \\
\hline V7 & 59 & 0 & 6,5932 & 7 & 8 & 2,6725 & 10 & 0 & 10 & 5 & 7 & 8 & 40,53419 \\
\hline V9 & 59 & 0 & 7,2034 & 8 & 8 & 2,3473 & 10 & 0 & 10 & 6 & 8 & 8 & 32,586 \\
\hline V10 & 59 & 0 & 6,8305 & 8 & 8 & 2,35 & 10 & 0 & 10 & 6 & 8 & 8 & 34,40451 \\
\hline V11 & 58 & 1 & 6,1552 & 7 & 7 & 2,4047 & 10 & 0 & 10 & 5 & 7 & 8 & 39,06778 \\
\hline V12 & 59 & 0 & 6,2034 & 7 & 8 & 2,4968 & 10 & 0 & 10 & 5 & 7 & 8 & 40,2489 \\
\hline V13 & 59 & 0 & 6,9153 & 7 & 7 & 2,3215 & 10 & 0 & 10 & 6 & 7 & 8 & 33,57049 \\
\hline V14 & 57 & 2 & 4,9474 & 6 & 8 & 3,0025 & 10 & 0 & 10 & 2 & 6 & 7,5 & 60,68844 \\
\hline V15 & 59 & 0 & 6,2712 & 7 & 7 & 2,7844 & 10 & 0 & 10 & 5 & 7 & 8 & 44,3998 \\
\hline V16 & 59 & 0 & 6,7627 & 7 & 7 & 2,602 & 10 & 0 & 10 & 6 & 7 & 9 & 38,47576 \\
\hline V17 & 57 & 2 & 5,4561 & 6 & 7 & 3,2572 & 10 & 0 & 10 & 3 & 6 & 8 & 59,69832 \\
\hline V18 & 59 & 0 & 6,9492 & 7 & 10 & 2,5826 & 10 & 0 & 10 & 6 & 7 & 9 & 37,16399 \\
\hline V19 & 59 & 0 & 5,2881 & 6 & 6 & 3,0516 & 10 & 0 & 10 & 3 & 6 & 7 & 57,70693 \\
\hline V20 & 59 & 0 & 5,7288 & 6 & 3 & 3,0952 & 10 & 0 & 10 & 3 & 6 & 8 & 54,02877 \\
\hline V21 & 59 & 0 & 5,8136 & 6 & 8 & 3,0988 & 10 & 0 & 10 & 3 & 6 & 8 & 53,3026 \\
\hline V22 & 59 & 0 & 4,9492 & 5 & 5 & 2,5759 & 9 & 0 & 9 & 3 & 5 & 7 & 52,0468 \\
\hline V23 & 59 & 0 & 6,0678 & 7 & 8 & 2,8337 & 10 & 0 & 10 & 4 & 7 & 8 & 46,70062 \\
\hline V24 & 59 & 0 & 6 & 6 & 9 & 3,0286 & 10 & 0 & 10 & 3 & 6 & 9 & 50,47667 \\
\hline $\mathrm{V} 25$ & 59 & 0 & 6,8305 & 7 & 8 & 2,6271 & 10 & 0 & 10 & 5 & 7 & 9 & 38,46131 \\
\hline V26 & 57 & 2 & 6 & 7 & 7 & 2,5704 & 10 & 0 & 10 & 4,5 & 7 & 8 & 42,84 \\
\hline V27 & 58 & 1 & 5,7241 & 6 & 6 & 2,7644 & 10 & 0 & 10 & 3,8 & 6 & 8 & 48,29405 \\
\hline V28 & 58 & 1 & 5,9655 & 6 & 8 & 2,9318 & 10 & 0 & 10 & 3,8 & 6 & 8 & 49,14592 \\
\hline V29 & 59 & 0 & 5,8136 & 6 & 8 & 2,9623 & 10 & 0 & 10 & 4 & 6 & 8 & 50,95466 \\
\hline $\mathrm{V} 30$ & 59 & 0 & 4,7458 & 5 & 0 & 3,3145 & 10 & 0 & 10 & 1 & 5 & 8 & 69,8407 \\
\hline V31 & 59 & 0 & 7,3559 & 8 & 8 & 2,4478 & 10 & 0 & 10 & 7 & 8 & 10 & 33,27669 \\
\hline $\mathrm{V} 32$ & 59 & 0 & 6,3559 & 7 & 8 & 2,7653 & 10 & 0 & 10 & 5 & 7 & 8 & 43,50761 \\
\hline V33 & 59 & 0 & 6,0169 & 7 & 7 & 2,3378 & 10 & 0 & 10 & 5 & 7 & 8 & 38,85389 \\
\hline V34 & 58 & 1 & 5,3276 & 6 & 8 & 3,2248 & 10 & 0 & 10 & 2,8 & 6 & 8 & 60,53007 \\
\hline V35 & 59 & 0 & 5,5932 & 6 & 8 & 2,8108 & 10 & 0 & 10 & 4 & 6 & 8 & 50,25388 \\
\hline V36 & 59 & 0 & 7,0678 & 7 & 7 & 2,3771 & 10 & 0 & 10 & 6 & 7 & 9 & 33,63281 \\
\hline V37 & 59 & 0 & 5,6102 & 7 & 8 & 3,2003 & 10 & 0 & 10 & 3 & 7 & 8 & 57,04431 \\
\hline V38 & 58 & 1 & 5,5 & 6,5 & 7 & 3,147 & 10 & 0 & 10 & 4 & 6,5 & 8 & 57,21818 \\
\hline V39 & 59 & 0 & 6,4576 & 7 & 8 & 2,8486 & 10 & 0 & 10 & 5 & 7 & 9 & 44,11236 \\
\hline V40 & 59 & 0 & 5,1017 & 6 & 8 & 2,9402 & 10 & 0 & 10 & 2 & 6 & 8 & 57,63177 \\
\hline V41 & 59 & 0 & 5,5593 & 7 & 8 & 2,7995 & 10 & 0 & 10 & 3 & 7 & 8 & 50,35706 \\
\hline V42 & 59 & 0 & 5,9153 & 6 & 8 & 2,6149 & 10 & 0 & 10 & 4 & 6 & 8 & 44,2057 \\
\hline V43 & 59 & 0 & 5,661 & 6 & 7 & 2,7706 & 10 & 0 & 10 & 4 & 6 & 8 & 48,94188 \\
\hline V44 & 59 & 0 & 5,8136 & 7 & 7 & 2,8975 & 10 & 0 & 10 & 3 & 7 & 8 & 49,84003 \\
\hline V45 & 58 & 1 & 5,2586 & 6 & 7 & 2,7502 & 10 & 0 & 10 & 3,8 & 6 & 7,3 & 52,29909 \\
\hline V46 & 59 & 0 & 5,9153 & 7 & 7 & 2,628 & 10 & 0 & 10 & 4 & 7 & 8 & 44,42716 \\
\hline V47 & 59 & 0 & 5,1017 & 6 & 7 & 3,0665 & 10 & 0 & 10 & 2 & 6 & 8 & 60,10742 \\
\hline V48 & 58 & 1 & 4,7586 & 5 & 0 & 3,0854 & 10 & 0 & 10 & 2 & 5 & 8 & 64,8384 \\
\hline V49 & 59 & 0 & 5,5424 & 6 & 5 & 2,6994 & 10 & 0 & 10 & 4 & 6 & 8 & 48,70453 \\
\hline V50 & 59 & 0 & 5,9831 & 6 & 6 & 2,6813 & 10 & 0 & 10 & 4 & 6 & 8 & 44,81456 \\
\hline V51 & 59 & 0 & 6,2203 & 7 & 7 & 2,6914 & 10 & 0 & 10 & 4 & 7 & 9 & 43,26801 \\
\hline V52 & 59 & 0 & 5,4746 & 6 & 7 & 2,6021 & 9 & 0 & 9 & 4 & 6 & 7 & 47,53041 \\
\hline V53 & 59 & 0 & 5,9322 & 7 & 7 & 2,6252 & 10 & 0 & 10 & 4 & 7 & 7 & 44,2534 \\
\hline
\end{tabular}


Tabela 8 - Estatísticas Descritivas Média Gerência (Continuação)

\begin{tabular}{|c|c|c|c|c|c|c|c|c|c|c|c|c|c|}
\hline $\mathbf{V}$ & Vál & Mis & Med & Mna & Mod & DPd & Amp & Mín & Máx & Qa25 & Qa50 & Qa75 & Coef Var \\
\hline V54 & 59 & 0 & 5,7797 & 7 & 7 & 2,761 & 10 & 0 & 10 & 4 & 7 & 8 & 47,77065 \\
\hline V55 & 58 & 1 & 5,3793 & 6 & 7 & 2,6545 & 10 & 0 & 10 & 4 & 6 & 7 & 49,34657 \\
\hline V56 & 59 & 0 & 5,339 & 6 & 5 & 2,3897 & 9 & 0 & 9 & 4 & 6 & 7 & 44,75932 \\
\hline V57 & 59 & 0 & 5,2881 & 6 & 6 & 2,4778 & 10 & 0 & 10 & 4 & 6 & 7 & 46,85615 \\
\hline V58 & 59 & 0 & 6,0169 & 7 & 8 & 2,7823 & 10 & 0 & 10 & 5 & 7 & 8 & 46,24142 \\
\hline V59 & 59 & 0 & 5,7627 & 7 & 7 & 2,6609 & 10 & 0 & 10 & 4 & 7 & 8 & 46,17454 \\
\hline V60 & 59 & 0 & 7,1017 & 7 & 7 & 2,3393 & 10 & 0 & 10 & 6 & 7 & 9 & 32,94 \\
\hline V61 & 59 & 0 & 6,0847 & 7 & 7 & 2,4232 & 10 & 0 & 10 & 4 & 7 & 8 & 39,82448 \\
\hline V62 & 59 & 0 & 5,0678 & 5 & 7 & 2,6579 & 10 & 0 & 10 & 3 & 5 & 7 & 52,44682 \\
\hline V63 & 59 & 0 & 4,9492 & 5 & 8 & 2,8065 & 10 & 0 & 10 & 3 & 5 & 7 & 56,70613 \\
\hline V64 & 59 & 0 & 4,3729 & 5 & 0 & 3,0052 & 10 & 0 & 10 & 2 & 5 & 7 & 68,72327 \\
\hline V65 & 59 & 0 & 4,7966 & 6 & 6 & 2,7087 & 9 & 0 & 9 & 3 & 6 & 7 & 56,47125 \\
\hline V66 & 59 & 0 & 5,3898 & 6 & 8 & 2,5799 & 9 & 0 & 9 & 4 & 6 & 8 & 47,86634 \\
\hline V67 & 58 & 1 & 5,5 & 6 & 8 & 2,5972 & 9 & 0 & 9 & 4 & 6 & 8 & 47,22182 \\
\hline V68 & 59 & 0 & 5,2542 & 6 & 8 & 2,7266 & 10 & 0 & 10 & 3 & 6 & 8 & 51,89372 \\
\hline V69 & 59 & 0 & 6,0169 & 7 & 8 & 2,6619 & 10 & 0 & 10 & 4 & 7 & 8 & 44,24039 \\
\hline V70 & 59 & 0 & 5,3051 & 6 & 8 & 2,9957 & 10 & 0 & 10 & 3 & 6 & 8 & 56,4683 \\
\hline V71 & 59 & 0 & 4,5932 & 5 & 6 & 2,755 & 9 & 0 & 9 & 2 & 5 & 7 & 59,97997 \\
\hline V72 & 59 & 0 & 6,4746 & 7 & 8 & 2,3588 & 10 & 0 & 10 & 6 & 7 & 8 & 36,43159 \\
\hline V73 & 59 & 0 & 5,0508 & 6 & 7 & 2,7444 & 9 & 0 & 9 & 3 & 6 & 7 & 54,33595 \\
\hline V74 & 59 & 0 & 5,3559 & 6 & 8 & 2,6702 & 9 & 0 & 9 & 3 & 6 & 8 & 49,8553 \\
\hline V75 & 59 & 0 & 5,2712 & 6 & 7 & 2,4623 & 10 & 0 & 10 & 5 & 6 & 7 & 46,71232 \\
\hline V76 & 59 & 0 & 6,4576 & 7 & 7 & 2,3512 & 10 & 0 & 10 & 6 & 7 & 8 & 36,40981 \\
\hline V77 & 59 & 0 & 6,1186 & 7 & 6 & 2,5126 & 10 & 0 & 10 & 6 & 7 & 8 & 41,06495 \\
\hline V78 & 57 & 2 & 4,8772 & 5 & 5 & 2,4354 & 9 & 0 & 9 & 3,5 & 5 & 7 & 49,93439 \\
\hline V79 & 59 & 0 & 6,0678 & 6 & 7 & 2,3332 & 9 & 1 & 10 & 5 & 6 & 8 & 38,45216 \\
\hline V80 & 59 & 0 & 5,9661 & 7 & 7 & 2,3923 & 9 & 1 & 10 & 5 & 7 & 8 & 40,09822 \\
\hline V81 & 59 & 0 & 5,339 & 6 & 5 & 2,5025 & 9 & 0 & 9 & 3 & 6 & 7 & 46,87207 \\
\hline V82 & 59 & 0 & 5,1186 & 6 & 7 & 2,7983 & 10 & 0 & 10 & 2 & 6 & 7 & 54,66925 \\
\hline V83 & 58 & 1 & 6,7931 & 7 & 7 & 2,7 & 10 & 0 & 10 & 6 & 7 & 9 & 39,74621 \\
\hline V84 & 59 & 0 & 4,9153 & 5 & 5 & 2,6864 & 10 & 0 & 10 & 3 & 5 & 7 & 54,65384 \\
\hline V85 & 59 & 0 & 5,9661 & 7 & 7 & 2,5255 & 10 & 0 & 10 & 4 & 7 & 8 & 42,33084 \\
\hline V86 & 59 & 0 & 6,7627 & 7 & 7 & 2,4165 & 10 & 0 & 10 & 6 & 7 & 9 & 35,73277 \\
\hline V87 & 59 & 0 & 5,2373 & 5 & 5 & 2,5484 & 10 & 0 & 10 & 3 & 5 & 7 & 48,65866 \\
\hline V88 & 59 & 0 & 5,5085 & 6 & 8 & 3,0079 & 10 & 0 & 10 & 2 & 6 & 8 & 54,6047 \\
\hline V89 & 59 & 0 & 5,2373 & 5 & 7 & 2,7502 & 10 & 0 & 10 & 3 & 5 & 8 & 52,51179 \\
\hline V90 & 58 & 1 & 5,0172 & 5 & 5 & 2,7688 & 10 & 0 & 10 & 3 & 5 & 7 & 55,18616 \\
\hline V91 & 59 & 0 & 5,661 & 6 & 7 & 2,7456 & 10 & 0 & 10 & 4 & 6 & 8 & 48,50026 \\
\hline V92 & 59 & 0 & 5,3559 & 6 & 6 & 2,734 & 10 & 0 & 10 & 4 & 6 & 7 & 51,04651 \\
\hline V93 & 59 & 0 & 5,8136 & 6 & 7 & 2,345 & 10 & 0 & 10 & 4 & 6 & 7 & 40,33645 \\
\hline V94 & 59 & 0 & 6,5424 & 7 & 7 & 2,5415 & 10 & 0 & 10 & 6 & 7 & 8 & 38,8466 \\
\hline V95 & 59 & 0 & 6,322 & 7 & 7 & 2,374 & 9 & 1 & 10 & 5 & 7 & 8 & 37,55141 \\
\hline V96 & 59 & 0 & 6,0169 & 7 & 8 & 2,6941 & 10 & 0 & 10 & 5 & 7 & 8 & 44,77555 \\
\hline V97 & 59 & 0 & 4,7119 & 5 & 5 & 2,7857 & 9 & 0 & 9 & 2 & 5 & 7 & 59,12052 \\
\hline V98 & 59 & 0 & 5,2034 & 6 & 7 & 2,5783 & 10 & 0 & 10 & 4 & 6 & 7 & 49,55029 \\
\hline V99 & 59 & 0 & 5,6102 & 6 & 7 & 2,7544 & 10 & 0 & 10 & 4 & 6 & 8 & 49,09629 \\
\hline V100 & 59 & 0 & 5,6441 & 6 & 7 & 2,1316 & 9 & 1 & 10 & 4 & 6 & 7 & 37,76687 \\
\hline
\end{tabular}




\subsubsection{Contexto Bivariado}

No contexto bivariado, foram aplicadas basicamente duas técnicas de análise: a Análise de Correlação e o Teste Qui-quadrado.

\subsubsection{Análise de Correlação}

Segundo Cooper e Schindler (2003, p. 423), com a correlação calcula-se um índice para mensurar a natureza da relação entre as variáveis, sendo a análise afetada pelas suposições de nível de mensuração e das distribuições implícitas nos dados. O coeficiente de correlação de Pearson $r$ simboliza a estimativa do coeficiente de associação linear baseada nos dados da amostra, e varia de +1 até -1 . A primeira exigência de $r$ é a linearidade, em que $r$ deve ser diferente de zero. A segunda é a distribuição normal bivariada. O coeficiente $\rho$ representa a correlação populacional entre determinado par de variáveis.

O teste Qui-quadrado disponível no software SPSS usa a correlação amostral $r$ para inferência sobre $p$, segundo a formulação das seguintes hipóteses:

$$
\begin{aligned}
& \mathrm{H}_{0}: \rho=0 \\
& \mathrm{H}_{1}: \rho \neq 0
\end{aligned}
$$

Ao obter a matriz de correlação entre variáveis, Cooper e Schindler (2003, p. 428) acrescentam que diversas explicações alternadas podem ser fornecidas para os resultados da correlação: a variável X causa a Y; a variável Y causa a X; X e Y são ativados por uma ou mais variáveis diferentes; $\mathrm{X}$ e $\mathrm{Y}$ influenciam uma à outra reciprocamente.

Com os valores de $\rho$ diferentes de zero pôde-se rejeitar a hipótese $\mathrm{H}_{0}$. $\mathrm{O}$ quadro 33, a seguir, retrata os valores das correlações mais altas, todas acima de 0,8 , entre variáveis da Amostra Total da pesquisa. Note-se, de antemão, que a maioria das altas correlações destacadas aconteceu entre variáveis de uma mesma dimensão. Os grupos de variáveis que mais estiveram correlacionadas com variáveis de outras dimensões foram as da dimensão Relação Causal com as variáveis da dimensão Equilíbrio; as de Análise Crítica com as de Equilíbrio; e as de Clareza com as variáveis de Dinamismo. 
A variável v100 relativa à avaliação da medição de desempenho de BPM no PNAFE encontra-se relacionada unicamente com variáveis da dimensão Análise Crítica. Este fato dá a entender aos gestores do programa que ao verificar a presença marcante das variáveis da dimensão Análise Crítica nos macro-processos sob suas responsabilidades, foi notado um reflexo positivo na avaliação geral do desempenho de BPM.

Esta análise leva a entender também que ao priorizar as variáveis da dimensão Relação Causal, o gestor estará automaticamente influenciando positivamente as variáveis contidas na dimensão Equilíbrio. Da mesma forma, ao valorizar a presença das variáveis da dimensão Análise Crítica na medição de desempenho de BPM no PNAFE, o gestor estará impactando positivamente as variáveis da dimensão Equilíbrio. Para as variáveis de Clareza e Dinamismo aconteceu o mesmo fato.

Um resultado curioso se deu com a dimensão Aprendizado. Ela se constitui na única dimensão em que não foram encontradas altas correlações entre suas variáveis, nem com variáveis de outras dimensões.

Quadro 33 - Altas correlações entre variáveis da Amostra Total

\begin{tabular}{|c|c|c|c|c|c|c|c|c|c|c|c|}
\hline D & $\mathbf{V}$ & Correlata & D & $\mathbf{V}$ & Correlata & D & $\mathbf{V}$ & Correlata & D & $\mathbf{V}$ & Correlata \\
\hline \multirow{7}{*}{ 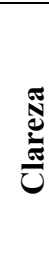 } & 17 & 20,21 & \multirow{3}{*}{$\stackrel{\Perp}{\Xi}$} & 49 & 32 & \multirow{4}{*}{ 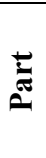 } & 66 & 67 & \multirow{10}{*}{ 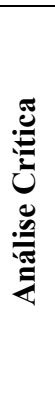 } & 88 & $89,91,94$ \\
\hline & 19 & 24 & & 50 & 51 & & 67 & 66 & & 89 & $82,88,92,99,100$ \\
\hline & 20 & 17,21 & & 51 & 50 & & 70 & 71,82 & & 90 & 91,92 \\
\hline & 21 & $17,20,44$ & \multirow{9}{*}{ 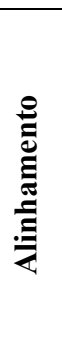 } & 52 & 53,54 & & 71 & 70 & & 91 & 88,90 \\
\hline & 24 & 19 & & 53 & 52 & & 72 & 83 & & 92 & $87,89,90,97,98$ \\
\hline & 27 & 28,44 & & 54 & 52 & Е & 74 & 75,82 & & 94 & $88,95,100$ \\
\hline & 28 & 27 & & 55 & 56,57 & & 75 & 74,87 & & 95 & 94 \\
\hline \multirow{7}{*}{ 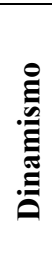 } & 32 & 49 & & 56 & 55,57 & \multirow{6}{*}{ 产 } & 79 & 80 & & 97 & 92 \\
\hline & 40 & 41 & & 57 & 55,56 & & 80 & 79 & & 98 & 92,99 \\
\hline & 41 & 40 & & 62 & 63,64 & & 82 & $70,74,84,87,89,99$ & & 99 & $82,84,89,98,100$ \\
\hline & 43 & 44,45 & & 63 & 62 & & 83 & 72 & \multirow[b]{2}{*}{$\varangle$} & & \\
\hline & 44 & $21,27,43$ & & 64 & 62 & & 84 & 82,99 & & \multirow{3}{*}{\multicolumn{2}{|c|}{$89,94,99$}} \\
\hline & 45 & 43,46 & & & & & 87 & $75,82,92$ & & & \\
\hline & 46 & 45 & & & & & & & & & \\
\hline \multicolumn{12}{|c|}{ Legenda: D - Dimensão. V - Variável. Correlata - Variável Correlata. } \\
\hline \multicolumn{12}{|c|}{ Inte - Integração. Part - Participação. Caus - Relação Causal. A - Avaliação Geral. } \\
\hline
\end{tabular}

Foram obtidas também duas matrizes de correlação entre variáveis segmentadas pelo perfil do respondente (Alta Gerência ou Média Gerência), não sendo identificadas diferenças significativas. Merece ainda destaque o fato de as correlações entre as variáveis v20-v21 (dimensão Clareza) e v90-v91 (dimensão Análise Crítica) terem obtido valor de $r$ maior que 
0,9 na matriz da amostra total, bem como as correlações entre v40-v41 e v45-v46 (dimensão Dinamismo), e v82-v87 (dimensão Equilíbrio) em ambas as matrizes de Alta e Média Gerência.

\subsubsection{Teste Qui-quadrado}

O Teste Qui-quadrado é usado para testar diferenças significantes entre a distribuição observada dos dados entre as categorias e a distribuição esperada com base na hipótese nula (COOPER e SCHINDLER, p. 400). Ele é utilizado para verificar a independência ou a associação existente ou não, entre duas variáveis.

Foram formuladas as seguintes hipóteses, considerando faixas de valores da Avaliação Geral da medição de desempenho de BPM como variável independente e a Função de o gestor e a Região ao qual pertence como variáveis dependentes:

$\mathrm{H}_{0}$ : A variável de avaliação geral do desempenho de BPM no PNAFE independe da função exercida pelos gestores.

$\mathrm{H}_{1}$ : A variável de avaliação geral do desempenho de BPM no PNAFE depende da função exercida pelos gestores.

$\mathrm{e}$

$\mathrm{H}_{0}$ : A variável de avaliação geral do desempenho de BPM no PNAFE independe da região a que pertencem os gestores.

$\mathrm{H}_{1}$ : A variável de avaliação geral do desempenho de BPM no PNAFE depende da região a que pertencem os gestores.

O resultado do teste Qui-quadrado para a primeira hipótese indicou nível de significância de 0,928. Portanto, não se rejeita $\mathrm{H}_{0}$, indicando assim que não se pôde discriminar o fato de o gestor pertencer à Alta ou à Média Gerência da avaliação geral do gerenciamento de desempenho de BPM.

Para a segunda hipótese formulada, obteve-se um nível de significância de 0,675 , que indica também a não rejeição de $\mathrm{H}_{0}$. Neste caso, a variável Região também não discrimina os gestores de São Paulo dos gestores dos demais estados na Avaliação Geral do desempenho de BPM no âmbito do PNAFE. 
Restringindo-se à região de São Paulo, foi novamente aplicado o teste Qui-quadrado, a fim de testar as seguintes hipóteses:

$\mathrm{H}_{0}$ : A variável de avaliação geral do desempenho de BPM no PNAFE independe da função exercida pelos gestores de São Paulo.

$\mathrm{H}_{1}$ : A variável de avaliação geral do desempenho de BPM no PNAFE depende da função exercida pelos gestores de São Paulo.

O resultado do teste Qui-quadrado para esta hipótese indicou nível de significância de 0,662. Portanto, não se rejeita $\mathrm{H}_{0}$, indicando assim que não se pôde discriminar o fato de o gestor de São Paulo pertencer à Alta ou à Média Gerência da avaliação geral do gerenciamento de desempenho de BPM.

Este fato permite inferir que, mesmo com a ausência de entrevistados que tenham exercido a função de Média Gerência nos demais estados, por uma limitação ditada pela pesquisa, não haveria também distinção na avaliação geral do desempenho de BPM entre membros da Alta e da Média Gerência nos programas estaduais de modernização do PNAFE de fora de São Paulo.

\subsection{Fidedignidade e Validade}

Selltiz et al (1987, p. 3-4) afirmam que fidedignidade e validade são requisitos que se aplicam tanto no delineamento quanto na mensuração da pesquisa. Entendem que no delineamento são examinadas as conclusões da pesquisa e perguntado se são corretas e aplicáveis. E na mensuração são examinados os escores ou observações e perguntado se são precisos e replicáveis.

Nos próximos itens serão apresentados os mecanismos para a avaliação do construto SMDBPM, em termos de fidedignidade (ou confiabilidade) e validade.

\subsubsection{Fidedignidade do construto}

Segundo Peter (1979), fidedignidade ou confiabilidade de um instrumento de medida é a extensão em que suas mensurações possuem erro aleatório pequeno. Em outras palavras, se o 
instrumento é capaz de produzir resultados consistentes quando repetidas mensurações são realizadas.

Selltiz et al (1987, p. 4) afirmam que a fidedignidade está diretamente relacionada à replicabilidade de uma pesquisa. Para que um escore reflita o construto subjacente, há que se contar com elevada fidedignidade, acrescenta Gulliksen (1950, p. 193-194).

Cooper e Schindler (2003, p. 606) acrescentam que a confiabilidade é uma condição necessária, porém insuficiente, para a validade. Portanto, se uma medida não é confiável, ela não pode ser válida.

De acordo com Hair et al (2005, p. 90) confiabilidade é o grau em que uma variável ou conjunto de variáveis é consistente com o que se pretende medir. Para os autores, se muitas medidas são realizadas, as medidas confiáveis serão muito consistentes em seus valores.

Para a análise da fidedignidade, planejou-se o uso do coeficiente Alfa de Cronbach ( $\alpha$ ), que segundo Cooper e Schindler (2003, p. 187-188) é capaz de revelar o grau em que os itens de um instrumento são homogêneos e refletem o mesmo construto implícito. Este coeficiente de consistência interna foi calculado para cada uma das nove dimensões do instrumento de coleta de dados da pesquisa quantitativa. Por meio desta análise também será possível avaliar a sensibilidade do coeficiente de Cronbach em cada dimensão, calculando-o seguidamente, com a exclusão de cada aspecto da dimensão e comparando-se os resultados.

Foram estabelecidas as seguintes nove hipóteses de nulidade:

$\mathrm{H}_{0,10}$ : Não há fidedignidade na mensuração da dimensão aprendizado para o gerenciamento de processos de BPM

$\mathrm{H}_{1,10}$ : Há fidedignidade na mensuração da dimensão aprendizado para o gerenciamento de processos de BPM.

$\mathrm{H}_{0,11}$ : Não há fidedignidade na mensuração da dimensão clareza para o gerenciamento de processos de BPM.

$\mathrm{H}_{1,11}$ : Há fidedignidade na mensuração da dimensão clareza para o gerenciamento de processos de BPM.

$\mathrm{H}_{0,12}$ : Não há fidedignidade na mensuração da dimensão dinamismo para o gerenciamento de processos de BPM.

$\mathrm{H}_{1,12}$ : Há fidedignidade na mensuração da dimensão dinamismo para o gerenciamento de processos de BPM.

$\mathrm{H}_{0,13}$ : Não há fidedignidade na mensuração da dimensão integração para o gerenciamento de processos de BPM.

$\mathrm{H}_{1,13}$ : Há fidedignidade na mensuração da dimensão integração para o gerenciamento de processos de BPM. 
$\mathrm{H}_{0,14}$ : Não há fidedignidade na mensuração da dimensão alinhamento para o gerenciamento de processos de BPM.

$\mathrm{H}_{1,14}$ : Há fidedignidade na mensuração da dimensão alinhamento para o gerenciamento de processos de BPM.

$\mathrm{H}_{0,15}$ : Não há fidedignidade na mensuração da dimensão participação para o gerenciamento de processos de BPM.

$\mathrm{H}_{1,15}$ : Há fidedignidade na mensuração da dimensão participação para o gerenciamento de processos de BPM.

$\mathrm{H}_{0,16}$ : Não há fidedignidade na mensuração da dimensão relação causal para o gerenciamento de processos de BPM.

$\mathrm{H}_{1,16}$ : Há fidedignidade na mensuração da dimensão relação causal para o gerenciamento de processos de BPM. $\mathrm{H}_{0,17}$ : Não há fidedignidade na mensuração da dimensão equilíbrio para o gerenciamento de processos de BPM. $\mathrm{H}_{1,17}$ : Há fidedignidade na mensuração da dimensão equilíbrio para o gerenciamento de processos de BPM.

$\mathrm{H}_{0,18}$ : Não há fidedignidade na mensuração da dimensão análise crítica para o gerenciamento de processos de BPM.

$\mathrm{H}_{1,18}$ : Há fidedignidade na mensuração da dimensão análise crítica para o gerenciamento de processos de BPM.

Para Hair et al (2005, p. 111-112) o limite inferior geralmente aceito para o coeficiente de Cronbach é 0,70, apesar de poder ser reduzido para 0,60 em pesquisa exploratória. Em todas as dimensões os valores são aceitáveis, considerando-se a referência de 0,70. A tabela 9 apresenta os coeficientes Alfa de Cronbach obtidos para cada uma das dimensões.

Conclui-se que a fidedignidade da escala utilizada no modelo de gestão de processos, com todas as 94 variáveis, é boa, sendo que o maior e o menor valor do coeficiente Alfa de Cronbach é verificado, respectivamente, nas dimensões Clareza e Dinamismo $(0,9668)$ e Integração $(0,8958)$. 
Tabela 9 - Coeficiente Alfa de Cronbach

\begin{tabular}{|c|c|c|c|c|}
\hline Dimensão & $\begin{array}{c}\text { Coeficiente } \\
\boldsymbol{\alpha} \\
\text { da } \\
\text { Dimensão } \\
\end{array}$ & Variável & $\begin{array}{c}\text { Correlação } \\
\text { Corrigida } \\
\text { Item-total }\end{array}$ & $\begin{array}{c}\alpha \text { sendo } \\
\text { removida a } \\
\text { variável } \\
\text { específica } \\
\end{array}$ \\
\hline \multirow[t]{11}{*}{ Aprendizado } & 0,9340 & V5 & ,7243 & ,9279 \\
\hline & & V6 &, 7270 & ,9279 \\
\hline & & V7 & ,7562 & ,9265 \\
\hline & & V9 &, 8244 & ,9239 \\
\hline & & V10 & ,8074 & ,9248 \\
\hline & & V11 & ,7276 & 9277 \\
\hline & & V12 & ,7128 & ,9283 \\
\hline & & V13 & ,7909 & ,9253 \\
\hline & & V14 &, 5734 & ,9365 \\
\hline & & V15 & ,6936 & ,9296 \\
\hline & & V16 &, 7058 & ,9287 \\
\hline \multirow[t]{14}{*}{ Clareza } & 0,9668 & V17 & ,8705 & ,9630 \\
\hline & & V18 & ,7802 & ,9648 \\
\hline & & V19 & ,8102 & ,9642 \\
\hline & & V20 & ,8698 & ,9630 \\
\hline & & $\mathrm{V} 21$ &, 8651 & ,9631 \\
\hline & & V22 & ,7787 & 9649 \\
\hline & & V23 & ,8018 & ,9644 \\
\hline & & V24 &, 8631 & ,9631 \\
\hline & & $\mathrm{V} 25$ & ,7486 & ,9655 \\
\hline & & V26 & 6919 & ,9665 \\
\hline & & V27 & ,8703 & ,9631 \\
\hline & & $\mathrm{V} 28$ &, 8723 & ,9630 \\
\hline & & V29 &, 7475 & ,9655 \\
\hline & & V30 &, 7403 & ,9659 \\
\hline \multirow[t]{16}{*}{ Dinamismo } & 0,9668 & V31 & ,6390 & ,9669 \\
\hline & & V32 &, 8488 & ,9637 \\
\hline & & V33 &, 7444 & ,9654 \\
\hline & & V34 & ,7736 & ,9650 \\
\hline & & V35 & ,7695 & ,9650 \\
\hline & & V36 & ,7228 & ,9658 \\
\hline & & V37 & ,7075 & ,9662 \\
\hline & & V38 & ,7726 & ,9651 \\
\hline & & V39 &, 8154 & ,9643 \\
\hline & & V40 & ,8789 & ,9632 \\
\hline & & V41 &, 8981 & ,9629 \\
\hline & & V42 &, 7527 & ,9654 \\
\hline & & V43 &, 8245 & ,9641 \\
\hline & & V44 &, 8470 & ,9638 \\
\hline & & V45 &, 8278 & ,9641 \\
\hline & & V46 &, 8176 & ,9643 \\
\hline \multirow[t]{5}{*}{ Integração } & 0,8958 & V47 & ,8129 &, 8569 \\
\hline & & V48 & ,7192 & ,8808 \\
\hline & & V49 & ,6480 & ,8944 \\
\hline & & V50 &, 8190 & ,8592 \\
\hline & & V51 &, 7480 &, 8732 \\
\hline
\end{tabular}


Tabela 9 - Coeficiente Alfa de Cronbach (Continuação)

\begin{tabular}{|c|c|c|c|c|}
\hline Dimensão & $\begin{array}{c}\text { Coeficiente } \\
\boldsymbol{\alpha} \\
\text { da } \\
\text { Dimensão } \\
\end{array}$ & Variável & $\begin{array}{c}\text { Correlação } \\
\text { Corrigida } \\
\text { Item-total }\end{array}$ & $\begin{array}{c}\alpha \text { sendo } \\
\text { removida a } \\
\text { variável } \\
\text { específica } \\
\end{array}$ \\
\hline \multirow[t]{14}{*}{ Alinhamento } & 0,9655 & V52 & 8350 & ,9623 \\
\hline & & V53 &, 8322 & ,9624 \\
\hline & & V54 & ,8592 & ,9617 \\
\hline & & V55 &, 8611 & ,9618 \\
\hline & & V56 & ,8797 & ,9614 \\
\hline & & V57 & ,8539 & ,9619 \\
\hline & & V58 &, 8383 & ,9622 \\
\hline & & V59 &, 8025 & ,9630 \\
\hline & & V60 & ,6822 & ,9653 \\
\hline & & V61 & ,6738 & ,9655 \\
\hline & & V62 &, 8246 & ,9625 \\
\hline & & V63 & ,8159 & ,9627 \\
\hline & & V64 &, 7385 & ,9646 \\
\hline & & V65 &, 7408 & ,9642 \\
\hline \multirow[t]{6}{*}{ Participação } & 0,9212 & V66 & ,7291 & ,9128 \\
\hline & & V67 & ,9025 & ,8890 \\
\hline & & V68 & ,7559 & ,9094 \\
\hline & & V69 &, 7464 & ,9109 \\
\hline & & V70 &, 7784 & ,9067 \\
\hline & & V71 &, 7441 & ,9111 \\
\hline \multirow[t]{6}{*}{ Relação Causal } & 0,9101 & V72 & ,7621 & ,8928 \\
\hline & & V73 & ,7523 &, 8943 \\
\hline & & V74 &, 8024 &, 8861 \\
\hline & & V75 &, 7313 &, 8967 \\
\hline & & V76 & ,7379 & ,8959 \\
\hline & & V77 & ,7216 & ,8979 \\
\hline \multirow[t]{10}{*}{ Equilíbrio } & 0,9441 & V78 & 5254 & ,9493 \\
\hline & & V79 & ,7950 & ,9370 \\
\hline & & V80 & ,8634 & ,9347 \\
\hline & & V81 & ,7510 & ,9390 \\
\hline & & V82 &, 8549 & ,9340 \\
\hline & & V83 &, 7463 & ,9392 \\
\hline & & V84 & ,7934 & ,9373 \\
\hline & & V85 &, 7424 & ,9394 \\
\hline & & V86 &, 7974 & ,9370 \\
\hline & & V87 & ,8495 & ,9343 \\
\hline \multirow[t]{12}{*}{ Análise Crítica } & 0,9667 & V88 & ,8934 & ,9620 \\
\hline & & V89 & ,8683 & ,9627 \\
\hline & & V90 & ,8698 & ,9626 \\
\hline & & V91 &, 8568 & ,9630 \\
\hline & & V92 & ,9022 & ,9617 \\
\hline & & V93 & ,6695 & ,9678 \\
\hline & & V94 &, 8216 & ,9640 \\
\hline & & V95 & ,7657 & ,9654 \\
\hline & & V96 & ,7142 & ,9667 \\
\hline & & V97 &, 8213 & ,9640 \\
\hline & & V98 &, 8580 & ,9630 \\
\hline & & V99 &, 8715 & ,9626 \\
\hline
\end{tabular}

Um recurso típico para a melhoria da fidedignidade seria a retirada de itens sem os quais eventualmente a fidedignidade de uma escala seria elevada. Observa-se que quatro dimensões 
teriam uma pequena melhoria com a retirada de algumas variáveis, conforme explicado no quadro 34:

\section{Quadro 34 - Melhoria da fidedignidade das dimensões}

\begin{tabular}{|l|c|l|}
\hline \multicolumn{1}{|c|}{ Dimensão } & $\begin{array}{c}\text { Com a } \\
\text { retirada de }\end{array}$ & Coeficiente passaria \\
\hline Aprendizado & V14 & de 0,9340 para 0,9365 \\
\hline Dinamismo & V31 & de 0,9668 para 0,9669 \\
\hline Equilíbrio & V78 & de 0,9441 para 0,9493 \\
\hline Análise Crítica & V93 & de 0,9667 para 0,9678 \\
\hline
\end{tabular}

Decidiu-se pela manutenção de tais variáveis devido a dois aspectos:

- $\quad$ os coeficientes de correlação corrigida item-total são expressivos nas quatro variáveis: 0,5734; 0,6390; 0,5254; 0,6695;

- o impacto no coeficiente de Cronbach destas dimensões com as retiradas de tais variáveis seria muito pequeno, não justificando sua remoção.

Assim, os coeficientes de Cronbach obtidos corroboram a adequação da construção das nove dimensões que abrangem as principais variáveis de interesse e de análise neste trabalho, podendo-se afirmar que as nove dimensões (atributos normativos) podem ser consideradas fidedignas. Logo, a hipótese $\mathrm{H}_{0}$ foi rejeitada em todas as dimensões.

\subsubsection{Validade do construto}

Segundo Selltiz et al (1987, p. 4) uma pesquisa possui validade de construto quando identifica ou nomeia adequadamente as variáveis em estudo. De acordo com Hair et al (2005, p. 112), validade é o grau em que uma escala ou um conjunto de medidas representa com precisão o conceito de interesse. Para Aaker et al (1995) validade de um instrumento de mensuração é a extensão em que diferenças nos escores observados refletem diferenças verdadeiras entre objetos na característica sendo medida, e não erros sistemáticos ou aleatórios. A avaliação da validade de um construto pode ser realizada por meio do cálculo da correlação de suas 
medidas com a de outro construto que supostamente seja com ele fortemente associado. $\mathrm{O}$ exame da validade foi feito com a técnica de regressão linear múltipla.

Primeiramente, aplicou-se a técnica de análise fatorial em cada uma das nove dimensões de gestão de processos a fim de se reduzir o número de variáveis em cada uma para apenas um fator. Para os nove fatores obtidos calcularam-se os escores fatoriais. Para Hair et al (2005, p. 90), o escore fatorial é uma medida composta criada para cada observação sobre cada fator extraído na análise fatorial, podendo ser utilizado para representar os fatores em análises subseqüentes.

Na tabela 10 encontram-se informações sobre alguns indicadores de qualidade de ajuste das nove análises fatoriais processadas.

Tabela 10 - Resultados das análises fatoriais

\begin{tabular}{lcccc}
\hline \multicolumn{1}{c}{ Dimensão } & KMO & Bartlett's Test & $\begin{array}{c}\text { Sig para } \\
\text { Bartlett's Test }\end{array}$ & $\begin{array}{c}\text { \% Variância } \\
\text { explicada }\end{array}$ \\
\hline Aprendizado & 0.890 & 905,651 & 0,000 & 61,805 \\
\hline Clareza & 0,937 & 1601,860 & 0,000 & 70,166 \\
\hline Dinamismo & 0,931 & 1844,057 & 0,000 & 67,151 \\
\hline Integração & 0,807 & 400,540 & 0,000 & 71,548 \\
\hline Alinhamento & 0,915 & 1813,305 & 0,000 & 69,541 \\
\hline Participação & 0,838 & 551,807 & 0,000 & 72,027 \\
\hline Relação Causal & 0,798 & 499,090 & 0,000 & 69,234 \\
\hline Equilíbrio & 0,897 & 1022,023 & 0,000 & 67,604 \\
\hline Análise Crítica & 0,922 & 1663,001 & 0,000 & 73,456 \\
\hline
\end{tabular}

Todos os resultados apresentados indicam adequação do emprego da técnica análise fatorial e da obtenção de um fator para cada dimensão.

A medida de Kaiser - Meyer - Olkin (KMO) é o índice que compara as correlações totais entre pares de variáveis com as correlações parciais entre os pares. Quanto mais próxima esta medida estiver de um, maior a qualidade da análise fatorial. O menor valor obtido corresponde à dimensão relação causal $(0,798)$ e é bem próximo de 0,8 , sendo, portanto, 
aceitável segundo a classificação em faixas de medidas de Kaiser (1974, p. 31-36), conforme quadro 35:

\section{Quadro 35 - Qualidade da análise fatorial}

\begin{tabular}{|l|l|}
\hline \multicolumn{1}{|c|}{ Valor } & \multicolumn{1}{c|}{ Análise } \\
\hline maior ou igual a 0,9 & ótima \\
\hline maior ou igual a 0,8 e abaixo de 0,9 & confiável \\
\hline maior ou igual a 0,7 e abaixo de 0,8 & regular \\
\hline maior ou igual a 0,6 e abaixo de 0,7 & medíocre \\
\hline maior ou igual a 0,5 e abaixo de 0,6 & sem valor \\
\hline abaixo de 0,5 & inaceitável \\
\hline
\end{tabular}

O teste de esfericidade de Bartlett permite testar as seguintes hipóteses:

$\mathrm{H}_{0}$ : a matriz de correlação é uma matriz identidade

$\mathrm{H}_{1}$ : a matriz de correlação não é uma matriz identidade

A expectativa era rejeitar $\mathrm{H}_{0}$ para sinalizar a adequação do uso da análise fatorial. Tal hipótese foi rejeitada nas nove dimensões.

A porcentagem da variância explicada por fator (antes e depois da rotação dos fatores) é uma medida síntese, indicando o quanto da variância total das variáveis originais o fator representa. Reflete a importância de cada fator na substituição das variáveis quanto ao índice de informações preservadas. Em todas as dimensões houve resultados satisfatórios, variando de $61,805 \%$ (Aprendizado) a 73,456\% (Análise Crítica).

$\mathrm{Na}$ avaliação da validade dos construtos do gerenciamento de macro-processos os escores fatoriais das nove dimensões foram considerados como variáveis independentes. Cada gestor avaliou, de um modo geral, o gerenciamento de um macro-processo específico (variável v100). Esta avaliação foi utilizada como variável dependente na análise de regressão múltipla. Foram formuladas as seguintes hipóteses:

$\mathrm{H}_{0,19}$ : Não há uma relação linear entre a avaliação geral do gerenciamento do macro-processo e as nove dimensões.

$\mathrm{H}_{1,19}$ : Há uma relação linear entre a avaliação geral do gerenciamento do macro-processo e as nove dimensões. 
Para cada dimensão foram formuladas as seguintes hipóteses:

$\mathrm{H}_{0,20}$ : Não há influência da dimensão aprendizado em uma relação linear entre a avaliação geral do gerenciamento do macro-processo e as nove dimensões.

$\mathrm{H}_{1,20}$ : Há influência da dimensão aprendizado em uma relação linear entre a avaliação geral do gerenciamento do macro-processo e as nove dimensões.

$\mathrm{H}_{0,21}$ : Não há influência da dimensão clareza em uma relação linear entre a avaliação geral do gerenciamento do macro-processo e as nove dimensões.

$\mathrm{H}_{1,21}$ : Há influência da dimensão clareza em uma relação linear entre a avaliação geral do gerenciamento do macro-processo e as nove dimensões.

$\mathrm{H}_{0,22}$ : Não há influência da dimensão dinamismo em uma relação linear entre a avaliação geral do gerenciamento do macro-processo e as nove dimensões.

$\mathrm{H}_{1,22}$ : Há influência da dimensão dinamismo em uma relação linear entre a avaliação geral do gerenciamento do macro-processo e as nove dimensões.

$\mathrm{H}_{0,23}$ : Não há influência da dimensão integração em uma relação linear entre a avaliação geral do gerenciamento do macro-processo e as nove dimensões.

$\mathrm{H}_{1,23}$ : Há influência da dimensão integração em uma relação linear entre a avaliação geral do gerenciamento do macro-processo e as nove dimensões.

$\mathrm{H}_{0,24}$ : Não há influência da dimensão alinhamento em uma relação linear entre a avaliação geral do gerenciamento do macro-processo e as nove dimensões.

$\mathrm{H}_{1,24}$ : Há influência da dimensão alinhamento em uma relação linear entre a avaliação geral do gerenciamento do macro-processo e as nove dimensões.

$\mathrm{H}_{0,25}$ : Não há influência da dimensão participação em uma relação linear entre a avaliação geral do gerenciamento do macro-processo e as nove dimensões.

$\mathrm{H}_{1,25}$ : Há influência da dimensão participação em uma relação linear entre a avaliação geral do gerenciamento do macro-processo e as nove dimensões.

$\mathrm{H}_{0,26}$ : Não há influência da dimensão relação causal em uma relação linear entre a avaliação geral do gerenciamento do macro-processo e as nove dimensões.

$\mathrm{H}_{1,26}$ : Há influência da dimensão relação causal em uma relação linear entre a avaliação geral do gerenciamento do macro-processo e as nove dimensões.

$\mathrm{H}_{0,27}$ : Não há influência da dimensão equilíbrio em uma relação linear entre a avaliação geral do gerenciamento do macro-processo e as nove dimensões.

$\mathrm{H}_{1,27}$ : Há influência da dimensão equilíbrio em uma relação linear entre a avaliação geral do gerenciamento do macro-processo e as nove dimensões.

$\mathrm{H}_{0,28}$ : Não há influência da dimensão análise crítica em uma relação linear entre a avaliação geral do gerenciamento do macro-processo e as nove dimensões.

$\mathrm{H}_{1,28}$ : Há influência da dimensão análise crítica em uma relação linear entre a avaliação geral do gerenciamento do macro-processo e as nove dimensões. 
Considerando-se todas as análises realizadas neste estudo, chegou-se a 28 testes de hipóteses. Na tabela 11 constam os resultados dos processamentos realizados.

Tabela 11 - Resultados da análise de regressão múltipla

\begin{tabular}{|c|c|c|c|c|c|c|c|}
\hline Dimensão & $\begin{array}{r}\text { Coefi } \\
\text { Regr } \\
\text { Padro }\end{array}$ & & $\begin{array}{c}\text { Estatística } \\
t\end{array}$ & \multicolumn{2}{|l|}{ Sig.de $t$} & Tolerância & VIF \\
\hline Aprendizado &, 117 & $5^{\circ}$ & 1,168 & 246 & & ,247 & 4,051 \\
\hline Clareza & ,074 & & 476 & ,636 & & ,103 & 9,732 \\
\hline Dinamismo &, 120 & $4^{\circ}$ & ,813 & ,419 & & ,113 & 8,845 \\
\hline Integração & ,039 & & ,429 & ,669 & & ,304 & 3,290 \\
\hline Alinhamento & ,016 & &, 132 & 896 & &, 160 & 6,234 \\
\hline Participação &, 129 & $3^{\circ}$ & ,985 & 327 & & ,143 & 6,986 \\
\hline Relação Causal & ,231 & $2^{\circ}$ & 1,976 &, 052 & $1^{\circ}$ & ,181 & 5,538 \\
\hline Equilíbrio &,- 010 & &,- 073 & ,942 & &, 129 & 7,750 \\
\hline Análise Crítica & ,283 & $1^{\circ}$ & 1,917 & 059 & $2^{\circ}$ &, 113 & 8,845 \\
\hline \multicolumn{3}{|c|}{ Valor de $\mathbf{R}^{2}=0,802$} & $\mathbf{F}=36$, & \multicolumn{4}{|c|}{$\operatorname{Sig} \mathbf{F}=0,000$} \\
\hline
\end{tabular}

A aferição da importância relativa de cada dimensão deve ser precedida pela verificação da magnitude da multicolinearidade entre as variáveis independentes. Uma medida para esta análise é o fator de inflação de variância - VIF, cujo inverso é a tolerância. Hair et al (2005, p.167) enfatizam que um VIF acima de 10 (equivalente a uma tolerância abaixo de 0,10) exprime uma colinearidade alta. Neste estudo, nenhum VIF ultrapassou o valor 10 (o maior valor obtido é 9,732 para a dimensão clareza). Portanto, a multicolinearidade é de grau moderado, não causando nenhuma distorção nos resultados.

$\mathrm{O}$ coeficiente de determinação $\mathrm{R}^{2}=0,802$ indica que as nove dimensões explicam uma expressiva proporção da variância da avaliação global da gestão de processos. Este resultado, juntamente com o teste $\mathrm{F}$, evidencia uma relação linear entre a avaliação da gestão de processos e os escores fatoriais das nove dimensões. Portanto, rejeita-se $\mathrm{H}_{0,19}$ e confirma-se a validade do construto destas dimensões.

$\mathrm{Na}$ análise específica de cada dimensão observa-se que apenas Relação Causal e Análise Crítica apresentam influência estatisticamente significante sobre a avaliação global. Considerando-se os coeficientes padronizados, as dimensões que mais contribuem para a avaliação do desempenho dos gestores segundo a ordem de importância são: Análise Crítica, Relação Causal, Participação, Dinamismo e Aprendizado. 


\subsubsection{Dimensionalidade}

Hair et al (2005, p. 111) recomendam que as variáveis estejam fortemente associadas, umas com as outras, e representem um só conceito. Para isso, a análise fatorial pode ser utilizada para a avaliação empírica da dimensionalidade de um conjunto de itens, pela determinação do número de fatores e das cargas fatoriais de cada variável nestes fatores.

Contudo, esta análise partindo-se das 94 variáveis (v5 a v99 menos v8) a fim de se formarem os nove fatores, correspondentes às nove dimensões criadas, não foi possível de ser efetuada devido à desproporção da amostra total para com o número de parâmetros exigidos para a aplicação da análise fatorial. Segundo Hair et al (2005, p. 98) exigem-se um mínimo de cinco vezes mais observações do que o número de variáveis a serem analisadas, o que exigiria um total mínimo de 470 observações.

\subsection{Análise Multivariada dos Dados - Relação entre Gestores e Processos}

A relação entre gestores do PNAFE, suas características de função exercida no programa (alta gerência ou média gerência) e região no Brasil a que pertencem (estado de São Paulo ou demais estados) com os macro-processos de BPM que estiveram sob sua responsabilidade, supervisão ou acompanhamento, foram obtidas com a aplicação de três técnicas estatísticas de análise multivariada de dados: a análise multivariada de variância (MANOVA), a regressão logística e o escalonamento multidimensional.

A descrição dos procedimentos adotada em cada uma das técnicas estatísticas é explicada a seguir. Antes, porém, foi verificada a distribuição normal multivariada, com o cálculo do coeficiente $p k$ de Mardia.

\subsubsection{Distribuição Normal Multivariada}

De acordo com Hair et al (2005, p. 287), a normalidade multivariada considera que o efeito conjunto de duas variáveis é distribuído normalmente e que um recurso da maioria das pesquisas é testar a normalidade univariada de cada variável, conforme foi descrito no item 5.1.3.1. Apesar de a normalidade univariada não garantir a multivariada, se todas as variáveis 
atendem a esta condição, então quaisquer desvios da normalidade multivariada geralmente são inócuos, acrescentam Hair et al (2005, p. 287).

Ainda assim, foram formuladas as seguintes hipóteses para a distribuição normal multivariada:

$\mathrm{H}_{0}$ : o conjunto de variáveis da dimensão aprendizado apresenta normalidade multivariada

$\mathrm{H}_{1}$ : o conjunto de variáveis da dimensão aprendizado não apresenta normalidade multivariada

E da mesma maneira se procedeu para as demais dimensões.

Ao aplicar o teste para o cálculo do coeficiente $p k$ de Mardia, para as variáveis de cada uma das dimensões do SMD-BPM, com o uso do software Lisrel, v. 8.51, foram obtidos os seguintes resultados, conforme tabela 12 :

Tabela 12 - Normalidade Multivariada para as variáveis das dimensões do SMD-BPM

\begin{tabular}{lrrrrrrrr}
\hline \multirow{2}{*}{ Dimensão } & \multicolumn{3}{c}{ Assimetria } & \multicolumn{3}{c}{ Curtose } & \multicolumn{2}{c}{ Assimetria e Curtose } \\
\cline { 2 - 9 } & Value & Z-Score & P-Value & Value & Z-Score & P-Value & Chi $^{2}$ & P-Value \\
\hline Aprendizado & 31923 & 9837 & 0,000 & 170664 & 5954 & 0,000 & 132212 & 0,000 \\
\hline Clareza & 79996 & 18593 & 0,000 & 292178 & 8813 & 0,000 & 423376 & 0,000 \\
\hline Dinamismo & 95575 & 17597 & 0,000 & 340925 & 7443 & 0,000 & 365069 & 0,000 \\
\hline Integração & 13485 & 11898 & 0,000 & 53389 & 6158 & 0,000 & 179475 & 0,000 \\
\hline Alinhamento & 93050 & 23463 & 0,000 & 304252 & 9773 & 0,000 & 646015 & 0,000 \\
\hline Participação & 20373 & 14516 & 0,000 & 77377 & 7474 & 0,000 & 266578 & 0,000 \\
\hline Rel. Causal & 12878 & 10216 & 0,000 & 63663 & 5392 & 0,000 & 133444 & 0,000 \\
\hline Equilíbrio & 30841 & 12055 & 0,000 & 150805 & 6604 & 0,000 & 188923 & 0,000 \\
\hline Anal. Crítica & 53912 & 17024 & 0,000 & 220714 & 8385 & 0,000 & 360133 & 0,000 \\
\hline
\end{tabular}

Como se pôde observar, todas as hipóteses $\mathrm{H}_{0}$ foram rejeitadas, a qualquer nível de significância, em desacordo com a expectativa inicial de não rejeição. Contudo, Hair et al (2005, p. 287) asseguram que para amostras de tamanho moderado, como o caso em tela, violações modestas podem ser acomodadas, desde que as diferenças sejam decorrentes de assimetrias e não de observações atípicas. 
Por conseguinte, ao considerar os dois aspectos tolerados pelos autores, quais sejam, o fato de as distribuições univariadas apresentarem normalidade, bem como o tamanho modesto da amostra, entendendo neste caso que todas as observações atípicas foram expurgadas, a decisão do pesquisador foi pela continuidade da aplicação das técnicas de análise multivariada.

\subsubsection{Análise Multivariada de Variância - MANOVA}

De acordo com Hair et al (2005, p. 271-272) a análise multivariada de variância é uma técnica de dependência que compara as diferenças para duas ou mais variáveis dependentes métricas, com base num conjunto de variáveis não-métricas que atuam como independentes. Para os autores, a MANOVA é uma extensão da análise de variância - ANOVA, a fim de acomodar mais uma variável dependente. É utilizada para avaliar diferenças de grupos, simultaneamente, ao longo de múltiplas variáveis dependentes métricas.

Hair et al (2005, p. 286) recomendam que para os procedimentos do teste multivariado de MANOVA serem válidos, três suposições devem ser atendidas:

a) as observações devem ser independentes;

b) as matrizes de variância-covariância devem ser iguais para todos os grupos de tratamento;

c) o conjunto de variáveis dependentes deve seguir uma distribuição normal multivariada.

Assim sendo, o objetivo da MANOVA é reduzir a variância interna dos grupos, sendo que as suposições básicas do modelo, tais como homogeneidade das matrizes de variância e covariância nos grupos, são verificadas pelo Teste Box's M; e a correlação das medidas dependentes é verificada pelo Teste de esfericidade de Bartlett. Já o Levene's Test pretende verificar a igualdade de variâncias por variável dependente, complementando o Teste Box's $M$ que é um teste coletivo.

As seções 5.3.2.1 a 5.3.2.7 apresentam os testes e os conceitos estatísticos que constituem a essência da MANOVA. 


\subsubsection{Teste Box'M}

As hipóteses geradas para o Teste Box's M foram:

$\mathrm{H}_{0,29}$ : As variâncias das variáveis da dimensão aprendizado são coletivamente iguais nos grupos

$\mathrm{H}_{1,29}$ : As variâncias das variáveis da dimensão aprendizado não são coletivamente iguais nos grupos

E da mesma forma foram geradas as hipóteses $\mathrm{H}_{0,30}$ a $\mathrm{H}_{0,37}$ e $\mathrm{H}_{1,30}$ a $\mathrm{H}_{1,37}$ para as demais dimensões. A expectativa é não rejeitar a hipótese $\mathrm{H}_{0}$, ao nível de significância de $5 \%$.

Os grupos constantes das hipóteses referem-se às funções de Alta e Média Gerência e às regiões estado de São Paulo e demais Estados.

\subsubsection{Teste de esfericidade de Bartlett}

As hipóteses geradas para o Teste de esfericidade de Bartlett foram:

$\mathrm{H}_{0,38}$ : A matriz de correlações das variáveis da dimensão aprendizado é igual à matriz identidade

$\mathrm{H}_{1,38}$ : A matriz de correlações das variáveis da dimensão aprendizado é diferente da matriz identidade

E da mesma forma foram geradas as hipóteses $\mathrm{H}_{0,39}$ a $\mathrm{H}_{0,46}$ e $\mathrm{H}_{1,39}$ a $\mathrm{H}_{1,46}$ para as demais dimensões. A expectativa é rejeitar a hipótese $\mathrm{H}_{0}$, ao nível de significância de 5\%.

\subsubsection{Levene's Test}

Para Hair et al (2005, p. 79) é o teste que verifica a homoscedasticidade. As hipóteses geradas foram:

$\mathrm{H}_{0,47}$ : As variâncias das variáveis da dimensão aprendizado são iguais nos grupos

$\mathrm{H}_{1,47}$ : As variâncias das variáveis da dimensão aprendizado não são iguais nos grupos

E da mesma maneira foram geradas as hipóteses $\mathrm{H}_{0,48}$ a $\mathrm{H}_{0,55}$ e $\mathrm{H}_{1,48}$ a $\mathrm{H}_{1,55}$ para as demais dimensões. A expectativa é não rejeitar a hipótese $\mathrm{H}_{0}$, ao nível de significância de $5 \%$. 


\subsubsection{Stepdown Test}

Segundo Hair et al (2005, p. 292), a análise Stepdown pode ser usada para avaliar individualmente as diferenças das variáveis dependentes. Este teste procura ver a contribuição parcial de uma variável dependente na presença de outra. Ou seja, procura expurgar a correlação entre elas ou verificar se a correlação entre elas está em um nível aceitável, semelhante à análise da multicolinearidade das variáveis independentes na regressão múltipla.

O Stepdown Test é um procedimento que testa se uma variável dependente contribui com informações únicas para as diferenças nos grupos após a inclusão de suas antecessoras. As variáveis são significantemente diferentes nos grupos após o controle de sua intercorrelação. O teste é útil ainda para identificar redundâncias de uso de variáveis.

As variáveis que mais contribuíram com características próprias para os contrastes entre alta e média gerência (Função), bem como gestores de São Paulo e dos demais estados da federação (Região) foram as que apresentaram valores de significância $F$ menores ou iguais a 0,10 no Roy-Bargman Stepdown F Test.

Como o Stepdown Test não pode ser acionado diretamente pelo menu do software SPSS, recorreu-se a um algoritmo cuja sintaxe utilizada para a dimensão Aprendizado em relação à Função dos gestores está apresentada na figura 10, a seguir:

MANOVA V5 TO V16 BY FUNÇÃO $(1,2)$
/ PRINT SIGNIF (MULTI UNIV STEPDOWN)
/ POWER T(.05) F(.05)
/ METHOD=UNIQUE / ERROR WITHIN+RESIDUAL
/ DESIGN.

Figura 10 - Sintaxe Stepdown Test dimensão Aprendizado x Função

A Função 1 corresponde à Alta Gerência e Função 2 à Média Gerência. E para a dimensão Aprendizado em relação à Região a que pertencem os gestores, considerando Região 0 os Demais Estados e Região 1 o estado de São Paulo, substituiu-se a primeira linha de comando pela expressão da figura 11: 


MANOVA V5 TO V16 BY REGIÃO $(0,1)$
/ PRINT SIGNIF (MULTI UNIV STEPDOWN)
/ POWER T(.05) F(.05)
/ METHOD=UNIQUE / ERROR WITHIN+RESIDUAL
/ DESIGN.

Figura 11 - Sintaxe Stepdown Test dimensão Aprendizado x Região

As hipóteses geradas considerando as variáveis da dimensão Aprendizado e as variáveis de Função e Região foram:

$\mathrm{H}_{0,56}$ : A inclusão das variáveis da dimensão aprendizado na presença da variável função não melhora o modelo $\mathrm{H}_{1,56}$ : A inclusão das variáveis da dimensão aprendizado na presença da variável função melhora o modelo

$\mathrm{H}_{0,65}$ : A inclusão das variáveis da dimensão aprendizado na presença da variável região não melhora o modelo $\mathrm{H}_{1,65}$ : A inclusão das variáveis da dimensão aprendizado na presença da variável região melhora o modelo

Da mesma maneira foram geradas as hipóteses $\mathrm{H}_{0,57}$ a $\mathrm{H}_{0,64}$ e $\mathrm{H}_{1,57}$ a $\mathrm{H}_{1,64}$ para as demais dimensões em relação à variável Função e $\mathrm{H}_{0,66}$ a $\mathrm{H}_{0,73}$ e $\mathrm{H}_{1,66}$ a $\mathrm{H}_{1,73}$ para as demais dimensões em relação à variável Região. A expectativa é rejeitar $\mathrm{H}_{0}$ para significância de 5\%, a fim de que as variáveis incluídas possam ampliar a qualidade do modelo.

\subsubsection{Mean's Test}

O teste da hipótese de igualdade das médias compara a variância dentro dos grupos com a variância total. O Mean's Test tem como propósito avaliar as diferenças das variáveis nos grupos de forma coletiva, segundo quatro critérios: Pillai's Trace, Wilks'Lambda, Hotelling's Trace, Roy's Largest Root. As hipóteses geradas foram:

$\mathrm{H}_{0}$ : Os vetores médios das variáveis dependentes nos grupos são iguais

$\mathrm{H}_{1}$ : Os vetores médios das variáveis dependentes nos grupos não são iguais

Ou seja, as hipóteses considerando as variáveis da dimensão Aprendizado e a variável Função, e depois da dimensão Aprendizado para a variável Região foram: 
$\mathrm{H}_{0,74}$ : As variáveis da dimensão aprendizado combinadas variam nas diferentes situações da variável função

$\mathrm{H}_{1,74}$ : As variáveis da dimensão aprendizado combinadas não variam nas diferentes situações da variável função

$\mathrm{H}_{0,83}$ : As variáveis da dimensão aprendizado combinadas variam nas diferentes situações da variável região $\mathrm{H}_{1,83}$ : As variáveis da dimensão aprendizado combinadas não variam nas diferentes situações da variável região

E assim sucessivamente para as demais dimensões em relação à variável Função $\mathrm{H}_{0,75}$ a $\mathrm{H}_{0,82}$ e $\mathrm{H}_{1,75}$ a $\mathrm{H}_{1,82}$, e à variável Região as hipóteses $\mathrm{H}_{0,84}$ a $\mathrm{H}_{0,91}$ e $\mathrm{H}_{1,84}$ a $\mathrm{H}_{1,91}$. O interessante neste caso é rejeitar $\mathrm{H}_{0}$ ao nível de significância de $5 \%$.

\subsubsection{Teste Between-Subjects}

Este teste procura identificar qual das variáveis dependentes das dimensões é mais sensível à variável independente Função ou Região. Nele é realizada a avaliação do poder estatístico que é definido como a probabilidade de o teste estatístico identificar o efeito do tratamento (Rejeitar $\mathrm{H}_{0}$ ), quando este existe de fato. $\mathrm{O}$ tamanho do efeito é dado pelas diferenças nas médias nos grupos divididas pelo desvio-padrão. A estatística Obs Power trata-se de um complemento do Mean's Test e considera a probabilidade de rejeitar $\mathrm{H}_{0}$, sendo ela de fato falsa. O nível suficiente do poder estatístico é de no mínimo 0,80. As hipóteses foram:

$\mathrm{H}_{0,92}$ : As variáveis dependentes da dimensão aprendizado não são sensíveis à variável independente função $\mathrm{H}_{1,92}$ : As variáveis dependentes da dimensão aprendizado são sensíveis à variável independente função

$\mathrm{H}_{0,101}$ : As variáveis dependentes da dimensão aprendizado não são sensíveis à variável independente região $\mathrm{H}_{1,101}$ : As variáveis dependentes da dimensão aprendizado são sensíveis à variável independente região

E assim, para as demais dimensões foram geradas as hipóteses $\mathrm{H}_{0,93}$ a $\mathrm{H}_{0,100}$ e $\mathrm{H}_{1,93}$ a $\mathrm{H}_{1,100}$ para Função e $\mathrm{H}_{0,102}$ a $\mathrm{H}_{0,109}$ e $\mathrm{H}_{1,102}$ a $\mathrm{H}_{1,109}$ para Região. A expectativa nestes casos é rejeitar $\mathrm{H}_{0}$ ao nível de significância de 5\%.

\subsubsection{Hipóteses do modelo MANOVA}

As hipóteses do modelo MANOVA para as variáveis dependentes da dimensão Aprendizado e variável independente Função constam da figura 12: 
$\mathrm{H}_{0}:\left[\begin{array}{l}\mu_{v 5, \text { Função 1 }} \\ \mu_{v 6, \text { Função 1 }} \\ \cdots \\ \mu_{v 16, \text { Função 1 }}\end{array}\right]=\left[\begin{array}{l}\mu_{v 5, \text { Função 2 }} \\ \mu_{v 6, \text { Função 2 }} \\ \cdots \\ \mu_{v 16, \text { Função 2 }}\end{array}\right]$

onde $\mu=$ média;

v5 a v16 (exceto v8) são variáveis da dimensão Aprendizado;

e Função 1= Alta Gerência e Função 2= Média Gerência.

$\mathrm{H}_{1}$ : Existe pelo menos uma desigualdade entre os dois vetores

\section{Figura 12 - Hipóteses modelo MANOVA Aprendizado x Função}

Analogamente foram geradas as hipóteses para as demais dimensões em relação à variável independente Função e para todas as dimensões em relação à variável Região, em que Região 0= Demais Estados e Região 1= São Paulo. Foram geradas ainda mais duas MANOVAs, considerando os Escores Fatoriais das dimensões como variáveis dependentes e as variáveis Função e Região como independentes, com as seguintes hipóteses:

$$
\begin{aligned}
& \mathrm{H}_{0}:\left[\begin{array}{l}
\mu_{\text {scapren ,Função 1 }} \\
\mu_{\text {scclar ,Função 1 }} \\
\cdots \\
\mu_{\text {sccrit ,Função 1 }}
\end{array}\right]=\left[\begin{array}{l}
\mu_{\text {scapren ,Função 2 }} \\
\mu_{\text {scclar ,Função 2 }} \\
\cdots \\
\mu_{\text {sccrit ,Função 2 }}
\end{array}\right] \\
& \text { onde } \mu=\text { média; } \\
& \text { scapren, scclar, ..., sccrit são os Escores Fatoriais das dimensões; } \\
& \text { e Função 1= Alta Gerência e Função 2= Média Gerência. }
\end{aligned}
$$

Figura 13 - Hipóteses modelo MANOVA Escores Fatoriais x Função

A figura 13 mostra as hipóteses da MANOVA geradas para os escores fatoriais das dimensões em relação à Função dos gestores. De maneira análoga, substituindo-se as Funções 1 e 2 pelas Regiões 0 e 1, foram geradas as hipóteses da MANOVA para os escores fatoriais das 
dimensões em relação à variável Região. Neste trabalho, portanto, foi aplicado um total de vinte MANOVAs, classificadas da seguinte maneira:

a) Nove MANOVAs com variáveis independentes geradas a partir da Função dos entrevistados no PNAFE e variáveis dependentes que compunham o rol de variáveis de cada dimensão;

b) Nove MANOVAs com variáveis independentes geradas a partir da Região a que pertenciam os entrevistados no PNAFE e variáveis dependentes que compunham o rol de variáveis de cada dimensão;

c) Duas MANOVAs com variáveis independentes geradas a partir da Região a que pertenciam os entrevistados no PNAFE e a partir das suas Funções e como variáveis dependentes os Escores Fatoriais das nove dimensões.

\subsubsection{Principais resultados das MANOVAs}

Os dados dos principais resultados das saídas do SPSS após a aplicação das MANOVAs encontram-se resumidos na tabela 13 - Resumo MANOVAs Escores Fatoriais e na tabela 14 - Resumo MANOVAs Dimensões, a seguir dispostas:

Tabela 13 - Resumo MANOVAs nos Escores Fatoriais

\begin{tabular}{|c|c|c|c|c|c|c|c|c|c|c|c|}
\hline Dimensão & V Ind. & Box'M & Bartlett & \multicolumn{2}{|c|}{ Stepdown } & \multicolumn{2}{|c|}{ Levene's } & \multicolumn{2}{|c|}{ Between Subj } & \multirow{2}{*}{$\frac{\text { Mean's }}{0,016}$} & \multirow{2}{*}{$\frac{\text { Power }}{0,903}$} \\
\hline \multirow{5}{*}{$\begin{array}{l}\text { Escores } \\
\text { Fatoriais }\end{array}$} & \multirow[t]{3}{*}{ Função } & \multirow{3}{*}{0,000} & \multirow{3}{*}{0,000} & scclar &, 001 & sccau & ,930 & \multirow[t]{3}{*}{-} & \multirow[t]{3}{*}{-} & & \\
\hline & & & & sccau &, 012 & scdin & ,926 & & & & \\
\hline & & & & - & - & scequi & ,917 & & & & \\
\hline & \multirow[t]{2}{*}{ Região } & \multirow[t]{2}{*}{0,000} & \multirow[t]{2}{*}{0,000} & scclar & ,007 & scequi & ,893 & \multirow[t]{2}{*}{-} & \multirow[t]{2}{*}{ - } & \multirow[t]{2}{*}{0,058} & \multirow[t]{2}{*}{0,803} \\
\hline & & & & sccau &, 009 & scpart &, 825 & & & & \\
\hline
\end{tabular}

\section{Legendas Tabelas 13 e 14}

Variável Ind. - Variável Independente

Box'M - Significância Box's M Test of Equality of Covariance Matrices

Bartlett's Test - Significância do Bartlett's Test of Sphericity

Stepdown - Variáveis que contribuíram no Stepdown Test

Levene's Test - Significância das variáveis no Levene's Test of Equality of Error Variances

Between Subj - Variáveis sensíveis ao Between-Subjects Test

Mean's Test - Valores de Pillai's Trace, Wilks'Lambda, Hotelling's Trace e Roy's Largest Root

Power - Valor do poder estatístico retirado do Observed Power em Multivariate Tests Effect 
Tabela 14 - Resumo MANOVAs nas Dimensões

\begin{tabular}{|c|c|c|c|c|c|c|c|c|c|c|c|}
\hline \multirow{2}{*}{$\begin{array}{l}\text { Dimensão } \\
\text { Aprendizado }\end{array}$} & \multirow{2}{*}{$\frac{\text { V. Ind. }}{\text { Função }}$} & \multirow{2}{*}{$\frac{\text { Box' }^{\prime} \mathbf{M}}{0,000}$} & \multirow{2}{*}{$\frac{\text { Bartlett }}{0,000}$} & \multicolumn{2}{|c|}{ Stepdown } & \multicolumn{2}{|c|}{ Levene's } & \multicolumn{2}{|c|}{ Between Subj } & \multirow{2}{*}{$\frac{\text { Mean's }}{0,044}$} & \multirow{2}{*}{$\frac{\text { Power }}{0,864}$} \\
\hline & & & & V12 & ,019 & V13 & ,738 & V6 & 0,050 & & \\
\hline & & & & V15 & ,066 & V16 & ,695 & & & & \\
\hline & & & & V6 & ,097 & V11 & ,599 & V12 & 0,039 & & \\
\hline & & & & V9 & ,099 & V9 & ,471 & & & & \\
\hline & Região & 0,000 & 0,000 & V12 &, 020 & V11 & ,953 & V12 & 0,020 & 0,164 & 0,722 \\
\hline & & & & V13 &, 057 & V13 & 919 & V6 & 0,051 & & \\
\hline \multirow[t]{6}{*}{ Clareza } & Função & 0,000 & 0,000 & V30 &, 044 & V24 & ,971 & V30 & 0,012 & 0,200 & 0,748 \\
\hline & & & & V24 & 051 & V23 & ,968 & V29 & 0,020 & & \\
\hline & & & & & & & & V24 & 0,038 & & \\
\hline & Região & 0,000 & 0,000 & V30 &, 025 & V27 & ,939 & V30 & 0,024 & 0,106 & 0,826 \\
\hline & & & & V21 & ,048 & V23 & ,937 & $\mathrm{V} 25$ & 0,052 & & \\
\hline & & & & V25 &, 076 & V19 & ,933 & & & & \\
\hline \multirow[t]{7}{*}{ Dinamismo } & Função & 0,000 & 0,000 & V44 &, 000 & V35 & ,947 & V38 & 0,006 & 0,000 & 0,997 \\
\hline & & & & V37 &, 004 & V36 & ,858 & V33 & 0,015 & & \\
\hline & & & & V33 &, 028 & V31 & ,833 & V39 & 0,050 & & \\
\hline & & & & V38 & ,041 & V44 & ,773 & & & & \\
\hline & Região & 0,000 & 0,000 & V44 & ,000 & V41 & ,894 & - & - & 0,013 & 0,960 \\
\hline & & & & V37 &, 012 & V31 & ,842 & & & & \\
\hline & & & & V33 &, 070 & V39 & ,828 & & & & \\
\hline \multirow[t]{2}{*}{ Integração } & Função & 0,000 & 0,000 & V48 & ,001 & V48 & ,437 & - & - & 0,008 & 0,883 \\
\hline & Região & 0,000 & 0,000 & V48 &, 015 & V48 & ,718 & - & - & 0,027 & 0,791 \\
\hline \multirow[t]{10}{*}{ Alinhamento } & Função & 0,000 & 0,000 & V55 & ,004 & V63 & 630 & V55 & 0,022 & 0,003 & 0,982 \\
\hline & & & & V58 & ,008 & V58 & ,549 & & & & \\
\hline & & & & V61 &, 010 & V55 & ,456 & & & & \\
\hline & & & & V65 & ,059 & - & - & & & & \\
\hline & & & & V60 &, 071 & - & - & & & & \\
\hline & Região & 0,000 & 0,000 & V65 & ,001 & V55 & ,842 & V55 & 0,051 & 0,000 & 0,999 \\
\hline & & & & V54 & ,002 & V60 & ,806 & & & & \\
\hline & & & & V58 & ,009 & V63 & ,775 & & & & \\
\hline & & & & V55 & ,018 & V58 &, 752 & & & & \\
\hline & & & & V61 & ,019 & V53 & ,739 & & & & \\
\hline \multirow[t]{2}{*}{ Participação } & Função & 0,000 & 0,000 & - & - & V70 & ,785 & - & - & 0,899 & 0,150 \\
\hline & Região & 0,000 & 0,000 & - & - & V70 & ,988 & - & - & 0,985 & 0,091 \\
\hline \multirow{6}{*}{$\begin{array}{l}\text { Relação } \\
\text { Causal }\end{array}$} & Função & 0,001 & 0,000 & V72 &, 026 & V72 & ,989 & V72 & 0,026 & 0,090 & 0,677 \\
\hline & & & & V75 &, 030 & V76 & ,795 & V73 & 0,033 & & \\
\hline & Região & 0,001 & 0,000 & V75 &, 003 & V72 & ,991 & V73 & 0,003 & 0,001 & 0,973 \\
\hline & & & & V73 &, 022 & V76 &, 724 & V77 & 0,003 & & \\
\hline & & & & V77 &, 026 & V75 & ,549 & V74 & 0,029 & & \\
\hline & & & & V72 & ,067 & & & & & & \\
\hline \multirow[t]{4}{*}{ Equilíbrio } & Função & 0,000 & 0,000 & V80 &, 000 & V82 & ,859 & - & - & 0,014 & 0,921 \\
\hline & & & & V85 &, 074 & V86 & ,796 & & & & \\
\hline & Região & 0,000 & 0,000 & V80 &, 000 & V83 & ,982 & - & - & 0,003 & 0,968 \\
\hline & & & & V85 & ,096 & V82 & ,891 & & & & \\
\hline \multirow{9}{*}{$\begin{array}{l}\text { Análise } \\
\text { Crítica }\end{array}$} & Função & 0,000 & 0,000 & V90 &, 020 & V96 & ,981 & - & - & 0,010 & 0,949 \\
\hline & & & & V89 &, 014 & V97 & ,766 & & & & \\
\hline & & & & V97 &, 035 & V91 & ,652 & & & & \\
\hline & & & & V94 &, 072 & V90 & ,529 & & & & \\
\hline & & & & V93 & , 101 & & & & & & \\
\hline & Região & 0,000 & 0,000 & V94 &, 003 & V96 & ,984 & - & - & 0,018 & 0,927 \\
\hline & & & & V93 & ,051 & V99 & ,932 & & & & \\
\hline & & & & V89 & ,066 & V98 & ,924 & & & & \\
\hline & & & & V97 & ,067 & V88 &, 823 & & & & \\
\hline
\end{tabular}


Baseado nas hipóteses geradas pelos testes em relação aos resultados obtidos, pôde-se concluir que:

a) para o Box'M Test, as hipóteses $\mathrm{H}_{0}$ de todas as dimensões do SMD-BPM e da dimensão dos escores fatoriais foram rejeitadas, significando que as variâncias das variáveis em cada dimensão não são iguais ao longo dos grupos;

b) para o Teste de esfericidade de Bartlett, as hipóteses $\mathrm{H}_{0}$ de todas as dimensões do SMDBPM e da dimensão dos escores fatoriais também foram rejeitadas, significando que a matriz de correlações das variáveis de cada dimensão é diferente da matriz identidade;

c) no Levene's Test, as variáveis que constam das tabelas 13 e 14 foram as que mais contribuíram para a não rejeição de $\mathrm{H}_{0}$, que era a expectativa do teste;

d) no Stepdown Test, as variáveis que constam das tabelas 13 e 14 foram as que, uma vez incluídas na presença das variáveis Função e Região, mais contribuíram para o aperfeiçoamento do modelo, rejeitando assim $\mathrm{H}_{0}$. Apenas as variáveis da dimensão Participação na presença das variáveis Função e Região não contribuíram para a melhoria do modelo, sendo as únicas nas quais ocorreu a não rejeição de $\mathrm{H}_{0}$;

e) o teste da igualdade das médias, ou Mean's Test, busca saber se as variáveis das dimensões do SMD-BPM combinadas não variam nas diferentes situações das variáveis Função e Região. De acordo com os dados das tabelas 13 e 14, a $\mathrm{H}_{0}$ foi rejeitada na maior parte dos casos, excetuando-se nas relações: Aprendizado-Região, ClarezaFunção e Clareza-Região, Participação-Função e Participação-Região, Relação CausalFunção e Escores Fatoriais-Região;

f) A estatística Obs Power, relativa ao nível mínimo de poder estatístico de 0,80, também aconteceu na maioria das situações, excetuando-se mais significativamente nas relações Participação-Função, Participação-Região e Relação Causal-Função. Já nas relações Aprendizado-Região, Clareza-Função e Integração-Região os valores do poder estatístico ficaram abaixo do mínimo, porém bem próximos de 0,80 ; 
g) Com relação ao teste Between Subjects, constam da tabela 14 as variáveis pertencentes às dimensões que se mostraram sensíveis às variáveis Função e Região chegando-se à rejeição da hipótese $\mathrm{H}_{0}$. Nas relações Dinamismo-Região, Integração-Função e Integração-Região, Participação-Função e Participação-Região, Equilíbrio-Função e Equilíbrio-Região, Análise Crítica-Função e Análise Crítica-Região, Escores FatoriaisFunção e Escores Fatoriais-Região (tabela 46), a hipótese $\mathrm{H}_{0}$ não foi rejeitada, entendendo-se nestes casos que nenhuma das variáveis de suas dimensões se mostrou sensível às variáveis Função ou Região, conforme o caso.

\subsubsection{Análise Univariada de Variância - ANOVA}

De acordo com Hair et al (2005, p. 272) a ANOVA é a técnica estatística utilizada para determinar se as amostras de dois ou mais grupos surgem de populações com médias iguais. Esta análise usa apenas uma medida dependente.

As hipóteses geradas neste estudo em relação à variável função e à única variável dependente avaliação geral (v100) foram:

\footnotetext{
$\mathrm{H}_{0}$ : A média da avaliação geral do desempenho dos processos de BPM é estatisticamente igual nos grupos da variável função

$\mathrm{H}_{1}$ : A média da avaliação geral do desempenho dos processos de BPM é estatisticamente diferente nos grupos da variável função
}

Da mesma maneira, as hipóteses considerando a variável independente região foram:

$\mathrm{H}_{0}$ : A média da avaliação geral do desempenho dos processos de BPM é estatisticamente igual nos grupos da
$\quad$ variável região
$\mathrm{H}_{1}$ : A média da avaliação geral do desempenho dos processos de BPM é estatisticamente diferente nos grupos
$\quad$ da variável região

As hipóteses podem também ser representadas da seguinte forma: 


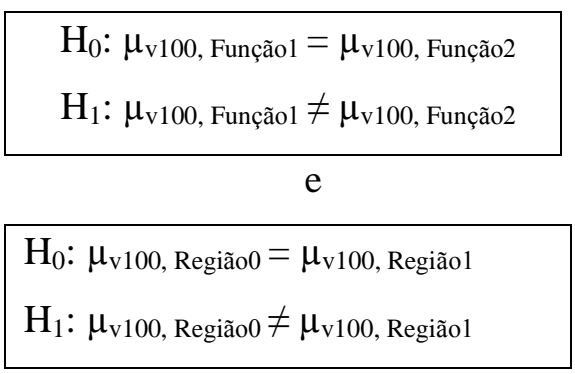

Os dados dos principais resultados e respectivas análises após a aplicação nas duas ANOVAs encontram-se resumidos na tabela 15.

\section{Tabela 15 - Resumo ANOVAs Avaliação Geral}

\begin{tabular}{lccc}
\hline $\begin{array}{c}\text { Variável } \\
\text { Independente }\end{array}$ & $\begin{array}{c}\text { Sig. } \\
\text { Levene's }\end{array}$ & Sig. F & Obs Power \\
\hline Função & 0,879 & 0,649 & 0,074 \\
\hline Região & 0,570 & 0,506 & 0,102 \\
\hline
\end{tabular}

Considerando os valores de significância do Levene's Test e de F acima de 0,05 e os baixos valores do Obs Power (poder estatístico) a decisão é pela não rejeição de $\mathrm{H}_{0}$. Ou seja, não houve distinção entre as médias da avaliação geral da medição de desempenho dos BPM do PNAFE dos gestores da alta e da média gerência, bem como entre os gestores de São Paulo e dos demais estados da federação.

Esses resultados ratificam aqueles obtidos no teste Qui-quadrado, descritos no item 5.1.4.2, ao mostrar esta ausência de distinção entre respondentes da alta e média gerência e entrevistados de São Paulo e dos demais estados.

\subsubsection{Regressão Logística}

De acordo com Hair et al (2005, p. 210), a regressão logística é uma forma especializada de regressão que é formulada para prever e explicar uma variável dependente do tipo binária (dois grupos) e não uma medida dependente métrica. O objetivo principal é encontrar uma função logística formada por meio de ponderações das variáveis (atributos) que permita estabelecer a probabilidade de ocorrência de determinados eventos e a importância (peso) das variáveis para esta ocorrência. 
Em outras palavras, verificar neste trabalho as variáveis de uma determinada dimensão ou entre os escores fatoriais aquelas que mais discriminam ou que são mais eficientes na caracterização dos dois grupos da variável de Avaliação Geral do gerenciamento dos macroprocessos de negócio (v100), distinguindo-os entre gerenciamento de BPM satisfatório e insatisfatório.

Para atender ao requisito de variável dependente binária, não métrica, a v100 foi transformada em v100T, tomando-se sua mediana e dividindo-se em dois grupos que assumiram valores $0 \mathrm{e}$ 1. Como o valor da mediana de v100 é 6, o grupo que assumiu o valor 0 -gerenciamento insatisfatório - para v100T compreende as observações que receberam notas entre 0 e 6 . $\mathrm{O}$ segundo grupo, que compreende as notas entre 7 e 10, assumiu o valor 1 - gerenciamento satisfatório - para v100T, rotulada de desempenho do gerenciamento.

As variáveis independentes foram aquelas pertencentes ao conjunto de variáveis que compõem cada uma das dimensões do SMD-BPM e os escores fatoriais das dimensões.

A estimação do modelo de regressão logística e os principais testes de significância estatística desta técnica serão descritos a seguir.

\subsubsection{Método Forward Stepwise}

O método de seleção das variáveis mais eficientes na caracterização dos dois grupos da variável de Avaliação Geral aplicado neste trabalho foi o Forward Stepwise (Wald). Este modelo se inicia com o termo da constante e em cada passo é introduzida a variável com o menor nível de significância para o escore estatístico, definido aqui como 0,05.

O processo continua até que nenhuma variável seja mais elegível para ser incluída ou haja convergência na comparação de estatísticas de qualidade da estimação em iterações sucessivas. 


\subsubsection{Função de Verossimilhança - $L$}

A função de verossimilhança (L) é definida como a probabilidade de obter os resultados da amostra dadas as estimativas dos parâmetros do modelo logístico. Como esta probabilidade possui valor menor do que um, convencionou-se usar a expressão $-2 \mathrm{LL}=\left(-2^{*} \log _{10} \mathrm{p}\right)$, em que p é a probabilidade (ou likelihood), na expectativa de que -2LL seja mínimo.

Esta estatística representa uma medida do quão bem o modelo se ajusta, como se fosse uma espécie do valor da soma de quadrados de erros da regressão múltipla.

\subsubsection{Teste Qui-quadrado}

A estatística Qui-quadrado testa a significância do Improvement, ou seja, verifica a diferença entre a estatística -2LL inicial e final, após a inclusão de todas as variáveis que contribuem para melhorar o poder de explicação do modelo. A expectativa é de que este valor seja elevado e de que a significância estatística se mostre inferior ao nível de 5\%.

Este teste é semelhante ao teste F do modelo de regressão linear múltipla, indicando que pelo menos um dos coeficientes do modelo é diferente de zero. As hipóteses geradas foram:

$\mathrm{H}_{0}$ : Todos os coeficientes das variáveis independentes são iguais a zero

$\mathrm{H}_{1}$ : Pelo menos um dos coeficientes das variáveis independentes é diferente de zero

A expectativa é rejeitar $\mathrm{H}_{0}$ ao nível de significância de 5\%.

\subsubsection{Teste de Hosmer e Lemeshow}

A medida de Hosmer e Lemeshow testa a hipótese nula de igualdade entre as previsões da probabilidade de satisfação versus insatisfação e as probabilidades realmente observadas. Portanto, trata-se de um teste do ajuste do modelo aos dados.

As hipóteses geradas foram: 
$\mathrm{H}_{0}$ : As classificações em grupos da variável desempenho do gerenciamento posteriormente previstas são iguais às observadas

$\mathrm{H}_{1}$ : As classificações em grupos da variável desempenho do gerenciamento posteriormente previstas não são iguais às observadas

A expectativa é não rejeitar $\mathrm{H}_{0}$ ao nível de significância de $5 \%$.

\subsubsection{Estatísticas Cox \& Snell e Nagelkerke}

Estas estatísticas são valores que indicam a qualidade do ajuste geral do modelo, comparáveis ao $\mathrm{R}^{2}$ da regressão linear múltipla. Assim sendo, a expectativa é de que quanto mais próximo se esteja da unidade, melhor o resultado dos testes. Segundo Hair et al (2005, p. 264) a medida $\mathrm{R}^{2}$ de Cox \& Snell é limitada, por não alcançar o valor máximo 1, sendo por isso mais rigorosa, diferentemente do $\mathrm{R}^{2}$ de Nagelkerke, cujo domínio insere-se entre 0 e 1 .

\subsubsection{Estatística Wald}

A significância estatística dos coeficientes estimados para as variáveis independentes e a constante também podem ser avaliadas. O Teste Wald verifica se as variáveis são significantes individualmente, justificando assim suas inclusões no modelo. A expectativa de significância para o teste é para um nível de até 0,10 .

\subsubsection{Nível de Correção da Classificação}

A matriz (tabela) de classificações permite comparar a verdadeira classificação dos macroprocessos nas duas categorias da variável dependente (a priori) com as previstas (a posteriori) pelo modelo de regressão logística. Um indicador da qualidade do ajuste do modelo é o percentual de acerto das classificações a posteriori dos processos nas situações de avaliação geral insatisfatória (valor 0 ) ou satisfatória (valor 1 ).

A expectativa é de que estes percentuais estejam o mais próximos de $100 \%$, indicando o melhor ajuste do modelo. Hair et al (2005, p. 226-227) mencionam um outro critério para averiguação do percentual de correção da classificação, qual seja, a medição da precisão preditiva relativa à chance. No caso em tela, o critério de chances proporcionais, indicado para situações em que os tamanhos de grupos sejam diferentes, o valor mínimo aceito para a correção é de $62,5 \%$. 


\subsubsection{Estatística $\operatorname{Exp}(\beta)$}

A estatística $\operatorname{Exp}(\beta)$ indica o impacto na desigualdade $\mathrm{e}^{\mathrm{z}}$ de uma variação em uma das variáveis, mantendo-se as demais constantes. $\mathrm{Z}$ é a equação da regressão composta pelo valor da constante mais uma ou mais parcelas compostas pelo produto de uma variável explicativa com o seu valor do coeficiente $\beta$ no último passo. $O \operatorname{Exp}(\beta)$ pode ser obtido também ao se provocar a mudança de uma unidade em uma das variáveis explicativas e verificar posteriormente o impacto provocado por esta alteração.

\subsubsection{Principais Resultados da Regressão Logística}

Os principais valores estatísticos e saídas do software SPSS, relativos ao uso da técnica da regressão logística encontram-se resumidos nas tabelas 16 e 17. Foram geradas dez regressões, sendo as variáveis independentes aquelas pertencentes a cada conjunto de variáveis que compõem cada uma das dimensões e os Escores Fatoriais e v100T a variável dependente.Os principais resultados das análises realizadas foram:

a) no caso da regressão logística aplicada aos escores fatoriais das dimensões, as variáveis com coeficientes logísticos significantes, segundo a estatística de Wald no último passo, foram a sccrit (escore da dimensão Análise Crítica) e a scapren (escore da dimensão Aprendizado). As demais variáveis foram excluídas pelo teste. De maneira semelhante, constam das colunas "Ord Ent Var" e "Sig W Ult P", contidas nas duas tabelas citadas, aquelas variáveis aceitas no teste em cada uma das dimensões do SMD-BPM. Por exemplo, na tabela 50, na dimensão Aprendizado as variáveis que mais discriminaram o gerenciamento satisfatório do insatisfatório dos macro-processos nesta dimensão foram a v16 $(0,000)$ no primeiro passo; a v14 $(0,002)$ no segundo passo e a v5 $(0,013)$ no terceiro passo;

b) na tabela 16 , no $2^{\circ}$ passo (P2), foi apurada a diferença entre $-2 \mathrm{LL}$ inicial e final (ou Improvement) de 67,903. O desejável era que esta diferença fosse sempre elevada, indicando assim a adequação do modelo final construído. $\mathrm{O}$ valor da significância estatística do modelo final apresentou valor 0,000, por conseguinte, inferior ao nível de $5 \%$, como outrora esperado. Na tabela 17, todos os valores do Improvement foram altos, bem como todos os valores da significância dos modelos finais para cada dimensão 
foram iguais a 0,000 , e assim, menores do que 0,05 . Este fato indica a rejeição da hipótese $\mathrm{H}_{0}$ e, desta maneira, entende-se que todos os modelos finais para cada uma das dimensões foram adequados;

c) para o Teste Hosmer \& Lemeshow, as classificações em grupo previstas foram iguais às observadas (alocação a posteriori comparada com a priori) para os Escores Fatoriais e para as dimensões Aprendizado, Clareza, Dinamismo, Integração, Participação, Equilíbrio e Análise Crítica. As demais obtiveram valores de significância inferiores a $5 \%$, rejeitando assim $\mathrm{H}_{0}$, contrariamente à expectativa inicial do teste;

d) considerando a coluna dos valores do Teste de Nagelkerke, contida nas tabelas 16 e 17, apenas a dimensão Integração apresentou valor abaixo da metade da unidade, contrariando a expectativa de valores próximos de um, indicativa da qualidade do ajuste geral do modelo. Para o Teste de Cox \& Snell, considerado mais rigoroso e menos relevante, somente os Escores Fatoriais e as dimensões Dinamismo e Análise Crítica indicaram um bom poder de explicação para o modelo;

e) os percentuais indicativos do grau de ajuste do modelo tanto para os Escores Fatoriais quanto para todas as dimensões variaram entre os valores de 76,3\% (Integração) e 87,3\% (Dinamismo), indicando que em todas as situações houve boa qualidade de ajuste do modelo às classificações dos processos, nas situações de avaliação geral satisfatória e insatisfatória. Considerando ainda o valor de $62,5 \%$ como percentual mínimo de correção, pelo critério de chances proporcionais, todas as dimensões e os Escores Fatoriais atenderam a este requisito;

f) no caso da Regressão Logística para os Escores Fatoriais das dimensões, o impacto da desigualdade $\operatorname{Exp}(\beta)$ aconteceu da seguinte maneira: a desigualdade é igual a $\mathrm{e}^{\mathrm{z}}$ de tal maneira que $Z=-0,768+2,644 *$ sccrit $+2,020 *$ scapren. Fixando-se um valor para scapren e aumentando-se uma unidade em sccrit, a expressão $\mathrm{e}^{\mathrm{z}}$ aumenta de um fator 14,066. Isto significa que o impacto na probabilidade de o gerenciamento de um macroprocesso passar da categoria insatisfatório (valor 0) para satisfatório (valor 1) é positivo e é maior do que no caso de se manter um valor fixo para sccrit e aumentar de uma unidade scapren. O impacto neste último caso seria de 7,540. Em outras palavras, a presença maior do sccrit na comparação entre gerenciamento de processos aumenta a 
chance de o processo ser bem gerenciado em relação à scapren. Da mesma maneira acontece para as demais dimensões, observando-se sempre as colunas Coeficiente $\beta$ e $\operatorname{Exp}(\beta)$ contidas na tabela 17 .

Tabela 16 - Regressão Logística nos Escores Fatoriais

\begin{tabular}{|c|c|c|c|c|c|c|c|c|c|c|c|c|}
\hline Dimensão & $\mathbf{P}$ & $-2 \mathrm{Ll}$ & $\begin{array}{l}\text { Imp. } \\
\text { Chi }^{2}\end{array}$ & $\begin{array}{l}\text { Sig. } \\
\text { Imp. } \\
\text { Chi }^{2}\end{array}$ & $\begin{array}{c}\text { Cox } \\
\text { Snell } \\
\mathbf{R}^{2}\end{array}$ & $\begin{array}{c}\text { Nagel } \\
\mathbf{R}^{2}\end{array}$ & $\begin{array}{l}\text { Sig. } \\
\text { Hos } \\
\text { Lem }\end{array}$ & $\begin{array}{l}\text { Ord } \\
\text { Ent } \\
\text { Var }\end{array}$ & $\begin{array}{c}\text { Coef } \\
\beta \\
\text { Últ. } \\
\text { P }\end{array}$ & $\begin{array}{c}\text { Sig } \\
\text { W } \\
\text { Ult. } \\
\text { P }\end{array}$ & $\begin{array}{c}\operatorname{Exp} \\
(\beta)\end{array}$ & $\begin{array}{l}\% \\
\text { Cor }\end{array}$ \\
\hline \multirow{3}{*}{$\begin{array}{c}\text { Escores } \\
\text { Fatoriais }\end{array}$} & 1 & & & & & & & Sccrit & 2,644 &, 000 & 14,066 & \\
\hline & 2 & 56,463 & 67,903 & ,000 & ,530 & ,707 & 871 & Scapren & 2,020 &, 014 & 7,540 & 85,6 \\
\hline & $\mathrm{C}$ & & & & & & & &,- 768 & ,088 & 0,464 & \\
\hline
\end{tabular}

\section{$\underline{\text { Legenda Tabelas } 16 \text { e } 17}$}

$\mathrm{P}$ - Passo;

C- Constante

$-2 \mathrm{Ll}--2$ Log likelihood;

Imp. $\mathrm{Chi}^{2}$ - Improvement Chi-square;

Sig. Imp. Chi ${ }^{2}$ - Significância Improvement Chi-square;

Cox Snel $\mathrm{R}^{2}$ - Cox \& Snell R Square;

Nagel $\mathrm{R}^{2}$ - Nagelkerke $R$ Square;

Sig. Hos Lem - Significância Hosmer and Lemeshow Test;

Ord Ent V - Ordem de Entrada das Variáveis;

Coef $\beta$ Ult $\mathrm{P}-$ Coeficiente logístico $\beta$ no Último Passo;

Sig. Wald Ult Passo - Significância da estatística Wald no Último Passo;

$\operatorname{Exp}(\beta)$ - Expressão do coeficiente logístico $\beta$ no Último Passo;

\% Cor - Percentual de Correção Total. 
Tabela 17 - Regressão Logística nas Dimensões

\begin{tabular}{|c|c|c|c|c|c|c|c|c|c|c|c|c|}
\hline Dimensão & $\mathbf{P}$ & $-2 \mathrm{LI}$ & $\begin{array}{l}\text { Imp. } \\
\text { Chi2 }\end{array}$ & $\begin{array}{l}\text { Sig. } \\
\text { Imp. } \\
\text { Chi2 }\end{array}$ & $\begin{array}{c}\text { Cox } \\
\text { Snell } \\
\text { R2 }\end{array}$ & $\begin{array}{l}\text { Nagel } \\
\text { R2 }\end{array}$ & $\begin{array}{l}\text { Sig. } \\
\text { Hos } \\
\text { Lem }\end{array}$ & $\begin{array}{l}\text { Ord } \\
\text { Ent } \\
\text { Var }\end{array}$ & $\begin{array}{c}\text { Coef } \\
\boldsymbol{\beta} \\
\text { UUlt. } \\
\mathbf{P}\end{array}$ & $\begin{array}{c}\text { Sig } \\
\text { W } \\
\text { Ult. } \\
\text { P }\end{array}$ & $\begin{array}{c}\operatorname{Exp} \\
(\boldsymbol{\beta})\end{array}$ & $\begin{array}{l}\% \\
\text { Cor }\end{array}$ \\
\hline \multirow[t]{4}{*}{ Aprendizado } & 1 & & & & & & & V16 &, 851 & ,000 & 2,342 & \\
\hline & 2 & & & & & & & V14 & ,361 & 002 & 1,435 & \\
\hline & 3 & 81,078 & 72,792 &, 000 & ,481 & ,641 & ,747 & V5 &, 454 &, 013 & 1,574 & 82,9 \\
\hline & $\mathrm{C}$ & & & & & & & & $-11,335$ &, 000 & 0,000 & \\
\hline \multirow[t]{3}{*}{ Clareza } & 1 & & & & & & & $\mathrm{~V} 21$ &, 451 &, 040 & 1,570 & \\
\hline & 2 & 90,530 & 59,190 &, 000 & ,422 & ,563 & , 186 & V18 &, 479 &, 180 & 1,615 & 82,4 \\
\hline & $\mathrm{C}$ & & & & & & & & $-6,288$ & ,000 & 0,002 & \\
\hline \multirow[t]{5}{*}{ Dinamismo } & 1 & & & & & & & V41 &, 927 & ,001 & 2,527 & \\
\hline & 2 & & & & & & & V35 & ,609 & ,006 & 1,839 & \\
\hline & 3 & & & & & & & V44 & 1,052 & 002 & 2,863 & \\
\hline & 4 & 57,030 & 95,426 &, 000 & ,580 & ,773 & ,996 & V39 & $-0,944$ & ,003 & 0,389 & 87,3 \\
\hline & $\mathrm{C}$ & & & & & & & & $-9,764$ &, 000 & 0,000 & \\
\hline \multirow[t]{3}{*}{ Integração } & 1 & & & & & & & V47 &, 490 & ,000 & 1,633 & \\
\hline & 2 & 106,599 & 51,404 & ,000 & ,363 & ,484 & ,706 & V49 & ,222 &, 034 & 1,248 & 76,3 \\
\hline & $\mathrm{C}$ & & & & & & & & $-4,208$ & ,000 & , 015 & \\
\hline \multirow[t]{4}{*}{ Alinhamento } & 1 & & & & & & & V52 &, 458 & ,004 & 1,581 & \\
\hline & 2 & & & & & & & V59 & ,377 &, 022 & 1,458 & \\
\hline & 3 & 90,931 & 67,106 & ,000 & ,445 & ,593 & ,000 & V64 & ,210 & ,034 & 1,233 & 83,3 \\
\hline & $\mathrm{C}$ & & & & & & & & $-6,079$ & ,000 & 0,002 & \\
\hline \multirow[t]{3}{*}{ Participação } & 1 & & & & & & & V66 & ,652 & ,000 & 1,920 & \\
\hline & 2 & 93,514 & 65,832 & ,000 & ,436 & ,581 & ,579 & V70 & ,297 & ,005 & 1,345 & 82,6 \\
\hline & $\mathrm{C}$ & & & & & & & & $-5,382$ & ,000 &, 005 & \\
\hline \multirow{3}{*}{$\begin{array}{l}\text { Relação } \\
\text { Causal }\end{array}$} & 1 & & & & & & & V74 & ,692 & ,000 & 1,997 & \\
\hline & 2 & 94,717 & 64,698 &, 000 &, 430 &, 574 &, 026 & V72 & ,364 &, 048 & 1,439 & 82,6 \\
\hline & $\mathrm{C}$ & & & & & & & & $-6,863$ &, 000 & 0,001 & \\
\hline \multirow[t]{5}{*}{ Equilíbrio } & 1 & & & & & & & V84 &, 688 &, 000 & 1,990 & \\
\hline & 2 & & & & & & & V79 &, 372 & ,033 & 1,450 & \\
\hline & 3 & & & & & & & V78 &,- 541 & ,001 &, 582 & \\
\hline & 4 & 81,015 & 75,627 &, 000 & ,488 & ,651 &, 170 & V81 &, 410 &, 043 & 1,507 & 86,7 \\
\hline & $\mathrm{C}$ & & & & & & & & $-5,639$ &, 000 & ,004 & \\
\hline \multirow{3}{*}{$\begin{array}{l}\text { Análise } \\
\text { Crítica }\end{array}$} & 1 & & & & & & & V89 & ,619 & ,000 & 1,856 & \\
\hline & 2 & 78,239 & 82,537 &, 000 &, 509 & ,679 &, 816 & V95 & ,644 &, 002 & 1,905 & 86,2 \\
\hline & $\mathrm{C}$ & & & & & & & & $-7,707$ & , 000 &, 000 & \\
\hline
\end{tabular}

\subsubsection{Escalonamento Multidimensional}

O escalonamento multidimensional (ES) é a técnica de análise multivariada que permite a representação espacial das percepções de relações entre objetos. Ou seja, é a técnica que proporciona uma visualização dos macro-processos do PNAFE mais próximos ou mais distantes em um mapeamento, de acordo com os critérios pelos quais são gerenciados.

Para Hair et al (2005, p. 423) o objetivo do escalonamento multidimensional é transformar julgamentos de consumidores (usuários), quanto à similaridade ou preferência, em distâncias 
representadas em espaço multidimensional, esperando-se que esta configuração possa tornar os dados mais compreensíveis.

O primeiro passo foi transformar as variáveis string vP em variáveis numéricas vPNum. Desta maneira, o macro-processo A recebeu o valor numérico 1, o B recebeu o valor 2, e assim sucessivamente, até o macro-processo J assumir o valor 10.

Como alguns macro-processos receberam freqüências de observações menores do que dez, criou-se a variável vPGpo, onde o grupo vPGpo1 foi formado pelos macro-processos 1Controle de Acesso, 2- Legislação, 5- AIDF, 6- Conta Fiscal, 7- IPVA e 8- Serviços Diversos - Área Tributária e denominado macro-processo Área Tributária. Os demais grupos respeitaram a classificação original dada à variável vPNum com grupos formados por apenas um macro-processo, ou seja, vPGpo2: 3- Cadastro, vPGpo3: 4- Declarações, vPGpo4: 9- Área Financeira e vPGpo5: 10- Organização e Gestão.

A tabela 18 apresenta os valores das variáveis VPGpo para cada um dos escores fatoriais das dimensões do SMD-BPM.

Tabela 18 - VPGpo para os Escores Fatoriais das dimensões

\begin{tabular}{lrrrrrrrrr}
\hline Grupos Macro-processos & Scapren & Scclar & Scdin. & Scinte & Scalin & Scpart & Sccau & Scequi & Sccrit \\
\hline 1.Área Tributária &, 2577 &, 1332 &, 2661 &, 1787 &, 0874 &, 2041 &, 2723 &, 1965 &, 1536 \\
\hline 2.Cadastro &, 2553 &,- 4119 &,- 1100 &, 0862 &,- 2178 &, 0101 &, 5222 &, 1763 &, 0299 \\
\hline 3.Declarações &, 3311 &, 2306 &, 4284 &, 3704 &, 2972 &, 1615 &, 2546 &, 1368 &, 2794 \\
\hline 4.Área Financeira &,- 0349 &, 0413 &,- 1367 &,- 1614 &,- 0701 &,- 0952 &,- 2758 &,- 1391 &,- 0764 \\
\hline 5.Organização e Gestão &,- 2841 &,- 0640 &,- 1901 &,- 1530 &,- 0478 &,- 1243 &,- 2360 &,- 1442 &,- 1329 \\
\hline
\end{tabular}

Os resultados apurados a partir dos escores fatoriais das nove dimensões revelam um bom fator de ajustamento. O S-stress improvement (medida de ajuste entre similaridades - inputs e configuração espacial - outputs), que estabelece o momento de interromper o processo, ocorreu na segunda iteração, quando foi atingido o nível 0,00061. Nessa iteração, o S-stress geral obtido foi de 0,02093, com um Stress da matriz de 0,04570, que ainda pode ser considerado bom pelo critério de interpretação de Kruskal (máximo de 5\%). 
O RSQ que corresponde ao coeficiente de correlação ao quadrado entre os dados de dissimilaridade e as distâncias espaciais euclideanas - que equivale ao $\mathrm{R}^{2}$ - coeficiente de determinação ou explicação do modelo de análise de regressão, foi de 0,99726 , o que indica uma boa qualidade de ajustamento.

\subsubsection{Principais resultados do Escalonamento Multidimensional}

O mapa gerado, considerando a distância euclideana nessa forma de conversão dos dados, é mostrado a seguir na figura 14. É interessante destacar que os pontos nesse mapa, representando os grupos de macro-processos, revelam que:

a) aqueles ligados à Área Financeira e de Organização e Gestão dos projetos do PNAFE estão bem próximos, confirmando o fato da proximidade dos dirigentes de ambas as áreas do PNAFE, e até de casos de acúmulo temporário de funções;

b) os processos do grupo Declarações, por sua vez, estão próximos daqueles ligados à Área Tributária, o que confirma a similaridade pelo fato de os primeiros serem uma espécie de subgrupo do setor tributário nas Secretarias Estaduais Fazendárias. Os macroprocessos ligados ao Cadastro do programa de modernização é que se mostraram significativamente distantes de todos os demais, mesmo sendo também uma espécie de subgrupo dos processos da Área Tributária;

c) Os macro-processos ligados ao Cadastro se mostraram bem próximos da dimensão 2 do escalonamento multidimensional (eixo das ordenadas) do mapa perceptual, diferentemente dos demais que se mostraram mais próximos da dimensão 1 (eixo das abscissas). 


\section{Derived Stimulus Configuration}

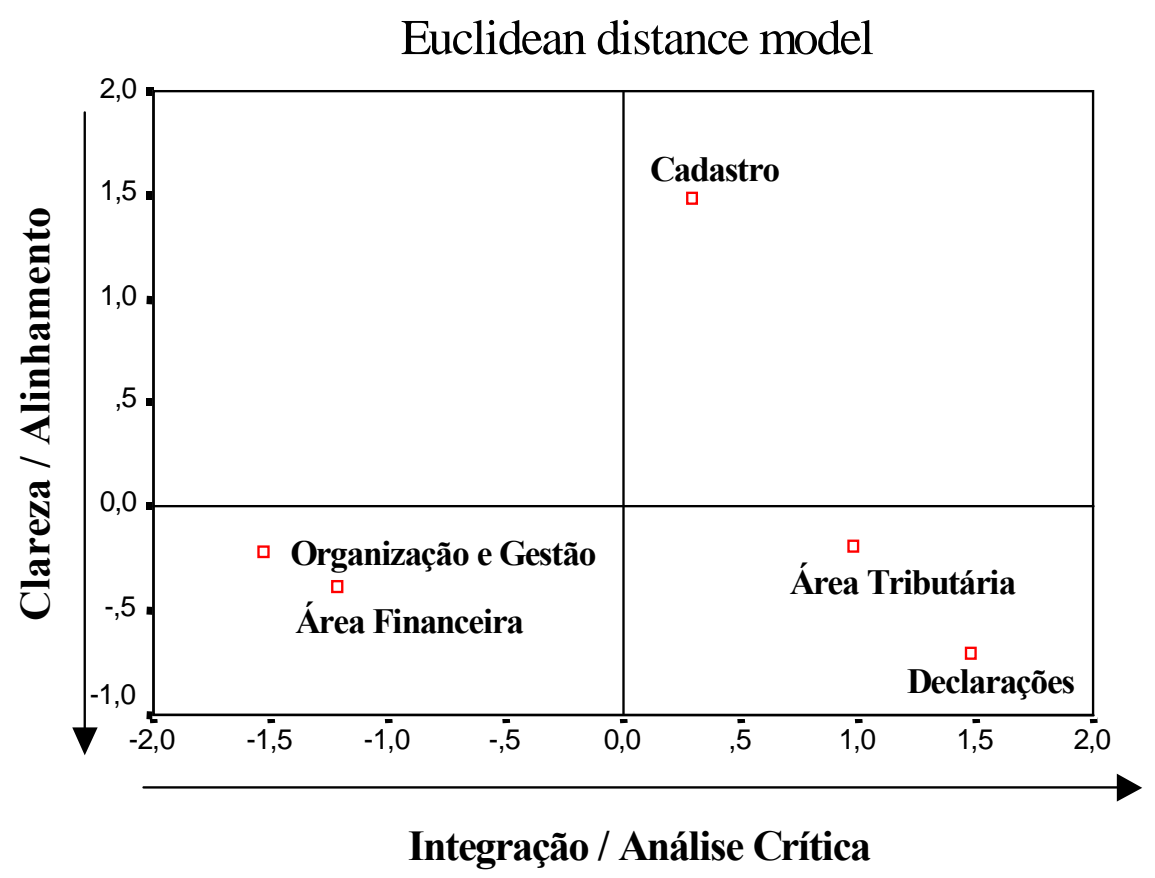

Figura 14 - Mapa perceptual dos grupos de macro-processos do PNAFE

Segundo Aaker et al (1995, p. 634) para nomear as dimensões (eixos) da figura 14 pode-se correlacionar os escores dos atributos de cada objeto (elemento da amostra), com cada dimensão do mapeamento gerado pelo escalonamento multidimensional. A tabela 19 mostra, a seguir, os valores dos coeficientes da Correlação de Pearson obtidos para cada atributo normativo associado às duas dimensões do escalonamento multidimensional.

Tabela 19 - Valores das correlações entre dimensões do SMD-BPM e dimensões do EM

\begin{tabular}{lcc}
\hline \multicolumn{1}{c}{ Dimensão } & Abscissa & Ordenada \\
\hline Aprendizado & 0,941 & 0,195 \\
\hline Clareza & 0,302 & $-0,945$ \\
\hline Dinamismo & 0,894 & $-0,444$ \\
\hline Integração & 0,979 & $-0,093$ \\
\hline Alinhamento & 0,602 & $-0,773$ \\
\hline Participação & 0,951 & $-0,145$ \\
\hline Relação Causal & 0,807 & 0,588 \\
\hline Equilíbrio & 0,915 & 0,362 \\
\hline Análise Crítica & 0,972 & $-0,214$ \\
\hline
\end{tabular}


A partir das correlações estabelecidas, foram feitas as nomeações das dimensões conforme os valores mais altos obtidos, em módulo. Pode-se concluir ainda que:

a) os maiores coeficientes de Pearson, em módulo, estão associados à dimensão 1 (eixo das abscissas) do mapa e, por isso, entende-se que ela é a que mais contribuiu para a dissimilaridade entre os macro-processos;

b) por terem apresentado valores de coeficientes maiores, a dimensão 1 do escalonamento (eixo das abscissas) recebeu o rótulo das dimensões Integração / Análise Crítica, e a dimensão 2 do escalonamento (eixo das ordenadas) recebeu o rótulo de Clareza / Alinhamento, só que em sentido contrário, já que seus valores são negativos;

c) a nomeação dos eixos permitiu verificar que os gestores dos macro-processos ligados à Área Tributária e a Declarações consideraram que as variáveis das dimensões Integração e Análise Crítica tiveram destaque na medição de desempenho dos projetos que gerenciaram. Em sentido inverso, os gestores dos macro-processos da Área Financeira e de Organização e Gestão consideraram que estas dimensões estiveram menos presentes;

d) da mesma maneira, os gestores dos macro-processos ligados ao Cadastro entenderam que as variáveis das dimensões Clareza / Alinhamento foram as que tiveram menos presença na medição de desempenho de seus processos de negócio. 


\section{CAPÍTULO 6 - PRINCIPAIS CONCLUSÕES}

O presente estudo se propôs a identificar quais eram os atributos, classificados por dimensões (atributos normativos), que deveriam fazer parte da medição e avaliação de desempenho do gerenciamento de BPM no PNAFE e que, de fato, estiveram presentes. Seu objetivo principal foi conceber e validar estes atributos dentro de um modelo teórico de medição de desempenho de BPM no PNAFE, a partir dos sistemas de medição de desempenho organizacionais validados na literatura acadêmica e recente modelo arquitetônico para gerenciamento e controle de processos de negócio RiverFish.

Este estudo intentou ainda, de modo específico, analisar as possíveis relações entre os gestores, os principais processos de negócio do programa, englobados em macro-processos, e os atributos normativos do modelo teórico proposto.

A identificação e fundamentação teórica dos atributos dos modelos inicial e evoluído, intermediários no estudo, bem como do modelo final SMD-BPM, encontram-se relatadas no capítulo 2. A concepção e validação do modelo final, bem como os principais resultados na relação entre gestores, processos e atributos foram detalhados nos capítulos 4 e 5. Com isso, acredita-se que o estudo tenha respondido como foi medido o desempenho dos processos de BPM no PNAFE, assim como tenha atendido aos objetivos principais e específicos propostos na seção 1.2. Uma síntese do estudo, suas principais conclusões e contribuições, bem como suas limitações e sugestões para futuras pesquisas encontram-se descritas a seguir.

\subsection{Síntese do Estudo}

De acordo com a seção 4.1, a pesquisa foi realizada em quatro fases: 1- Revisão bibliográfica dos sistemas de medição de desempenho organizacionais - SMDO, do Business Process Management e do modelo arquitetônico para gerenciamento de processos RiverFish e o seu Plano de Navegação; 2- Pesquisa qualitativa para desenvolvimento do modelo de sistema de medição de desempenho evoluído de BPM - SMDE-BPM; 3- Pesquisa quantitativa para tratamento dos dados, validação do construto, verificação de sua fidedignidade, e análise da 
relação entre gestores, processos e atributos; e 4- Formalização da proposta do modelo final SMD-BPM.

Considerando o material encontrado na literatura acadêmica sobre medição de desempenho organizacional, a revisão bibliográfica se baseou em compilações apresentadas em trabalhos científicos recentes, a partir dos quais foram buscadas fontes secundárias de pesquisa e sua fundamentação básica. Neste contexto, há que se destacar duas publicações: o trabalho de Figueiredo (2003) e o documento KPMG LLP (2001).

A partir dos 128 atributos identificados em nove dos principais SMDO conhecidos, elencados por Figueiredo (2003), e dos seis principais SMDOs, do documento da KPMG LLP (2001), em meio a outras contribuições descritas no item 2.1; a conceitos de BPM (item 2.2) e ao modelo arquitetônico RiverFish (item 2.3), foi possível conceber o SMDI-BPM para uso na pesquisa qualitativa.

A amostra intencional da pesquisa qualitativa, conforme detalhado na seção 4.5, foi desenvolvida por meio de entrevistas em profundidade envolvendo 15 gestores do programa do estado de São Paulo, entre dirigentes da UCE e líderes de projeto. O resultado desta pesquisa possibilitou o aperfeiçoamento do Modelo Inicial SMDI-BPM (Apêndice 1) para o Modelo Evoluído SMDE-BPM (Apêndice 2), entendido pelo pesquisador como um avanço significativo na busca de um modelo consistente a ser testado.

$\mathrm{Na}$ pesquisa quantitativa de sondagem (survey) planejou-se uma amostra aleatória simples constituída por 158 entrevistas, tendo sido respondidos 127 formulários (conforme modelo do Apêndice 3), o que corresponde a uma taxa de retorno de 80,3\%. Do universo de dirigentes nacionais e estaduais (Alta Gerência), 89,3\% atenderam ao solicitado, ficando ausentes da amostra total apenas os representantes dos estados do Ceará, Sergipe e Piauí.

Do universo de líderes de projeto de São Paulo (Média Gerência), 102 foram convidados a responder e 77 responderam à demanda, correspondendo a uma taxa de retorno de 75,4\%. Estes altos índices de retorno permitiram ao pesquisador acreditar que as opiniões emitidas pelos respondentes representaram em parte as dos não respondentes. 
O formulário contendo os atributos do modelo para a medição do gerenciamento de BPM do PNAFE foi constituído por cinco variáveis relativas a aspectos pessoais dos respondentes; uma relativa ao macro-processo de negócio em que o dirigente esteve envolvido; 95 variáveis, divididas em nove dimensões, ditas atributos normativos, em que os entrevistados identificavam a presença ou não de cada atributo nos processos do PNAFE, segundo uma escala de intensidade de 0 a 10, onde 0 representava que o atributo esteve totalmente ausente, e 10 que ele esteve totalmente presente; e uma última variável em que o respondente atribuía um valor avaliativo, também numa escala de 0 a 10 , ao gerenciamento realizado no respectivo macro-processo.

Uma vez coletados os dados da pesquisa quantitativa, procurou-se identificar outliers, pelo cálculo da distância de Mahalanobis, e missings values, para os questionários em que houve abstenção do entrevistado em responder a mais de $10 \%$ das questões formuladas. Nesta etapa, dez formulários de entrevistas foram descartados.

\subsection{Contribuições das Análises do Contexto Univariado}

A Amostra Total foi dividida segundo critérios da Função exercida pelo gestor no programa e da Região a que ele pertencia (seção 5.1.3). Deste universo, 58 respondentes se enquadraram na Função de Alta Gerência, e 59 na de Média Gerência. Do total de 117 formulários válidos, 69 foram respondidos por gestores do estado de São Paulo e 48 de outros estados da federação.

Em seguida, foi verificada a normalidade univariada das variáveis, atendendo aos requisitos de assimetria e curtose. Neste caso, somente a variável v8 - foco na melhoria do processo extrapolou os limites aceitáveis das duas condições e, por conseguinte, foi excluída do rol de variáveis do modelo proposto, bem como daquelas submetidas às demais análises.

A partir das estatísticas descritivas, diversas conclusões podem ser emitidas. Destaque-se, entre outras, as variáveis que apresentaram maiores e menores médias na Amostra Total, na Alta Gerência e Média Gerência, conforme quadro 36. 
Quadro 36 - Maiores e menores médias entre as variáveis da amostra

\begin{tabular}{|l|l|l|l|l|l|}
\hline Amostra & Média & Var & Nome da Variável & Valor \\
\hline \multirow{2}{*}{ Total } & Maior & v31 & acesso imediato do usuário às informações que necessita & 7,2308 \\
\cline { 2 - 7 } & Menor & v30 & uso de técnicas estatísticas para validação dos resultados das medições & 4,1026 \\
\hline $\begin{array}{l}\text { Alta } \\
\text { Gerência }\end{array}$ & Maior & v72 & influência dos objetivos organizacionais nos processos & 7,4483 \\
\cline { 2 - 7 } \\
\hline $\begin{array}{l}\text { Média } \\
\text { Gerência }\end{array}$ & Maior & v31 & acesso imediato do usuário às informações que necessita & 3,4483 \\
\cline { 2 - 7 } & Menor & v64 & uso de indicadores segundo a estrutura hierárquica da organização & 7,3559 \\
\hline
\end{tabular}

Este é um dado interessante para os gestores descobrirem possíveis falhas pontuais nos gerenciamentos de BPM do PNAFE. Pelo quadro 36 depreende-se que a Alta Gerência acusou como maior ausência no programa o uso de técnicas estatísticas para validação dos resultados das medições - v30, enquanto que a Média Gerência apontou a falta do uso de indicadores segundo a estrutura hierárquica da organização - v64. Em contrapartida, a Alta Gerência entendeu como o atributo mais presente a influência dos objetivos organizacionais nos processos - v72, enquanto a Média Gerência entendeu como atributo mais presente o acesso imediato do usuário do processo às informações que necessita - v31.

Outra medida de proveito para se tirarem conclusões é o coeficiente de variação das variáveis. Todas as variáveis da amostra apresentaram alta dispersão, com valores acima de $30 \%$. O quadro 37 resume a descrição das variáveis que apresentaram maiores coeficientes de variação, em detalhe na seção 5.1.3.2. Para a Amostra Total e a Alta Gerência foram selecionados valores de coeficiente de variação acima de $70 \%$. Na Média Gerência foram escolhidos valores acima de $60 \%$.

Interessante verificar que os atributos de menor consenso entre os gestores de sua existência no gerenciamento de BPM do PNAFE, para a Amostra Total e suas duas estratificações, foram: o uso de técnicas de análise estatística para validação dos resultados das medições; o uso de indicadores segundo a estrutura hierárquica da organização; e uso de medidas de desempenho que possam ser controladas pelo usuário. Os dois primeiros atributos foram os que apresentaram, inclusive, menores médias na Alta e Média Gerências. 
Quadro 37 - Variáveis com maior coeficiente de variação

\begin{tabular}{|c|c|c|c|c|}
\hline $\mathbf{V}$ & Variáveis que apresentaram maior coeficiente de variação (dispersão) & AT & $\mathbf{A G}$ & MG \\
\hline v14 & identificação de conflitos entre indicadores de desempenho do processo & & & $\mathrm{X}$ \\
\hline v30 & uso de técnicas de análise estatística para validação dos resultados das medições & $\mathrm{X}$ & $\mathrm{X}$ & $\mathrm{X}$ \\
\hline v34 & sinais de alarme para desempenho fora dos limites estabelecidos & & & $\mathrm{X}$ \\
\hline v38 & customização dos indicadores às necessidades de diferentes grupos de usuários & & $\mathrm{X}$ & \\
\hline $\mathrm{v} 47$ & integração dos indicadores de desempenho com o sistema de gestão da organização & & & $\mathrm{X}$ \\
\hline $\mathrm{v} 48$ & integração dos indicadores de desempenho com sistemas de negócio (ex: ERP) & $\mathrm{X}$ & $\mathrm{X}$ & $\mathrm{X}$ \\
\hline v64 & uso de indicadores segundo a estrutura hierárquica da organização & $\mathrm{X}$ & $\mathrm{X}$ & $\mathrm{X}$ \\
\hline v71 & uso de medidas de desempenho que possam ser controladas pelo usuário & & $\mathrm{X}$ & \\
\hline
\end{tabular}

\subsection{Contribuições das Análises do Contexto Bivariado}

A análise do quadro 33, contido em 5.1.4.1, permitiu, por exemplo, verificar que a variável Avaliação Geral do gerenciamento de BPM no PNAFE encontra-se relacionada unicamente com as variáveis da dimensão Análise Crítica. Portanto, pode-se concluir que ao valorizar a presença dos atributos desta dimensão, por ocasião da medição de desempenho de seus processos de negócio, os gestores estarão influenciando positivamente na avaliação geral dos processos sob suas responsabilidades.

Ainda neste contexto, a priorização da presença de atributos de uma determinada dimensão no gerenciamento dos BPM pode impactar positivamente os atributos de outra dimensão. Ou seja, o gestor que se deparar com resultados insatisfatórios na dimensão Equilíbrio, por exemplo, além de focar seu trabalho na valorização dos atributos desta dimensão, poderá obter resultados positivos nesta dimensão ao promover os atributos da dimensão Relação Causal. Da mesma forma aconteceu nas correlações entre as dimensões Análise CríticaEquilíbrio e Clareza-Dinamismo.

Esta última informação pode direcionar ações dos gestores no sentido de, uma vez impossibilitado de agir, ainda que temporariamente, sobre um atributo específico de uma dimensão que lhe fuja à competência ou governabilidade, trabalhar em outro atributo de uma outra dimensão e assim mesmo colher resultados significativos na área desejada. 
A dimensão Aprendizado foi a única em que suas variáveis não se correlacionaram com seus pares ou com variáveis de outras dimensões. O que leva a entender que ao trabalhar os atributos desta dimensão, não se devem esperar reflexos nem entre as suas variáveis e nem impactos em outras dimensões.

No universo da Amostra Total, as variáveis que obtiveram maior valor de correlação diretamente com outra variável foram: a clareza na definição dos dados coletados para medir desempenho de processos - v20 com a clareza na definição da fonte de dados para medir desempenho de processos - v21; e a capacidade de auditoria da medição de desempenho v90 com a análise crítica para revisão de metas e padrões de desempenho do processo - v91.

Esta correlação deve ser interpretada da mesma maneira do entendimento formulado para as dimensões. Ou seja, a clareza na definição dos dados coletados influencia diretamente na clareza da definição da fonte de dados para medir desempenho de processos; e a capacidade de auditoria se correlaciona fortemente com a crítica à revisão de metas e padrões de desempenho do processo.

Igualmente nas matrizes de Alta e Média Gerências, as correlações entre duplas de variáveis que alcançaram maiores valores foram: o monitoramento de parâmetros críticos para detectar mudanças no ambiente externo - v40 com o monitoramento de parâmetros críticos para detectar mudanças no ambiente interno - v41; as medidas de desempenho orientadas para o longo prazo - v45 com o fornecimento de subsídios para o conhecimento do desempenho da organização ao longo do tempo - v46; e o uso de indicadores de resultados (fim) e de processos (meio) - v82 com o uso de diversas dimensões de desempenho (ex: financeira, cliente, inovação, etc.) - v87.

A aplicação dos testes Qui-quadrado, corroborada pelas análises das ANOVAs (seção 5.3.2.9), revelou resultados a princípio inesperados ao pesquisador. As hipóteses $\mathrm{H}_{0}$ a serem testadas indicavam que a variável de Avaliação Geral independia da Função exercida ou da Região às quais pertenciam os gestores. Surpreendentemente, ambas não foram rejeitadas. Este foi o indicativo de que não se pôde discriminar gestor da Alta Gerência com o da Média Gerência, nem o gestor de São Paulo com o de outros estados quanto à avaliação do desempenho do gerenciamento de BPM no PNAFE. 
Restringindo-se à região de São Paulo, foi novamente aplicado o teste Qui-quadrado, com a finalidade de testar a seguinte hipótese: a variável de Avaliação Geral do gerenciamento de desempenho de BPM no PNAFE independe da função exercida pelos gestores de São Paulo. Novamente a hipótese $\mathrm{H}_{0}$ não foi rejeitada, indicando que também não houve discriminação entre os gestores da Alta e Média Gerência em São Paulo.

Este fato permitiu ao pesquisador inferir que, mesmo com a impossibilidade geográficotemporal de ter coletado dados de gestores da Média Gerência de outros estados, a avaliação geral do gerenciamento de BPM no PNAFE nestes estados também não distingue gestores de Alta e Média Gerência e, de certa forma, cobre uma lacuna ditada por uma das limitações do estudo.

\subsection{Contribuições das Análises de Fidedignidade e Validade do modelo SMD-BPM}

Segundo Selltiz et al (1987, p. 3-4) uma pesquisa é válida quando suas conclusões são corretas, e fidedigna quando seus resultados são replicáveis. Afirmam ainda que a fidedignidade e a validade são requisitos que se aplicam tanto ao momento em que se examinam as conclusões da pesquisa e se questiona se são corretas e aplicáveis, quanto ao instante em que se examinam os escores ou observações e se pergunta se são precisos e replicáveis.

A fidedignidade do construto foi verificada pelo cálculo do coeficiente de Cronbach, capaz de revelar o grau em que os itens de um instrumento são homogêneos e refletem o mesmo construto implícito. Este coeficiente tem como limite inferior geralmente aceito o valor de 0,70 , podendo ser reduzido a 0,60 no caso de pesquisa exploratória. $O$ coeficiente $\alpha$ foi calculado para cada uma das nove dimensões do SMDE-BPM, tendo alcançado o valor mínimo de 0,8958 para dimensão Integração, e máximo de 0,9668 para as dimensões Clareza e Dinamismo. Estes valores próximos da unidade são indicativos de que o construto goza de alta fidedignidade em todas as nove dimensões.

Para Hair et al (2005, p. 112), a validade é o grau em que um conjunto de medidas representa com precisão o conceito de interesse. Este exame de validade foi realizado com a aplicação da 
técnica de regressão linear múltipla, utilizando-se os escores fatoriais das dimensões, anteriormente calculados com a aplicação da técnica estatística de Análise Fatorial.

O cálculo dos escores fatoriais se fez necessário por conta do grande de número de variáveis do modelo, a fim de que se pudesse trabalhar com uma medida síntese de cada dimensão. $\mathrm{O}$ menor valor percentual de variância explicada foi de 61,805\% para a dimensão Aprendizado e o maior foi de $73,456 \%$ para a dimensão Análise Crítica, revelando um resultado satisfatório para todas as dimensões.

Constatou-se a existência de uma relação linear entre os Escores Fatoriais das dimensões e a Avaliação Geral de desempenho do gerenciamento de BPM no PNAFE, tendo em vista que:

- $\quad$ a multicolinearidade entre os escores das dimensões foi de grau moderado;

- o valor do coeficiente de determinação $\mathrm{R}^{2}$ igual a 0,802 explica uma expressiva proporção da variância da avaliação geral do desempenho dos gerenciamentos;

- $\quad$ o valor do teste F apresentou significância absoluta de 0,000 , conforme quadro 40, do item 5.2.2.

Estes dados confirmaram a validade do construto.

As duas últimas análises permitiram atingir um dos objetivos principais do estudo (item 1.2.1). Concluiu-se, portanto, que o modelo SMDE-BPM proposto para medição de desempenho do gerenciamento dos BPM do PNAFE foi entendido como fidedigno e válido, transformando-se então no modelo conceitual final SMD-BPM (Apêndice 4).

A tabela 11, da seção 5.2.2, mostrou ainda, numa análise específica de cada dimensão, que apenas as dimensões Relação Causal e Análise Crítica apresentaram influência estatisticamente significante sobre a Avaliação Geral. E que as dimensões que mais contribuíram para esta avaliação, segundo a ordem de importância foram: 

1) Análise Crítica;
2) Relação Causal;
3) Participação;
4) Dinamismo;
5) Aprendizado.

Em última análise, este é outro indicativo importante a ser observado pelos gestores do PNAFE, no sentido de que estas dimensões, na ordem em que foram aqui listadas, consistem naquelas em que a avaliação geral do gerenciamento exigiu maior presença de seus atributos.

\subsection{Contribuições das MANOVAs}

As dimensões do SMD-BPM no PNAFE, cujas médias variaram por Função e por Região, e as variáveis dentro de cada uma delas responsáveis com mais intensidade por esta variação, conforme descrito no item 5.3.2.7, estão resumidas no quadro 38. Também foram incluídas neste quadro as médias de cada variável em destaque, processadas no contexto bivariado, conforme item 5.1.3.2. Este acréscimo teve por objetivo fornecer dados complementares para a sinalização de possíveis problemas em estratos específicos de Função e/ ou Região.

Note-se que as variáveis da dimensão Clareza, em relação à Função, receberam avaliações mais baixas dos gestores da Alta Gerência do que daqueles da Média Gerência. E o inverso aconteceu com as variáveis da dimensão Relação Causal.

Esta análise pode ser útil como indicativo para se pesquisarem as razões de estes atributos com menor média não terem correspondido às expectativas iniciais dos dirigentes estaduais do PNAFE. Portanto, as três variáveis destacadas no quadro 38 na dimensão Clareza-Função devem ser priorizadas pela Alta Gerência, assim como as duas da dimensão Relação CausalFunção devem receber maior atenção da Média Gerência. 
Quadro 38 - Dimensões cujas médias variaram por Função e Região

\begin{tabular}{|c|c|c|c|c|}
\hline Dimensão & $\begin{array}{l}\text { Variável } \\
\text { Ind. }\end{array}$ & Variáveis que mais influenciaram & $\begin{array}{l}\text { Média da } \\
\text { Alta } \\
\text { Gerência }\end{array}$ & $\begin{array}{l}\text { Média da } \\
\text { Média } \\
\text { Gerência }\end{array}$ \\
\hline \multirow[t]{2}{*}{ Aprendizado } & \multirow[t]{2}{*}{ Região } & $\begin{array}{l}\text { comportamento do processo ao longo do tempo } \\
\text { percebido pelo usuário }\end{array}$ & 7,0893 & 6,2034 \\
\hline & & $\begin{array}{l}\text { incentivo ao aprendizado do processo pelos } \\
\text { usuários }\end{array}$ & 7,3966 & 6,5932 \\
\hline \multirow[t]{5}{*}{ Clareza } & \multirow[t]{3}{*}{ Função } & $\begin{array}{l}\text { uso de técnicas de análise estatística para } \\
\text { validação dos resultados das medições }\end{array}$ & 3,4483 & 4,7458 \\
\hline & & $\begin{array}{l}\text { divulgação dos resultados das medições para } \\
\text { todos os envolvidos no processo }\end{array}$ & 5,0345 & 5,8136 \\
\hline & & $\begin{array}{l}\text { facilidade de compreensão de indicadores de } \\
\text { desempenho por todos os usuários }\end{array}$ & 5,0862 & 6,0000 \\
\hline & \multirow[t]{2}{*}{ Região } & $\begin{array}{l}\text { uso de técnicas de análise estatística para } \\
\text { validação dos resultados das medições }\end{array}$ & 3,4483 & 4,7458 \\
\hline & & $\begin{array}{l}\text { clareza na definição das regras (internas) dos } \\
\text { processos }\end{array}$ & 6,5000 & 6,8305 \\
\hline \multirow[t]{2}{*}{ Participação } & Função & - & - & - \\
\hline & Região & - & - & - \\
\hline \multirow[t]{2}{*}{$\begin{array}{l}\text { Relação } \\
\text { Causal }\end{array}$} & \multirow[t]{2}{*}{ Função } & $\begin{array}{llll}\text { influência dos objetivos organizacionais nos } \\
\text { processos }\end{array}$ & 7,4483 & 6,4746 \\
\hline & & $\begin{array}{lllll}\text { impacto de alguns indicadores em } & \text { outros } \\
\text { indicadores de desempenho de processos } & \end{array}$ & 6,2105 & 5,0508 \\
\hline
\end{tabular}

Analogamente, para a dimensão Aprendizado-Região, as duas variáveis arroladas no quadro apresentaram médias superiores para a Alta Gerência em relação à Média Gerência. O contrário aconteceu com a dimensão Clareza-Região, já que os maiores valores de médias das duas variáveis apresentadas foram os da Média Gerência. Neste caso, por exemplo, os gestores nacionais do PNAFE devem averiguar o que justifica os gestores estaduais, de uma determinada região, não identificarem a presença de atributos encontrados em outra região, dentro do mesmo programa de modernização.

Diferentemente das demais, a dimensão Participação não apresentou variáveis mais influentes. Como esta dimensão diz respeito a aspectos como participação de usuários no desenvolvimento do sistema de medição de desempenho dos BPM, motivação e satisfação dos usuários com o sistema, e entendimento e domínio do sistema pelos usuários do sistema, pode-se afirmar que gestores da Alta e Média Gerência, bem como de São Paulo ou dos demais Estados, precisam incentivar a participação de maneira mais efetiva de representantes de diferentes grupos de usuários dos processos na concepção e implantação dos atributos propostos no SMD-BPM. 
A análise dos resultados da MANOVA, apresentada nas tabelas 13 e 14, da seção 5.3.2.7, permitiu ainda indicar as variáveis que, uma vez incluídas na dimensão a que pertencem, mais contribuíram para o aperfeiçoamento do modelo proposto. Estas variáveis estão resumidas no quadro 39 disposto a seguir.

Para a dimensão Participação não houve novamente destaque de variáveis para Função e para Região. Na dimensão Integração, um único atributo pode alavancar o sistema de medição de desempenho de BPM para Função e Região: a integração dos indicadores de desempenho com sistemas de negócio contribuiu ao mesmo tempo para Função e Região.

No conjunto de dez variáveis da dimensão Equilíbrio, os atributos - equilíbrio entre medidas de eficiência e efetividade e o conhecimento de ameaças e oportunidades no ambiente externo da organização - foram os que mais impulsionaram a melhoria do modelo.

A dimensão Alinhamento foi a que apresentou maior número de variáveis contributivas. Cinco para Função e para Região, sendo quatro iguais para ambas. Neste caso, para um rol de 14 variáveis da dimensão, o impacto na dimensão para aperfeiçoamento do modelo se encontra mais dividido, requerendo dos gestores um enfoque menos concentrado em determinados atributos.

As variáveis discriminadas na coluna à direita do quadro 39 encontram-se listadas em ordem de prioridade conforme o grau de contribuição na dimensão de cada uma delas para a melhoria do modelo.

A contribuição do conteúdo deste quadro aos gestores nacionais ou estaduais do PNAFE vem no sentido de que possam vislumbrar os atributos que necessitam ser enfatizados para se alcançarem melhores resultados nos sistemas de medição de desempenho do gerenciamento de seus processos de negócio. 


\section{Quadro 39 - Variáveis que mais contribuíram para a melhoria do modelo}

\begin{tabular}{|c|c|c|}
\hline Dimensão & V. Ind. & Variáveis que mais contribuíram para melhorar o modelo \\
\hline \multirow[t]{6}{*}{ Aprendizado } & \multirow[t]{4}{*}{ Função } & comportamento do processo ao longo do tempo percebido pelo usuário \\
\hline & & apoio ao debate entre usuários de diversos níveis hierárquicos \\
\hline & & incentivo ao aprendizado do processo pelos usuários \\
\hline & & visão crítica para o aperfeiçoamento do processo \\
\hline & \multirow[t]{2}{*}{ Região } & comportamento do processo ao longo do tempo percebido pelo usuário \\
\hline & & assimilação das iniciativas de melhoria \\
\hline \multirow[t]{5}{*}{ Clareza } & \multirow[t]{2}{*}{ Função } & uso de técnicas de análise estatística para validação dos resultados das medições \\
\hline & & facilidade de compreensão de indicadores de desempenho por todos os usuários \\
\hline & \multirow[t]{3}{*}{ Região } & uso de técnicas de análise estatística para validação dos resultados das medições \\
\hline & & clareza na definição da fonte de dados para medir desempenho de processos \\
\hline & & clareza na definição das regras (internas) dos processos \\
\hline \multirow[t]{7}{*}{ Dinamismo } & \multirow[t]{4}{*}{ Função } & acompanhamento da medição de desempenho do processo ao longo do tempo \\
\hline & & coleta de dados automatizada para alimentação do sistema de medição \\
\hline & & flexibilidade na modificação de indicadores de desempenho \\
\hline & & customização dos indicadores às necessidades de diferentes grupos de usuários \\
\hline & \multirow[t]{3}{*}{ Região } & acompanhamento da medição de desempenho do processo ao longo do tempo \\
\hline & & coleta de dados automatizada para alimentação do sistema de medição \\
\hline & & flexibilidade na modificação de indicadores de desempenho \\
\hline \multirow[t]{2}{*}{ Integração } & Função & integração dos indicadores de desempenho com sistemas de negócio (ex ERP) \\
\hline & Região & integração dos indicadores de desempenho com sistemas de negócio (ex ERP) \\
\hline \multirow[t]{10}{*}{ Alinhamento } & \multirow[t]{5}{*}{ Função } & uso de medidas de desempenho alinhadas com o custo do processo \\
\hline & & uso de medidas de desempenho alinhadas com o resultado do processo \\
\hline & & cobertura de todas as áreas funcionais da organização por onde passa o processo \\
\hline & & $\begin{array}{l}\text { uso de medidas de desempenho similares em processos semelhantes de outras áreas } \\
\text { funcionais }\end{array}$ \\
\hline & & direcionamento aos processos-chave de negócio \\
\hline & \multirow[t]{5}{*}{ Região } & $\begin{array}{l}\text { uso de medidas de desempenho similares em processos semelhantes de outras áreas } \\
\text { funcionais }\end{array}$ \\
\hline & & uso de medidas de desempenho alinhadas com a qualidade do processo \\
\hline & & uso de medidas de desempenho alinhadas com o resultado do processo \\
\hline & & uso de medidas de desempenho alinhadas com o custo do processo \\
\hline & & cobertura de todas as áreas funcionais da organização por onde passa o processo \\
\hline \multirow[t]{2}{*}{ Participação } & Função & - \\
\hline & Região & - \\
\hline \multirow{6}{*}{$\begin{array}{l}\text { Relação } \\
\text { Causal }\end{array}$} & \multirow[t]{2}{*}{ Função } & influência dos objetivos organizacionais nos processos \\
\hline & & impacto de medidas de resultado em medidas de alavancagem de processos \\
\hline & \multirow[t]{4}{*}{ Região } & impacto de medidas de resultado em medidas de alavancagem de processos \\
\hline & & impacto de alguns indicadores em outros indicadores de desempenho de processos \\
\hline & & $\begin{array}{l}\text { influência do desempenho passado no planejamento do desempenho futuro dos } \\
\text { processos }\end{array}$ \\
\hline & & influência dos objetivos organizacionais nos processos \\
\hline \multirow[t]{4}{*}{ Equilíbrio } & \multirow[t]{2}{*}{ Função } & equilíbrio entre medidas de eficiência e efetividade do processo \\
\hline & & conhecimento de ameaças e oportunidades no ambiente externo da organização \\
\hline & \multirow[t]{2}{*}{ Região } & equilíbrio entre medidas de eficiência e efetividade do processo \\
\hline & & conhecimento de ameaças e oportunidades no ambiente externo da organização \\
\hline \multirow{9}{*}{$\begin{array}{l}\text { Análise } \\
\text { Crítica }\end{array}$} & \multirow[t]{5}{*}{ Função } & capacidade de auditoria da medição de desempenho \\
\hline & & envolvimento de usuários na crítica dos indicadores de desempenho do processo \\
\hline & & integração e correlação entre indicadores de desempenho \\
\hline & & conhecimento do desempenho do processo no presente \\
\hline & & conhecimento do desempenho do processo no passado \\
\hline & Região & conhecimento do desempenho do processo no presente \\
\hline & & conhecimento do desempenho do processo no passado \\
\hline & & envolvimento de usuários na crítica dos indicadores de desempenho do processo \\
\hline & & integração e correlação entre indicadores de desempenho \\
\hline
\end{tabular}




\subsection{Contribuições das Regressões Logísticas}

A aplicação da técnica estatística da Regressão Logística permitiu destacar, entre os aspectos importantes, as variáveis que de fato mais distinguiram os processos de gerenciamento satisfatório do insatisfatório. Resumo da tabela 17, descrita na seção 5.3.3.9, o quadro 40 apresenta na coluna do meio as variáveis que promoveram esta distinção.

Quadro 40 - Variáveis que mais distinguem o grau do gerenciamento

\begin{tabular}{|c|c|c|c|c|}
\hline Dimensão & Var & $\begin{array}{l}\text { Variáveis que distinguem o gerenciamento satisfatório do } \\
\text { insatisfatório }\end{array}$ & $\begin{array}{c}\text { Coef } \\
\beta\end{array}$ & $\begin{array}{c}\operatorname{Exp} \\
(\beta)\end{array}$ \\
\hline \multirow[t]{3}{*}{ Aprendizado } & v16 & $\begin{array}{l}\text { coerência com técnicas administrativas de melhoria contínua do } \\
\text { processo }\end{array}$ &, 851 & 2,342 \\
\hline & $\mathrm{v} 14$ & identificação de conflitos entre indicadores de desempenho do processo & ,361 & 1,435 \\
\hline & v5 & conhecimento do processo como um todo pelos usuários & ,454 & 1,574 \\
\hline \multirow[t]{2}{*}{ Clareza } & v21 & $\begin{array}{l}\text { clareza na definição da fonte de dados para medir desempenho de } \\
\text { processos }\end{array}$ & 451 & 1,570 \\
\hline & v18 & clareza na definição de metas e objetivos dos processos & 479 & 1,615 \\
\hline \multirow[t]{4}{*}{ Dinamismo } & $\mathrm{v} 41$ & $\begin{array}{l}\text { monitoramento de parâmetros críticos para detectar mudanças no } \\
\text { ambiente interno }\end{array}$ & ,927 & 2,527 \\
\hline & v35 & $\begin{array}{l}\text { identificação de medidas de desempenho indicativas de progressos dos } \\
\text { processos }\end{array}$ & 609 & 1,839 \\
\hline & v44 & $\begin{array}{l}\text { acompanhamento da medição de desempenho do processo ao longo do } \\
\text { tempo }\end{array}$ & 1,052 & 2,863 \\
\hline & v39 & informação pertinente em tempo real para toda a organização &,- 944 & 0,389 \\
\hline \multirow[t]{2}{*}{ Integração } & v47 & $\begin{array}{l}\text { integração dos indicadores de desempenho com o sistema de gestão da } \\
\text { organização }\end{array}$ & ,490 & 1,633 \\
\hline & $\mathrm{v} 49$ & ênfase maior nas medidas de avaliação de equipe sobre as individuais & ,222 & 1,248 \\
\hline \multirow[t]{3}{*}{ Alinhamento } & v52 & $\begin{array}{l}\text { uso de medidas de desempenho do processo derivadas da estratégia da } \\
\text { organização }\end{array}$ & ,458 & 1,581 \\
\hline & v59 & $\begin{array}{l}\begin{array}{l}\text { uso de medidas de desempenho do processo alinhadas com o } \\
\text { crescimento futuro do negócio }\end{array} \\
\end{array}$ & ,377 & 1,458 \\
\hline & v64 & uso de indicadores segundo a estrutura hierárquica da organização & ,210 & 1,233 \\
\hline \multirow[t]{2}{*}{ Participação } & v66 & participação de usuários no desenvolvimento do sistema de medição & ,652 & 1,920 \\
\hline & v70 & $\begin{array}{l}\text { alteração do sistema de medição a partir de reclamações e sugestões de } \\
\text { usuários }\end{array}$ & 297 & 1,345 \\
\hline \multirow{2}{*}{$\begin{array}{l}\text { Relação } \\
\text { Causal }\end{array}$} & v74 & influência dos indicadores de desempenho nas ações organizacionais & ,692 & 1,997 \\
\hline & v72 & influência dos objetivos organizacionais nos processos & ,364 & 1,439 \\
\hline \multirow[t]{4}{*}{ Equilíbrio } & $\mathrm{v} 84$ & uso de indicadores de todas as áreas envolvidas no processo & ,688 & 1,990 \\
\hline & v79 & equilíbrio entre medidas de eficiência e de eficácia &, 372 & 1,450 \\
\hline & v78 & equilíbrio entre medidas de desempenho financeiras e não financeiras &,- 541 &, 582 \\
\hline & v81 & equilíbrio entre medidas quantitativas e qualitativas &, 410 & 1,507 \\
\hline \multirow[t]{2}{*}{$\begin{array}{l}\text { Análise } \\
\text { Crítica }\end{array}$} & v89 & $\begin{array}{l}\text { envolvimento de usuários na crítica dos indicadores de desempenho do } \\
\text { processo }\end{array}$ & ,619 & 1,856 \\
\hline & v95 & projeção do desempenho do processo no futuro & ,644 & 1,905 \\
\hline
\end{tabular}

Por exemplo: para a dimensão Alinhamento, o gestor do programa que desejar ver o seu gerenciamento bem referendado, deve atentar prioritariamente para os seguintes atributos: uso de medidas de desempenho do processo derivadas da estratégia da organização; uso de 
medidas de desempenho do processo alinhadas com o crescimento futuro do negócio; e uso de indicadores segundo a estrutura hierárquica da organização.

As colunas do Coeficiente $\beta$ e de $\operatorname{Exp}(\beta)$ do quadro, explicados em detalhe na seção 5.3.3, indicam a ordem e a ponderação dos atributos para a realização desta distinção. Portanto, nos moldes do exemplo da dimensão Aprendizado, o gestor pode reconhecer, para as demais dimensões, aquelas que dentro do PNAFE mais discriminaram a avaliação do gerenciamento satisfatório do insatisfatório.

Um dado curioso foi encontrado nas dimensões Dinamismo e Equilíbrio. O coeficiente $\beta$ das variáveis v39 - informação pertinente em tempo real e v78 - equilíbrio entre medidas de desempenho financeiras e não financeiras apresentou valor negativo. Em outras palavras, mantendo-se constantes os outros coeficientes logísticos do modelo, o aumento de uma unidade em v39 e para v78 diminuiria a probabilidade de um processo ser classificado como bem gerenciado. Logo, segundo a ótica dos gestores entrevistados, os esforços despendidos nas variáveis v39 e v78 foram vistos como infrutíferos na forma de agentes propulsores para a melhoria do gerenciamento dos processos de negócio do PNAFE.

A tabela 16, da seção 5.3.3.9, exibiu a regressão logística para os escores fatoriais das dimensões. Neste quadro as duas dimensões que mais distinguiram o gerenciamento satisfatório de insatisfatório foram a Análise Crítica e o Aprendizado, sendo o valor $\operatorname{Exp}(\beta)$ da primeira praticamente o dobro da segunda.

Assim, aliando-se os resultados das nove regressões logísticas por dimensão e daquela com as dimensões consolidadas, uma informação importante para os gestores é que entre todas as variáveis elencadas no quadro 40 , distribuídas por suas dimensões, as que mais se destacaram em todo o modelo SMD-BPM, segundo a ordem de influência, distinguindo o gerenciamento satisfatório do insatisfatório, foram:

- na Análise Crítica: o envolvimento de usuários na crítica dos indicadores de desempenho do processo e a projeção do desempenho do processo no futuro;

- no Aprendizado: a coerência com técnicas administrativas de melhoria contínua do processo, o conhecimento do processo como um todo pelos usuários e a identificação de conflitos entre indicadores de desempenho do processo. 
Ainda como contribuição para os gestores do PNAFE pode-se, a partir das variáveis do quadro 40, selecionar aquelas que, entre todas de cada dimensão, possuíram o maior poder discriminante na diferenciação entre o gerenciamento satisfatório do insatisfatório. Esta seleção, conforme quadro 41, serve como uma síntese do modelo do SMD-BPM, para que num primeiro momento, por exemplo, os gestores possam direcionar a medição de desempenho de novos BPM, ou de processos de negócio em andamento, não se preocupando em atender simultaneamente a todos os atributos do modelo validado.

Esta síntese atende às observações realizadas pela comunidade acadêmica e por dirigentes de organizações no sentido de que um enfoque mais efetivo da medição de desempenho se resume em identificar um conjunto mínimo de medidas críticas, capaz de detectar quando o desempenho global de um processo passa à condição de inaceitável.

Com esta espécie de resumo de modelo do SMD-BPM, os gestores do PNAFE podem, na falta de condições de se implantar o modelo completo, direcionarem os trabalhos de gerenciamento de seus processos de negócio, no sentido de se empenharem mais no atendimento dos seguintes atributos:

\section{Quadro 41 - Variáveis que compõem uma síntese do modelo SMD-BPM}

\begin{tabular}{|l|c|l|}
\hline \multicolumn{1}{|c|}{ Dimensão } & Var & \multicolumn{1}{c|}{ Variáveis que mais distinguem o gerenciamento por dimensão } \\
\hline Aprendizado & v16 & coerência com técnicas administrativas de melhoria contínua do processo \\
\hline Clareza & v18 & clareza na definição de metas e objetivos dos processos \\
\hline Dinamismo & v44 & acompanhamento da medição de desempenho do processo ao longo do tempo \\
\hline Integração & v47 & integração dos indicadores de desempenho com o sistema de gestão da organização \\
\hline Alinhamento & v52 & uso de medidas de desempenho do processo derivadas da estratégia da organização \\
\hline Participação & v66 & participação de usuários no desenvolvimento do sistema de medição \\
\hline Relação Causal & v74 & influência dos indicadores de desempenho nas ações organizacionais \\
\hline Equilíbrio & v84 & uso de indicadores de todas as áreas envolvidas no processo \\
\hline Análise Crítica & v95 & projeção do desempenho do processo no futuro \\
\hline
\end{tabular}




\subsection{Contribuições do Escalonamento Multidimensional}

De acordo com a figura 14, da seção 5.3.4, os macro-processos classificados como de Organização e Gestão e Área Financeira guardam similaridades, bem como os macroprocessos do grupo Declarações com os da Área Tributária. Este resultado já era esperado, uma vez que a ligação entre dirigentes das áreas de coordenação geral do PNAFE e das subcoordenadorias financeiras é mais estreito, comparativamente aos dirigentes das subcoordenadorias tributárias. Inclusive, houve casos, constatados no programa, de dirigentes que avocaram para si as duas funções, ainda que temporariamente, por conta desta afinidade.

De maneira semelhante, os gestores dos macro-processos classificados como Declarações estão bem mais próximos daqueles da Área Tributária, por serem uma espécie de subconjunto dos macro-processos tributários.

O que chama a atenção é o fato de os macro-processos do grupo Cadastro terem apresentado posição tão díspare dos processos tributários, sendo o grupo cadastral também uma espécie de subconjunto da Área Tributária. No eixo das ordenadas, rotulado como Clareza e Alinhamento, enquanto os quatro outros grupos de macro-processos indicaram que estas dimensões estiveram presentes nos seus projetos, o macro-processo Cadastro se ressentiu significativamente da presença dos atributos destas dimensões. Este dado serve de alerta aos gestores dos processos de Cadastro: buscarem sobremaneira valorizar os atributos das dimensões Clareza e Alinhamento, de forma a apresentarem resultado semelhante ao apresentado pelos demais macro-processos.

Outra dicotomia se deu com o eixo das abscissas do mapa perceptual, rotulado com as dimensões Integração e Análise Crítica, conforme tabela 19, da seção 5.3.4. Enquanto os macro-processos dos grupos Declarações e Área Tributária identificaram mais fortemente, e do grupo Cadastro, mais discretamente, a presença de atributos destas duas dimensões, os macro-processos da Área Financeira e de Organização e Gestão se ressentiram deles. Para os gestores dos processos financeiros e de gestão nacional e estadual do PNAFE resta buscar o porquê de as variáveis das dimensões Integração e Análise Crítica terem se comportado tão antagônica e diferentemente dos resultados alcançados pelos processos tributários. 
Outro aspecto interessante é tirado da tabela 19, da seção 5.3.4, e diz respeito aos processos que se destacaram por exibirem bom ou mau desempenho, em relação às nove dimensões do SMD-BPM. A partir dos escores fatoriais pôde-se constatar que no gerenciamento dos BPM os macro-processos da Área Tributária e de Declarações apresentaram valores positivos, e os de Organização e Gestão e da Área Financeira, valores negativos, em todas as dimensões. Em relação aos macro-processos do grupo Cadastro, os valores ficaram distribuídos entre positivos e negativos.

Estes resultados sinalizam para a coordenação geral do PNAFE que os macro-processos da Área Financeira e de Organização e Gestão foram os que apresentaram pior desempenho no gerenciamento de seus BPM em relação aos demais. E os conjuntos de macro-processos da Área Tributária e de Declarações foram os melhores.

O quadro 42 apresenta para cada um dos cinco grupos de macro-processos do PNAFE, as dimensões nas quais cada um apresentou os melhores e os piores desempenhos. Por exemplo, um bom indicativo para os gestores dos processos de negócio do grupo Organização e Gestão, que na análise anterior apresentou junto com os macro-processos financeiros pior desempenho no gerenciamento do que os demais, é dar atenção especial aos atributos com pior avaliação, ou seja, menos presentes no seu sistema de medição de desempenho de BPM pertencentes às dimensões Aprendizado e Relação Causal. Em contrapartida, nos macro-processos do grupo Declarações, de melhor desempenho em relação aos demais, cabe entender que as dimensões mais perceptíveis pelos gestores foram Dinamismo e Integração.

Quadro 42 - Dimensões do SMD-BPM relacionadas aos macro-processos

\begin{tabular}{|c|c|c|}
\hline Macro-processos & Melhores Dimensões & Piores Dimensões \\
\hline \multirow[t]{2}{*}{ Área Tributária } & 1. Relação Causal & 1. Alinhamento \\
\hline & 2. Dinamismo & 2. Clareza \\
\hline \multirow[t]{2}{*}{ Cadastro } & 1. Relação Causal & 1. Clareza \\
\hline & 2. Aprendizado & 2. Alinhamento \\
\hline \multirow[t]{2}{*}{ Declarações } & 1. Dinamismo & 1. Equilíbrio \\
\hline & 2. Integração & 2. Participação \\
\hline \multirow[t]{2}{*}{ Área Financeira } & 1. Clareza & 1. Relação Causal \\
\hline & 2. Aprendizado & 2. Dinamismo \\
\hline \multirow[t]{2}{*}{ Organização e Gestão } & 1. Alinhamento & 1. Aprendizado \\
\hline & 2. Clareza & 2. Relação Causal \\
\hline
\end{tabular}




\subsection{Contribuições do modelo arquitetônico RiverFish}

O quadro 43 exibe a relação entre as propriedades do modelo de arquitetura RiverFish, explicadas na seção 2.3, e as variáveis que mais influíram para o aperfeiçoamento do SMDBPM, obtidas da aplicação da MANOVA. Note-se que na maior parte das variáveis das dimensões, ao menos uma propriedade do RiverFish pôde ser associada. Nos casos em que a variável esteve relacionada qualitativamente com mais de uma propriedade, optou-se pela de mais forte associação.

As quatro principais propriedades do modelo arquitetônico RiverFish para controle de BPM, estão indicadas na segunda coluna do quadro RF da seguinte forma:

1) Reaproveitamento;

2) Formalização;

3) Instanciação;

4) Precisão na localização de interações.

Um exemplo de como as propriedades da arquitetura RiverFish, associadas aos atributos dos sistemas de medição de desempenho organizacional, contribuíram para a composição do modelo do SMD-BPM é dado em relação à propriedade Reaproveitamento (também conhecida como Re-configuração). As dimensões e variáveis que se identificaram com esta propriedade foram: em Dinamismo - flexibilidade na modificação de indicadores de desempenho; em Relação Causal - impacto de alguns indicadores em outros indicadores de desempenho de processos e influência do desempenho passado no planejamento do desempenho futuro dos processos.

A flexibilidade na modificação de indicadores indica a capacidade do sistema de medição de desempenho em se adaptar a novas demandas, ou seja, de re-configurar seus indicadores de resultados ou seus mecanismos de controle dos BPM. Já o impacto de alguns indicadores em outros indicadores está relacionado ao reaproveitamento do conhecimento anterior agindo sobre indicadores de resultados de outras áreas. E a influência do desempenho passado no planejamento do desempenho futuro também reutiliza a experiência anterior do SMD para planejar ou re-configurar os instrumentos de medição de processos novos ou redesenhados. 


\section{Quadro 43 - Propriedades do RF encontradas nas variáveis mais influentes do modelo}

\begin{tabular}{|c|c|c|}
\hline Dimensão & RF & Variáveis que mais contribuíram para melhorar o modelo \\
\hline \multirow[t]{5}{*}{ Aprendizado } & 2 & comportamento do processo ao longo do tempo percebido pelo usuário \\
\hline & - & apoio ao debate entre usuários de diversos níveis hierárquicos \\
\hline & 3 & incentivo ao aprendizado do processo pelos usuários \\
\hline & 2 & visão crítica para o aperfeiçoamento do processo \\
\hline & 3 & assimilação das iniciativas de melhoria \\
\hline \multirow[t]{4}{*}{ Clareza } & 2 & uso de técnicas de análise estatística para validação dos resultados das medições \\
\hline & 3 & facilidade de compreensão de indicadores de desempenho por todos os usuários \\
\hline & 4 & clareza na definição da fonte de dados para medir desempenho de processos \\
\hline & 4 & clareza na definição das regras (internas) dos processos \\
\hline \multirow[t]{4}{*}{ Dinamismo } & 2 & acompanhamento da medição de desempenho do processo ao longo do tempo \\
\hline & 3 & coleta de dados automatizada para alimentação do sistema de medição \\
\hline & 1 & flexibilidade na modificação de indicadores de desempenho \\
\hline & 3 & customização dos indicadores às necessidades de diferentes grupos de usuários \\
\hline Integração & 4 & integração dos indicadores de desempenho com sistemas de negócio (ex: ERP) \\
\hline \multirow[t]{6}{*}{ Alinhamento } & 2 & uso de medidas de desempenho alinhadas com o custo do processo \\
\hline & 2 & uso de medidas de desempenho alinhadas com o resultado do processo \\
\hline & 3 & cobertura de todas as áreas funcionais da organização por onde passa o processo \\
\hline & 2 & uso de medidas de desempenho similares em processos semelhantes de outras áreas \\
\hline & - & direcionamento aos processos-chave de negócio \\
\hline & 2 & uso de medidas de desempenho alinhadas com a qualidade do processo \\
\hline \multirow{4}{*}{$\begin{array}{l}\text { Relação } \\
\text { Causal }\end{array}$} & 2 & influência dos objetivos organizacionais nos processos \\
\hline & 4 & impacto de medidas de resultado em medidas de alavancagem de processos \\
\hline & 1 & impacto de alguns indicadores em outros indicadores de desempenho de processos \\
\hline & 1 & $\begin{array}{l}\text { influência do desempenho passado no planejamento do desempenho futuro dos } \\
\text { processos }\end{array}$ \\
\hline \multirow[t]{2}{*}{ Equilíbrio } & 2 & equilíbrio entre medidas de eficiência e efetividade do processo \\
\hline & 4 & conhecimento de ameaças e oportunidades no ambiente externo da organização \\
\hline \multirow{5}{*}{$\begin{array}{l}\text { Análise } \\
\text { Crítica }\end{array}$} & 2 & capacidade de auditoria da medição de desempenho \\
\hline & 2 & envolvimento de usuários na crítica dos indicadores de desempenho do processo \\
\hline & 2 & integração e correlação entre indicadores de desempenho \\
\hline & 2 & conhecimento do desempenho do processo no presente \\
\hline & 2 & conhecimento do desempenho do processo no passado \\
\hline
\end{tabular}

Uma outra associação das propriedades do RiverFish pôde ser feita com as variáveis que mais distinguiram o gerenciamento satisfatório de BPM do PNAFE do insatisfatório, resultado da aplicação da regressão logística. O quadro 43 exibe os resultados encontrados. Da mesma forma que no quadro anterior, a coluna RF indica a propriedade do RiverFish encontrada na variável. No caso de mais de uma, foi escolhida a de mais forte afinidade. Apenas em quatro variáveis elencadas não foi possível encontrar uma associação indubitável.

A conclusão curiosa a que se chegou, analisando os resultados desta associação, foi a presença majoritária da propriedade Formalização. Conforme relatado na seção 2.3, o desenvolvimento de qualquer processo de negócio deve ser definido por um plano de navegação. Este plano serve como um registro formal das transições ao qual um dado é submetido durante todo o processo. O Plano de Navegação, apoiado na Álgebra de Processos, 
é composto por um conjunto de símbolos de ações (eventos), de operações e de axiomas descrevendo de maneira formal todo o processo.

Em outras palavras, esta propriedade exige que todo o processo seja registrado formalmente em seus diversos aspectos, a fim de assegurar que sua medição de desempenho seja eficaz, além das vantagens oriundas do conhecimento, modelagem, possibilidade de redesenho e sistematização dos processos que o formalismo traz.

As variáveis da dimensão Equilíbrio, por exemplo, ratificam este raciocínio. Os atributos uso de indicadores de todas as áreas envolvidas no processo; equilíbrio entre medidas de eficiência e de eficácia; e equilíbrio entre medidas quantitativas e qualitativas - remetem obrigatoriamente à existência de registros formalizados de medidas de desempenho.

Até mesmo o atributo de equilíbrio entre medidas de desempenho financeiras e não financeiras, classificado como de maior afinidade com a propriedade Instanciação, também possui intrinsecamente este caráter de formalização de registros.

Quadro 44 - Propriedades do RF na distinção da qualidade do gerenciamento

\begin{tabular}{|c|c|c|}
\hline Dimensão & RF & Variáveis que mais distinguiram o gerenciamento satisfatório do insatisfatório \\
\hline \multirow[t]{3}{*}{ Aprendizado } & 2 & coerência com técnicas administrativas de melhoria contínua do processo \\
\hline & 2 & identificação de conflitos entre indicadores de desempenho do processo \\
\hline & 2 & conhecimento do processo como um todo pelos usuários \\
\hline \multirow[t]{2}{*}{ Clareza } & 4 & clareza na definição da fonte de dados para medir desempenho de processos \\
\hline & 2 & clareza na definição de metas e objetivos dos processos \\
\hline \multirow[t]{4}{*}{ Dinamismo } & 2 & monitoramento de parâmetros críticos para detectar mudanças no ambiente interno \\
\hline & 2 & identificação de medidas de desempenho indicativas de progressos dos processos \\
\hline & 2 & acompanhamento da medição de desempenho do processo ao longo do tempo \\
\hline & - & informação pertinente em tempo real para toda a organização \\
\hline \multirow[t]{2}{*}{ Integração } & 2 & integração dos indicadores de desempenho com o sistema de gestão da organização \\
\hline & - & ênfase maior nas medidas de avaliação de equipe sobre as individuais \\
\hline \multirow[t]{3}{*}{ Alinhamento } & 2 & uso de medidas de desempenho do processo derivadas da estratégia da organização \\
\hline & 2 & $\begin{array}{l}\text { uso de medidas de desempenho do processo alinhadas com o crescimento futuro do } \\
\text { negócio }\end{array}$ \\
\hline & 2 & uso de indicadores segundo a estrutura hierárquica da organização \\
\hline \multirow[t]{2}{*}{ Participação } & - & participação de usuários no desenvolvimento do sistema de medição \\
\hline & - & alteração do sistema de medição a partir de reclamações e sugestões de usuários \\
\hline \multirow{2}{*}{$\begin{array}{l}\text { Relação } \\
\text { Causal }\end{array}$} & 2 & influência dos indicadores de desempenho nas ações organizacionais \\
\hline & 2 & influência dos objetivos organizacionais nos processos \\
\hline \multirow[t]{4}{*}{ Equilíbrio } & 2 & uso de indicadores de todas as áreas envolvidas no processo \\
\hline & 2 & equilíbrio entre medidas de eficiência e de eficácia \\
\hline & 3 & equilíbrio entre medidas de desempenho financeiras e não financeiras \\
\hline & 2 & equilíbrio entre medidas quantitativas e qualitativas \\
\hline \multirow{2}{*}{$\begin{array}{l}\text { Análise } \\
\text { Crítica }\end{array}$} & 1 & envolvimento de usuários na crítica dos indicadores de desempenho do processo \\
\hline & 2 & projeção do desempenho do processo no futuro \\
\hline
\end{tabular}




\subsection{Limitações do Estudo}

As limitações de um estudo possuem diversas ordens. A primeira pode ser considerada como de caráter operacional e se deu por conta da impossibilidade geográfica do deslocamento do pesquisador para a aplicação dos formulários de entrevistas aos gerentes de macro-projeto, líderes de projetos e membros de equipes de projetos de modernização de todos os estados da federação, excetuando-se São Paulo.

Em que pese o empenho da UCE-SP e da coordenação do PNAFE, com o apoio da UCE-RS, e a facilidade trazida pela e-survey, o pesquisador sentiu uma segunda limitação pela necessidade de um trabalho de conscientização pessoal com os entrevistados de outros estados, a fim de que a pesquisa não adquirisse um caráter institucional e compulsório do programa, ou que fosse encarada como uma obrigação ou cobrança a mais nas atividades cotidianas dos gestores.

A terceira foi de caráter temporal. O estudo pôde contemplar, de maneira pontual e em determinado estágio de desenvolvimento do programa, somente a medição de desempenho dos BPM num curto espaço de tempo. Não foi possível traçar uma curva de tendência dos resultados ao longo do tempo.

A quarta limitação diz respeito ao entendimento e julgamento humano. Em que pese a preocupação do pesquisador com a objetividade e clareza das questões, podem ser considerados como fatores de risco aqueles que vão desde a interpretação e compreensão dos atributos do questionário, até a imprevisibilidade do uso dos resultados deste estudo e possíveis questionamentos sobre a qualidade do gerenciamento de BPM no PNAFE até então.

A quinta foi de natureza metodológica. Neste contexto, várias restrições foram constatadas tais como:

a) o perfil dos entrevistados da amostra incluiu apenas dirigentes e não usuários dos macro-processos do PNAFE;

b) a validação do modelo deve ser verificada em outros estágios (momentos) de desenvolvimento do programa; 
c) o não atendimento da normalidade multivariada a fim de garantir a confiabilidade de algumas técnicas de análise multivariada;

d) o fato de algumas variâncias para explicação por escore fatorial ficarem abaixo do limite mínimo ideal de 70\%;

e) a desproporção da amostra total para com o número de parâmetros exigidos a fim de que se possibilitasse a aplicação da análise fatorial confirmatória das dimensões.

\subsection{Algumas propostas para pesquisas futuras}

Uma contribuição importante para a evolução do presente estudo, como sugestão para futuras pesquisas, seria a aplicação do SMD-BPM, ainda no âmbito do PNAFE, em macro-processos de outros estados da federação, não se restringindo aos gestores da Alta Gerência aqui abordados. Ou ainda, uma pesquisa sazonal dentro do programa, a fim de que não se tenha apenas uma impressão momentânea do desempenho do gerenciamento de BPM, mas que se possa obter um entendimento do SMD-BPM ao longo do tempo.

Extrapolando as fronteiras do PNAFE, porém ainda na esfera da administração pública, o modelo pode ser ampliado e aperfeiçoado se aplicado não somente no contexto das administrações estaduais fazendárias, mas em qualquer organização pública da esfera municipal, estadual e federal brasileira ou estrangeira.

Com um escopo ainda maior, seria de grande valia o aproveitamento do levantamento bibliográfico apresentado, em sinergia com o modelo arquitetônico RiverFish, suas eventuais extensões e aprimoramentos, ou ainda com a adaptação de outro modelo de controle e gerenciamento de processos de negócio, a fim de se customizar o modelo SMD-BPM proposto a organizações da iniciativa privada nacionais ou do exterior. 


\section{REFERÊNCIAS BIBLIOGRÁFICAS}

AAKER, D. A.; KUMAR, V.; DAY, G. S. Marketing Research. 5. ed. New York: John Wiley \& Sons, 1995.

AALST, W. M. P. van der. Making Work Flow: on the application of Petri nets to Business Process Management. In: ESPARZA, J.; LAKOS, C. (Org.) Application and Theory of Petri Nets 2002, Lecture Notes in Computer Science. Berlin: Springer-Verlag, v. 2360, p.1-22, 2002.

AALST, W. M. P. van der; BERENS, P. J. S. Beyond Workflow Management: product-driven case handling, Group'01, ACM. Colorado, USA: Boulder, p. 42-51, Set./Oct. 2001.

AALST, W. M. P. van der; DONGEN, B. F. van; HERBST, J.; MARUSTER, L.; SCHIMM, G.; WEIJTERS, A. J. M. M. Workflow Mining: a survey of issues and approaches. Data and Knowledge Engineering, 2003a.

AALST, W. M. P. van der; HEE, K. M. van. Workflow Management: models, methods and systems. Cambridge: MIT Press, 2002.

AALST, W. M. P. van der; HOFSTEDE, A. H. M. ter; WESKE, M. Business Process Management: A Survey. In: AALST, W.M.P. van der, HOFSTEDE, A.H.M. ter; WESKE, M. (Org.) INTERNATIONAL CONFERENCE ON BUSINESS PROCESS MANAGEMENT (BPM 2003), Lecture Notes in Computer Science. Berlin: Springer-Verlag, p. 1-12, 2003 b.

ARMISTEAD, C.; PRITCHARD, J. P.; MACHIN, S. Strategic Business Process Management for Organisational Effectiveness. Long Range Planning. n. 1, v. 32, p. 96-106, 1999.

BERGSTRA, J. A.; MIDDELBURG, C. A. Process algebra for hybrid systems. Computer Science Report 03-06. Eindhoven: Department of Mathematics and Computer Science, University of Technology, Jun. 2003.

BERGStRA, J. A.; PONSE, A.; SMOKA, S. A. (Org.) Handbook of Process Algebra. Amsterdam: Elsevier Science B. V., 2001.

BITITCI, U. S.; TURNER, T.; BEGEMANN, C. Dynamics of performance measurement systems. International Journal of Operations \& Production Management, v. 20, n. 6, p. 692-704, 2000.

BOURNE, M.; MILlS, J.; WILCOX, M.; NEELY, A.; PLATTS, K. Designing, implementing and updating performance measurement systems. International Journal of Operations \& Production Management, v. 20, n. 7, p. 754-771, 2000.

BRASIL. Ministério da Fazenda. Secretaria Executiva. Unidade de Coordenação de Programas - UCP. Governo Eletrônico e as Administrações Tributárias Estaduais Brasileiras: quarto benchmark 2005. Brasília: PNAFE, Ago. 2005a, 55p. 
BRASIL. Ministério da Fazenda. Secretaria Executiva. Unidade de Coordenação de Programas - UCP. Governo Eletrônico e as Administrações Tributárias Estaduais Brasileiras: terceiro benchmark 2002. Brasília: PNAFE, Out. 2002, 25p.

BRASIL. Ministério da Fazenda. Secretaria Executiva. Unidade de Coordenação de Programas - UCP. Modernização Fiscal dos Estados Brasileiros. Brasília: PNAFE, Mai. 2005b, 40p.

BRASIL. Ministério do Planejamento, Orçamento e Gestão. Secretaria de Orçamento Federal. Programa 1171: Fortalecimento da Administração Fiscal dos Estados - PNAFE. Brasília, 2005c.

BRYMAN, A. Research methods and organization studies. London: Routledge, 1989.

BURBECK, S. The Tao of e-Business Services. IBM Corporation, 2000. Disponível em: <http://www-4.ibm.com/software/developer/library/ws-tao/index.html>. Acesso em: 04/07/2005.

BURLTON, R. Business Process Management: profiting from process. Indianapolis: Sams, 2001.

CASTELLS, M. A sociedade em rede. Trad. Roneide Venâncio Majer. 3.ed. São Paulo: Paz e Terra, 1999. 1v.

CLARK, L. A. Development, application and evaluation of an organizational performance measurement system. Ph. D. Dissertation. Virginia Tech, Blackburg, VA, USA, 1995.

COOPER, D. R.; SCHINDLER, P. S. Métodos de Pesquisa em Administração. Trad. Luciana de Oliveira da Rocha. 7. ed. Porto Alegre: Bookman, 2003.

CRUZ, T. E-Workflow: como implantar e aumentar a produtividade. São Paulo: ENADEM, 2004. 252p.

DAVENPORT, T. H.. Reengenharia de Processos. Rio de Janeiro: Campus, 1994.

DAVENPORT, T. H.; SHORT, J. E. The New Industrial Engineering: information technology and business process redesign. Sloan Management Review, v. 31, n. 4, p. 11-27, summer 1990.

DE SORDI, J. O. Gestão por processos: uma abordagem da moderna administração. São Paulo: Saraiva, 2005.

DELPHI GROUP. BPM 2005: market milestone report, 2005. Disponível em <http://www.delphigroup.com>. Acesso em: 07/04/2006.

DE TONI, A.; TONCHIA, S. Performance measurements systems, models, characteristics and measures. International Journal of Operations \& Production Management, v. 21, n. 1/2, p. 48-70, 2001.

DRUCKER, P. F. Desafios gerenciais para o século XXI. Trad. Nivaldo Montingelli Jr. São Paulo: Pioneira, 1999. 
ELLIS, C. A. Information Control Nets: a mathematical model of office information flow. In: CONFERENCE ON SIMULATION, MEASUREMENT AND MODELING OF COMPUTER SYSTEMS, 1979, Boulder, Colorado. Proceedings... Colorado: ACM Press, p. 225-240, 1979.

ELLIS, C. A.; NUTT, G. Workflow: the process spectrum. In: NSF WORKSHOP ON WORKFLOW AND PROCESS AUTOMATION IN INFORMATION SYSTEMS, 1996, Athens, Georgia. Proceedings... Athens: A Sheth Editor, may. 1996, p. 140-145.

FERREIRA, J. E.; TAKAI, O. K.; PU, C. Integration of Business Processes with Autonomous Information Systems: a case study in Government Services. In: INTERNATIONAL IEEE CONFERENCE ON E-COMMERCE TECHNOLOGY 2005 (CEC-05), 7., 2005, Munich, Germany. Proceedings... jul. 2005a. CD-ROM

FERREIRA, J. E.; TAKAI, O. K.; PU, C. Integration of Collaborative Information System in Internet Applications using RiverFish Architecture. In: INTERNATIONAL CONFERENCE ON COLLABORATIVE COMPUTING: NETWORKING APPLICATIONS AND WORK SHARING, 2005, San Jose, USA. Proceedings... 2005b. CD-ROM

FIGUEIREDO, M. A. D. Sistema de Medição de Desempenho Organizacional: um modelo para auxiliar a sua auto-avaliação. Rio de Janeiro, 2003. Tese (Doutorado em Engenharia de Produção) - Coordenação dos Programas de Pós-Graduação em Engenharia da Universidade Federal do Rio de Janeiro.

FOKKINK, W. J. Introduction to Process Algebra: texts in theoretical computer science. Berlin: Springer-Verlag, 2000.

FORZA, C. Survey research in operations management: a process-based perspective. International Journal of Operations \& Production Management. v.22, n.2, p. 152-194, 2002.

GARTNER. Gartner's Application Development and Maintenance Research Note, The BPA Market Cathes another Major Updraft, 2002. Disponível em: <http://www.gartner.com>. Acesso em: 02/07/2005.

GHALAYINI, A. M.; NOBLE, J. S.; CROWE, T. J. An integrate dynamic performance measurement system. International Journal of Production Economic, v. 48, n. 3, p. 207$225,1997$.

GONÇALVES, J. E. L. Processo, que processo? São Paulo, Revista de Administração de Empresas, v. 40, n. 4, Out./Dez., 2000.

GULLIKSEN, H. Theory of Mental Tests. New York: John Wiley \& Sons, 1950.

HAIR, J. F.; ANDERSON, R. E.; TATHAM, R. L.; BLACK, W. C. Análise Multivariada de Dados. Trad. Adonai Schlup Sant'Anna e Anselmo Chaves Neto. 5. ed. Porto Alegre: Bookman, 2005.

HAMMER, M. Reengineering the corporation. London: Nicholas Breadley Publishing, 1997. 
HAMMER, M. Reengineering Work: don't automate, obliterate. Harvard Business Review. p. 104-112, Jul./Aug .1990.

HAMMER, M.; CHAMPY, J. Reengenharia revolucionando a empresa. 15. ed. Rio de Janeiro: Campus, 1994.

HAMMER, M.; STANTON, S. A. The reegineering revolution. Government Executive, n. 9, v. 27, 1995.

HAMPTON, D. R. Administração Contemporânea. Trad. L. Blandy e A. C. A. Maximiano. São Paulo: McGraw-Hill, 3. ed., 1992.

HARRINGTON, H. J. Aperfeiçoando processos empresariais: estratégia revolucionária para o aperfeiçoamento da qualidade, da produtividade e da competitividade. Trad. Luiz Liske. São Paulo: Makron Books, 1993.

HOLLINGSWORTH, D. The Workflow Reference Model. Document Number TC00-1003, Hampshire: Workflow Management Coalition, jan. 1995.

HOLT, A. W. Coordination Technology and Petri Nets. In: Advances in Petri Nets 1985, G. Rozenberg Editor, Lecture Notes in Computer Science. Berlin: Springer-Verlag, v. 222, p. 278-296, 1985.

HOURNEAUX JR., F. Avaliação de desempenho organizacional: estudos de casos de empresas do setor químico. São Paulo, 2005. Dissertação (Mestrado em Administração) Programa de Pós-Graduação em Administração, Faculdade de Economia, Administração e Contabilidade da Universidade de São Paulo.

HRONEC, S. M. Sinais vitais: usando medidas de desempenho da qualidade, tempo e custos para traçar a rota para o futuro. Rio de Janeiro: Makron Books, 1994.

JABLONSKI, S.; BUSSLER, C. Workflow Management: modeling, concepts, architecture and implementation. London: International Thomson Computer Press, 1996.

KAISER, H. F. An index of factorial simplicity. Psychometrika, v. 39, p. 31-36, 1974.

KAPLAN, R. S.; NORTON, D. P. A estratégia em ação: Balanced Scorecard. Trad. Luiz Euclides Trindade Frazão Filho. 13.ed. Rio de Janeiro: Campus, 1997.

KAYDOS, W. Measuring, Managing and Maximizing Performance. Cambridge: Productivity Press, 1991.

KENNERLEY, M. P.; NEELY, A. Performance measurement frameworks: a review. In: NEELY, A. Business Performance Measurement: theory and practice, Cambridge: University Press, 2002.

KIEPUSZEWSKI, B; HOFSTEDE, A. H. M. ter; AALST, W. M. P. van der. Fundamentals of Control Flow in Workflows. Brisbane: 2002. QUT Technical report, FIT-TR-2002-03 Queensland University of Technology, Australia. Disponível em: <http://www.tm.tue.n1/it/research/patterns >. Acesso em: 16/06/2005. 
KINNEAR, T. C.; TAYLOR, J. R. Marketing research: an applied approach. 5.ed. New York: McGraw-Hill, 1996.

KISH, L. Survey Sampling. New York: John Wiley \& Sons, 1965.

KPMG LLP. Achieving Measurable Performance Improvement in a Changing World: the search for new insights. USA, White Paper, 2001.

LAKATOS, E. M.; MARCONI, M. A. Fundamentos em metodologia científica. 5.ed. São Paulo: Atlas, 2003.

LAUDON, K. C.; LAUDON, J. P. Sistemas de informação gerenciais: administrando a empresa digital. Trad, Arlete Simille Marques. 5.ed. São Paulo: Prentice Hall, 2004.

LAWRENCE, P. (Org.) Workflow Handbook 1997. Workflow Management Coalition. New York: John Wiley \& Sons, 1997.

LEYMANN, F.; ROLLER, D. Production Workflow: concepts and techniques. New Jersey: Prentice Hall PTR, 1999.

MARCOULIDES, G. A. Modern Methods for Business Research. (Org.) Hillsdale, New Jersey: Lawrence Erlbaum Associates, 1998.

MARTINS, G. de A. Estatística Geral e Aplicada. São Paulo: Atlas, 2001.

MARTINS, R. A. Sistemas de medição de desempenho: um modelo para estruturação de uso. São Paulo, 1998. Tese (Doutorado em Engenharia de Produção) - Escola Politécnica da Universidade de São Paulo.

MENEZES, P. F. B. Linguagens Formais e Autômatos. 2.ed. Porto Alegre: Sagra Luzzato, 1998, 168p.

MORGAN, R. E.; STRONG, C. A. Business performance and dimensions of strategic orientation. Journal of Business Research, n. 56, p. 163-176, 2003.

NEELY, A. D. The performance measurement revolution: why now and what next? International Journal of Operations \& Production Management, v. 15, n. 4, p. 80-116, 1999.

NEELY, A. D.; MILLS, J.; PLATTS, K; BOURNE, M. Designing performance measures: a structured approach. International Journal of Operations \& Production Management, v. 19, n. 2, p. 205-228, 1997.

NEELY, A. D.; ADAMS, C.; KENNERLEY, M. The Performance Prism: the scorecard for measuring and managing business success. London: Prentice Hall, Pearson Education Limited, 2002.

PARASURAMAN, A. Marketing Research. 2. ed. Addison: Wesley Publishing Company, 1991.

PETER, J. P. Reliability: a review of psychometric basics and recent marketing research. Journal of Marketing Research, feb./1979, p. 6-17. 
PROGRAMA DAS NAÇÕES UNIDAS PARA O DESENVOLVIMENTO - PNUD. Documentos diversos. Disponível em: <http://www.pnud.org.br>. Acesso em: 04/07/2005.

RATTON, C. A. Sistemas de medição de desempenho: o estado da arte em empresas líderes no Brasil. Rio de Janeiro: 1998. Dissertação (Mestrado em Engenharia de Produção) Departamento de Engenharia Industrial da Pontifícia Universidade Católica do Rio de Janeiro.

REIS, A. H. M. de A. M. Pesquisa qualitativa em marketing: uma visão crítica a respeito da utilização desta metodologia no Brasil, a partir do testemunho de clientes e usuários de São Paulo. São Paulo, 1994. Dissertação (Mestrado em Administração) - Programa de PósGraduação em Administração, Faculdade de Economia, Administração e Contabilidade da Universidade de São Paulo.

ROBSON, I. From process measurement to performance improvement. Business Process Management Journal, v. 10, n. 5, p. 510-521, 2004.

RUMMLER, G. A.; BRACHE, A. P. Melhores Desempenhos das Empresas: uma abordagem prática para transformar as organizações através da reengenharia. Trad. Kátia Aparecida Roque. 2. ed. São Paulo: Makron Books, 1994.

SALTERIO, S.; WEBB, A. The balanced scorecard. CA Magazine, v. 136, n. 6, ago-2003, p. 39.

SELlTIZ, C.; WRIGHTSMAN, L. S.; COOK, S. W. Métodos de Pesquisa nas relações sociais. 4. ed. norte-americana (Org.) Louise H. Kidder. Trad. Maria Martha Hubner d'Oliveira e Miriam Marinotti Del Rey. 2.ed. brasileira. (Org.) José Roberto Malufe e Bernadete A. Gatti. São Paulo: EPU, v. 1-3, 1987.

SINK, D. S.; TUTTLE, T. C. Planejamento e Medição para a Performance. Rio de Janeiro: Qualitymark, 1993.

SMITH, H.; FINGAR, P. Business Process Management: the third wave. Tampa: MeghanKiffer Press, 2003.

SOUZA, C. A de. Sistemas integrados de gestão empresarial: estudos de caso de implementação de sistemas ERP. São Paulo, 2000. Dissertação (Mestrado em Administração) - Programa de Pós-Graduação em Administração, Faculdade de Economia, Administração e Contabilidade da Universidade de São Paulo.

SPANYI, A. Business Process Management is a Team Sport: play it to win! Tampa: Anclote Press, 2003.

THATTE, S. XLANG: web services for business process design. Microsoft, 2001.

VENKATRAMAN, N. IT induced business reconfiguration. In: VENKATRAMAN, N. The corporation of the 1990s. New York: Oxford University Press, p. 122-158,1993.

WORKFLOW MANAGEMENT COALITION - WfMC. Workflow Management Coalition Terminology \& Glossary. Document Number WFMC-TC-1011. Winchester. United Kingdom. Feb. 1999. 
WODTKE, D.; WEIKUM, G. A formal foundation for distributed workflow execution based on state charts. In: INTERNATIONAL CONFERENCE DATABASE THEORY - ICDT'97, 7., 1997, Delphi, Greece. Proceedings... Lecture Notes in Computer Science, Springer, v. 1186,p. 230-246, 1997.

WEB SERVICES FLOW LANGUAGE - WSFL. Disponível em: $<$ http://www.ibm.com/software/solutions/webservices/pdf/WSFL.pdf $>$. Acesso em $16 / 06 / 2005$.

ZISMAN, M. D. Representation, Specification and Automation of Office Procedures. Pennsylvania. 1977. PhD thesis - Warton Scholl of Business, University of Pennsylvania. 


\section{APÊNDICES}

APÊNDICE 1 - MODELO INICIAL SMDI - BPM

APÊNDICE 2 - MODELO EVOLUÍDO SMDE - BPM

APÊNDICE 3 - INSTRUMENTO DE COLETA DE DADOS

APÊNDICE 4 - MODELO FINAL SMD - BPM 


\section{ANEXOS}

ANEXO A - TERCEIRO BENCHMARK DO PNAFE

ANEXO B - QUARTO BENCHMARK DO PNAFE

ANEXO C - A ARQUITETURA RIVERFISH E A ÁLGEBRA DE PROCESSOS 


\section{ANEXO C - A ARQUITETURA RIVERFISH E A ÁLGEBRA DE PROCESSOS}

\section{As propriedades da arquitetura RiverFish se apóiam na Álgebra de Processos}

FONTE: Ferreira et al (2005a)

As propriedades da arquitetura RiverFish estão embasadas nas seguintes definições e conceitos da Álgebra de Processos: 1- Reaproveitamento - na definição 6; 2- Formalização nas definições de 1, 2, 3 e 4; 3- Instanciação - na definição 7; e a 4da interação - nas definições 6 e 7.

Definição 1: Define-se P como um conjunto de processos.

Definição 2: $\Phi \in$ P: é o estado final ou deadlock do processo P.

Definição 3: Seja A o conjunto de ações. $A=\left\{a_{1}, a_{2}, \ldots, a_{n}\right\}$

Para cada ação a $€$ A, a._: $P \rightarrow$ P. a._é um operador de construção do processo $P$.

Exemplos: $P_{1}: a_{1} . a_{2} . \Phi ; P_{2:} a_{1} . a_{2} \Phi+a_{2} . a_{3} . \Phi$

$\mathrm{O}$ operador + representa a execução da ação alternativa para a execução do processo $\mathrm{P}_{2}$

A figura 1 ilustra os processos $\mathrm{P}_{1}$ e $\mathrm{P}_{2}$ utilizando grafos. Segundo Menezes (1998), grafo é uma forma de representação de estados e suas transições. Na figura, os estados dos grafos são expressos pelas transições do processo $\mathrm{P}_{\mathrm{i}}$, sendo irrelevante nomeá-los explicitamente.

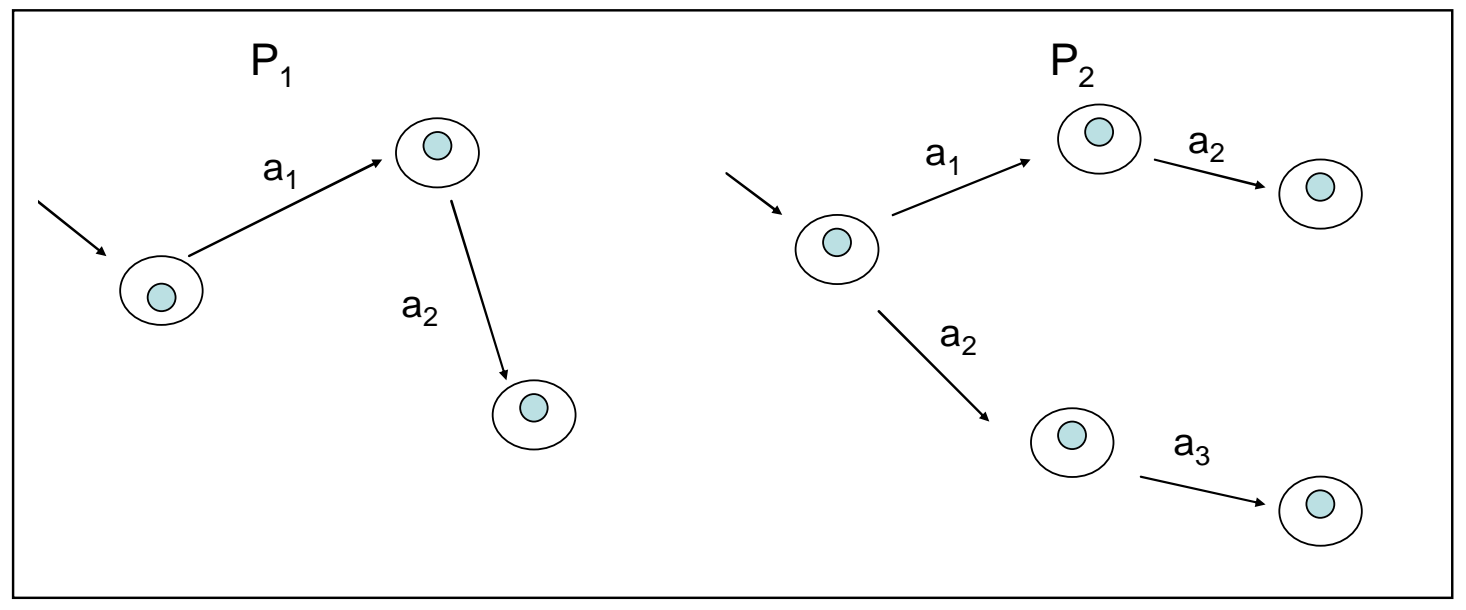




\section{Figura 1 - Representação dos processos P1 e P2}

Definição 4: Os estados do processo $\mathrm{P}_{\mathrm{j}}$ são representados pela seqüência de execução das ações $\mathrm{a}_{\mathrm{i}}$; ou seja:

$a_{1 .} a_{2 .} \Phi \rightarrow a_{2 .} \Phi \rightarrow \Phi$, define os estados: $a_{1} . a_{2} . \Phi, a_{2} . \Phi, \Phi$.

Por questões de escopo, foram omitidas deste texto propriedades e extensões da Álgebra de Processos e que podem ser verificadas em Bergstra et al (2001).

Definição 5: Seja F o conjunto de funções que transformam as consistências em ações. Assim, $\mathrm{F}=\left\{\mathrm{F}_{1}, \mathrm{~F}_{2}, \ldots, \mathrm{F}_{\mathrm{m}}\right\}$, onde cada $\mathrm{F}_{\mathrm{i}}$ transforma o passo pi em ações. Se P é o conjunto de passos e A o conjunto de ações, então P é o domínio e A é a imagem de F:

$\mathrm{F}_{\mathrm{i}}: \mathrm{P} \rightarrow \mathrm{A}$

Observe que $\mathrm{F}_{\mathrm{i}}$ não necessariamente precisa ser uma função binária. Ela poderia gerar $\mathrm{n}$ ações possíveis para um determinado passo. No exemplo, necessitou-se apenas de duas ações para representar as situações de consistência: atendida completamente ou não atendida.

Definição 6: Os processos são representados por composição de passos de negocio (ações simples ou pontos de verificação). Em outras palavras, o Plano Navegacional é descrito por um grafo com $n$ entradas para os $n$ processos dos objetivos de negócio. Esses processos compartilham vários sub-caminhos do Plano Navegacional.

Definição 7: A instância do Plano Navegacional, como já vista, é a representação de um processo requerido por um determinado usuário. A instância do Plano Navegacional armazena para cada requisição de um usuário todas as ações realizadas. A utilização desse conceito proporciona a especificidade da execução de cada processo para cada requisitante.

De acordo com as definições acima, pode-se agora representar um processo de negócio P1 ilustrado na figura 2 da seguinte forma: 
$\mathrm{P}_{1}=\mathrm{a} 1 \mathrm{a} 1 . \mathrm{a} 2 . \mathrm{a} 3 \cdot((\mathrm{a} 5 \cdot(\mathrm{a} 7 . \Phi+\mathrm{a} 6 \cdot \mathrm{ag} \cdot \Phi))+(\mathrm{a} 4 . \mathrm{ag} \cdot(\mathrm{a} 7 . \Phi+\mathrm{a} 6 . \mathrm{ag} \cdot \Phi)))$

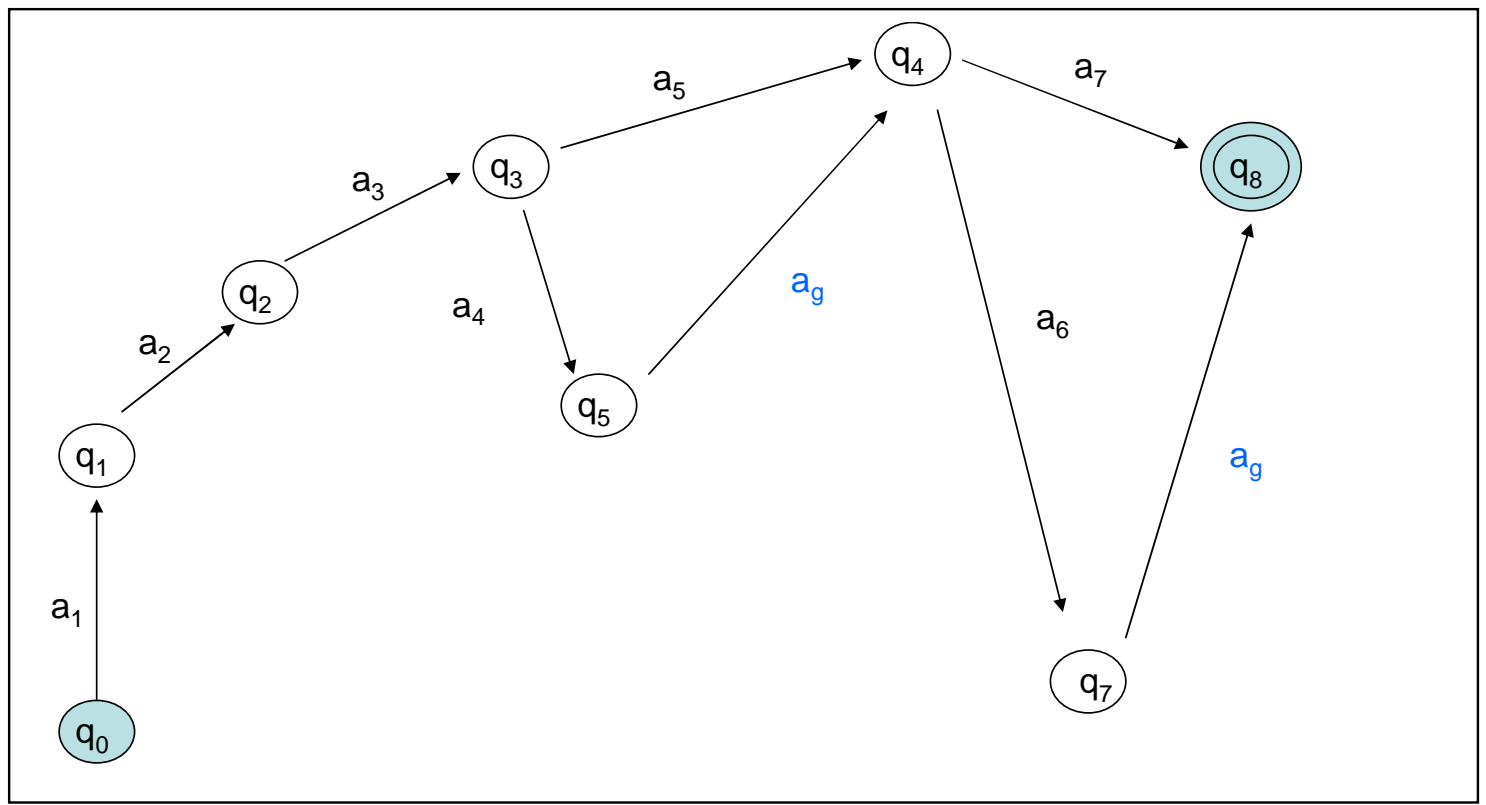

Figura 2 - Processo P1 descrito por meio de um Grafo

Em um objetivo de negócio existem vários processos que utilizam parte das ações contidas em $\mathrm{P}_{1}$. Assim, conforme ilustra a figura 2, pode haver um outro processo $\mathrm{P} 2$, descrito pela expressão abaixo, que reutiliza várias ações de $\mathrm{P}_{1}$.

$\mathrm{P}_{2}=\mathrm{a} 11 . \mathrm{a} 21 . \mathrm{a} 31 .(\mathrm{a} 5 \cdot(\mathrm{a} 7 \cdot(\mathrm{a} 9 . \Phi+\mathrm{a} 8 . \mathrm{ag} . \Phi)+\mathrm{a} 6 . \mathrm{ag} \cdot(\mathrm{a} 8 \cdot \mathrm{ag}+\mathrm{a} 9 . \Phi))+\mathrm{a} 4 . \mathrm{ag} \cdot$

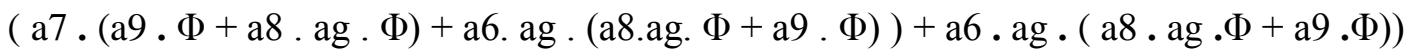

$\mathrm{Na}$ figura 3 encontram-se graficamente representados as quatro propriedades do RiverFish. A figura ilustra ainda o Plano Navegacional representando os processos $\mathrm{P}_{1}$ e $\mathrm{P}_{2}$.

Cada novo processo especificado é incluído no Plano Navegacional reutilizando caminhos já existentes ou incluindo novos. Um sub-caminho do grafo comum aos dois processos de negócio $\mathrm{P}_{1}$ e $\mathrm{P}_{2}$, pode reutilizar uma representação dos processos em segmentos de processos disjuntos. 


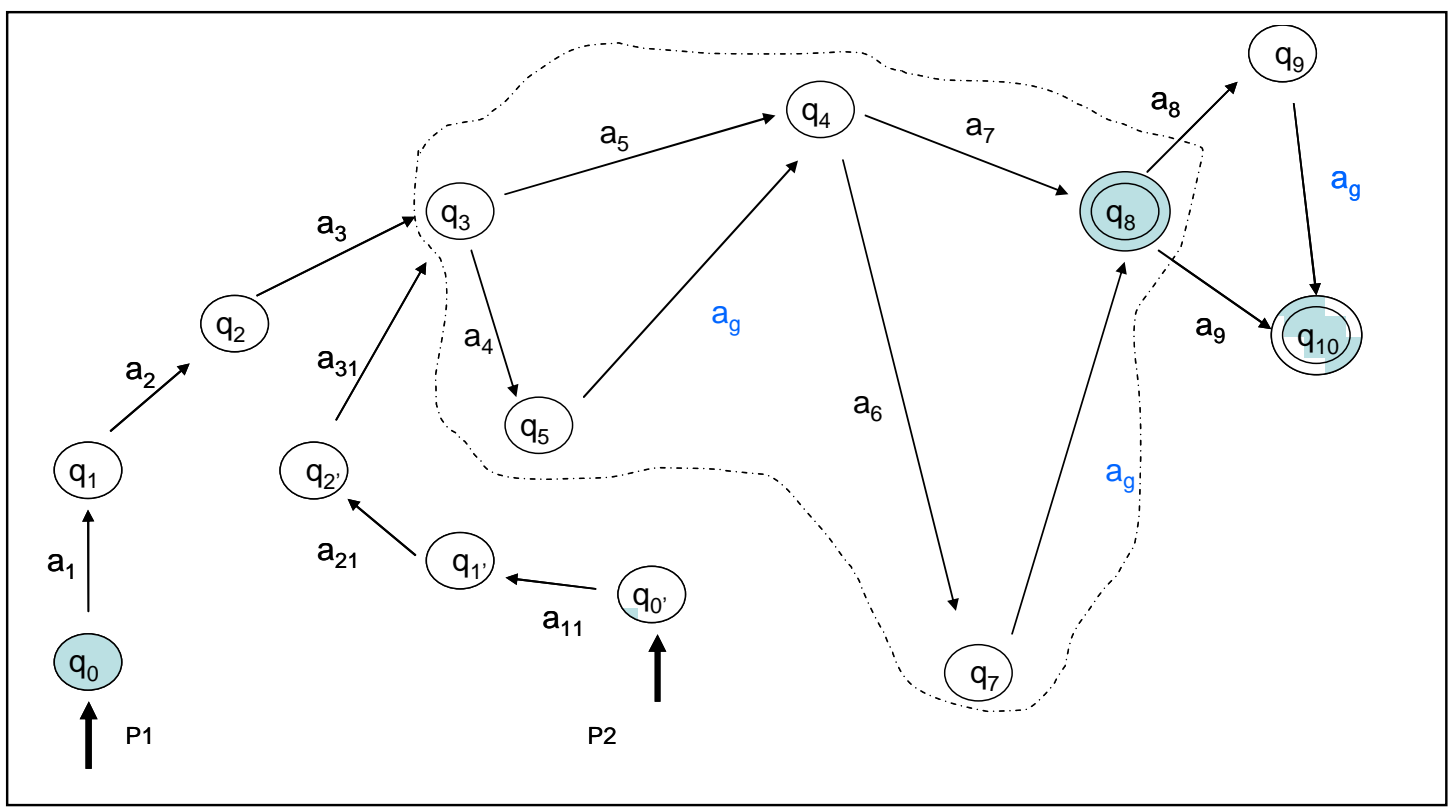

Figura 3 - Representação do Plano Navegacional com reaproveitamento de processos 